
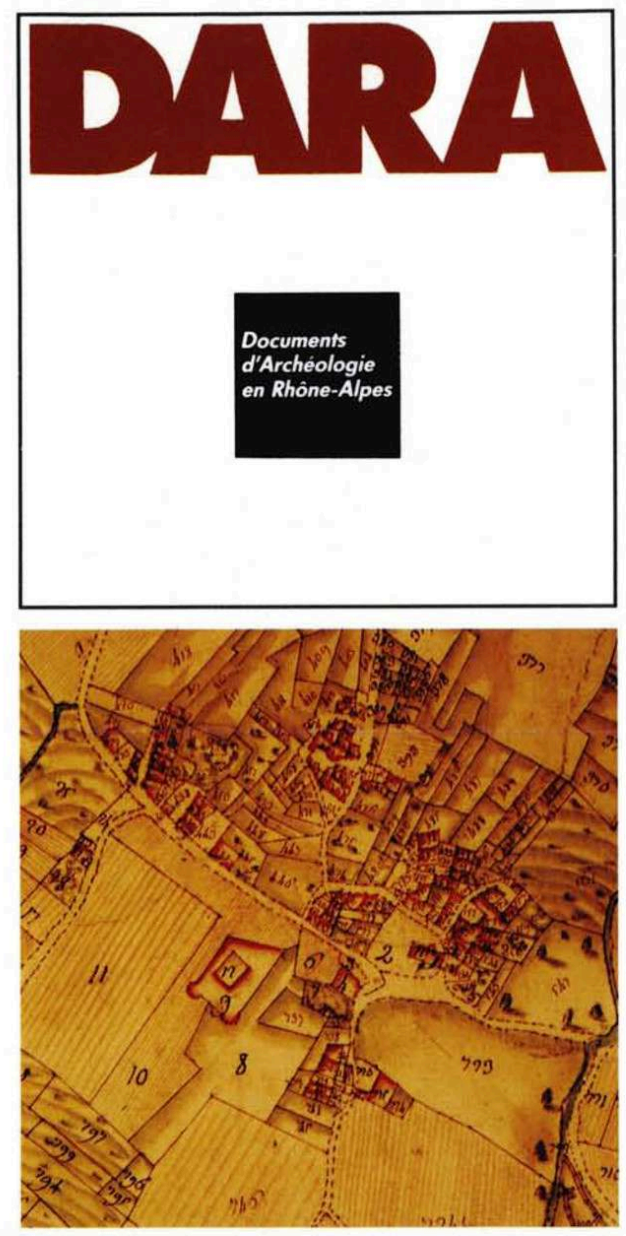

LE CHÂTEAU ET LA SEIGNEURIE DU VUACHE

HAUTE-SAVOIE

Frédéric RAYNAUD 


\section{Le château et la seigneurie du Vuache}

Haute-Savoie

\section{Frédéric Raynaud}

DOI : 10.4000/books.alpara.1647

Éditeur : Alpara

Lieu d'édition : Lyon

Année d'édition : 1992

Date de mise en ligne : 2 juin 2016

Collection : DARA

ISBN électronique : 9782916125251

\section{Coboooks}

http://books.openedition.org

\section{Édition imprimée}

Nombre de pages : 147

\section{Référence électronique}

RAYNAUD, Frédéric. Le château et la seigneurie du Vuache : Haute-Savoie. Nouvelle édition [en ligne]. Lyon : Alpara, 1992 (généré le 12 janvier 2021). Disponible sur Internet : <http://books.openedition.org/ alpara/1647>. ISBN : 9782916125251. DOI : https://doi.org/10.4000/books.alpara.1647.

Ce document a été généré automatiquement le 12 janvier 2021. Il est issu d'une numérisation par reconnaissance optique de caractères.

(c) Alpara, 1992

Conditions d'utilisation :

http://www.openedition.org/6540 
Situé actuellement aux confins de la Haute-Savoie et du Genevois, le château du Vuache se dressait au Moyen Âge, sur le versant d'un petit chaînon jurassien formant limite entre les comtés de Genève et de Savoie. Ce site castral (commune de Vulbens) a fait l'objet de fouilles archéologiques d'urgence, préalables à la construction d'un lotissement. Grâce aux découvertes effectuées sur le terrain, auxquelles a été associée une recherche dans les archives, c'est l'histoire du château et de la seigneurie qui a pu être reconstituée.

Depuis sa création au XIII ${ }^{\mathrm{e}}$ siècle, et jusqu'à son abandon au XVII ${ }^{\mathrm{e}}$, les différentes phases de construction, de modifications, et de dégradation du monument ont été identifiées et mises en relation avec ce que l'on sait des familles détentrices de la seigneurie et les événements de l'histoire régionale.

Édifié sur les vestiges d'un site fossoyé antérieur, le château mis au jour par les fouilles apparaît comme formé d'une enceinte octogonale flanquée de tours et refermant un vaste logis. L'évolution architecturale du monument montre un renforcement progressif et parallèle des moyens de défense, du confort résidentiel et du rôle économique. Le cadre de la vie quotidienne en milieu seigneurial est également bien illustré par les objets découverts ; qui concernent autant l'armement, le décor, la table, la cuisine, la parure, que les loisirs ou l'alimentation.

Ce volume présente une étude globale d'un château et d'une seigneurie savoyarde médiévale, et permet de suivre leur évolution à travers près de cinq siècles. Il témoigne de la vitalité des recherches régionales dans le domaine de l'archéologie des châteaux. 


\section{SOMMAIRE}

\section{Introduction}

Chapitre 1. Cadre géographique et historique

Géographie du Vuache

Avant le Moyen Âge

L'époque romaine

Au Moyen Âge

\section{Chapitre 2. La seigneurie du Vuache}

Les seigneurs du Vuache

Le domaine direct

La paroisse de Chevrier

Le domaine utile ou réserve seigneuriale

Les dimes et droits seigneuriaux

\section{Chapitre 3. Le château du Vuache}

Données archéologiques

Données historiques

Restitution et datation

\section{Conclusion}

État 1

État 2

État 3

Annexes

Annexe 1. Les objets de la vie quotidienne

Michel Dhénin

Annexe 2. La vaisselle de terre

Bruna Maccari-Poisson

Annexe 3. La vaisselle de verre

Danielle Foy

Annexe 4. La faune

Claude Olive et Louis de Roguin

Annexe 5. Inventaire de 1612

Bibliographie

Crédits 
NOTE DE L'ÉDITEUR

À Simon et Mérédith 


\section{Introduction}

1 Cet ouvrage a pour origine une opération de fouilles de sauvetage sur le site du château $\mathrm{du}$ Vuache (Commune de Vulbens, Haute-Savoie). Aux recherches archéologiques sur l'édifice castrai, il était indispensable d'associer une étude des archives conservées. Ces données textuelles permettent de restituer l'élévation disparue du bâtiment mais également d'appréhender le contexte sociologique dont il était le point central : la seigneurie, châtellenie ou mandement, cadre de la société rurale du Moyen Âge et du début de l'Époque Moderne.

2 S'étendant de la crête du mont Vuache à la rive gauche du Rhône, le territoire concerné a longtemps été marqué par le rôle de frontière que joua le fleuve, séparant, dans l'Antiquité, les provinces séquane et allobroge, limite Nord de la Narbonnaise et au Moyen Âge, les comtés de Genève et de Savoie.

3 L'intérêt stratégique de cette région s'explique par l'importance du passage du défilé du Pas-del'Ecluse, accès méridional au territoire genevois, en amont duquel le fleuve était guéable. Il est souligné par la présence d'un oppidum au sommet de la montagne puis du château médiéval. Le site choisi pour l'édification de ce château permettait le contrôle des deux principales voies de communication et la surveillance d'une vaste région.

4 Dès les premières mentions écrites remontant au XIIIe s., les termes de domaine, de châtellenie, ou mandement, relevant tous de la seigneurie banale sont étroitement associés au château. Ils couvrent le territoire de quatre paroisses formant le domaine direct, ou la directe, qui associé au domaine utile, ou réserve, constitue la propriété éminente du seigneur foncier.

5 Son étude a pu être entreprise grâce à la variété des documents conservés et en particulier grâce à la Mappe Sarde. Ce cadastre, dressé en 1730, représente très précisément la réserve seigneuriale, bien que dans un état relativement récent et passager, ainsi que l'organisation du paysage autour des villages et hameaux qui composent le domaine direct.

6 Le paysage peut être analysé en suivant plusieurs pistes grâce à la représentation cartographique très précise de la Mappe et aux indications fournies par les tabelles où sont enregistrées les parcelles regroupées en lieux-dits que désignent des toponymes. 
7 Certaines parcelles de la réserve seigneuriale sont soumises à la taille, mais les biens certifiés appartenant au seigneur avant 1584, en sont exemptés; cette indication permet de restituer les quelques parcelles mentionnées au XIVe s. et certaines de celles acquises au XVe s.

8 Les sources écrites relatives aux constructions sont peu nombreuses, comptes de châtellenies et inventaires. Elles permettent cependant une interprétation plus fiable des vestiges découverts et de la fonction des différentes pièces ou bâtiments annexes, pour proposer un essai de restitution des élévations disparues.

9 L'opération de fouilles de sauvetage programmées répondait aux menaces de destruction du sous-sol par la construction d'un lotissement de maisons individuelles, d'immeubles locatifs et d'un nouveau centre communal. Nous avons pu réaliser quatre campagnes de recherches de 1982 à 1985, pendant les mois d'été. Le projet ne menaçant que partiellement et superficiellement les niveaux archéologiques dont la stratification s'est révélée peu complexe, mais dont les apports étaient souvent volumineux, il n'était donc pas nécessaire de procéder à une fouille extensive tant en plan qu'en profondeur.

10 La partie sud du site, cour intérieur et enceinte, a été explorée par une série de tranchées parallèles est-ouest, dans la largeur du château, complétée par deux autres perpendiculaires et, enfin, une dernière suivant l'axe du mur de courtine est ; la partie nord, occupée par le logis seigneurial, a été partiellement dégagée en surface jusqu'au niveau du dernier sol. Des sondages ponctuels ont été effectués aux endroits menacés susceptibles de fournir le maximum d'informations. Au sud, un sondage profond a permis l'étude d'un bâtiment annexe et de l'élévation du mur d'enceinte, mieux conservé. Une tranchée ouverte dans la bassecour, en face de l'entrée du château, n'a pas pu être étudiée, faute de temps, mais a permis de repérer l'angle d'une des piles du pont qui enjambait le fossé.

11 Implanté à proximité immédiate du village de Vulbens, sur les vestiges d'une occupation primitive qui correspond peut-être à un site fossoyé, le château du Vuache est un petit édifice castrai de plaine. Il présente une structure très ramassée qui offre une capacité de résistance certaine grâce à l'accumulation des moyens de défense, tours et courtines, surmontées de coursières et hourds, probablement dès l'origine. Un vaste logis seigneurial appuyé sur la courtine nord lui donne un caractère résidentiel. Le château est implanté au centre d'une vaste basse-cour entourée d'une palissade qui ne parait pas être une ligne de défense avancée mais plutôt un organe distinct en liaison avec le rôle domanial de l'édifice. Quelques modifications architecturales permettront de renforcer ses moyens de défenses, d'accroître le confort des habitants ou de répondre à des besoins économiques.

12 Au début du XVIe s., après avoir été en partie incendié, le château du Vuache est occupé par des troupes franco-helvétiques durant les guerres opposant le duc de Savoie à la ville de Genève, refuge de Calvin. Un niveau archéologique, très riche en matériel, correspond à l'incendie d'un bâtiment annexe et au bivouac des soldats. Une transformation radicale de l'architecture intérieure est entreprise par la construction d'une cour centrale probablement peu de temps avant l'abandon du site.

13 Abandonné au milieu du XVIIe s., au moment du transfert du siège de la châtellenie vers le hameau voisin du Faramaz, l'édifice castrai servit probablement de carrière et disparut progressivement au cours des deux siècles suivants. Dès 1701, dans les sommaires de titre de fiefs du comte de Menthon-Lornay et du marquis Millet de 
Charles coseigneurs du Vuache, le bâtiment est déjà en ruines «le dit château, à présent réduit à mazures». Il est également qualifié de «mazures» dans la tabelle des propriétés du cadastre de 1730 où son plan apparaît sommairement dressé : seules les deux tours sud correspondent approximativement avec le plan des structures retrouvées; une cour est représentée, apparemment entourée par quatre corps de logis ; le fossé, peutêtre déjà entièrement comblé, n'est pas indiqué ; aucun chemin ne se dirige vers le bâtiment et la basse-cour est divisée en parcelles mises en culture.

14 Après l'arasement des derniers vestiges, le terrain est entièrement exploité en champs et vergers et au début de l'intervention archéologique, l'emplacement du site n'était seulement décelable que par un léger tertre formé par l'accumulation des déblais de démolition. Les modestes dimensions de ce bâtiment castrai incitaient à le considérer au premier abord comme une maison forte; cependant, tous les textes étudiés, à l'exception d'une charte de 1296 où il y a hésitation entre "castrum seu domus fortem ", le désignent comme étant un véritable château.

15 L'étude des différentes sources le fait apparaître dans ses trois fonctions complémentaires, forteresse et gîte d'étape militaire, lieu de résidence temporaire des seigneurs successifs et centre administratif dans le cadre de la seigneurie. Lors des investitures de fiefs du XVe s., c'est par leur château que les seigneurs du Vuache revendiquaient leurs droits sur un territoire regroupant quatre paroisses constituées de plusieurs hameaux. Deux d'entre eux, Raclaz et Faramaz, étaient inféodés à des petits aristocrates détenant des maisons fortes et un troisième, Cologny, dépendait des Templiers puis des Hospitaliers. C'est, à notre avis, cette place au sein de la hiérarchie féodale et les droits seigneuriaux qui lui sont attachés qui déterminent la qualité de château applicable au Vuache.

L'illustration de la vie quotidienne dans le château est possible grâce à différentes études qui complètent ici les données historiques: de nombreux objets ayant été exhumés lors des fouilles, céramiques, verreries, objets métalliques, et quelques monnaies révèlent les diverses activités exercées. Les ossements d'animaux nous renseignent sur les activités cynégétiques et l'élevage ainsi que sur la présence d'animaux domestiques.

17 Cette monographie qui constitue une tentative de recherche globale sur un château occupé du Moyen Âge à l'époque moderne et sur le territoire qui en dépendait permet de réinsérer des structures dans leur cadre historique et de suivre leur évolution à travers leurs cinq siècles d'existence. 


\section{Chapitre 1. Cadre géographique et historique}

1 Situé à trente kilomètres de Genève, le château du Vuache occupe une position centrale au sein d'un territoire dont l'occupation humaine remonte à la fin du Paléolithique supérieur (14000-9500 av. J.-C.), et qui est, de nos jours, divisé entre les trois communes de Chevrier, Vulbens et Dingy (canton de Saint-Julien-en-Genevois).

\section{Géographie du Vuache}

2 La région occupée par l'ancienne seigneurie du Vuache se situe sur le versant nord de la montagne du Vuache, face à l'extrême pointe occidentale du territoire suisse (fig. 1).

3 Le mont Vuache est un petit chaînon jurassien, culminant à $950 \mathrm{~m}$ d'altitude, long de 11 $\mathrm{km}$ du Défilé-de-l'Ecluse à l'ouest à celui du Malpas à l'est; il pénètre l'Avant-Pays savoyard, région de plateaux et de collines formant une vaste dépression entre Jura et Préalpes. Il ferme le bassin du lac Léman au sud-ouest en dominant la rive gauche du Rhône à sa sortie de la plaine de Genève, avant que le fleuve ne s'engage dans le défilé du Pas-de-l'Écluse entre le Grand-Crêt-d'Eau et la montagne du Vuache.

1- CARTE géographique de LA PARTIE NORd du comté de GeNèVe au MOYen Âge 


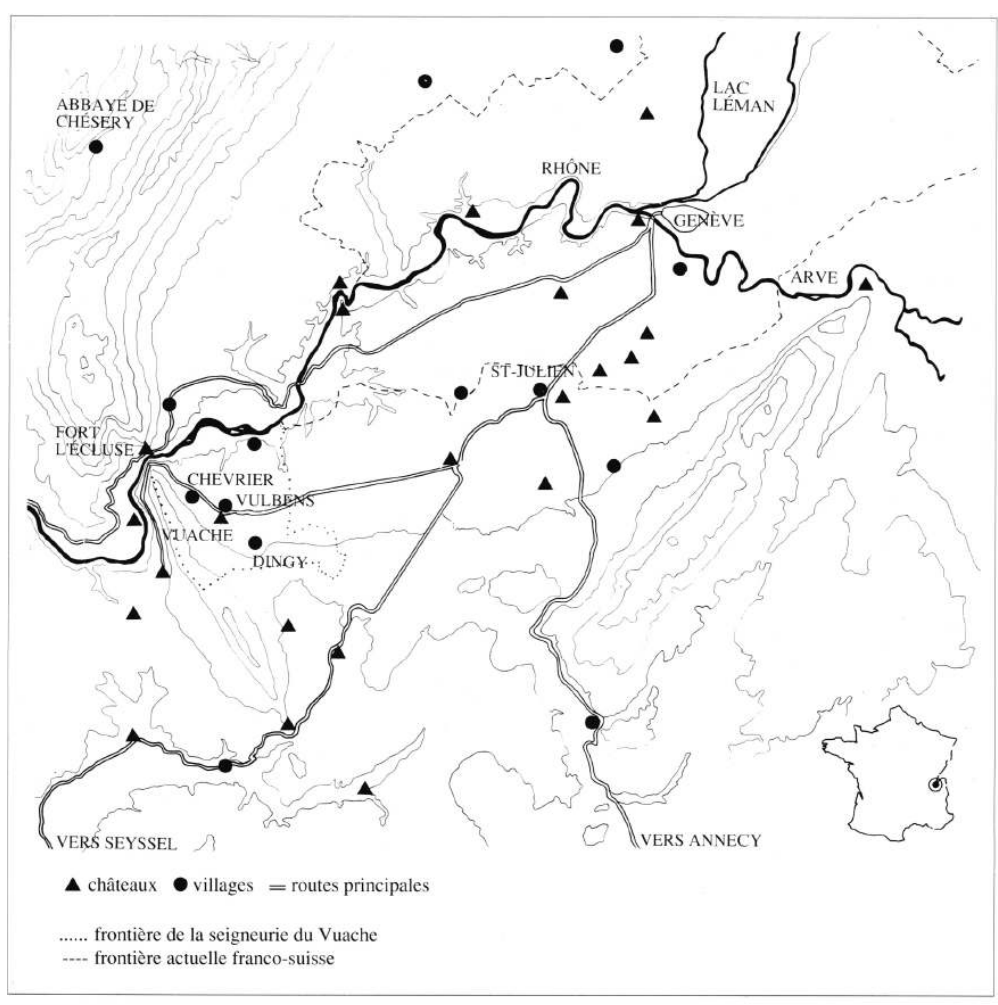

Carte topographique $1: 100000$ e

I.G.N.

4 Ce relief est constitué par le plissement de couches de calcaire de l'Urgonien, dû à la poussée des Alpes. Celui-ci affleure sous des dépôts marins du Miocène ayant formé un grès tendre appelé régionalement molasse, recouvert luimême par des dépôts morainiques et argileux du quaternaire. L'érosion glaciaire et post-glaciaire du quaternaire, entamant facilement les couches de molasse, a mis en relief la crête de la montagne faite de dépôts tertiaires et crétacés.

Les deux versants sont très différents : le côté méridional se présente sous forme de grandes falaises escarpées, sculptées dans le calcaire, alors que le versant septentrional est dû au modelage des couches de molasse sur un flanc de voûte synclinale, s'élevant rapidement et s'arrondissant avant d'atteindre le sommet (Cholley, 1925: p. 67) Ce versant se décompose en trois étages : la zone montagnarde, depuis la cime jusqu'à la courbe de niveau $600 \mathrm{~m}$, précédée par un plateau entre les niveaux $600 \mathrm{~m}$ et $400 \mathrm{~m}$ et lui-même bordé par la rive érodée du fleuve à $350 \mathrm{~m}$ d'altitude moyenne. Au pied de la montagne, de nombreuses sources donnent naissance à de petites rivières qui ont creusé profondément leur lit dans la molasse, et qui se jettent dans le Rhône.

Entre deux grandes forêts, au sud sur les pentes de la montagne et au nord-est, sur la rive du Rhône et en bordure de la frontière franco-suisse, le paysage est composé de vastes zones d'herbages et de cultures. Des feuillus et des buissons, disposés en lignes délimitent des groupes de champs ou de pâturages et encadrent les chemins, ce qui n'est pas sans rappeler le paysage bocager. Mais la prédominance actuelle des vastes surfaces en herbe et cet aspect de bocage sont liés à l'extension de l'élevage à partir du XIXe s. (Périllat, $1966:$ p. 6).

7 L'habitat s'organise autour des villages de peu d'importance, avec un nombre de hameaux réduits et quelques maisons isolées au milieu de leurs terres. 


\section{Avant le Moyen Âge}

\section{Aux origines}

Les glaciers du quaternaire qui ont à plusieurs reprises recouvert la totalité de la Savoie, rendaient impossible une présence humaine continue aux époques Paléolithiques inférieures.

9 Après le retrait du glacier wurmien, la région s'ouvre aux populations de l'époque magdalénienne (fig. 2). Des traces de leur séjour ont été retrouvées dans un abri sous roche, surplombant la rivière des Usses, à l'extrémité sud-est de la montagne du Vuache ; cette grotte fut également occupée au cours du Néolithique (Jayet, 1931).

2- Carte historique de la seigneurie du Vuache

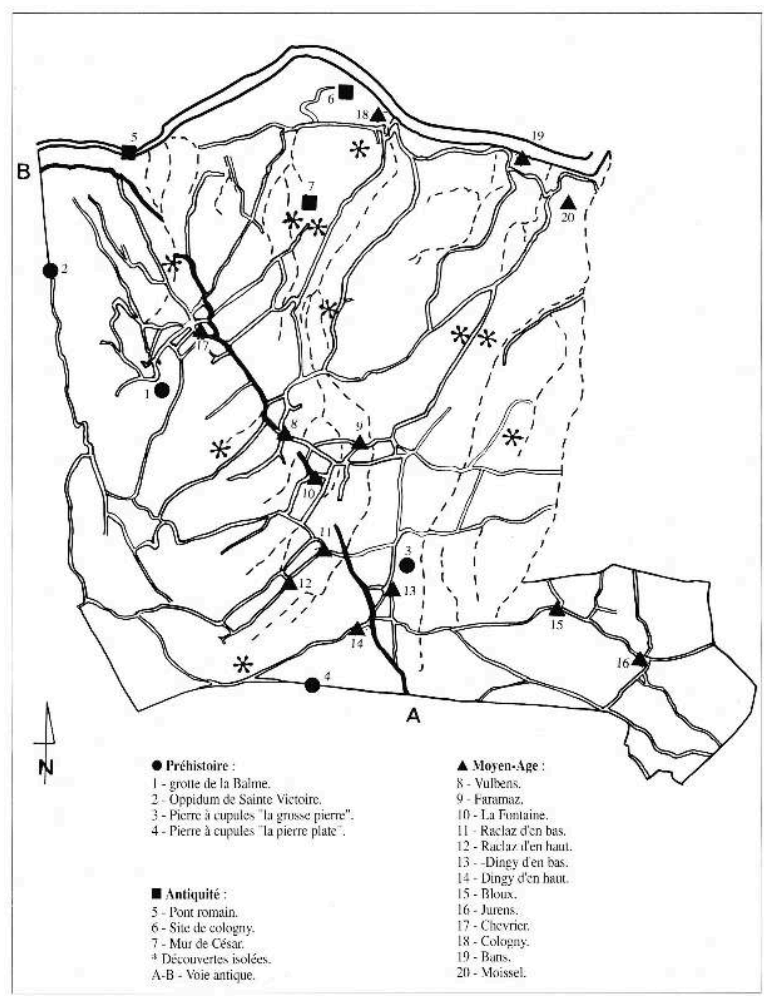

Sur le versant septentrional, à $735 \mathrm{~m}$ d'altitude, au-dessus de Chevrier, la grotte de La Balme, (fig. $\left.2, \mathbf{n}^{\circ} \mathbf{1}\right)$ a également livré des vestiges de différentes époques dont les plus anciens sont datés du Néolithique.

En 1880, E.Tissot, ingénieur météorologiste, informé par les habitants du lieu de découvertes (silex taillés, os sculpté et coin en serpentine) faites quelques années auparavant par M. Cuvier, chargé de la construction du chemin de fer (Tissot, $1880: \mathrm{p}$. 110), entreprend une nouvelle fouille de cet abri. Il met au jour une pointe de flèche en silex et une grande épingle de bronze protohistorique ${ }^{1}$ parmi de nombreux débris d'ossements d'animaux et tessons de céramique pré et protohistorique, romaine, médiévale et moderne (époque de la Révolution) (Tissot, 1880 : p. 44). Le toponyme de La Balme, déjà mentionné sur le cadastre sarde de $1730^{2}$, serait un mot d'origine prélatine signifiant : anfractuosité rocheuse (Wipf, 1982 : p. 78). Il est probable, exception 
faite pour les époques les plus anciennes de son occupation, que cette grotte ne servait pas d'habitat permanent mais plutôt de refuge en cas de danger; les populations du Néolithique et de l'âge du Bronze, tirant leur subsistance de la chasse, de la pêche, de l'élevage et de l'agriculture, auraient trouvé sur la rive du Rhône, un endroit fertile plus propice à leur installation.

Signalons également, sur le territoire de la commune de Dingy, la présence de deux monuments mégalithiques, aujourd'hui disparus, mais localisables grâce à la Mappe Sarde; il s'agit de "pierres à cupules", gros blocs de forme tabulaire dont la surface est parsemée de petits godets (cupules) dont la nature archéologique est incertaine et dont le degré d'antiquité est loin d'être établi; elles sont souvent considérées comme appartenant à l'âge du Bronze. La première (Tissot, $1880:$ p. 110) correspond au microtoponyme : $\mathrm{n}^{\circ} 114$ « la grosse pierre " (parcelle 636) (fig. 2, $\mathrm{n}^{\circ}$ 3), la seconde est représentée à cheval sur la limite avec la paroisse de Savigny, et se situe au lieu-dit révélateur $\mathrm{n}^{\circ} 215$ «la pierre plate» (parcelles 1330-1334) (fig. 2, $\mathbf{n}^{\circ} \mathbf{4}$ et fig. 3).

\section{3 : Représentation de la pierre à cupules au lieu-dit « La Pierre Plate » cadastre de 1730}

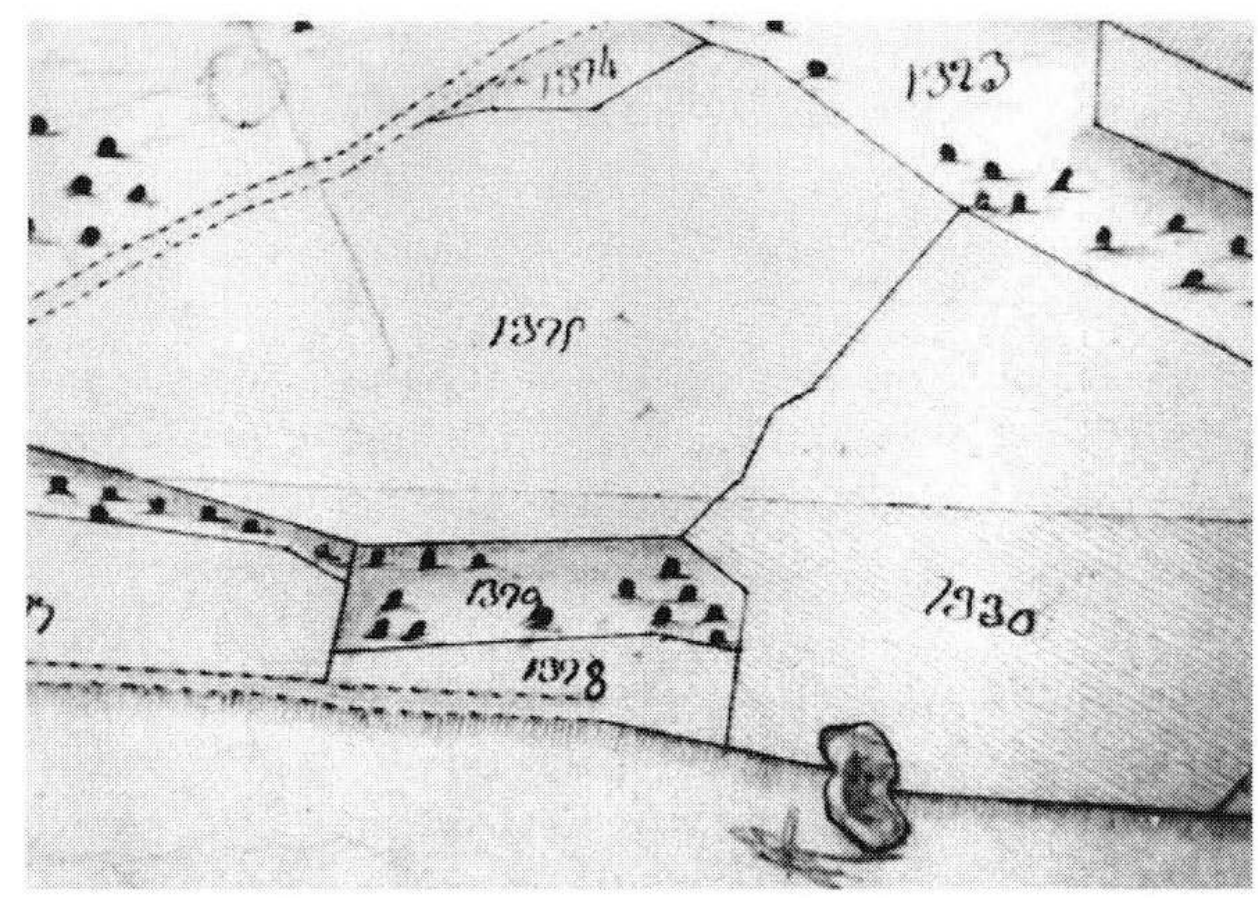

\section{Lâge du Fer}

13 À l'âge du Fer, le territoire étudié fait partie de l'Allobrogie, province qui s'étendait entre le Rhône et l'Isère et dont Genève était une des principales métropoles.

L'extrémité ouest du sommet de la montagne du Vuache est défendue par un mur de pierres sèches, d'une largeur indéterminée, s'étendant sur plus de $170 \mathrm{~m}$ sur le front sud et sur une longueur inconnue à l'est. Il complète l'escarpement rocheux offrant un retranchement naturel. L'ancien chemin d'accès forme un coude à l'angle sud-ouest de la position et longe ensuite le mur à l'intérieur. Cet oppidum (fig. $2, \mathbf{n}^{\circ} 2$ ) du type «éperon barré » permettait de surveiller la région genevoise et surtout la vallée du Rhône, frontière entre le pays des Séquanes et celui des Allobroges. Le préhistorien 
savoyard C. Thury, à la fin du siècle dernier (Thury, 1899: p. 322) et L. Blondel archéologue cantonal de Genève (Blondel, 1956) attribuent sa construction au début de l'âge du Fer (période de Hallstatt, 800-500 av. J.-C.). Pour sa part, P. Guichonnet, professeur à l'université de Genève, sans exclure une occupation hallstattienne, propose l'hypothèse d'une construction dans le cadre d'un système d'alerte et de défense mis en place pour faire face, soit à l'invasion romaine, soit à la menace d'incursions guerrières venues du Nord (Cimbres, Teutons) et donc correspondant à l'époque de la Tène III (120-58 av. J.-C.) (Guichonnet, 1973 : p. 54).

Deux toponymes importants, car correspondant à des noms de village, seraient issus de la langue celtique : Bans, dérivé de "pen(n)» signifiant extrémité, confins ; et Dingy, dérivé de «dan i ciac » traduisible par sous le bois (Wipf, 1982 : p. 200 et 218). Ces deux toponymes s'accordent parfaitement avec la situation géographique des lieux, qui se distinguent des autres villages implantés de part et d'autre d'une voie romaine.

\section{L'époque romaine}

L'Allobrogie est incorporée à la province de Narbonnaise en 118 av. J.-C., à la suite de la défaite des troupes indigènes face aux armées romaines en 122 et 121 av. J.-C. Cependant la pacification du pays dura jusqu'en 62 av. J.-C. Durant cette période, la région subit l'invasion des tribus barbares des Cimbres et des Teutons.

La tentative d'émigration des Helvètes par le territoire allobroge, en 58 av. J.-C., conduit Jules César à Genève, dont le pont commande l'accès septentrional de la Narbonnaise. Il y organise la protection de la province, en faisant détruire le pont et fortifier la rive gauche du Rhône, depuis le lac Léman jusqu'au Mont Vuache. Il fait construire un «mur long de 1900 pas, haut de 16 pieds ", précédé d'un fossé et renforcé de postes de garde et de redoutes aux endroits les plus vulnérables (là où le fleuve était guéable) $)^{3}$. Les Helvètes sont ainsi contraints d'emprunter le difficile passage du défilé du Pas-de-l'Écluse, sur la rive droite du Rhône. Cette construction est évoquée par Appien $^{4}$ et Dion Cassius ${ }^{5}$, non pas comme un mur d'un seul tenant mais plutôt comme la fortification des points sensibles de la frontière. Nous avons repéré un seul vestige, bien discutable, pouvant appartenir à cette construction. Il s'agit d'un double fossé en bordure de la terrasse du Rhône, long d'environ $200 \mathrm{~m}$ et visible sous une haie en limite de parcelles (fig. $2, \mathbf{n}^{\circ} 7$ ).

De nombreuses découvertes de vestiges antiques témoignent d'une occupation importante de l'Avant-Pays savoyard à l'époque romaine. Dans sa partie nord, cette région était traversée par deux routes principales: d'abord celle reliant Milan à Genève, par le col du Petit-Saint-Bernard et la rive du lac d'Annecy, la seconde correspondant au passage terrestre, obligé en raison de l'impraticabilité du Rhône, entre le défilé du Pas-del'Écluse et son confluent avec la rivière des Usses. Cette voie fluviale unissait Lyon à Genève et audelà, par le lac Léman, avec le plateau suisse et les régions septentrionales par le bassin du Rhin (Broise, 1974). Ces deux routes se rejoignaient à Carouge, quelques kilomètres avant la cité genevoise. Construites à l'époque augustéenne elles pourraient faire suite à des cheminements préhistoriques (Dufournet, 1978).

19 Les marchandises déchargées à l'emporium d'Albigny-Condion, au sud de Seyssel, étaient acheminées par portage jusqu'à Genève; il était cependant possible de raccourcir ce chemin en se servant à nouveau du Rhône, soit à la remontée, mais plus sûrement à la 
descente, entre "Le Port des Isles », appellation médiévale du site de "Cologny » à Bans, en aval et la ville de Genève, en amont (Dufournet. 1978 : p. 126).

Un axe secondaire de ce réseau longeait la montagne du Vuache par Dingy, Vulbens et Chevrier (approximativement les routes départementales 7 et 908) et traversait le Rhône par un pont (fig. $\mathbf{2}, \mathbf{n}^{\circ}$ ) ) pour rejoindre l'établissement romain de Collonges sur la rive droite (Marteaux, 1894). Une des piles du pont, en gros appareil, était encore visible au siècle dernier, au pied du Mont Vuache, à $50 \mathrm{~m}$ en aval du pont actuel (Gay, 1887 : p. 8). Ce vestige a été repéré lors de la levée de la carte d'Etat-Major, en 1883 ; il est dénommé "La Folia, château ruiné». Nous n'avons retrouvé aucune mention d'un éventuel château à cet emplacement, par contre le toponyme "La Folia », équivalent savoisien de «La Feuillée ", «Les Fayes ", «Les Fées » (folon, folonne en savoisien), pourrait éventuellement s'appliquer à un pont que l'inconscient collectif aurait placé sous la protection d'êtres mythiques (Marteaux, 1941: p. 59-75). Cette voie romaine (fig. 2, A-B) est facilement repérable sur le cadastre sarde malgré des lacunes dues aux glissements de terrains, en particulier entre le hameau de La Fontaine et le village de Vulbens au lieu-dit «Lavanchy», terme savoisien dont le sens serait: l'avalanche (Boyer, 1979 : p. 96).

21 Pour essayer d'appréhender l'occupation du territoire étudié à l'époque romaine, nous ne disposons que de très peu d'éléments : les recherches (non publiées ?) menées par le colonel Stoffel, à la demande de Napoléon III, en 1865, sur la rive gauche du fleuve, pour retrouver des vestiges de la construction de César; quelques découvertes fortuites signalées sur le territoire de Chevrier et de Vulbens et enfin le repérage sur carte, des lieux ayant livré des tuiles romaines lors des labours ${ }^{6}$. N'étant sur place que pendant une courte période de l'année, nous n'avons pas pu procéder à une prospection systématique du terrain pour vérifier ces informations et rechercher d'autres indices de sites. Il n'a donc pas été possible d'établir de chronologie plus précise.

Au lieu-dit "Cologny » ou "Collogny » (fig. $2, \mathbf{n}^{\circ}$ 6), sur la rive du Rhône, le site, en partie fouillé par le colonel Stoffel (Gay, 1887 : p. 9), à qui l'on doit la découverte d'une petite statue de Mercure en argent ${ }^{7}$, semble revêtir une importance particulière : il fait face à un établissement romain, repéré sur la rive droite, au lieu-dit « Les Isles » et sur le territoire de l'actuelle commune de Collonges, et dont les toponymes équivalents, remonteraient à Colonica (Béatrix, 1851 : p. 9). Un vicus s'étendait peut-être sur les deux rives, reliées par un gué qui perdura pendant le Moyen Age et jusqu'à l'époque moderne. Cette agglomération avait-elle un rôle commercial lié à la navigation sur le Rhône? Nous avons vu plus haut que ce pont aurait pu servir de point de rupture de charges, sur l'axe Seyssel-Genève et également de lieu d'embarcation des productions locales (tuileries romaines repérées à Arcine (Varaschin, 1982) et à Savigny (Fenouillet, 1913 : p. 14) vers la métropole genevoise).

A l'ouest du village de Chevrier, des trouvailles sont signalées dans l'enquête menée par l'Académie Florimontane auprès des instituteurs sur les vestiges antiques de leur circonscription. Une statuette de Bacchus en bronze et un camée serti dans une bague en or ${ }^{8}$ ont été découverts fortuitement lors du réaménagement de la route, en 1870. Une grande statue de déesse en calcaire, haute de $3 \mathrm{~m}$, trouvée lors de la construction de la voie de chemin de fer, en 1876 a été morcelée pour servir de remblai ${ }^{9}$. Nous n'avons pas d'autres éléments permettant de replacer ces découvertes dans leur contexte. 
Dans son histoire de Genève, R. Montendon mentionne la découverte faite à Vulbens d'un petit vase et d'une anse d'amphore (Montendon, 1922 : p. 180, n² 272). Ici non plus aucune description n'est faite du contexte de cette trouvaille; l'anse d'amphore porte l'estampille : CAT.Q, abréviation de Caius Antonius Quietus, fabricant connu du sud de la Bétique, de la fin du Ier siècle et du début du IIe s. ap. J.-C. ${ }^{10}$.

L'ensemble de ces données, malgré d'importantes lacunes et sans que la nature et la chronologie des sites repérés soient établies, démontre cependant l'importance de l'implantation romaine sur ce terroir, à l'égal des régions voisines mieux étudiées. L'emprise de l'occupation humaine s'étend depuis le Rhône jusqu'aux pentes de la montagne, englobant l'ensemble du plateau traversé par la voie romaine.

L'exploitation agricole a dû conditionner le peuplement autour de l'éventuel vicus de Cologny, dont l'existence pourrait être en rapport avec la voie fluviale, très active durant l'Antiquité.

A deux reprises, en 260 et 277 ap. J.-C., la région genevoise est dévastée par les Alamans, tribu germanique du haut Danube. Le sentiment d'insécurité qu'ils provoquèrent incita les habitants de Genève à protéger la ville derrière un rempart et ceux des campagnes à réarmer les oppida (Guichonnet, 1973 : p. 68). En 1927, lors de la reconstruction de la chapelle implantée sur le site de l'oppidum du Vuache, l'abbé Pergot, curé de Vulbens, dit avoir observé

«les fondations d'un bâtiment rectangulaire de $12 \mathrm{~m}$ de long sur $10 \mathrm{~m}$ de large, construit en petits moellons de calcaire, liés au sable jaune, des débris de fer, des claveaux de tuf et des tuiles romaines » (Pergod, 1937 : p.56).

Cette construction de type antique, témoigne-t-elle de la réoccupation ou du réarmement du site de Sainte Victoire?

En 284 ap. J.-C., l'arrivée au pouvoir de l'empereur Dioclétien rétablit la tranquillité pour plus d'un siècle. L'organisation de l'Empire se modifie et de nouvelles circonscriptions territoriales sont délimitées : Genève devient le chef-lieu de la Civitas Genavensium, englobant l'actuel canton de Genève, la Haute-Savoie, l'Albanais et les Bauges.

\section{Au Moyen Âge}

La fin de l'Antiquité et le début du Moyen Âge sont, dans la région genevoise, dominés par deux événements majeurs: l'installation des Burgondes et le triomphe du christianisme. Pour cette période, les documents sont rares et peu explicites mais l'observation des indices hagiographiques et toponymiques permet de formuler quelques hypothèses.

Originaires de Scandinavie, les Burgondes bénéficient d'un traité avec Rome qui leur accorde, en 443 ap. J.-C., le statut de confédérés et le pays de Sapaudia. Ils y fondent le premier royaume de Bourgogne et font de Genève leur capitale. Les propriétaires galloromains sont tenus de partager leurs biens avec eux, à raison de deux tiers des terres, un tiers des esclaves et la moitié des forêts, de la curtis (centre d'exploitation agricole) et des vergers (Van Berchem, 1972 : p. 65). L'intégration des nouveaux venus, se faisant au sein de l'organisation agraire existante, tend à démontrer la continuité du domaine latin, malgré l'instabilité politique et les invasions des IIIe et IVe s. 

interprétations. Les deux thèses les mieux fondées la placent soit dans l'actuel canton de Genève avec une fraction du Bugey et de la Haute-Savoie, soit sur la rive droite du Rhône, de part et d'autre du Jura, dans la province des Séquanes. Par la suite, les Burgondes s'étendirent progressivement en dehors du territoire qui leur avait été attribué : Lyon est occupée en 470 et devient capitale principale de leur royaume. A la fin du Ve s., leur territoire s'étend de la Champagne méridionale à la Durance et aux Alpes maritimes.

Si la région du Vuache ne faisait pas partie du territoire initial, elle a dû être très vite annexée à cause de la possibilité qu'offre le sommet de la montagne pour la surveillance de la vallée du Rhône et pour la protection de Genève, qui reste capitale, mais joue un rôle secondaire après 470 . Le toponyme de Vuache semble provenir du germanique Watha : guet, garde qui a donné en allemand moderne wacht : surveiller, guetter (Dufournet, 1978: p. 173). Il est donc envisageable que l'oppidum du Mont Vuache ait connu durant cette période, peut-être occasionnellement, une occupation militaire.

Sous quelle forme ont été occupés le plateau et la rive du Rhône autour du village de Cologny? Par des groupes de colons ruraux ou bien ont-ils constitué le domaine d'un noble burgonde? Nous en avons peut-être la trace dans le toponyme du village de Vulbens (fig. $\mathbf{2}, \mathbf{n}^{\circ}$ 8) dont la première mention écrite est "Villa Wulbeengi» dans un texte de 1026 (R.G., $\mathrm{n}^{\circ}$ 172) ; villa était sans doute le qualificatif du domaine du XIe s. et Wulbengi son appellation la plus ancienne. Elle est formée du génitif Wolf et du suffixe datif et locatif-inge, signifiant: "la ferme-des-loups » ou plus probablement: «la ferme-de Wolf » du nom de son propriétaire d'origine germanique (Wipf, 1982 : p. 146). Le hameau de Faramaz (fig. 2, $\mathbf{n}^{\circ} \mathbf{9}$ ), distant de $800 \mathrm{~m}$ de Vulbens, porte également un toponyme qui peut être d'origine germanique, faisant référence aux Faramanni: hommes venus après, seconde vague de colonisation burgonde ou population étrangère, peut-être des Lombards ? Dans tous les cas recensés en Haute-Savoie, J. Vuy note que des contrées spéciales sont attribuées aux Faramans, toujours à l'écart de domaines burgondes (Vuy, 1889 : p. 60).

En 379. Genève devient siège d'évêché, dépendant de l'archevêché de Vienne et centre d'un vaste diocèse couvrant une superficie de $6800 \mathrm{~km}^{2}$, divisé en neuf circonscriptions dont huit décanats ruraux. Les paroisses qui nous intéressent dépendaient du décannat de Vuillonex (Mariotte, 1981).

Suivant le travail de G. Manteyer, la titulature des paroisses pourrait indiquer la date d'émergence de celles-ci ; il se fonde sur le fait que la ferveur populaire pour un saint, spontanée ou provoquée par des moines, n'était forte que pendant une période relativement restreinte (Manteyer, 1924). Cette méthode appliquée à la Savoie (P. Dufournet, 1978 : p. 177; A. Varaschin, 1982) a permis d'établir l'hypothèse de trois grandes époques de dédicaces à certains saints pour la vallée du haut Rhône. Les trois églises paroissiales de Chevrier, Vulbens et Dingy, (fig. 2, $\mathbf{n}^{\circ} \mathbf{7}, \mathbf{8}, \mathbf{1 3}, \mathbf{1 4}$ ) respectivement dédiées à Saint-Martin, SaintMaurice et Saint-Pierre appartiennent au premier groupe correspondant au Ve $\mathrm{s}$. Le culte de ces saints particulièrement vénérés par les moines de Saint-Claude, indiquerait peut-être l'influence de cette abbaye qui a connu une grande expansion à travers tout le Jura et la vallée du haut Rhône (Dufournet, 1978 : p. 178). 
ensemble de circonstances favorables permet aux premiers successeurs de Clovis de se rendre maîtres du royaume burgonde, après plusieurs campagnes infructueuses et de nombreux assassinats. Le pays est annexé en 534 et partagé entre Childebert Ier, Clotaire Ier et Théodebert, fils de Thierry Ier. Le territoire bourguignon passe ensuite du royaume franc à l'empire carolingien ; après la mort de Charlemagne, la Savoie fait partie de la Lotharingie. De cette époque, datent les premières mentions du Comté de Genève (Duparc, 1978): en 888, à l'abbaye de Saint-Mauriced'Agaune, le marquis Rodolphe est proclamé roi de Bourgogne par les grands seigneurs des pays jurassiens. Le second royaume de Bourgogne s'étend à l'origine, sur les régions qui constituent aujourd'hui la Suisse Romande et la FrancheComté ; petit à petit, les Comtés de Vienne et de Lyon puis le royaume de Provence sont annexés.

A partir de 962, le royaume de Bourgogne devient vassal de l'empereur germanique, Otton le Grand. Il est définitivement rattaché au Saint Empire Germanique en 1032 (Poupardin, 1907 : chap. 1). Pendant cette période, le système féodal achève de se mettre en place et, au début du XIIe s., le comte de Genève apparaît comme un grand seigneur et un prince puissant (Duparc, 1978).

Les premiers textes concernant notre secteur sont du XIe s. Il existe cependant un document qui s'applique probablement au Xe s., mais qui par sa nature même est peu fiable : il s'agit de la légende de Sainte Victoire à qui un culte est rendu dans la chapelle érigée au sommet du Mont Vuache, lors d'une procession annuelle qui s'est maintenue jusqu'au début du siècle. Cette histoire est consignée par deux auteurs, d'après des sources orales : l'instituteur de Chevrier, en 1890 et l'abbé Pergot, curé de Vulbens, en $1934^{11}$. Lors d'une attaque perpétrée par les Sarrasins, Victoire, moniale vivant dans un couvent, qui devait se situer aux alentours de Chevrier, tente de se réfugier au sommet de la montagne (ancien oppidum !) avec ses compagnes. Mais restée en arrière pour fermer le couvent, elle est poursuivie par les envahisseurs avant d'atteindre le refuge et préfère se jeter du haut de la falaise surplombant le Rhône plutôt que de tomber entre leurs mains. Elle est miraculeusement secourue par l'intervention divine qui lui permet d'atteindre, sans dommage, la rive opposée.

Cette légende nous amène à nous poser trois questions :

- L'incursion des Sarrasins fait-elle partie des nombreux raids menés périodiquement depuis la Provence, dans les Alpes et la vallée du Rhône? A partir de 906, date du pillage de l'abbaye de Novalaise et jusqu'à la capture de l'abbé de Cluny, en 972, les Sarrasins sont signalés par des pillages et des incendies de monastères et de villages, des massacres de voyageurs et des prises d'esclaves. La région genevoise est dévastée en 939 et l'abbaye de Saint-Mauriced'Agaune en 940 (Latouche, 1931). La région du Vuache a-t-elle donc été envahie et pillée par des troupes mauresques? Nous n'en avons aucune preuve directe, mais cela est possible de par la proximité des théâtres de raids connus. Il est admis que dans la région, les Sarrasins ont semé la terreur et contribué à désorganiser les systèmes économiques et politiques.

- Existait-il un couvent de religieuses à Chevrier? Nous n'avons aucun indice tangible, mais nous verrons qu'au XIIe s. ce village dépendait de l'abbaye de Chézery (R.G., n²48). Le couvent de Chevrier a-t-il été ruiné lors de ce raid, puis abandonné ? Etait-il issu de l'expansion de l'abbaye de Saint Claude, comme d'autres, contemporains, situés dans les zones limitrophes (Dufournet, 1978, p. 176) et la paroisse voisine de Savigny en 1110 (R.G., $\mathrm{n}^{\circ}$ 248)?

- L'oppidum du Vuache a-t-il servi de refuge aux populations jusqu'au Xe s. ? 
41 En tout cas, et de notre point de vue, il est intéressant de noter que son existence est restée gravée dans la mémoire collective grâce à cette légende et au pèlerinage commémoratif. suivant, sous le règne de Rodolphe III, dernier roi de Bourgogne. En 1026, le prêtre Ulrich et sa femme Girelda font donation à l'abbaye de Saint-Maurice-d'Agaune de biens considérables, consistant en terres, serfs et serves, situés en la "Villa Wulbeengi » (Vulbens). Avec le consentement du roi Rodolphe, ces biens sont remis aux donateurs, en précaire et sous le cens annuel de six sols (R.G., $n^{\circ} 172$ ). Ulrich était le fils d'Aldiud, ancienne concubine du roi Conrad de Bourgogne et le demi-frère de Buchard, archevêque de Lyon et abbé de Saint-Maurice (Duparc, 1978). Il meurt sans enfant et la plupart de ses biens passe à son neveu Aimon, évêque de Sionen-Valais (Duparc, 1978).

Bannis " (Bans). Ce document est cité par JY. Mariotte dans son dictionnaire des communes savoyardes mais nous n'avons pas retrouvé sa référence, malgré les recherches menées dans ce but.

44 A cette époque, le terme "villa» continue de désigner un grand domaine royal, aristocratique ou ecclésiastique (Bonnasié, 1981 : p. 199). Qui en était ici le détenteur? Ulrich possédait-il l'ensemble de la Villa Wulbengi ou seulement une partie en indivision avec un autre propriétaire ecclésiastique ou laïc ?

Entre 1173 et 1178, l'abbaye de Chézery détient le territoire compris du Mont-Sion à Chaumont et depuis Valleiry jusqu'au Vuache, (R.G., $n^{\circ}$ 393) mais les termes utilisés dans cette charte ne permettent pas de déterminer si la région du Vuache est incluse dans leur domaine ou si elle en est limitrophe et dans ce cas limitée à la paroisse de Savigny. En 1236, noble Pierre de Vulbens, chevalier, notifie qu'il a injustement contesté un don à l'abbaye de Saint-Maurice, fait par un de ses hommes liges, nommé Rex et demeurant à Soral (Suisse, canton de Genève) (R.G., $n^{\circ} 703$ ).

En 1196, le prieuré clunisien de Saint-Victor, situé dans le faubourg nord de Genève, possède des droits sur le territoire de Bans (fig. 2, $\mathbf{n}^{\circ}$ 19), puisque c'est le prieur qui autorise la construction de « l'oratoire » des Templiers de Cologny (fig. 2, $\mathbf{n}^{\circ}$ 18) (R.G., $\mathrm{n}^{\circ}$ 465). Ce monastère, membre (filiale) de la Commanderie de Compessières, est situé à proximité immédiate du lieu-dit «Port des Yelts» ou «Port des Isles » où les Templiers font fonctionner un bac à traille traversant le Rhône, qui permet de relier les régions septentrionales, la Michaille et le Pays de Gex, à la route allant de Genève à Chambéry, sans avoir à aller chercher un pont, soit à Genève à $20 \mathrm{~km}$ en amont, soit à Seyssel à 40 km en aval (Ganter, 1971). La maison du Temple de « Cologny sous Banz » existe toujours, transformée en centre d'exploitation agricole depuis la Révolution.

Quelques années plus tard, en 1239, Hugues de Sallenoves, lègue à son fils puîné Vuilhemme, le "fief du Vuache, depuis Dingy jusqu'au Rhône" qu'il tient de Pierre de Vulbens (R.G., $\mathrm{n}^{\circ}$ 224). Le chevalier était donc seigneur de Vulbens et du Vuache; probablement mort sans héritier, son domaine serait passé à son suzerain le seigneur de Sallenoves. Résidait-il à Vulbens ? L'état antérieur au château de pierre, découvert partiellement au cours des fouilles et correspondant certainement à un édifice castrai de terre pourrait répondre à cette dernière question. Son pouvoir seigneurial s'étendait directement sur les deux paroisses de Vulbens et Dingy. 

l'internationalisation de ses foires (Guichonnet, 1973). A partir de cette période nous pouvons, grâce aux documents, (fig. 4) suivre l'évolution du terroir qui était déjà en grande partie fixé autour des villages. Nous en avons une représentation très fiable pour la fin de l'Ancien Régime, antérieurement aux bouleversements des grandes réformes agraires de l'époque moderne.

Après l'acquisition du comté de Genève par la maison de Savoie en 1410, la cité genevoise échappe cependant au pouvoir du comte. En 1526, Genève signe un traité de combourgeoisie avec Fribourg et Berne. Dix ans plus tard et suite au triomphe de la Réforme, Charles III de Savoie assiège Genève au secours de laquelle se porteront les Bernois. Le conflit s'étend à toute la région; au cours de cet épisode, le château du Vuache est pris par les troupes bernoises puis occupé par une compagnie française jusqu'en 1559. 
4 : Détail de la carte de Cassini (XVIIle s.)

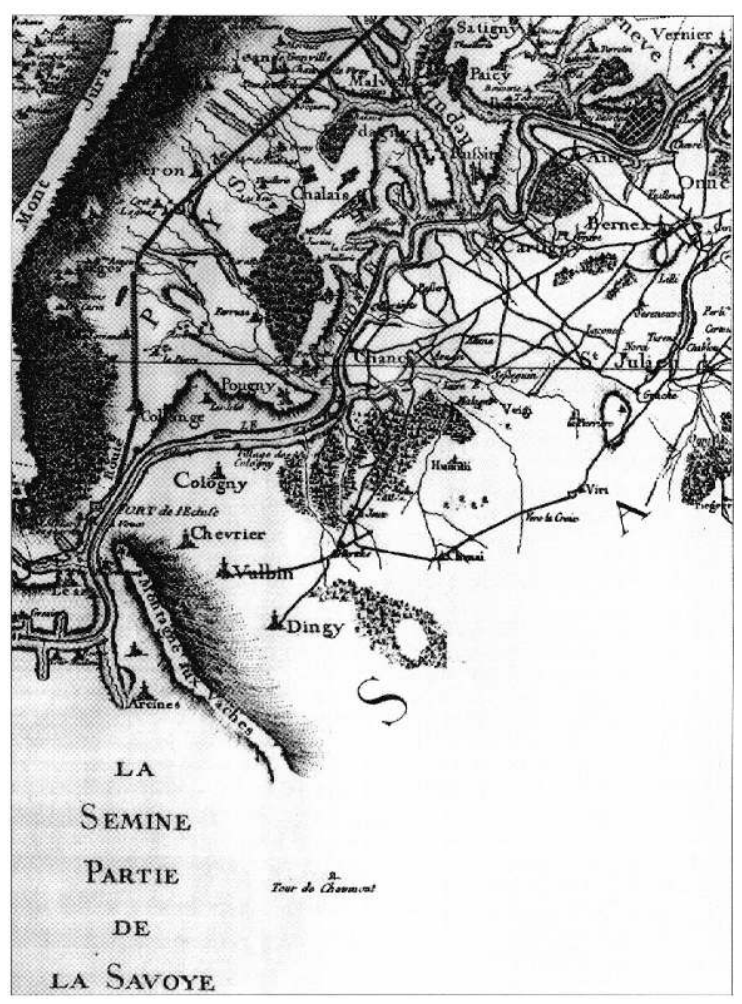

Carte topographique de la Seigneurie en 1730

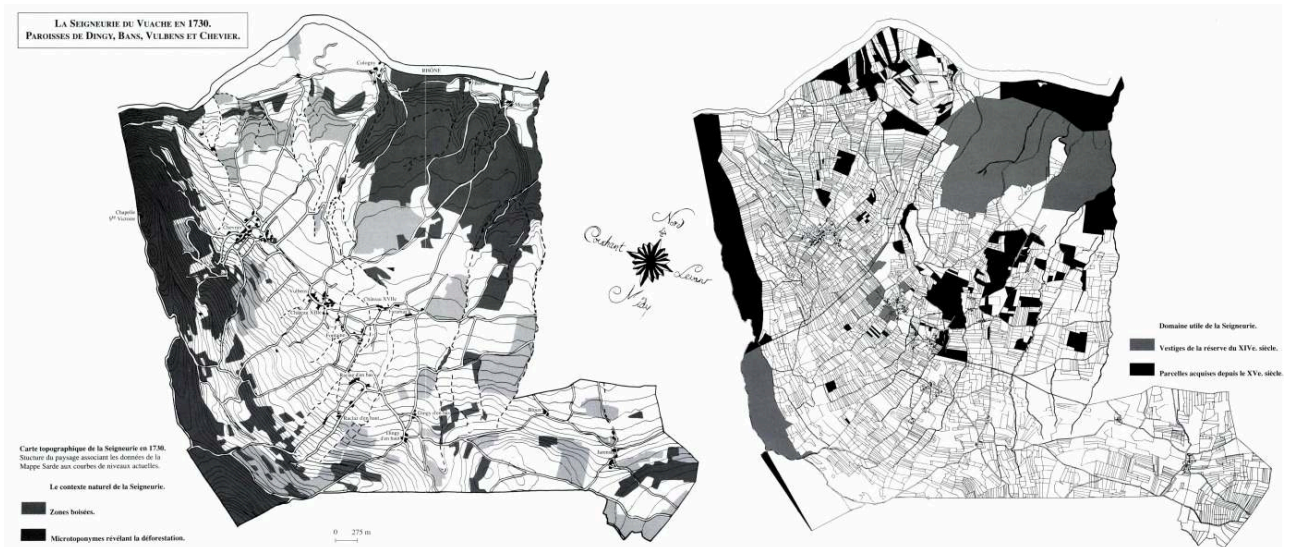

STRUCTURE DU PAYSAgE ASSOCIANT LES DONNÉES DE LA MAPPE SARDE AUX COURBES DE NIVEAU ACTUELLES

\section{NOTES}

1. Actuellement conservées au Musée d'Annecy.

2. Mappe Sarde A.D.H.S. 
3. D'après Jules César : "La guerre des Gaules" Livre I, chap. 8.

4. Appien : "celtica", IV, 15.

5. Dion Cassius: XXXVIII, 31.

6. Renseignements fournis par des agriculteurs et surtout par Mr P. Duret, professeur d'histoire, originaire de Dingy.

7. Actuellement conservée au Musée d'Art et d'Histoire de Genève.

8. Actuellement conservées au Musée d'Art et d'Histoire de Genève.

9. A.D.H.S : F 242, monographies communales rédigées par les instituteurs.

10. Corpus inscriptionum latinorum, XII, $5683-200$.

11. Cf. note 9 et A. Pergod : "Notice sur Sainte Victoire" Annecy 1937. 


\section{Chapitre 2. La seigneurie du Vuache}

1 L'évolution du château, de son rôle au sein de la société féodale et au centre de la seigneurie du Vuache apparaît grâce à l'ensemble des textes conservés. Ces documents sont variés : testaments, actes de concessions et de ventes, investitures des seigneurs, comptes de châtellenie, inventaires des biens seigneuriaux. Ils sont conservés aux archives de Genève, Annecy, Chambéry ou Langres.

- Les comptes de châtellenie, rédigés en latin par les châtelains des seigneurs de Vienne sur 10 rouleaux de parchemins dont certains sont très abîmés, couvrent la période de 1326 à 1343 . Ces documents sont très riches en renseignements concernant la vie économique et administrative du château ; les travaux d'entretien et de réfection des bâtiments qui y sont énumérés, offrent les premières indications sur l'édifice castral.

- Les chartes, actes de caractère privé, consignant par écrit des droits et règles d'intérêts variés; titres de propriétés, actes de vente, de donation, de privilèges octroyés ont été consultées. La plupart de celles antérieures à 1312, furent analysées et consignées par Lullin et Lefort dans le Regestre Genevois. Les archives notariales n'ont malheureusement pas pu être étudiées ${ }^{12}$.

- Les consignements de fiefs et leurs sommaires (inventaires des titres de propriétés) établis lors des investitures des fiefs inféodés par les princes de Savoie-Nemours étaient conservés par les archives de la cour savoyarde (A.D.S., série SA). Classés par fiefs et par ordre chronologique, ils fournissent quelques renseignements pour le XVe s. et le début de l'époque moderne $(1397,1447,1498,1701,1758)$; le patrimoine aristocratique y est énuméré mais mal localisé et souvent non détaillé.

Deux documents cependant présentent des inventaires détaillés du château du Vuache :

- En 1586, après le décès du chevalier de Villette, ses biens mobiliers (meubles et ustensiles métalliques de cuisine, vêtements, cheptel et numéraire) sont inventoriés (A.D.H.S., 7J 1223).

- En 1612, un inventaire est dressé lors de la passation de pouvoirs entre deux châtelains ; ce document répertorie chacune des portes contenues dans les édifices et le mobilier. La visite débute par le portail d'entrée puis présente la basse-cour et ses édifices, les tours et les pièces du logis en suivant l'ordre de progression du rédacteur. Le châtelain signale très précisement tous les travaux de restauration qu'il a fait exécuter.

3 Enfin, cette étude a pu utiliser un document majeur appelé communément Mappe Sarde. Ordonné par Victor Amédée II, élaboré de 1728 à 1736, ce document révèle la 
mensuration générale de la Savoie. Il est précieux tant par sa représentation graphique très précise du paysage du début du XVIIIe s. que par les nombreux renseignements contenus dans les tabelles.

4 Afin de limiter notre étude au domaine seigneurial, nous avons, après assemblage des cadastres des quatre paroisses de la seigneurie (fig. 5), sélectionné trois thèmes qui nous ont paru être les plus intéressants.

5 : Carte des quatre paroisses regroupées dans la seigneurie du Vuache

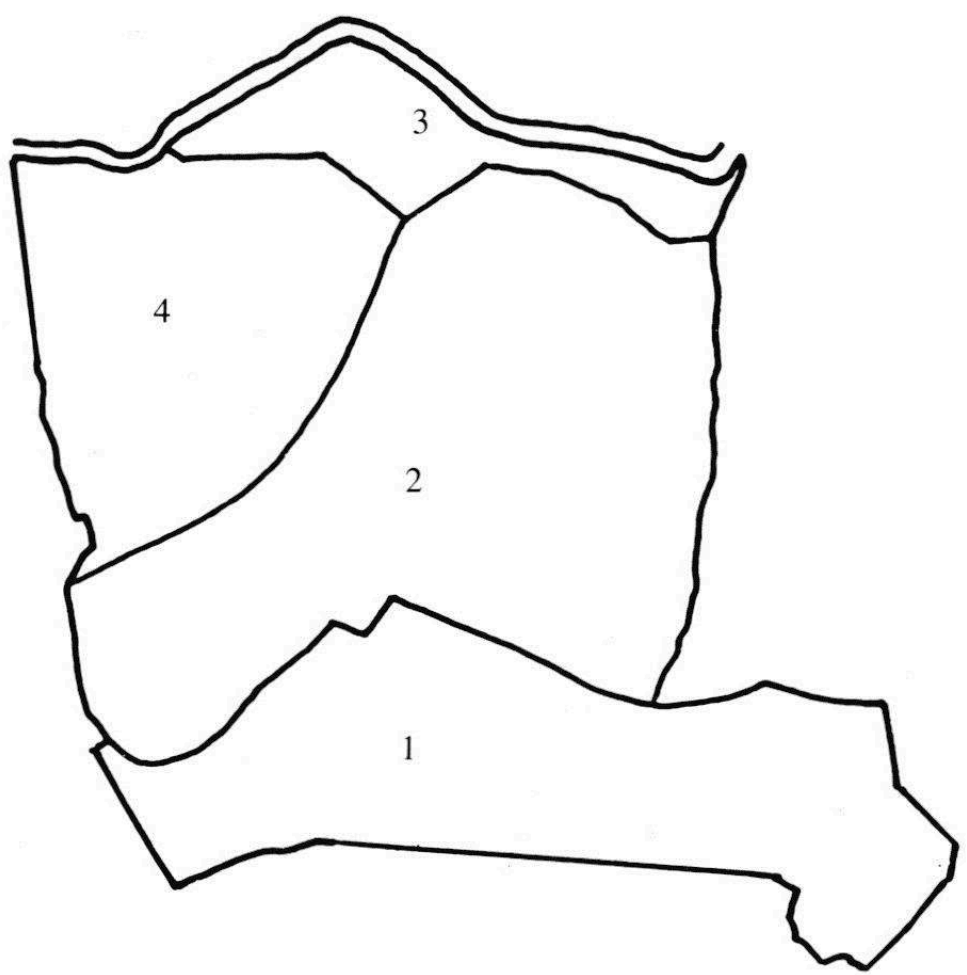

1 - VULBENS, 2 - DINgY, 3 - BANS, 4 - CHEVRIER.

- Les parcelles sont groupées en lieux-dits, suivant les indications de villageois spécialement recrutés pour guider les topographes, pour la plupart originaires du Piémont et de Lombardie; ces lieux-dits sont dénommés par un microtoponyme souvent révélateur des particularismes de chaque lieu.Nous avons donc dressé les cartes de ces microdivisions de l'espace pour chaque paroisse et essayé de trouver l'origine des noms donnés à ces lieux. Cette étude se révélant fort complexe et requérant une bonne connaissance du dialecte franco-provençal, nous n'avons retenu que les éléments particulièrement intéressants. La majorité d'entre eux, désignée par un microtoponyme faisant allusion à la topographie ou à la couverture végétale sont d'un intérêt historique plus difficilement appréhendable. Chaque lieu-dit porte un numéro correspondant à l'ordre d'enregistrement et est retranscrit avec l'orthographe de l'époque.

- En associant les données topographiques de la Mappe Sarde (cours d'eau, routes, constructions, forêts et microtoponymes correspondant à des déboisements et des bois) avec les courbes de niveaux actuelles, nous obtenons une carte topographique de la seigneurie, particulièrement utile pour l'analyse du domaine direct et du rapport entre l'habitat et l'édifice castrai (cf. dépliant : Carte topographique de la Seigneurie en 1730). 
- Dans le but d'enregistrer minutieusement la propriété foncière pour une équitable répartition de l'impôt, la Mappe présente le domaine utile tel qu'il était à la fin de l'Ancien Régime. A partir de celui-ci, nous avons, par déduction, pu étudier son évolution (cf. dépliant).

\section{Les seigneurs du Vuache}

5 Tout au long de leur histoire, soit par héritage, soit par transaction ou vente, le domaine, le château et les droits qui en dépendaient, sont passés entre les mains de nombreux propriétaires ou détenteurs temporaires illustres ou peu connus (fig. 6).

\section{6 : Tableau chronologique des seigneurs du Vuache}

\begin{tabular}{|c|c|}
\hline XIIes. & PIERRE de VULBENS \\
\hline av. 1236 & HUGUES de SALLENOVES \\
\hline 1236 & VULHEMME de VIRY-SALLENOVES \\
\hline av. 1252 & GUILLAUME II comte de GENEVE \\
\hline 1252 & HENRI de GENEVE (mort avant 1273) \\
\hline av. $1273-1290$ & ROBERT Evếque de GENEVE (mort en 1287) \\
\hline & GUI Évêque de LANGRES ( mort en 1290) \\
\hline av. 1296 & AMEDEE II comte de GENEVE \\
\hline 1296 & $\begin{array}{l}\text { JEANNE de GENEVE } \\
\text { epouse de PHILIPPE de VIENNE } \\
\text { COMTESSON de GENEVE } \\
\text { épouse de JFAN de VIEVNNE }\end{array}$ \\
\hline xives. & $\begin{array}{l}\text { HUGOVIN el JEAV de VIENNE } \\
\text { HUGUES et PHILIPPE de VIEVNE }\end{array}$ \\
\hline 1366 & $\begin{array}{l}\text { MARGUERTTE de BANAINS } \\
\text { épouse de JEAN de CHATLLON de MICHAIILIE }\end{array}$ \\
\hline 1383 & puis de GIR.ARD de TERNIER \\
\hline $\mathrm{xves}_{\mathrm{N}}$ & \\
\hline 1418 & RICHARD de MONTCHENU \\
\hline 1466 & GIRARD de MONTCHENU \\
\hline 1498 & ANTOINE de MONTCHENU \\
\hline xVIes. & \\
\hline 1500 & MARIN de MONTCHENU \\
\hline 1534 & $\begin{array}{l}\text { FRANCOISE de ROVOREE } \\
\text { épouse d'AMEDEE de MENTHON-LORNAY }\end{array}$ \\
\hline 1563 & $\begin{array}{l}\text { ALEXANDRA de MENTHON-LORNAY } \\
\text { épousc du chevalier de VILLETTE }\end{array}$ \\
\hline 1578 & baron BERNARD de MENTHON-L.ORNAY \\
\hline xVIIIes. & \\
\hline 1701 & comte RENE de MENTHON-LORNAY - JEAN-BAPTISTE MILIET de CHALLES \\
\hline 1708 & PIERRE LOUIS de LESCHERAINE: \\
\hline av. 1730 & $\begin{array}{l}\text { FRANCOIS-RENE de COUDREY de BLANCHEVILLE } \\
\text { époux de GASPARDE de LESCHERAINE }\end{array}$ \\
\hline 1758 & marquis JACQUES de LESCHERAINE \\
\hline
\end{tabular}

6 La première mention connue du fief du Vuache est faite dans le testament de Hugues de Sallenoves, en 1239 ; il lègue "le fief du Vuache depuis Dingy jusqu'au Rhône qu'il tenait de feu le chevalier Pierre de Vulbens ". L'usage du terme de "fief » correspond à la concession d'une terre contre un engagement dans les liens vassaliques. Il constituait l'apanage de son fils puîné Vuilhemme de Viry-Sallenoves (R.G., $n^{\circ} 224$ ).

7 En 1252, c'est le comte Guillaume de Genève qui légue à son fils Henri, les «castra » et mandements (territoire sur lequel s'exerce l'autorité politique du seigneur) de Ternier et de Vuache (R.G., $n^{\circ}$ 401). Nous ignorons comment et à quelle date, le comte a acquis le Vuache, de Vuilhemme de Viry-Sallenoves. Henri de Genève (décédé avant 1273) était le seul frère laïc du comte Raoul ; il prêta hommage au comte Pierre de Savoie en 1254 (R.G., $n^{\circ}$ 407) et laissa de son vivant, en garantie de dots dues à ses filles Béatrice de Lunel et Eléonore, épouse de Bertrand des Baux, prince d'Orange, l'ensemble de ses biens à son frère Robert, évêque de Genève, de 1276 à sa mort en 1287 (R.G., n 541). Robert garda ces biens sans exécuter l'obligation de doter ses nièces. 
8 A sa mort, ils passèrent à un autre frère, Gui de Genève (R.G., $\mathrm{n}^{\circ}$ 474). Evêque de Langres en 1266, ce dernier accompagna le roi de France Louis IX en croisade et assista aux sacres de Philippe III. Il fut conseiller et exécuteur testamentaire de Philippe III et de Philippe IV. (Duparc, 1978). En 1278, il engagea les «castra et cens de Terniaci et de Vaicho" auprès de Guillaume d'Avallon, chevalier châtelain d' «Anasiaci» (Annecy). Dans son testament, en 1290, il demande à ses neveux Jean, évêque de Valence et Gui, archidiacre de Dijon, de conserver en leurs possessions et à titre de tuteurs et curateurs, les terres de feu Henri de Genève, jusqu'à ce que les dots de leurs cousines fussent réglées (A.D.H.M., série GTI, doc. G 12).

9 Cette obligation a dû être acquittée puisqu'en 1296, nous retrouvons le château du Vuache en possession du comte Amédée II, fils de Raoul de Genève (fig. 7, 8).

En janvier 1296, le comte concéda le " castro seu domus fortem dou Vasho", une somme de 2000 livres et une rente annuelle de 200 livres sur les terres dudit château à sa nièce Jeanne de Genève, épouse de Philippe de Vienne, seigneur de Poigny et fille de feu Aymon, comte de Genève, en contrepartie de renonciation de droits sur son héritage (R.G., $\mathrm{n}^{\circ}$ 1406). Cet acte fut ratifié par Philippe de Vienne au mois de mai suivant (A.D.H.S., série SA, doc. 63).

11 Depuis le début du XIIIe s., les comtes de Genève ne résidaient plus à Genève mais avaient fait du château d'Annecy, leur résidence principale et séjournaient temporairement dans leurs châteaux secondaires.

7 : Cession faite par le comte Amédée de Genève du château du Vuache (1296)

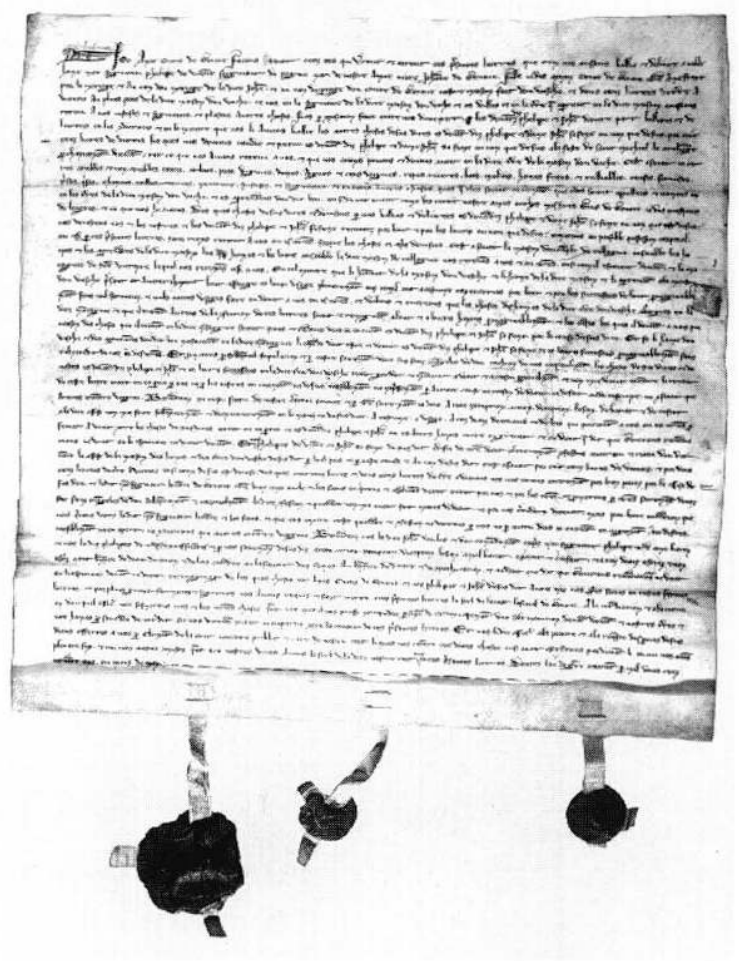

http://archives.cg74.fr/ 


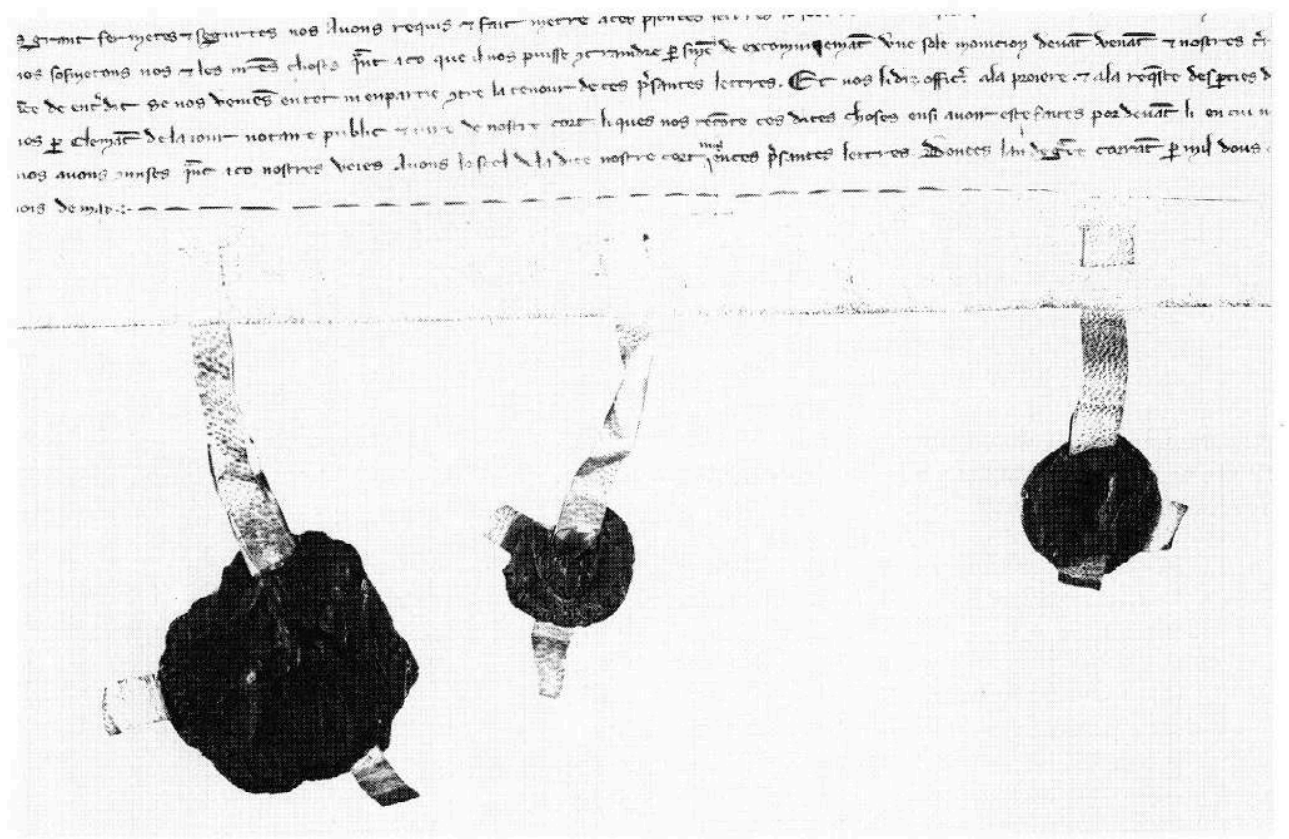

http://archives.cg74.fr/

Après la concession du domaine du Vuache à sa nièce, Amédée II conserva le droit de ban sur la seigneurie et continua à y demeurer occasionnellement (droit de gîte). Le 24 septembre 1306, il y rédigea son testament «in castro de Vaschio» (R.G., $\mathrm{n}^{\circ}$ 1594); en septembre 1307, il y reçut le dauphin Hugues de Faucigny et Aimon de Quart, évêque de Genève pour conclure une alliance officielle "actum apud el Vuacho in camera dicti comitis... » (R.G., $\mathrm{n}^{\circ}$ 1614). Il y meurt, semble-t-il à la suite d'un accident de chasse ou d'une maladie, le 22 mai 1308 ; ses obsèques furent célébrées deux jours plus tard, au couvent de SainteCatherine-du-Mont, près d'Annecy (R.G., n 1619).

Le château reste entre les mains de la famille de Vienne, soit de Jeanne de Genève et de ses fils, Hugonin et Jean qui en prêta hommage au comte Guillaume III de Genève, le 23 décembre 1314 (A.D.H.S., série SA, 136, fol. I), soit de Comtesson, soeur de Jeanne et épouse de Jean de Vienne, frère de Philippe, et de leurs fils Hugues et Philippe. Ce dernier prêta hommage en tant que seigneur du Vuache à Amédée III de Genève, en 1320 (A.D.H.S., série SA, 136, fol. II). Le domaine du Vuache était donc certainement divisé entre les deux sœurs et leurs fils mais nous ne savons pas suivant quelles modalités. Durant cette période, le comte de Genève détenant la seigneurie banale, seul le domaine utile aurait été concédé à la famille de Vienne.

Le 24 mai 1366, le comte de Genève autorisa la vente du Vuache, par Jean et Hugonin de Vienne, fils de Jeanne de Genève, à Marguerite de Banains (A.D.H.S., série SA, 136, fol.III). Son époux, le chevalier Jean de Chatillon de Michaille, avait vendu leur seigneurie de Banains en Dombes, le 6 octobre 1364, pour effectuer cet achat (Guichenon, 1662, p. 30-34).

Marguerite de Banains épousa en secondes noces, avant 1383, le chevalier Girard de Ternier, seigneur du Chatelard (De Foras, 1943). Moyennant la somme de 100 livres, 
Girard de Ternier fit inféoder le fief du Vuache par la maison de Savoie, en prêtant hommage au comte Louis de Savoie, le 13 juin 1397 (A.D.S., série SA, 136). Outre le domaine utile du Vuache, Girard de Ternier semble avoir acquis la seigneurie politique ou droit de ban qu'il transmettra à ses descendants.

En 1410, après l'extinction de la dynastie des comtes de Genève, Amédée III de Savoie, rachète les droits sur le comté, cependant la cité Genevoise conserve une relative indépendance. En 1418, à la mort du chevalier, le Vuache passa à son neveu Richard de Montchenu, coseigneur de Ternier et seigneur de Chaumont. Lors de l'hommage qu'il rendit au comte Louis de Savoie, en août 1447, il reconnaît "tenir le mandement du Vuache en fief de son château de Chaumont - sous hommage lige ».

17 En 1466, son fils Girard fut investi des «fiefs, château et biens du Vuache » et "reconnaît (les) tenir du prince Janus de Savoie en fief noble, lige, paternel et ancien, sous hommage lige et fidélité lige ».

18 En 1498, ses terres et biens du Vuache passèrent à son fils Antoine, seigneur de Montchenu, qui tenait également le « Vuache en fief de son château de Chaumont » (A.D.S., série $\mathrm{SA}, 136)$.

19 La seigneurie passa, en 1500, à Marin de Montchenu, chevalier du Vuache, baron de Chaumont, premier maître d'hôtel de François Ier. Il vendit une première fois le mandement et le château du Vuache à son épouse Antoinette de Pontbriand, en décembre 1533 et une seconde fois en avril 1534, à Françoise de Rovorée, épouse d'Amédée de Menthon Lornay; il s'en suivit des procès entre ces deux dames et des échauffourées entre leurs serviteurs (De Foras, 1943).

20 En 1536, au cours de la guerre qui opposa le duc de Savoie à la ville de Genève, le château du Vuache fut pris par les troupes bernoises, pillé et incendié. Mais Marin de Montchenu, stationnant avec François Ier et l'armée française au château de Chaumont, réussit à faire arrêter l'incendie. La place fut ensuite occupée par le capitaine Brémière et une compagnie de Suisses, soldats du Roi de France (Gilliard, 1935).

21 Après vingt-trois années d'occupation française, la Savoie est rendue au duc EmmanuelPhilibert lors du traité de Cateau-Cambrésis, le 25 avril 1559.

22 Françoise de Rovorée dut faire reconnaître ses droits sur la seigneurie car, en 1563, sa fille Alexandra de Menthon-Lornay, épouse du seigneur de Villette résidait au Vuache (A.D.H.S., série 7J, doc. 1223). A sa mort, en 1578, ses biens passent au baron Bernard de Menthon-Lornay et à sa femme Jeanne (A.D.H.S., série 7J, doc. 1146) (fig. 9). 
9 : Blason de la famille de Menthon-Lornay ornant une borne découverte sur le site

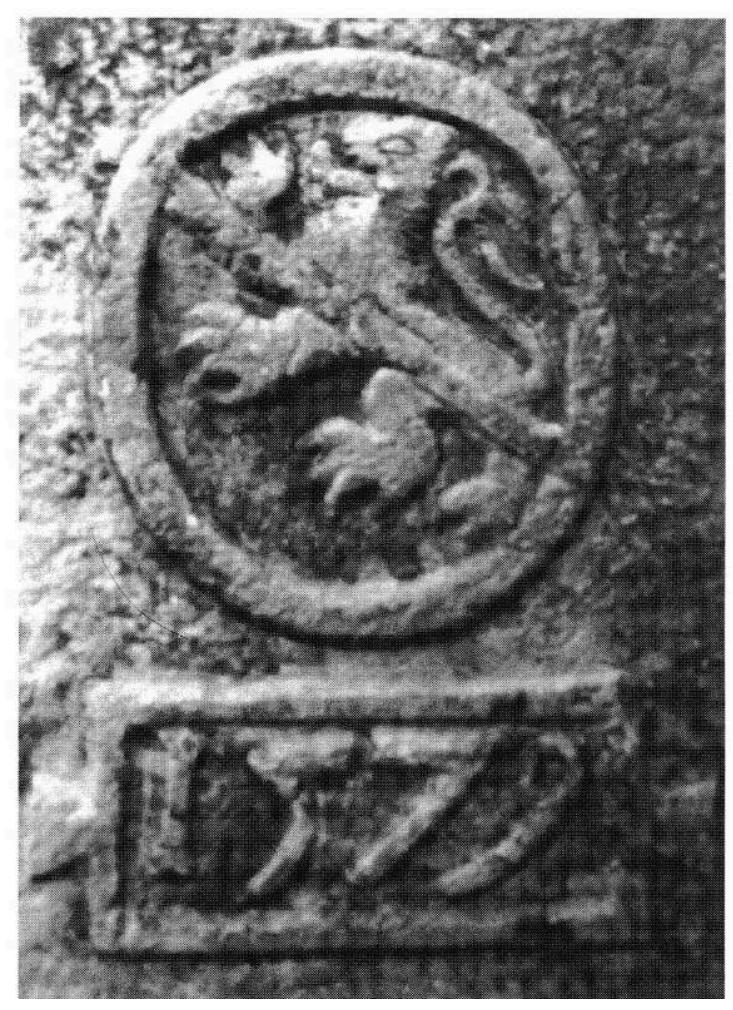

23 Au début du XVIIe s., le château de Vulbens est abandonné, une nouvelle résidence seigneuriale est construite autour de la tour de Faramaz (fig. 10). L'ancien château servit sans doute de carrière pour la construction du nouveau, distant de $800 \mathrm{~m}$. La seigneurie fut divisée en février 1701, entre le comte René de Menthon-Lornay, descendant de Bernard et de Jeanne, et le marquis Jean Baptiste Millet de Challes. En 1708, Pierre-Louis de Lescheraine racheta les deux parts. En 1730, lors de la levée de la Mappe Sarde, la seigneurie du Vuache appartenait à François René de Coudrey de Blancheville, époux de Gasparde de Lescheraine (A.D.S., série SA, 136). 


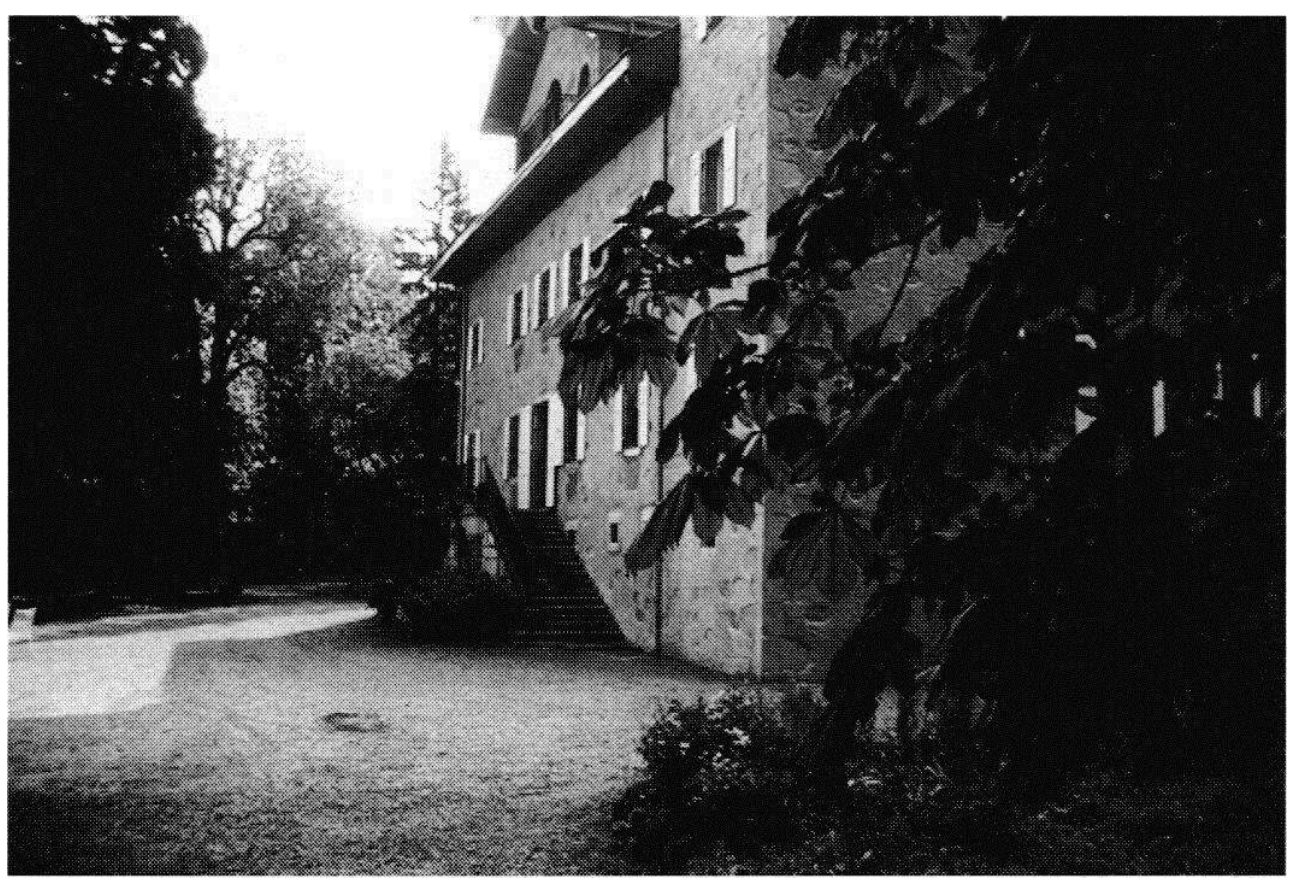

En 1758, le marquis Jacques de Lescheraine fut investi du fief du Vuache qu'il conserva jusqu'à l'abolition des droits seigneuriaux en 1792 (A.D.S., série SA, 1 et 136).

La première mention de 1239 est celle d'un seigneur foncier dont la famille a pris le nom de la seigneurie, et qui, de ce fait, pourrait en être les premiers vassaux.

En 1252, apparaît dans les textes la famille de Genève. Ils sont châtelains et possèdent la seigneurie banale. Les deux types de seigneurie, possession du sol et du pouvoir restent partagés jusqu'à la vente de 1366 par les descendants de Jeanne de Genève de Poigny.

Vers 1397, Girard de Ternier semble posséder le foncier et le droit de ban, mais nous ignorons comment il a acquis ce dernier. Lors de l'inféodation à la famille des TernierMontchenu, qui par alliance matrimoniale possédaient déjà le mandement, le comte opère une reconstitution du fief initial. On voit ainsi se resserrer les liens vassaliques : le comte de Savoie tient ses barons en leur redonnant un patrimoine dans le cadre de l'hommage lige, du fief pris comme base pour le recrutement de l'ost.

28 Si l'étude des textes a rendu possible la distinction entre les deux seigneuries, l'étude de la Mappe Sarde et de ses microtoponymes a livré de nombreux renseignements qui permettent de les restituer et d'étudier leur évolution.

La seigneurie comprend un domaine direct qui est soumis au cens, divisé en quatre paroisses, et un domaine utile ou réserve. Enfin à travers la répartition de la taille, il est possible d'évaluer l'emprise de la seigneurie politique.

\section{Le domaine direct}

Le domaine direct seigneurial correspond au mandement sur lequel s'exerçait le pouvoir politique, juridique et économique des seigneurs qui le tenaient en fief.

Pour le fief du Vuache, nous apprenons qu'en 1447, le seigneur Richard de Ternier détenait le «mere mixte empire, omnimode juridiction haute, moyenne, basse et dernier 
supplice sur les hommes délinquants dans le dit mandement ", à savoir les paroisses de Dingy, Chevrier, Vulbens et Bans. La seigneurie du Vuache conservera cette extension jusqu'à l'abolition des droits seigneuriaux en 1792 (A.D.S., série SA, 136).

Pour les siècles antérieurs à cette période, la structure du fief du Vuache est plus difficile à établir ; nous ne disposons que de trois documents pauvres en informations, recensés par Lullin et Lefort dans le Regestre genevois, ensemble des pièces connues en 1866 et antérieures à 1311.

En 1196, c'est le prieur de Saint-Victor de Genève qui autorisa l'installation des Templiers au hameau de Cologny, dépendant de la paroisse de Bans (R.G., $\mathrm{n}^{\circ} 465$ ).

En 1239, dans son testament, Hugues de Sallenoves légua " le fief du Vuache, depuis Dingy jusqu'au Rhône » qu'il tenait de feu Pierre de Vulbens (R.G., n 224).

En 1295, l'évêque de Genève notifia un accord entre le comte Amédée II de Genève et le chapitre de la cathédrale de Genève au sujet de plaintes formulées par ce dernier pour des exactions et empiétements sur sa juridiction, commis par le comte, le chapitre possédant tous les droits et juridiction sur les hommes de Cologny et de Chevrier (R.G., $\left.n^{\circ} 1402\right)$.

Les paroisses de Bans et de Chevrier, dépendantes de seigneurs ecclésiastiques n'ont donc été rattachées à la seigneurie du Vuache que tardivement. Bans a dû être intégré au domaine avant 1239 puisque à cette date le fief du Vuache s'étendait jusqu'au Rhône; Chevrier l'a probablement été au début du XIVe s. car, dès 1326, la dîme de ce village est perçue par le châtelain du seigneur (A.D.H.S., inv. 58, fol. 387, c. 126) et Cologny, à la fin du XIVe s. ou au début du XVe s. ; les Templiers, détenant des droits sur ce hameau ont pu facilement défendre leurs intérêts.

En l'absence de documents plus explicites, il est cependant difficile de déterminer comment les seigneurs du Vuache ont acquis ces territoires. Peut-être par transaction avec le chapitre ou peutêtre ont-ils usé du caractère ostentatoire du château, lors de l'inféodation au Duc de Savoie, pour spolier les anciens détenteurs.

La structure du paysage de la seigneurie est mise en évidence par la carte topographique (cf. dépliant) réalisée à partir de la Mappe Sarde. Elle paraît être conditionnée par la voie romaine qui traverse le territoire étudié, sur une longueur d'environ $5 \mathrm{~km}$ du sud-est au nord-ouest, en longeant la base de la voûte synclinale; la majorité des chemins secondaires se raccorde à cet axe et trois des chefs-lieux de paroisses sont implantés sur ses bords, la paroisse de Bans occupant une situation marginale de par son implantation sur la rive du fleuve. Le terroir s'étend entre deux grands espaces boisés recouvrant au sud-ouest, la cime de la montagne et au nord-est, l'angle formé par le confluent du Rhône et du ruisseau de la Vosogne. La microtoponymie relative aux déforestations et celle des hameaux extérieurs laissent supposer un terroir à l'origine plus restreint de part et d'autre de l'axe principal.

\section{La paroisse de Vulbens}

39 Au centre de la seigneurie, la paroisse de Vulbens (fig. 11) regroupait les hameaux de Faramaz à l'est et de La Fontaine au sud-est autour du chef-lieu. La population de ces trois villages se répartissait entre 32 feux en 1411, 34 feux en 1518 (Acad. Salès., tome 74, pp. 301 et 318), 52 feux soit 237 habitants en 1562 (A.D.S., série SA, SA 1961, p. 22) et 60 feux en 1605 (Rebord, 1922, p. 771). 


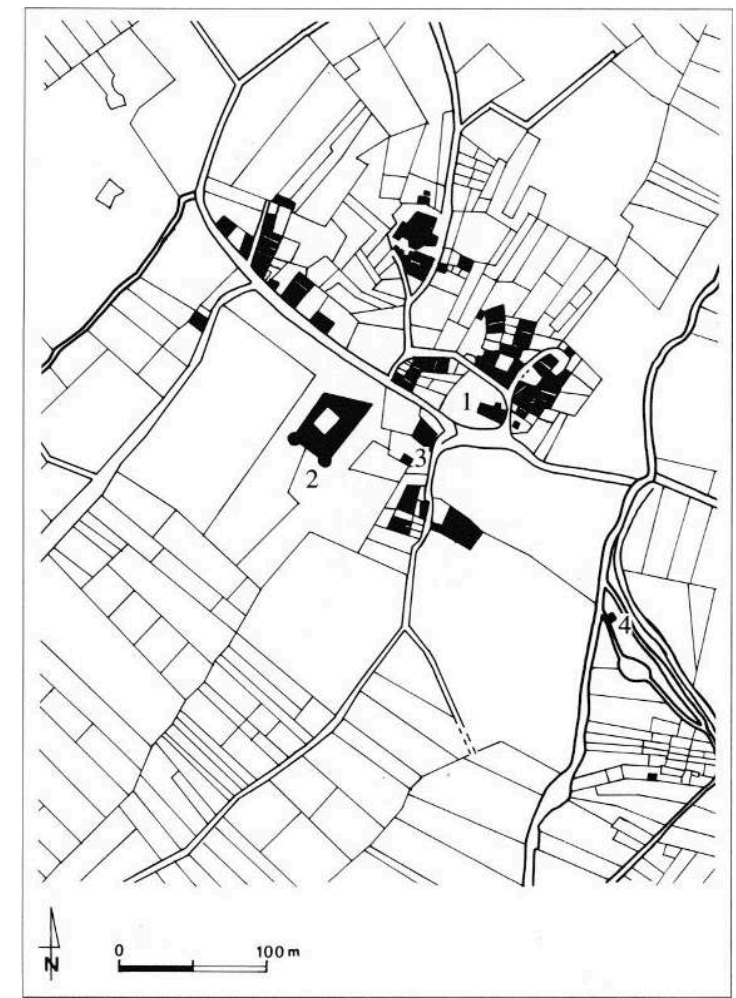

1 - Eglise et cimetière paroissiaux. 2 - Château du vuache. 3 - Four banal. 4 - Moulin banal sur bief.

L'église paroissiale entourée du cimetière, paraît être le point d'ancrage du village, au centre duquel elle est située, à proximité du château seigneurial et à l'intersection de la route romaine et du chemin menant au gué du village de Cologny. Elle est dédiée à Saint-Maurice (chef de la légion thébaine, massacrée à Agaune, à la fin du IIIe s.) (Mariotte, 1981). Elle abritait la chapelle seigneuriale de Sainte-Catherine, attestée depuis 1484 et celle du Rosaire desservie par une confrérie (Oursel, 1953). Cet édifice a été entièrement refait vers 1820-1830 par allongement de la nef et adjonction de deux collatéraux. Seul le chevet plat, éclairé par une fenêtre géminée du XVe s. a été conservé (fig. 12). Un nouveau clocher érigé au sud du bâtiment remplace l'ancien, visible sur la Mappe Sarde du côté nord.

L'habitat tel qu'il apparaît au début du XVIIIe s., se répartit en maisons contiguës, aménagées le long de chemins perpendiculaires à l'axe principal. 
12 : Chevet de l'église paroissiale Saint-Maurice-de-Vulbens

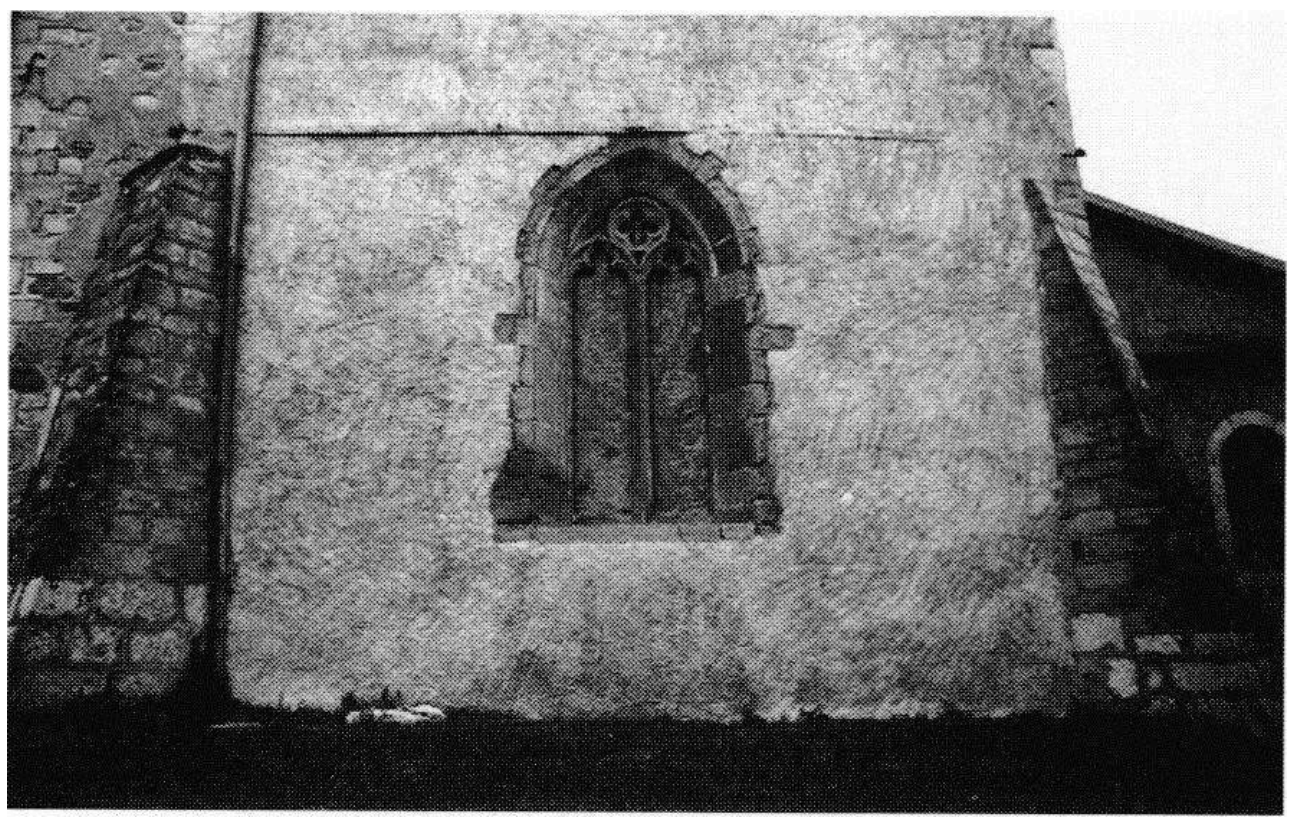

42 Le hameau de Faramaz était tenu par la famille noble de Faramans, résidante dans le donjon de Faramaz, qui correspond au microtoponyme $\mathrm{n}^{\circ} 15$ a la tour. Le seigneur du Vuache l'acquit avec les terres qui en dépendaient de Pierre de Faramans, avant 1466 (A.D.S., série SA, 136). Dans son testament rédigé en 1278, le seigneur Hugues de Sallenoves prévoyait un don pour la maladière de Fonz à côté de Dingy. Cette institution qui devait se trouver au hameau de La Fontaine (fons et font dans les documents anciens) n'est connue que par ce texte, elle a dû disparaitre rapidement (Mariotte, 1981).

43 Malgré sa superficie d'environ 1000 hectares, le finage n'est subdivisé qu'en 51 lieuxdits (fig. 13), la plupart correspondant à des caractères géomorphologiques ou à des cultures, cependant nous noterons : le $\mathrm{n}^{\circ} 5$, des perrières, s'étendant sur le territoire de la paroisse de Chevrier (le $\mathrm{n}^{\circ} 69$, les perrieres également), correspondant à une carrière, probablement d'extraction de molasse (Longnon, 1979, $\mathrm{n}^{\circ} 2592$ ) ; les $\mathrm{n}^{\circ} 26$, la chavanoz, $\mathrm{n}^{\circ} 38$, a chavanoux, $\mathrm{n}^{\circ} 39$, alla chavanna) et $\mathrm{n}^{\circ} 47$, au grand chavanoux, toponymes qui pourraient correspondrent à des habitats ruraux ou temporaires (Longnon, 1979, $\mathrm{n}^{\circ}$ 2676); au lieu-dit $\mathrm{n}^{\circ}$ 6, a la contaminaz forme régionale de condamine (parcelle appartenant au domaine primitif, cultivée par les paysans et dont les revenus servaient à l'entretien du seigneur) (Longnon, 1979, $\mathrm{n}^{\circ}$ 2760), le seigneur détient une partie du terrain en pré, ce terrain est exempté de taille car faisant partie du patrimoine seigneurial d'avant 1580 , le reste de l'espace était divisé en parcelles tenues par des paysans.

44 Les lieux-dits $n^{\circ} 1$ et $n^{\circ} 2$ correspondant à l'église paroissiale et au château ne portent pas de microtoponyme. 


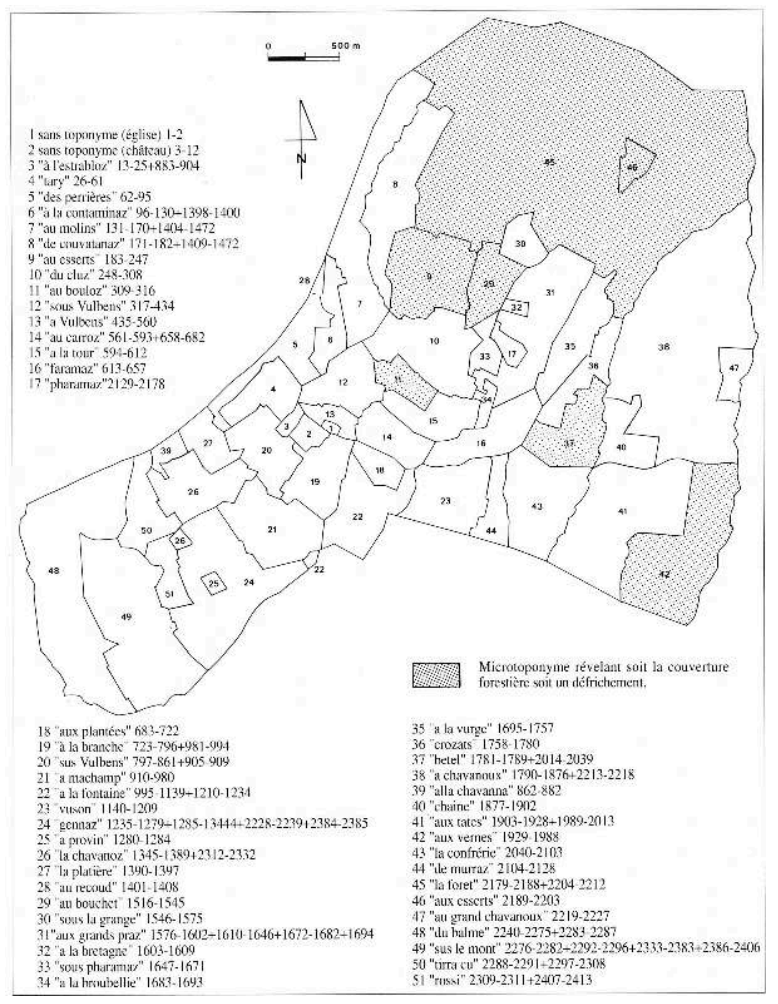

\section{La paroisse de Dingy}

Située sur le flanc de la montagne du Vuache, au sud-est de la seigneurie et couvrant une superficie de 800 hectares, la paroisse de Dingy se caractérise par son éclatement en plusieurs hameaux: Bloux et Jurens sont deux petits groupes de maisons, situés à l'écart de la voie romaine principale, dans une zone formant un appendice par rapport au domaine seigneurial. Les toponymes de ces villages seraient d'origine germanique, Bloux provenant d'un anthroponyme féminin (Longnon, 1979, $\mathrm{n}^{\circ}$ 2159) et Jurens désignant un lieu boisé surtout de pins (Gros, 1973, p. 238). Dingy-d'en-bas et Dingyd'en-haut sont deux petits hameaux, distants de $500 \mathrm{~m}$ (fig. 14) ; l'église paroissiale, dédiée à Saint-Pierre, se trouvait au village de Dingy-d'en-haut. Elle apparaît sur la Mappe Sarde, parcelle $n^{\circ} 676$; elle a été ultérieurement incorporée à un bâtiment d'exploitation agricole : on aperçoit encore le portail occidental (fig. 15) dont la clef d'arcade est décorée d'un blason (De Livron, seigneur de Savigny ?) et datée de 1554. (fig. 16) L'arc triomphal (fig. 17) est aujourd'hui inclus dans l'actuelle facade orientale. La nef sert d'étable et le choeur arasé, de fosse à purin. 
14 : Villages de Dingy-d'en-Haut et de Dingy-d'en-Bas en 1730

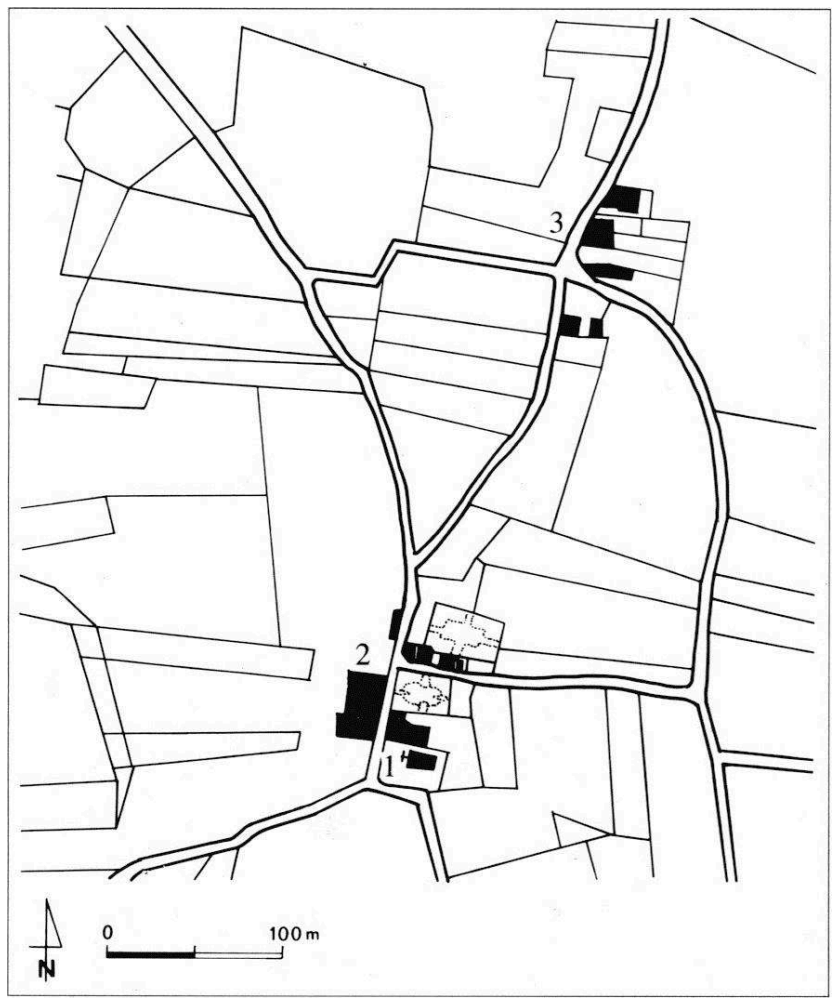

1 - EgLISE PAROISSIALE 2 - dingY d'EN haUt 3 - Dingy d'En bAS

15 : Façade de l'église paroissiale Saint-Pierre-de-Dingy

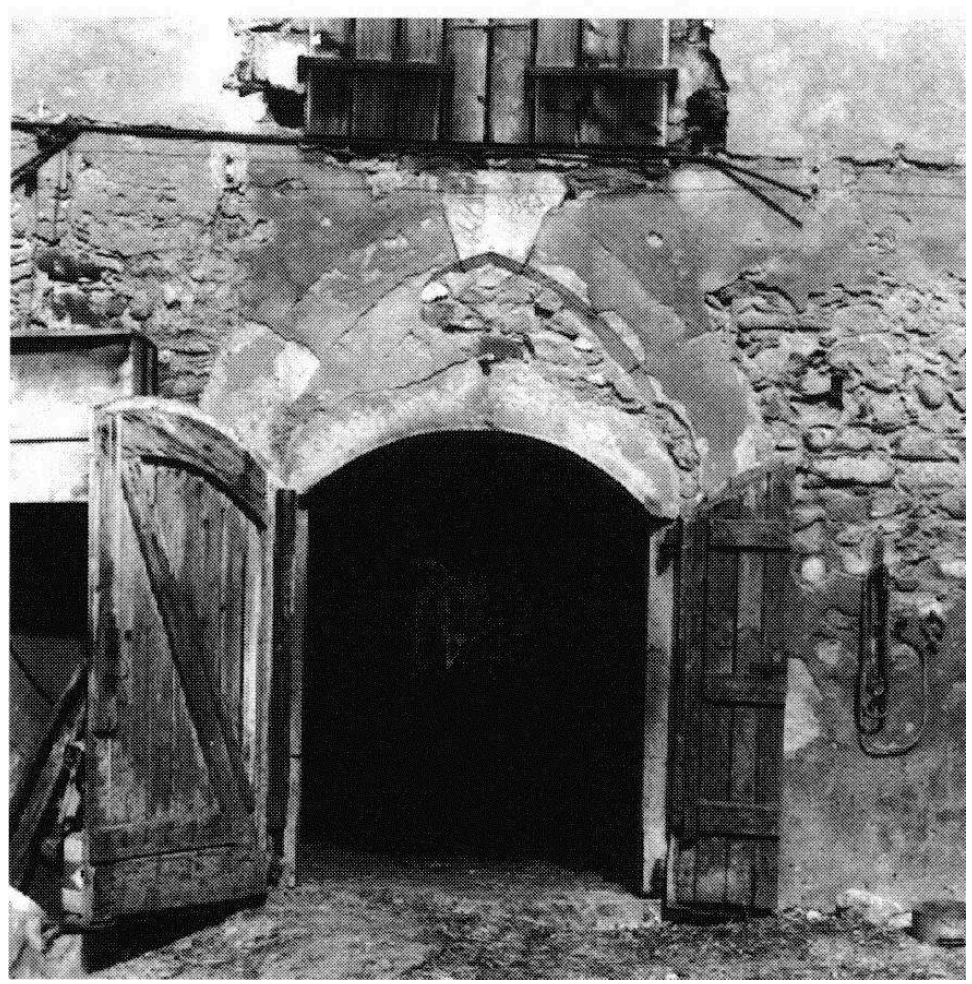


16 : Blason décorant le portail de l'église de Dingy

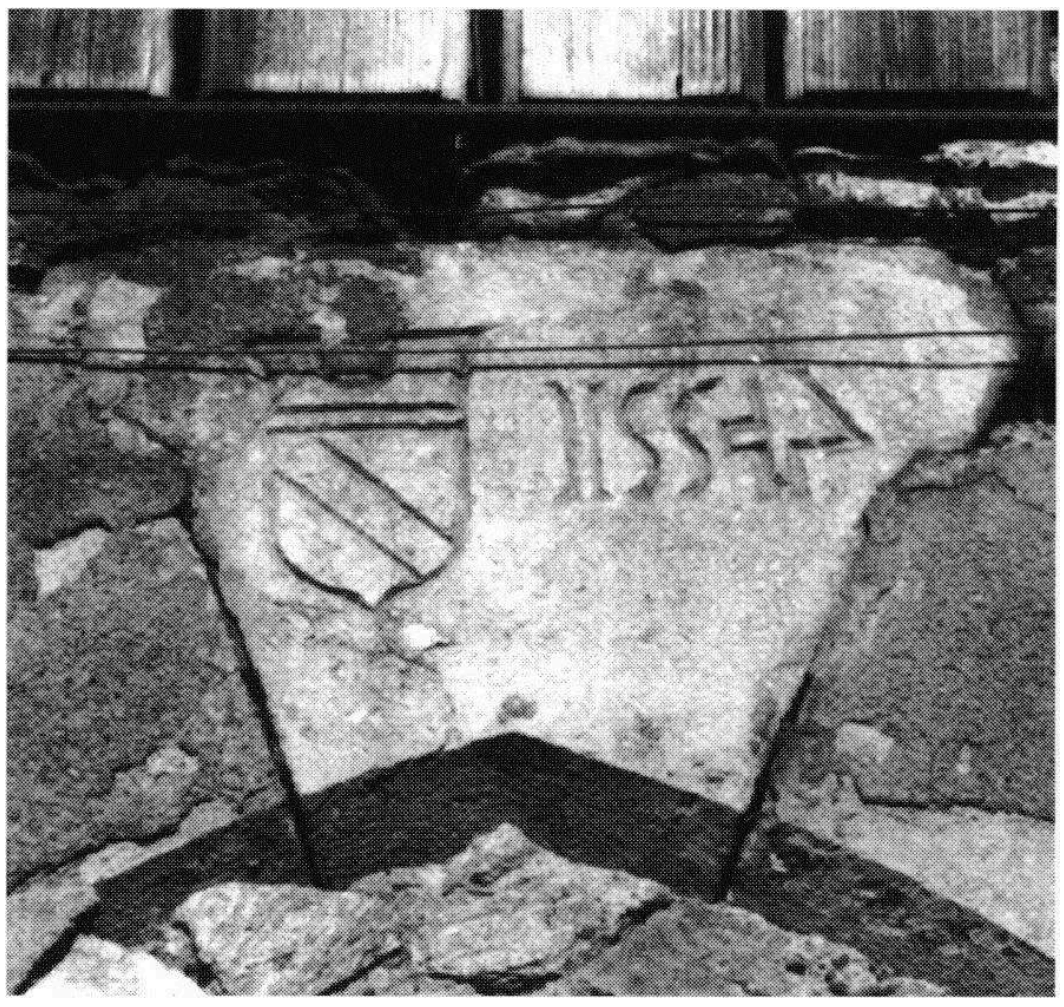

17 : Arc triomphal de l'église de Dingy

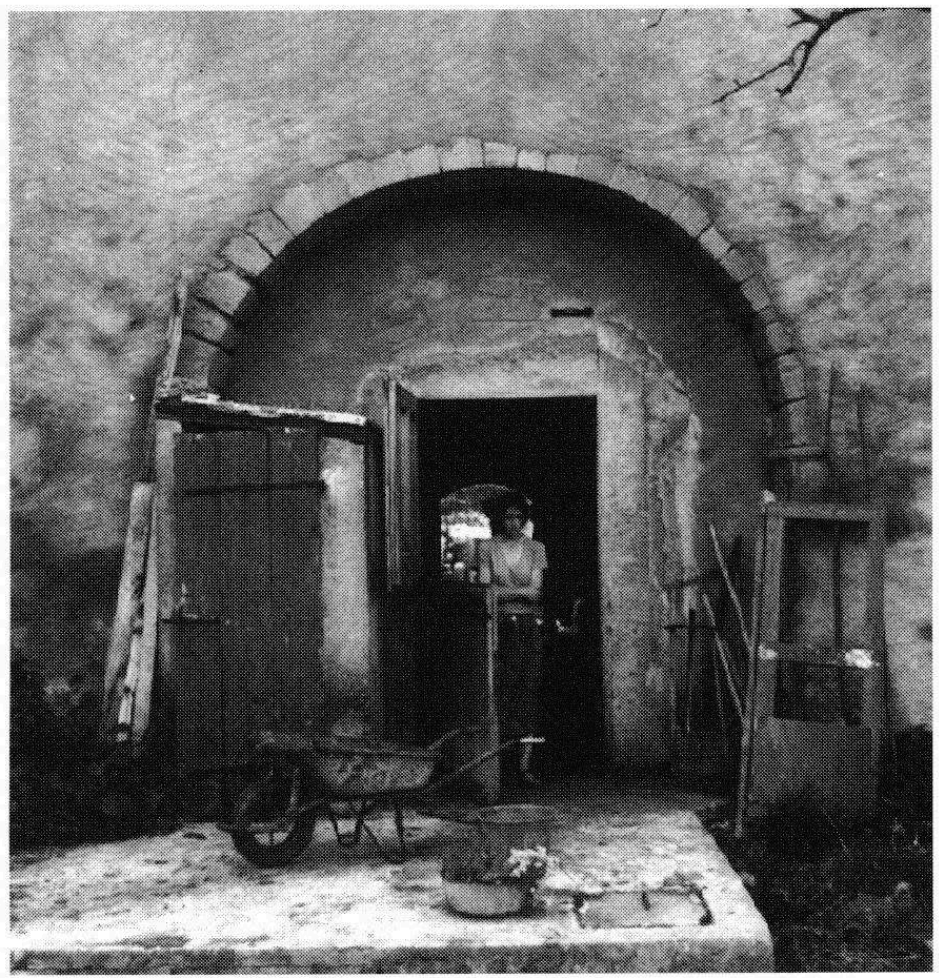

Les hameaux de Raclaz-d'en-bas (fig. 18) et de Raclaz-d'en-haut (fig. 19), distants de $800 \mathrm{~m}$, sont situés légèrement à l'écart de l'axe antique, de part et d'autre d'un grand 
quadrilatère formé par deux chemins menant à la montagne. A égale distance des deux villages, se trouve une maison forte. La première mention en est faite en 1447 quand une partie du hameau de Raclaz est affermée par le seigneur du Vuache à «certains hommes » (A.D.S., série SA, 136).

18: Village de Raclaz-d'en-Haut en 1730

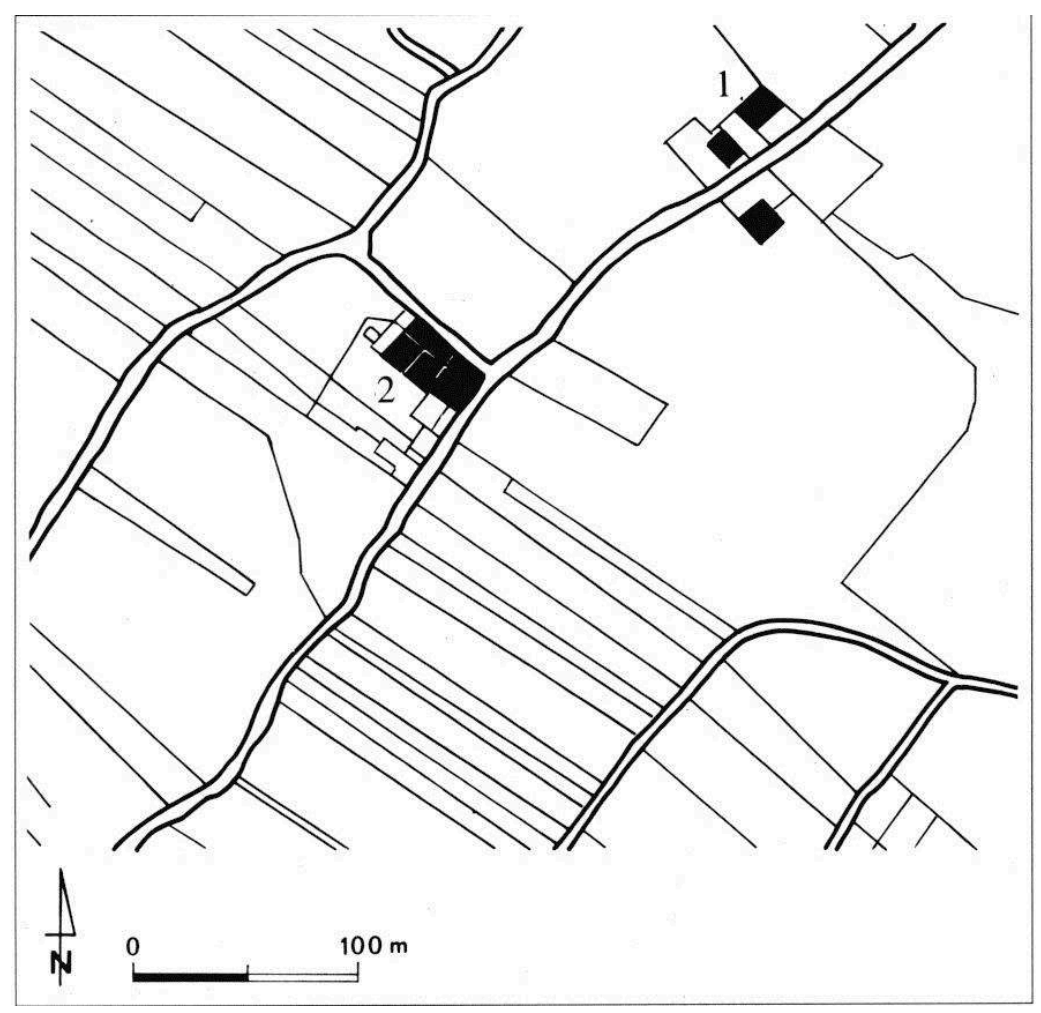

1 - Maison-forte. 2 - Hameau 


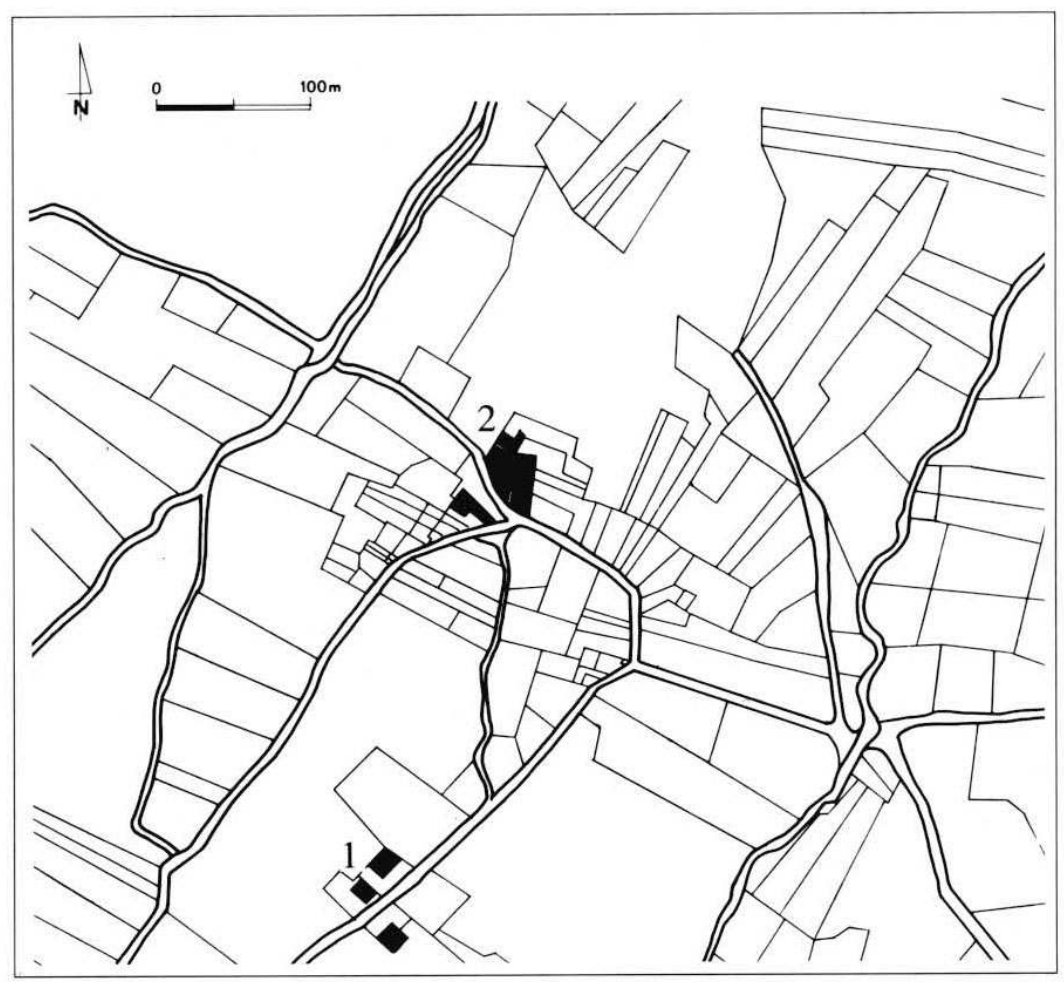

1 - Maison-forte. 2 - Hameau

47 Au début du XVIIIe s., la maison forte de Raclaz et les terres en dépendant sont en possession de l'abbé de Blancheville, frère du comte de Blancheville, seigneur du Vuache qui, lui, ne possède dans la paroisse de Dingy qu'une parcelle de broussailles (A.D.H.S., 1730, tabelle). Datable par ses éléments architectoniques de XVe s. (fig. 20), le logis est actuellement la seule partie conservée d'un ensemble qui regroupait autour de celui-ci des granges, des étables et d'autres bâtiments à fonction agricole. Il présente un plan rectangulaire. Au rez-de-chaussée, sont encore visibles un four à pain, une meule et des placards en blocs taillés pris dans la maçonnerie. A l'étage, la cuisine et une grande pièce sont éclairées par des fenêtres à accolades doubles ou à linteau trilobé (fig. 21) ; une grande cheminée aménagée dans le mur de refend permettait de chauffer ces deux salles. Une tour carrée renforce l'angle nord-est du bâtiment; son sommet a probablement été tronqué. 


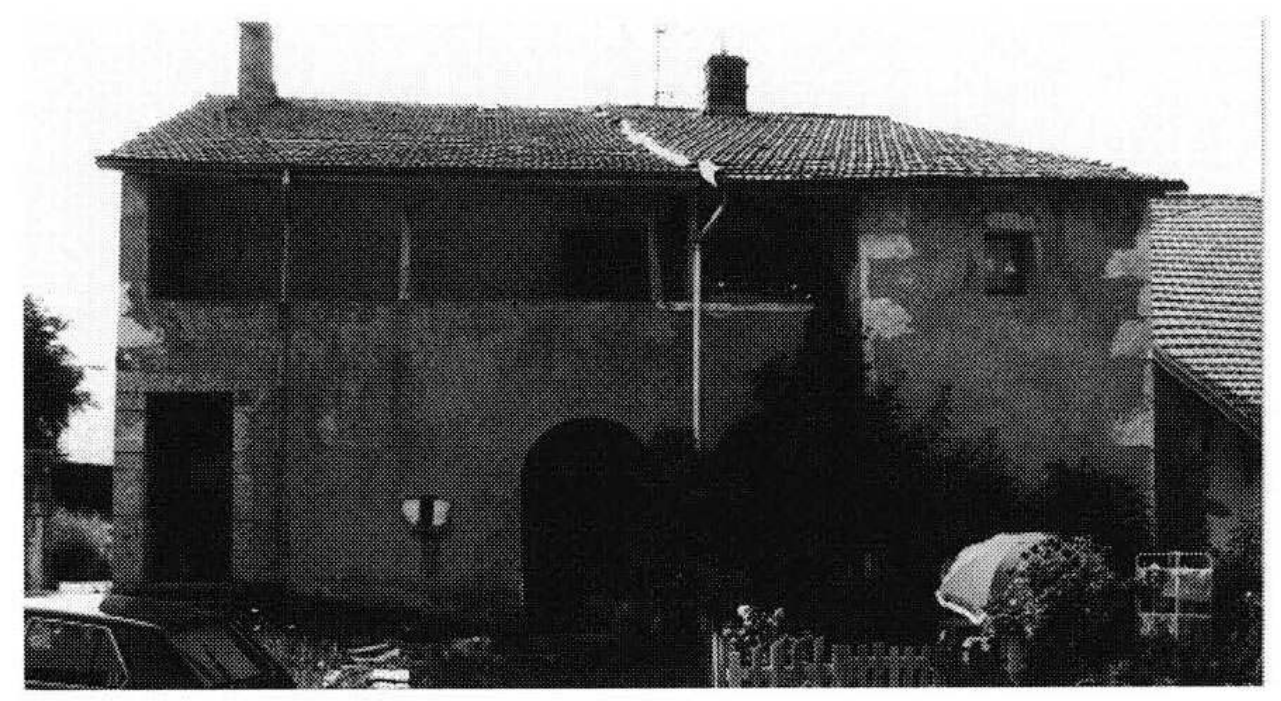

21 : Fenêtres du mur sud de la maison-forte de Raclaz

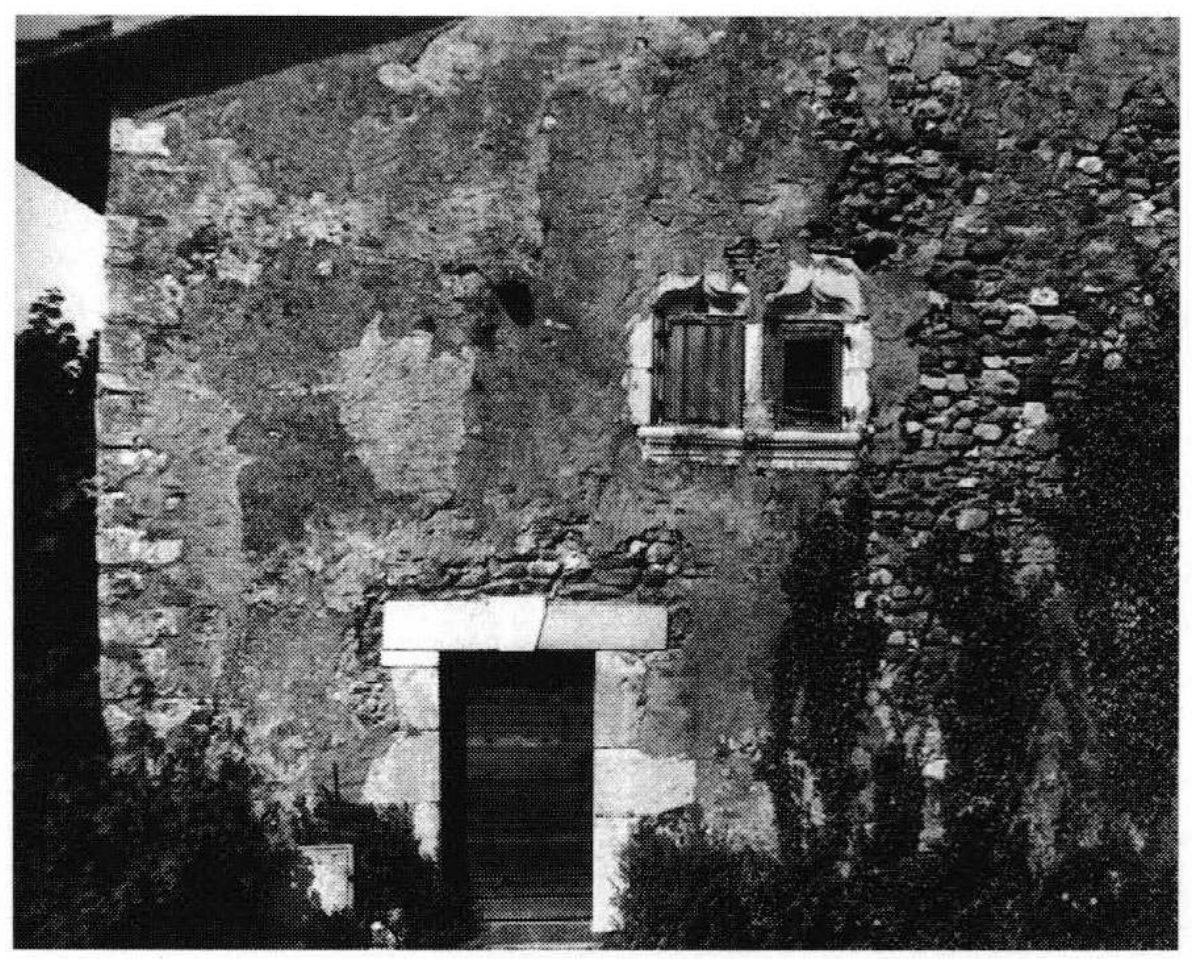

48 Lors de la levée de la Mappe Sarde, le territoire de la paroisse a été subdivisé en 223 lieux-dits (fig. 22). Quelques uns ne correspondent qu'à une seule parcelle, parfois de taille réduite, d'autres portent des microtoponymes similaires. Le $n^{\circ} 82$ est dénommé par la double appellation de la morenne et champ grillet. Nous noterons en particulier, les lieux-dits $n^{\circ} 29$, le toviére provenant du bas-latin tufaria, carrière de tuf (Wipf, 1982, $\mathrm{n}^{\circ}$ 3138), $n^{\circ} 175$, la faverge, au sud du village de Raclaz-d'en-bas, signalant la présence d'une forge (Longnon, 1979, $\mathrm{n}^{\circ}$ 584), $\mathrm{n}^{\circ}$ 119, dernier le tisseran, traduisible par : derrière chez le 
tisserand et $\mathrm{n}^{\circ} 179$, la ville, à l'ouest des deux hameaux de Raclaz, formé par des champs labourés, pouvant correspondre à un domaine agricole ou villa d'origine antique ou du Haut Moyen Age.

22 : Carte des lieux-dits de la paroisse de Dingy en 1730

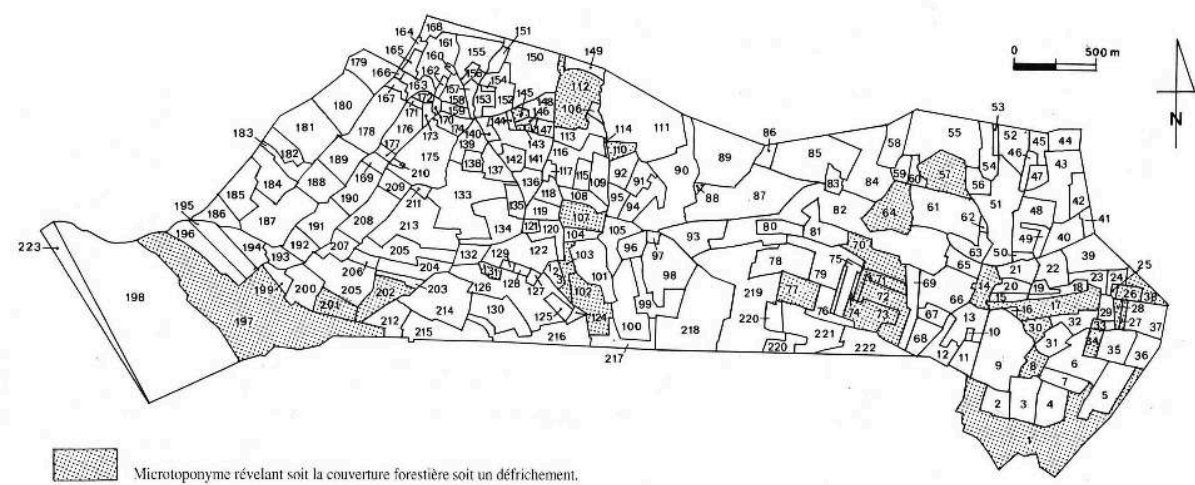

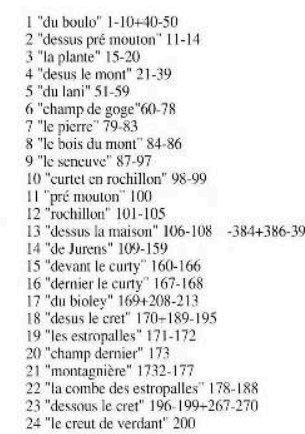

\begin{tabular}{|c|}
\hline 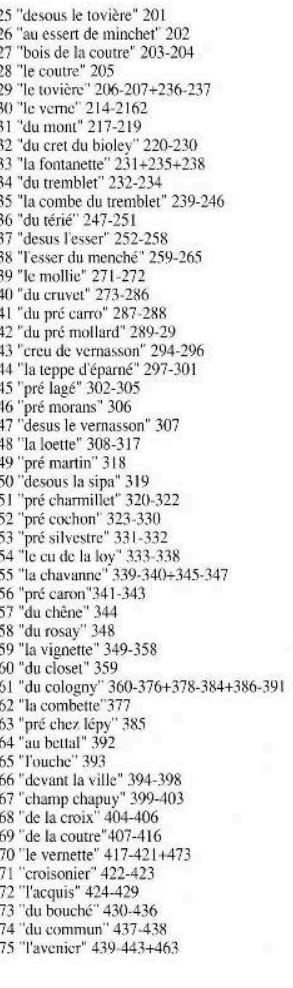 \\
\hline
\end{tabular}

76 "desous le plan" 444.447

77 " du buisson" 448-453

78 " desus le mollar" 457-462+464-468

80 "au cret de bleu" 46 ")-

82 "lin morenne et champ grillet " 474
83 "de bleu" $475-495$

83 " "de bleu" 475.495

84 " "ug grand pré $496-497$
85 "pré couzenen" 498-50।

86 "lia crotta" 502.504

87 "champ buffet" 505
88 "lesser" 506 "

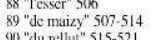

91 "pocrie recte" " $522-526$

93 "poerie reche" $548-557$

95 "champ de la vigne" $529-531$

96 "du pré aublanc" $541-545$
97 "champ des trente-deux viols" $546-547$

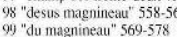

\begin{tabular}{|c|}
\hline 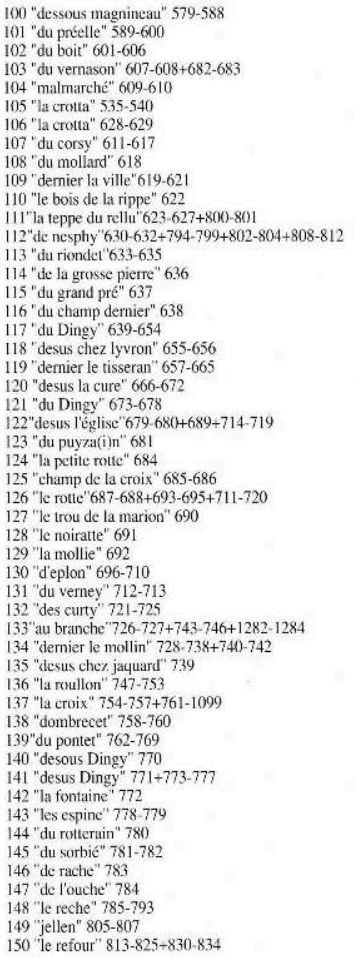 \\
\hline
\end{tabular}

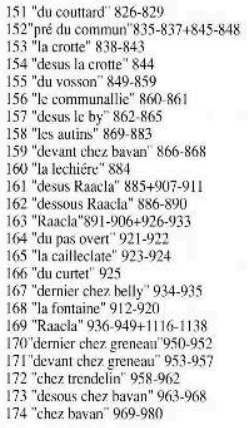

175 "la faverge" 981-987

176 "dernier les maisons" $988-99$

78 "verdenet" 995-1005

179 "la ville" 1006-1014

80 "la combe" 1015-1026

181 "le par" $1027-1040$

182 "champ du cret" 1041-1045

183 "du prélle" 1046+1050-1104
184 "le repe courbe" $1051-1054+1086-1087+1100-1101$

185 "la fontaine froide" 1055-1061+1068-1069

186 "desus le mont" 1062-1067
187 "la grange" 1070-1085+1088-1099

187 "la grange" 1070-1085+1088-1099
188 "du ropet" $1102-1103+1105-1108$

188 "du ropet" "1102-1103+1105-1110
189 "du setoir" |1109-1115

190 "desus chez masnin" 1138-1147

191 "la parrodc" 1148-1154

192 "vers la grange" 1155-1163

93 "cret munchu" 1164-1166

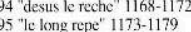

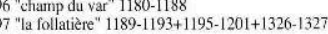

198 "desus la follatiere" 1194

" "vesus le chenalle" 1202

201 "lesser" 1209-1211

202 "malbois" 1212-121

"dessous malbois" 1215-1217+1245-125

"la selline" 1218-1220

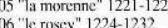

"desus molthois" 1233-1244+1324-1325+1328-1329

08 "chattoille" 1252-1268

"pomier quallieie" 1269-1275

211 "le champ desus la grange" 1277

212 "au ponter" 1278-1281

13 "du rosey" $1285-1310$

214 "desous le cret" 1311-1323
215 "la pierre plate" 1330-1334

216 "du plat" 1335-1371

"vers le mollie" 1396-1407

vers pré magnin 1407-14

"champ foillé" 1426-143

222 "de la ruchele lopard" 1432 
49 De nombreux lieux-dits de cette paroisse sont désignés par un anthroponyme, par exemple, $n^{\circ} 26$, au esser de minchet, $n^{\circ} 49$, pré martin, $n^{\circ} 87$, champ buffet, $n^{\circ} 159$, devant chez bavan, $\mathrm{n}^{\circ} 173$, desous chez bavan, $\mathrm{n}^{\circ} 174$, chez bavan; ce type de toponymes apparait au XIVe s. dans l'Ain et pourrait révéler des tenures allouées à des paysans.

50 En 1756, le secrétaire de la communauté villageoise faisait de sa paroisse un portrait désastreux :

"Le territoire de ladite communauté étant le quart tant en broussailles, genèvres, ruisseaux et en terrain partie aride et partie terres blanches et gluantes qui ne peuvent rien produire malgré tous les soins, à défaut de fumier pour n'avoir que très peu de foin, l'on est obligé de laisser inculte cette partie de terrain, on ne cultive de l'autre partie que le meilleur et un peu de médiocre qui après plusieurs labeurs réitérés produit quelque chose " (Mariotte, 1981).

51 La paroisse de Dingy comprenait 40 feux en 1411, 50 en 1481. à nouveau 40 en 1516 (Acad. Salès., tome 74, pp. 301, 315 et 318), 56 feux regroupant 226 habitants en 1561 (A.D.S., série SA, SA 1961, p. 24) et 30 feux en 1605 (Rebord, 1922 : p. 771).

52 A la Révolution, le territoire de cette paroisse a été divisé entre les communes de Vulbens et de Valleiry (Oursel, 1953).

\section{La paroisse de Bans}

Couvrant une superficie d'environ 300 hectares, subdivisée en 25 lieux-dits, la paroisse de Bans s'étire sur la plaine alluviale, le long de la rive gauche du Rhône. Elle regroupe trois villages : Bans (fig. 23), Cologny à l'ouest (fig. 24) et Moissel à l'est (fig. 25). L'église paroissiale, située au village de Bans, était dédiée à SaintGeorges (prince de Cappadoce, martyrisé en 303) et à Saint Annemond (Saint Chamond, évêque de Lyon, assassiné et inhumé à Lyon en 708, fondateur de la cathédrale Saint Pierre de Genève) (Oursel, 1953). En 1599, elle fut emportée dans le fleuve, lors d'un éboulement de terrain (Mariotte, 1981). Les paroissiens iront, par la suite, écouter la messe en l'église de Vulbens où leur seront administrés les sacrements (Rebord, 1922, p.771). Vers 1870, un nouvel éboulement de terrain entraîna, dans le Rhône, quatre ou cinq maisons et une soixantaine d'hectares (Gay, 1894, p. 7). 
23 : Village disparu de Bans en 1730

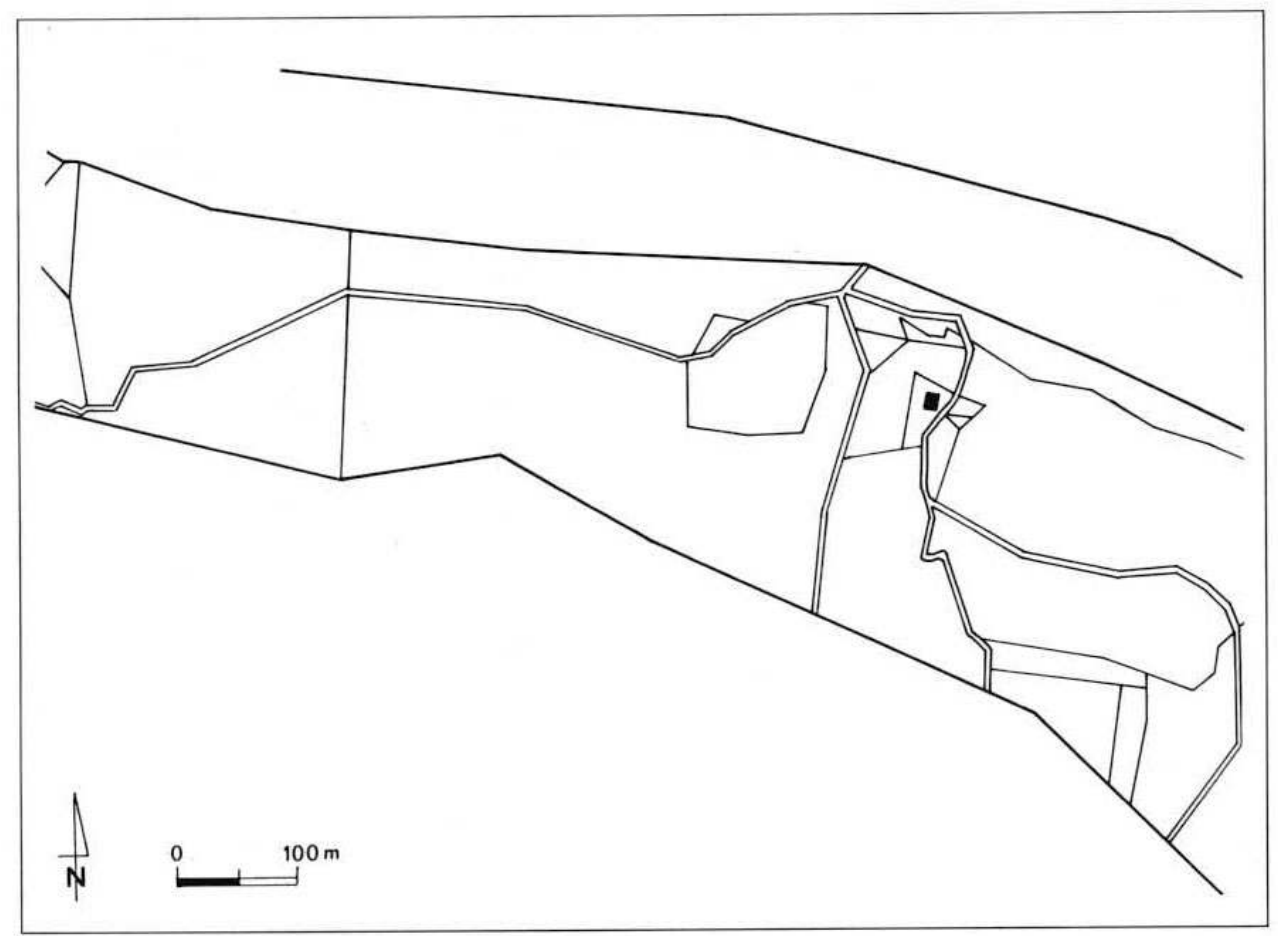

24 : Village de Cologny en 1730

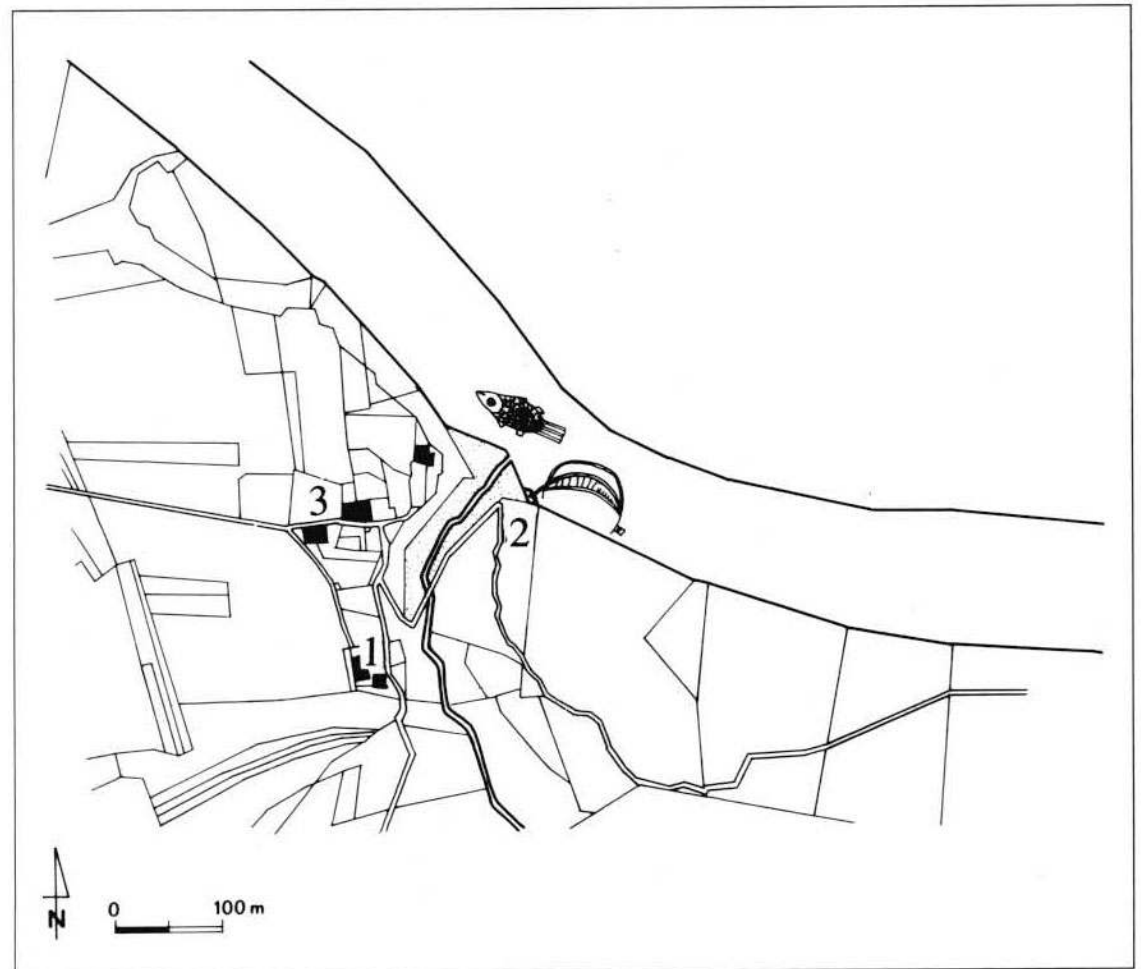

1 - Commanderie des Templiers. 2 - Port des « yelts ». 3 - Hameau. 


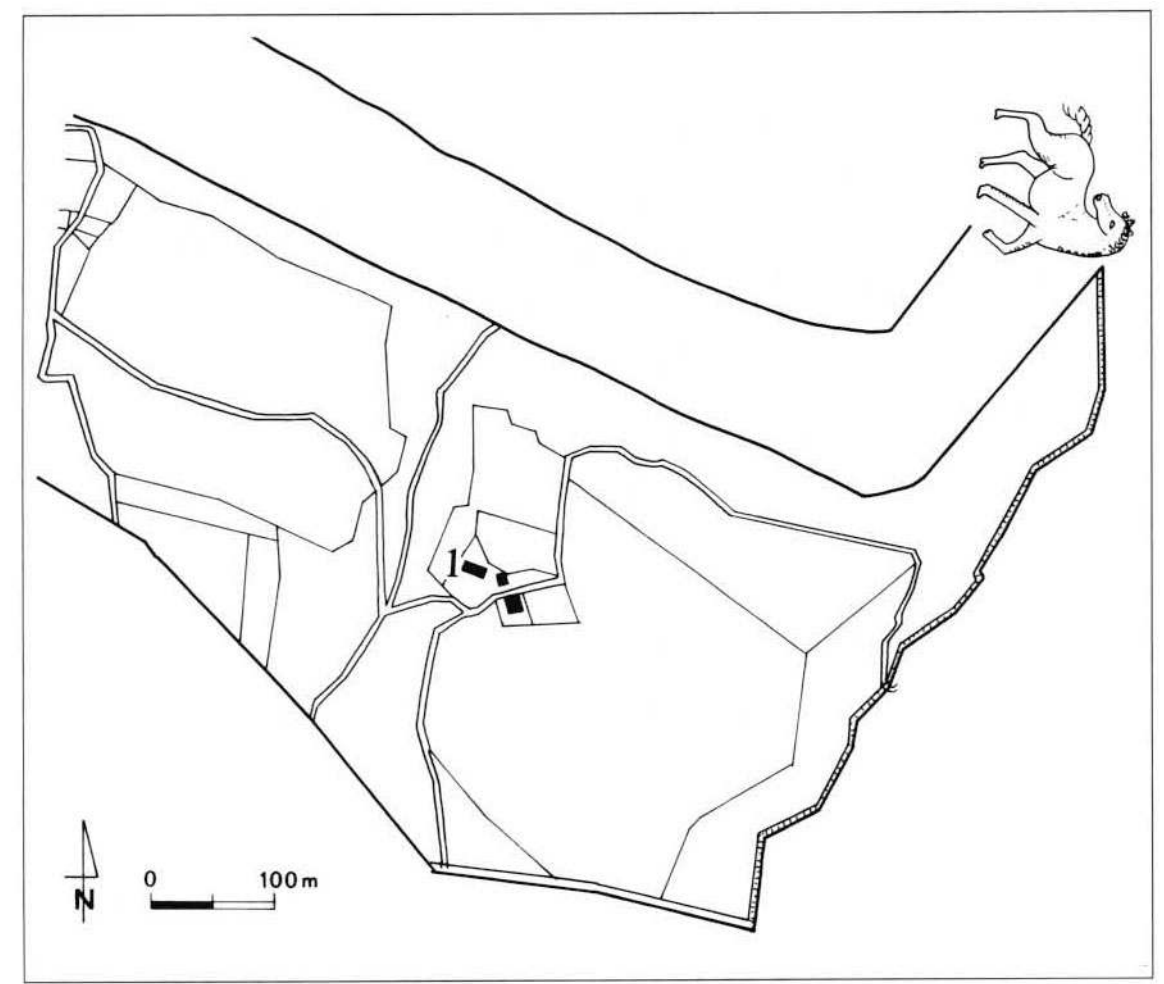

1 - TUILERIE APPARTENANT AU SEIgNEUR DU VUACHE

En 1412, la population comprenait 12 feux, il n'en reste que 7 en 1481, 6 en 1518 (Acad. Salès., tome 74, pp. 01, 315 et 318), 10 feux rassemblaient les 60 habitants en 1561 (A.D.S., série SA, SA 1961, P. 61), 8 feux sont recensés en 1605 (Rebord, 1922, p. 771).

A Cologny, un « oratoire » de l'ordre du Temple, filiale (membre) de la Commanderie de Compessières, fut érigé avant 1196 (R.G. $\mathrm{n}^{\circ}$ 465) ; en 1277, le précepteur de Cologny dépendait d'Etienne de Montferrand, précepteur des maisons du Temple de Dôle et du Genevois. En 1312, à la suppression de l'ordre, les Hospitaliers furent investis des biens que les Templiers possédaient dans le comté, la commanderie du Genevois reçut en particulier, ce membre de "Cologny sous Bans» (Mariotte, 1981). Les Templiers puis les Hospitaliers firent fonctionner le bac à traille du port des Isles «qui traversait le Rhône et assistèrent les voyageurs " (Ganter, 1971).

Le bâtiment conventuel se composait d'une maison, avec au rez-de-chaussée, une écurie et la cuisine, de laquelle on accédait, par une échelle, au galetas et à deux chambres, situées au dessus de la cuisine, le sous-sol était aménagé en caves, la grange et des écuries étaient au nord du logis, la chapelle, dédiée à la Sainte Vierge se trouvait à l'est, un four était situé à l'ouest (A.D.S., 1730, tabelles). L'ensemble des biens de la commanderie de Cologny furent rachetés par Bernadin Baud, le 9 germinal de l'an 3 (29 mars 1795) (Ganter, 1971, p. 240). Le territoire de cette paroisse est subdivisé en 25 lieux-dits (fig. 26). A l'ouest du village de Cologny, le lieu-dit $\mathrm{n}^{\circ} 2, d u$ corps de garde pourrait faire allusion à une installation militaire temporaire. 


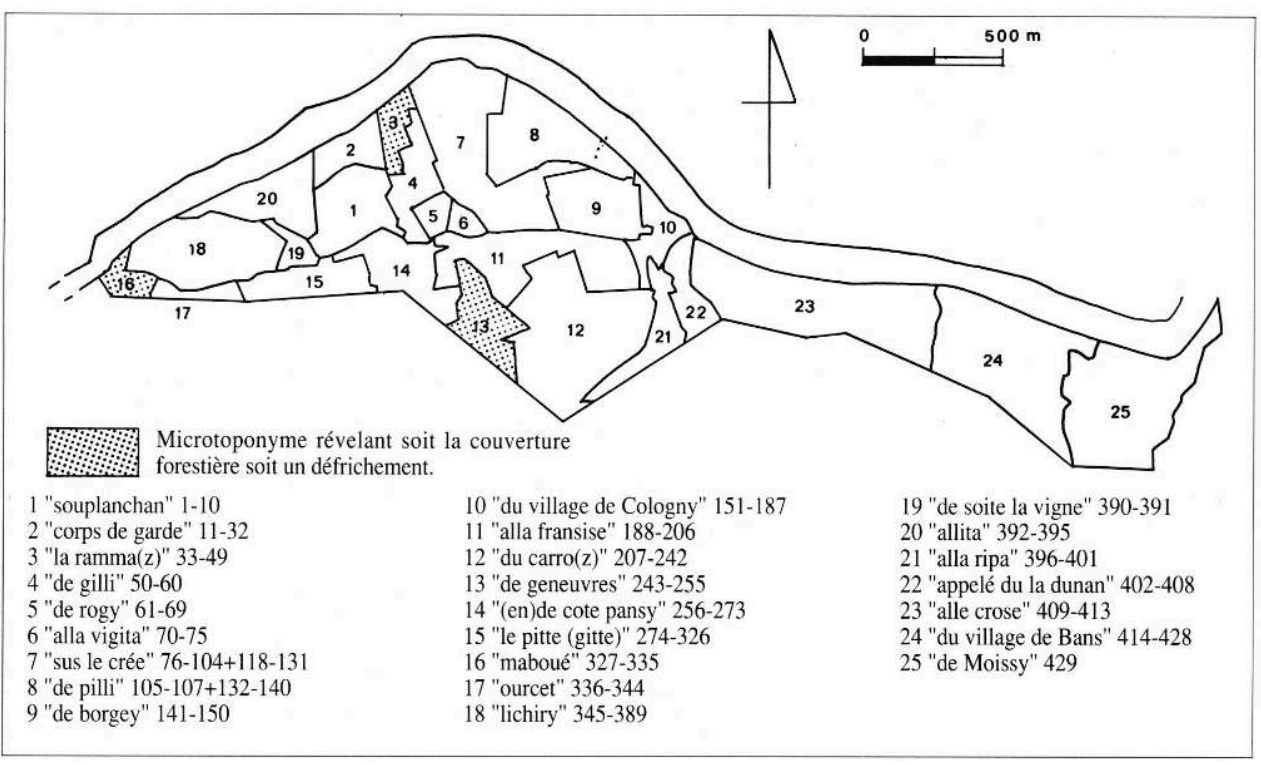

Mentionné au XIVe s. dans les comptes de châtellenie et aux XVe et XVIe s. dans les sommaires du fief du Vuache, le village de Moissel n'a laissé aucune autre trace dans l'histoire ; il avait disparu avant 1730 (fig. 25), lors de la levée de la Mappe Sarde. Seule y figure une tuilerie appartenant au seigneur, sise au lieu-dit, de moissy (A.D.H.S., 1730, tabelles); de même, le village de Bans (fig. 23) n'est représenté que par une seule maison. Ces deux villages occupaient une situation extrêmenent marginale par rapport au reste de la seigneurie, isolés par la forêt seigneuriale; à l'exception d'une parcelle, $\mathrm{n}^{\circ} 414$, appartenant au curé de Vulbens, le reste du territoire des deux hameaux fait partie du domaine utile du seigneur du Vuache lieux-dits $n^{\circ} 24, d u$ village de bans et $n^{\circ}$ 25, de moissy.

Le territoire de Bans fut réuni à celui de Vulbens lors de la création du département du Mont-Blanc, en 1792 (Mariotte, 1981).

\section{La paroisse de Chevrier}

Située dans la partie ouest de la seigneurie, près du Défilé-de-1'Écluse, la paroisse de Chevrier se composait d'un seul village, (fig. 27) implanté à $482 \mathrm{~m}$ d'altitude, sur le flanc de la montagne; il était principalement concentré le long de deux chemins, de part et d'autre de la voie antique. Son territoire couvrait une superficie de 535 hectares, subdivisée en 74 lieux-dits (fig. 28). La forme ancienne du toponyme, aux XIIIe et XIVe s., est « chivriaco » dont l'origine reste obscure. 
27 : Village de Chevrier en 1730

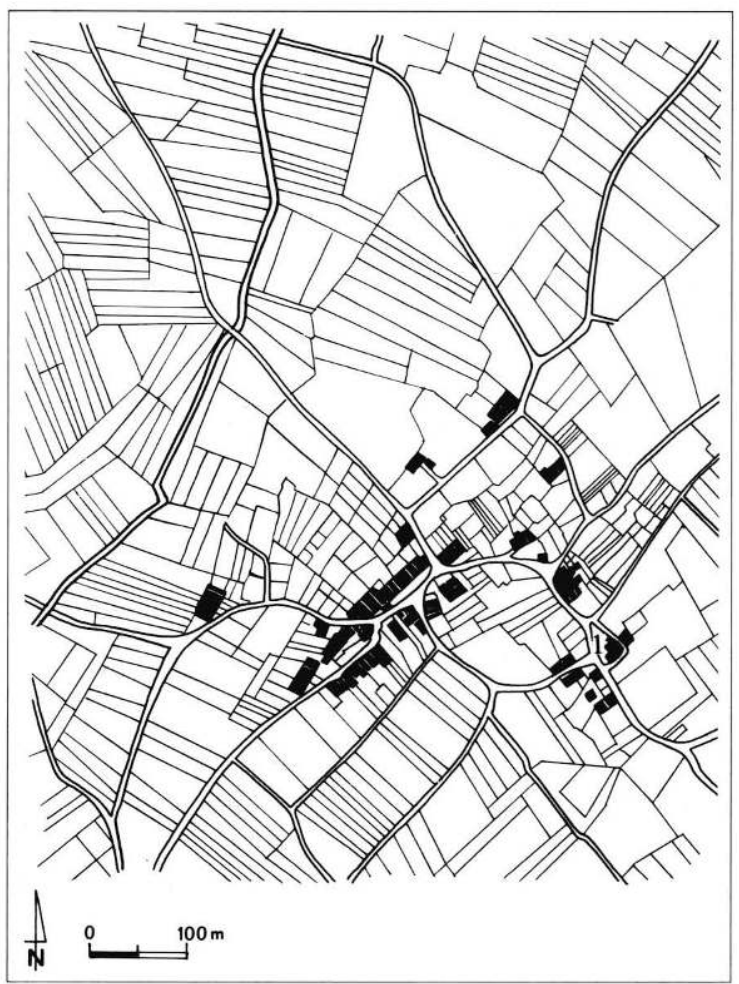

1 - EgLISE PAROISSIALE

28 : Carte des lieux-dits de la paroisse de Chevrier en 1730

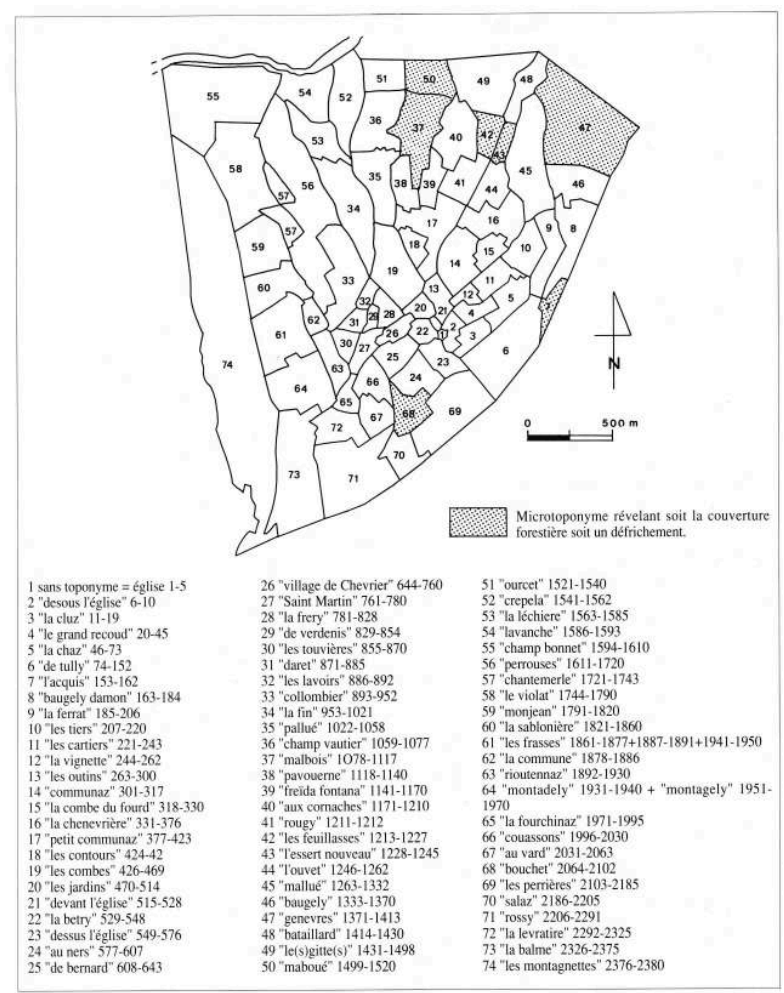


61 Ce village comprenait 30 feux en 1411, 27 feux en 1481 (Acad. Salès., tome 74, pp. 301 et 315), 44 feux soit 316 habitants en 1561 (A.D.S., série SA, SA 1961, p. 20) et à nouveau 30 feux en 1605 (Rebord, 1922 : p. 771).

L'église paroissiale (fig. 29) est placée sous le vocable de Saint-Martin (évêque de Tours, mort en 397) (Oursel, 1953 : p. 183). Elle est accolée à un bâtiment appartenant à la cure. Le chœur carré et aveugle est voûté en berceau brisé ; il s'ouvre par un arc triomphal, sur une nef rectangulaire et plafonnée. L'église est située à l'est du village duquel elle est séparée par une grande aire circulaire, lieu-dit $n^{\circ} 22$, la betry, où l'on battait, probablement, le blé au fléau (Pérogier, 1963).

63 Une série de six lavoirs correspondant au lieudit $\mathrm{n}^{\circ} 32$, les lavoirs, propriété communautaire et le lieu-dit $n^{\circ} 16$, la chenevrière, où cependant aucune parcelle n'est vouée à la culture du chanvre, sont peut-être à mettre en relation avec une activité artisanale de tissage de chanvre. En effet, plusieurs tisserands de chanvre, originaires dudit lieu, convaincus par la doctrine calviniste, se réfugièrent à Genève, dans la seconde moitié du XVIe s. (A.D.H.S., série F, F242). En 1730, très peu de parcelles sont consacrées à la culture du chanvre, activité certainement abandonnée avant cette époque.

Les lieux-dits $n^{\circ} 30$, les touvières, $n^{\circ} 60$, la sablonière et $n^{\circ} 69$, les perrières correspondent sans doute à des carrières de tuf de sable et de molasse.

Antérieurement dépendante de l'abbaye de Chézery (Ain), la paroisse de Chevrier n'a été rattachée à la seigneurie qu'au XIIIe s. Le seigneur versait à l'abbé dix coupes de blé sur sa part de la dîme paroissiale. A la Révolution, son territoire a été réuni à celui de Vulbens (Mariotte, 1981).

\section{9 : Façade de l'église paroissiale Saint-Martin-de-Chevrier}

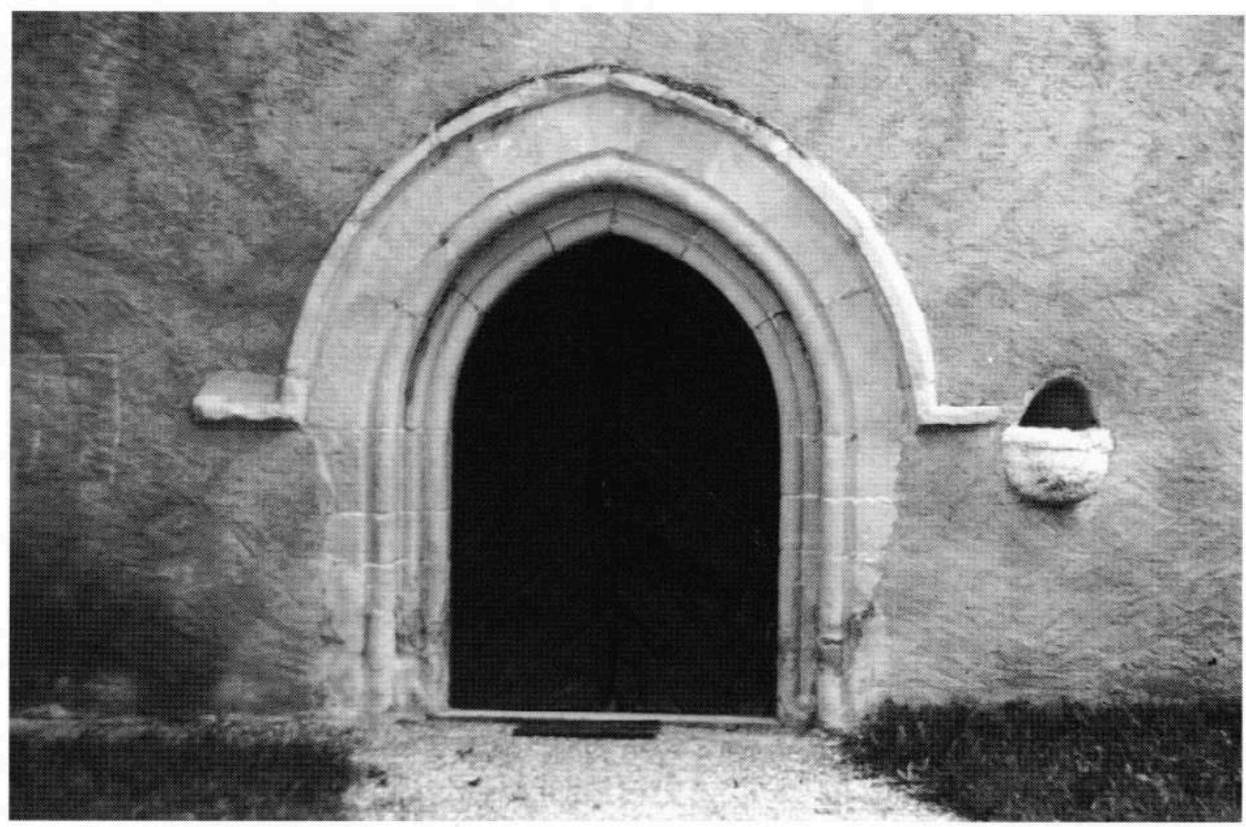




\section{Le domaine utile ou réserve seigneuriale}

66 Le domaine utile des seigneurs savoyards est très mal connu, faute d'études particulières sur l'évolution de ce régime de propriété et la place qu'il occupait au sein de l'organisation foncière. Une approche du domaine aristocratique du Vuache est possible, grâce aux documents conservés et surtout grâce à la Mappe Sarde qui offre l'intérêt de le représenter très précisément (cf. dépliant).

67 Les seules allusions directes au domaine utile que nous trouvons dans les comptes de châtellenies, de 1326 à 1341 , concernent une treille et un pressoir situés à côté du château ainsi que la forêt où les charpentiers travaillant à l'entretien des bâtiments seigneuriaux, allaient chercher leurs matériaux. Le séjour transitoire de chevaux d'attelage ou de guerre du seigneur ou de son suzerain le comte de Genève, laisse soupçonner la présence de prés pour leur pâturage (A.D.H.S., inv. 58, fol.387, c.126).

Pour le XVe s., nous disposons des inventaires des biens constituant la propriété aristocratique, établis lors des investitures des seigneurs par les princes de Savoie. Ces documents manquent toutefois de précision quant à la surface des parcelles et à leur localisation, les toponymes les désignant ne correspondent pas toujours à ceux de la Mappe Sarde. Le domaine utile du Vuache était constitué du château, des terres et des bâtiments à fonctions agricole et banale l'entourant. Cet ensemble est désigné dans les sommaires de fief, par l'expression très particulière de "l'ale du château » et correspond au lieu-dit $n^{\circ} 2$, ne portant pas de toponyme en 1730 . Des bois, en particulier le lieu-dit $\mathrm{n}^{\circ} 45$, la forêt et le moulin de lavandier, implanté sur un bief dérivé de la rivière de Fontaine Froide à $400 \mathrm{~m}$ à l'est du château, au lieu-dit $\mathrm{n}^{\circ} 19$, a la branche, font également partie de ce premier état du domaine.

69 En 1447, Richard de Monchenu possédait à proximité du château, une vigne d'environ 12 poses $^{13}$, une autre vigne au lieu-dit, en lavandier, d'une superficie de 2 poses et une vigne avec un bâtiment abritant un pressoir, un pré au lieu-dit, mulier de 6 seytorées et un pré de 2 seytorées ${ }^{14}$ situé au lieu-dit, l'ocombes. Il détenait également plusieurs autres parcelles de pré dont l'une se trouvait au nord de Vulbens et une autre à Faramaz, ainsi que la moitié d'un moulin par indivision avec l'Hospice de Cologny.

70 En 1466, lors de l'hommage de Girard de Montchenu, il apparaît que deux vignes, celle de 12 poses et celle où se trouvait le cellier, ont été réunies pour former une seule parcelle au lieu-dit, tary $\mathrm{n}^{\circ} 4$ de la Mappe Sarde; le pré de muliet a également été agrandi de 12 seytorées.

71 L'expansion du domaine se poursuivra sous le régime de ce seigneur par l'acquisition de nombreuses parcelles de vignes, prés, champs, vergers et d'un jardin appartenant à Pierre de Faramans et qui devaient constituer le domaine foncier de la maison forte de Faramaz; par celle d'un moulin soit raisse (scierie? en dialecte savoisien, raisse veut dire scie) acheté à Ansermet Guilliend, 7 fossorées ${ }^{15}$ de vignes encloses acquises de Claude Bedier, au lieu-dit, lavandier et qui ont été rattachées à la parcelle appartenant déjà au seigneur et 8 seytorées de prés, acquises de divers particuliers aggrandissant le pré seigneurial de mulier.

72 L'ensemble de ces acquisitions apparaît lors de l'investiture d'Antoine de Montchenu, fils de Girard, en 1498 (A.D.S., série SA, 136).

73 D'autres sommaires ont été dressés, en 1701, lors de l'indivision de la seigneurie entre le marquis Millet de Challes et le comte de Menthon, et en 1758, lors de l'investiture du 
marquis de Lescheraine mais ces documents ne nous apportent que peu de renseignements car ils ne détaillent pas les parcelles et sont relativement contemporains de la Mappe Sarde.

En 1730, lors de la levée de la Mappe Sarde, le seigneur François de Blancheville était propriétaire de nombreuses parcelles, tant en champs, prés, vignes, chenevrières et vergers qu'en bois, broussailles, friches et rochers, mais aussi de maisons, de ruines, de fours, de moulins et d'une tuilerie, répartis dans les paroisses de Bans, Chevrier et Vulbens; à Dingy, le seigneur ne possédait qu'une parcelle de broussailles mais son frère, l'abbé Humbert de Blancheville détenait la maison forte de Raclaz et les nombreuses terres en dépendant (A.D.H.S., 1730, tabelles). Ce domaine a éventuellement pu être créé à partir de terres appartenant antérieurement au patrimoine seigneurial.

Sur les tabelles cadastrales, certaines parcelles portent la mention « d'ancien patrimoine exempté de taille ». En effet, par édit du 27 mars 1584, le duc Charles-Emmanuel avait exempté de la tailleducale, à perpétuité, les terres appartenant à cette date à la noblesse et à l'Eglise. Dans le cas du Vuache, exceptées deux parcelles sises à Bans, ces terres se situent uniquement sur le territoire de la paroisse de Vulbens, les possessions seigneuriales des autres paroisses ont-elles été acquises après 1584 ?

76 Cette exemption n'était pas personnelle, attachée à la qualité du détenteur, mais réelle, attachée à la parcelle. Au Vuache, aucune parcelle tenue par un roturier ne semble avoir ce privilège : seules sont reconnues exemptées certaines parcelles appartenant au seigneur, une partie des biens fonciers de la commanderie de Cologny et les biens ecclésiastiques des curés desdits lieux ainsi que deux parcelles de prés et de broussailles appartenant au chapitre de Saint-Pierre de Genève. Cependant nous ne pouvons utiliser cette source qu'avec beaucoup de précautions : le seigneur, bien que n'ayant pas intérêt à céder un bien non imposable, a pu vendre des parcelles à l'Eglise, soit à la cure de Vulbens, soit au commandeur de Cologny ; les acquéreurs non nobles ont pu également ne pas pouvoir prouver l'origine aristocratique de leurs acquisitions. Certaines parcelles seigneuriales, comme les moulins de Copier et le château de Faramaz, construit au XVIIe s. autour du donjon de Faramaz ainsi que les terres l'entourant, déjà acquises à la fin du XVe s., sont soumises à la taille. Le seigneur se trouvait-il dans l'impossibilité de justifier de l'ancienneté de ces possessions? Les troupes bernoises, occupant le château du Vuache de 1536 à 1564 ont-elles en partie détruit les archives seigneuriales? Ces parcelles ont-elles été vendues puis rachetées? De fait, dans l'ensemble du duché, la noblesse ne serait pas parvenue à faire reconnaître comme féodaux plus de $12 \%$ de ses biens, annotés comme tels en marge des tabelles (Musée savoisien, 1981, pp. 27-36). D'autres terrains ont été vendus, en particulier, la vigne de lavandier. La réserve, telle qu'elle nous apparaît pour la fin du XVIe s., était moins importante qu'à la fin du siècle précédent. La fonction de premier «maistre d'hostel » du roi de France, François Ier, qu'occupait Marin de Montchenu, chevalier du Vuache et baron de Chaumont, a-t-elle contraint celui-ci à vendre des biens pour assumer financièrement sa charge ? Il céda la seigneurie du Vuache à Françoise de Rovorée en 1534.

77 Le domaine aristocratique antérieur au XVIe s. se caractérise par l'éclatement des terres en parcelles réparties en deux zones principales. La première se situe au nord-est du village de Faramaz, il s'agit peut-être ici des parcelles acquises avant 1493, dépendant de la maison forte de Faramaz ou de terres gagnées récemment par 
défrichement. La seconde se trouvait à proximité du château, cellesci pourraient être constituées des parcelles ou des vestiges de parcelles appartenant à la réserve antérieure à 1466 et mentionnées dans le premier inventaire.

Le seigneur détenait, certainement depuis l'origine, la totalité des bois, comme le souligne Antoine de Montchenu, qui en 1498, "reconnait tenir toute la forêt du bois et tout le bois du Vuache »; il s'agit là d'un des principaux privilèges aristocratiques. Il détient également l'espace environnant le château et englobant la basse-cour, constituant le "vol du chapon » surface calculée théoriquement par rapport à la distance couverte par ce volatile, et peut être des parcelles, peu éloignées, vouées à la culture de la vigne, aux lieuxdits, lavandier et tary et au pâturage, aux lieuxdits mulliet et sous Vulbens. Le seigneur ne possédait aucun champ, verger ou chenevrière au moins jusqu'à la fin du XVe s.

79 Peu étendu à son origine, le domaine du Vuache s'agrandit au XVe s., mais il s'accroît particulièrement entre 1498 et 1701, ceci malgré l'éloignement du lieu de résidence principale des seigneurs de cette période. Nous ne disposons malheureusement d'aucun document relatif à la réserve entre ces deux dates.

De nombreuses parcelles, situées dans les quatre paroisses de la seigneurie, appartiennent en 1730 au frère du seigneur du Vuache, l'abbé Humbert de Blancheville, sans que nous puissions déterminer si elles faisaient partie, à l'origine, du domaine seigneurial.

\section{Les dimes et droits seigneuriaux}

81 Les châtelains du château du Vuache étaient chargés de la collecte des dîmes des quatre paroisses (effectuée le jour de la fête de SaintMichel-Archange) et de la répartition entre les différents décimateurs dont le principal était le seigneur du Vuache.

La moitié de la dîme de Bans et Cologny était perçue par le seigneur, par indivis avec le curé de Bans et le prieur de Saint-Victor de Genève. En 1466, Girard de Montchenu vendit ses parts, à l'exception des dîmes de blé et de vin, aux révérends pères « macchabées » de la chapelle de Genève ; la dîme de Moissel appartenait en propre aux seigneurs du Vuache.

83 Ils percevaient la moitié des dîmes en froment et avoine de la paroisse de Chevrier par indivis avec le curé qui recevait les autres dîmes en seigle, orge et légumes. Ce droit lui avait été acquis par décision de Comtesson de Genève en 1326 (A.D.H.S., inv. 58, fol. 387, c. 126). Le seigneur devait sur sa part 10 coupes de blé à l'abbé de Chésery.

Sur la dîme de Dingy, que tenait le seigneur, le curé de Dingy recevait « 25 coupes de blé: avoine et froment, mesure du Vuache » et les nobles de Chenex percevaient « 7 coupes de blé moitié avoine et moitié froment » sur la dîme de Raclaz.

Le seigneur recevait la moitié de la dîme de Vulbens, l'autre moitié étant divisée entre le curé de Vulbens et l'abbé de Chésery (A.D.S., série SA, 136).

Les revenus de la seigneurie consistaient également en droits que le seigneur prélevait sur l'administration et le travail des habitants du mandement: taille, cens, lods et ventes, droits sur la pêche et sur l'orpaillage, etc. 


\section{NOTES}

12. Dans sa "lettre à la revue savolsienne" publiée en 1894, Victor Gay, ancien notaire écrit, page 12, détenir "par centaines, des titres, actes, reconnaisances, acensements de dimes, procédures concernant la terre seigneuriale $d u$ Vuache" ; ces documents m'ont été signalés par Monsieur Droubay comme étant en sa possession, puis comme ayant été "égarés".

13. Pose : mesure d'étendue de terre équivalente au journal.

14. Seytorée : étendue de pré qu'un homme peut faucher en un jour.

15. Fossorée : mesure utilisée pour la vigne, étendue de terre qu'un homme peut retourner au fossoir (houe). Il n'existe aucune étude, à notre connaissance, de ces anciennes mesures quelques indications utiles se trouvent dans les ouvrages de M. Bruchet " Notice sur l'ancien cadastre sarde", 1977, p. 59-64 et M. J. Desormaux : "Bibliographie des parlers de Savoie", Annecy 1923 p. 106-109. 


\section{Chapitre 3. Le château du Vuache}

1 La recherche archéologique, conditionnée par le projet d'aménagement, a permis la mise $\mathrm{L}$ au jour d'une grande partie des vestiges du bâtiment castrai totalement arasé. L'analyse stratigraphique a révélé la topographie de ce secteur avant toute occupation, la présence d'une fortification antérieure au château de pierre et l'évolution architecturale de celui-ci à travers cinq siècles de fonctionnement, du XIIe s. au XVIIe s. (fig. 30).

2 La confrontation des données archéologiques et de celles apportées par les textes permet une restitution de l'élévation disparue et d'interpréter la fonction des différentes structures.

30 : Plan de fouille du château du Vuache

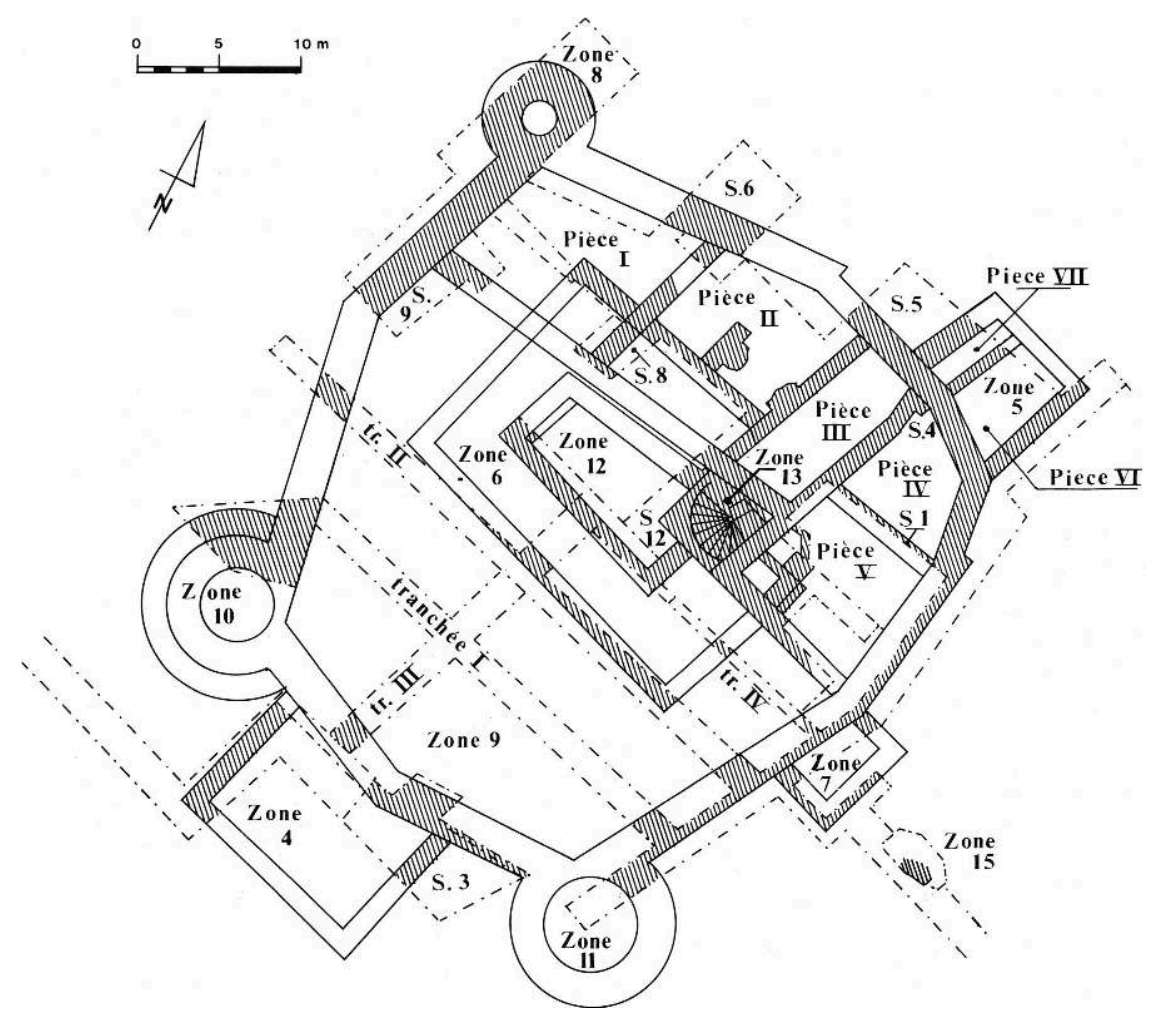




\section{Données archéologiques}

3 Destiné à devenir le centre de la circonscription seigneuriale et un point de défense important sur la frontière entre le Comté de Genève et celui de Savoie, le château du Vuache a été élevé sur un site qui parait être particulièrement propice à ces deux fonctions d'administration et de surveillance.

\section{Le site}

4 Les vestiges d'une occupation primitive du site ont été repérés sous les niveaux correspondant à la construction du château de pierre. La présence d'une levée de terre et le caractère particulier du matériel recueilli incitent à interpréter cette structure comme pouvant être une partie de la résidence des premiers seigneurs de Vulbens.

5 L'examen morphologique du terrain révèle la présence d'un petit cours d'eau qui a profondément creusé son lit dans les couches de molasses tertiaires. Il est aujourd'hui souterrain et en partie capté. On peut, cependant le remarquer en amont du site grace à une dépression étroite qui suit le sens de la pente. Cette résurgence alimentait probablement les douves du château, fournissant un moyen de défense naturel complémentaire au rempart de maçonnerie.

6 Aux alentours du château, la dépression s'élargit pour rejoindre un hémicycle correspondant à un front d'érosion glaciaire.

7 Le terrain naturel a pu être observé en plusieurs endroits du site; il est constitué d'apports détritiques stratifiés: une couche d'argile pure très compacte, de couleur grise très foncée a été mise au jour dans la partie septentrionale du site (C. 932) (fig. 31-35) ; cette couche constitue le substratum le plus important; elle a été repérée sur $0,40 \mathrm{~m}$ d'épaisseur minimum. Dans certains sondages, on a pu observer que ce niveau est en partie recouvert d'un dépôt naturel d'argile pure, compacte et de couleur ocrejaune (C. 914) (fig. 35) (pièce I et II) (fig. 30). Son épaisseur varie entre 0,10 m et $1 \mathrm{~m}$. Cette couche est veinée et partiellement recouverte par un lit irrégulier de sable et de gravier (C. 913) (fig. 35). Ces couches constituant le substrat géologique, résultent du processus d'érosion glaciaire. 


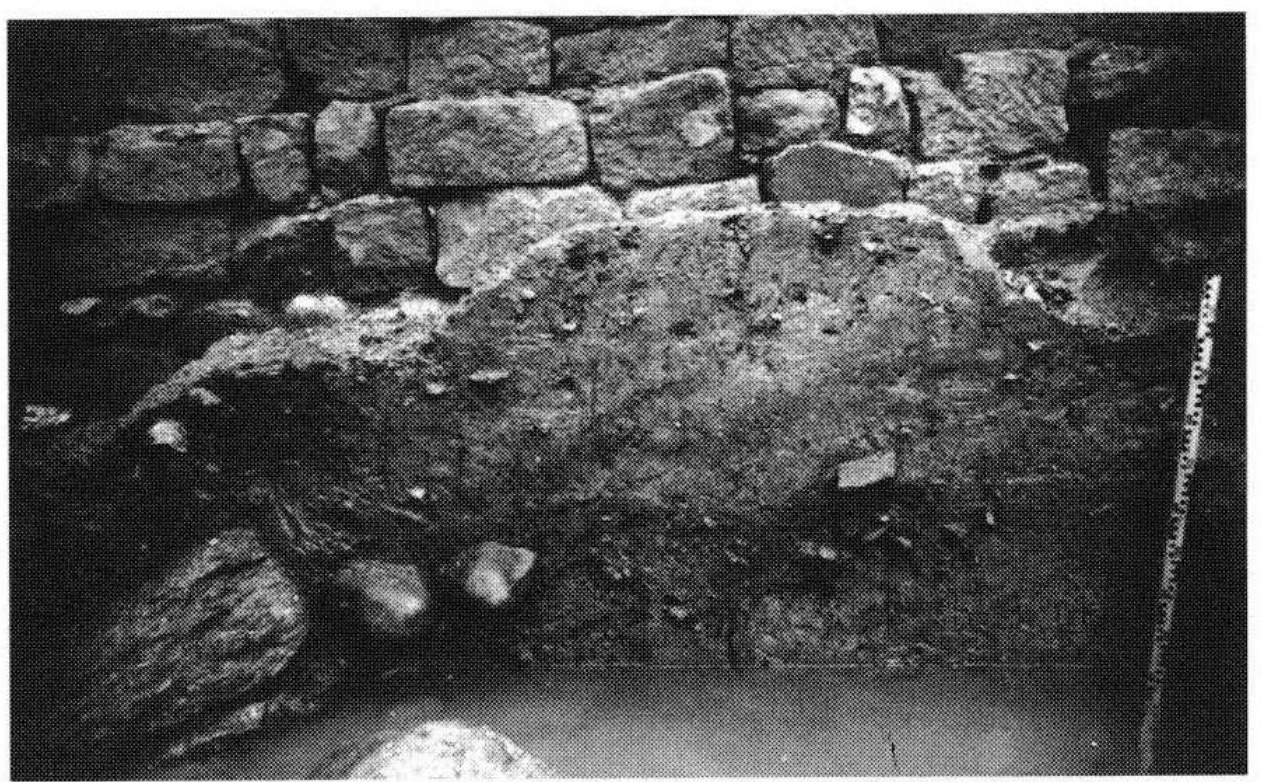

8 Le site castral domine le village de Vulbens duquel il est séparé par la route principale de la seigneurie reliant le gué de Cologny à la route de Genève à Chambéry, via Annecy ; le contrôle de ces voies de circulation paraît être le principal rôle stratégique du château du Vuache. Depuis le sommet des tours, la vision pouvait couvrir un vaste panorama englobant d'est en ouest: les contreforts du Salève, la ville et la plaine de Genève, la partie occidentale du Lac Léman et les crêtes du Jura, dominant le Pays de Gex.

\section{La fortification primitive}

9 Protégés des travaux du lotissement, car profondément enfouis sous les remblais accumulés à l'intérieur de l'enceinte, des niveaux archéologiques, correspondant à un aménagement antérieur au château de pierre, (fig. 32) ont été repérés grâce à des sondages pratiqués à l'ouest et au nord du site. Notre connaissance de cet état primitif reste limitée car elle ne concerne que deux secteurs, très ponctuellement observés et révélant une organisation peu explicite d'un ensemble certainement plus vaste. 
32 : Plan de l'état antérieur au château de pierre

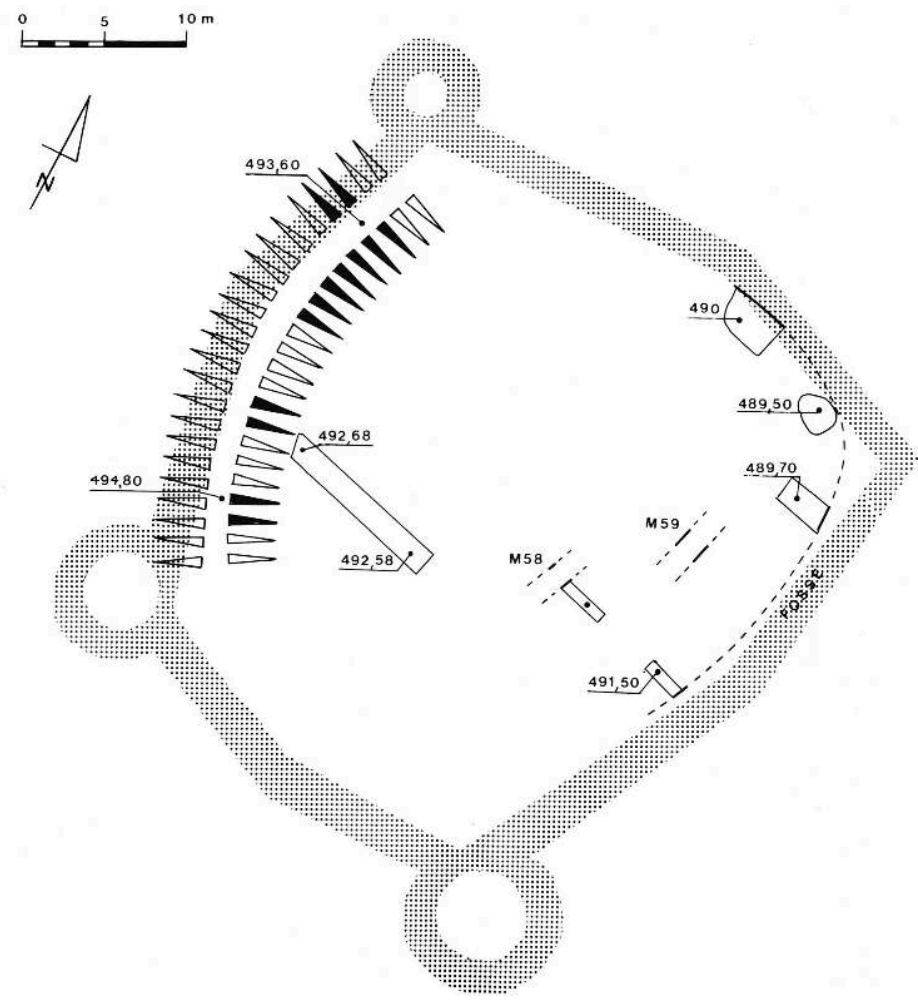

10 Le substrat géologique est recouvert par une couche d'argile jaune compacte, mêlée de petits galets et de quelques petits charbons de bois; ce niveau a été retrouvé sur l'ensemble des parties fouillées (fig. 32) ; C. 959, (fig. 33) C. 910 (fig. 35) ; au nord-est C. 129, pièce IV, (fig. 60) ; C. 165, pièce IV, (fig. 72) ; C. 219, pièce II, (fig. 56) et C. 4026, zone 6, (fig. 34).

11 Dans l'état de nos connaissances, il est difficile de déterminer si cette couche est due à la dégradation du terrain naturel lors de l'occupation ou s'il s'agit d'un apport volontaire recouvrant le paléosol.

\section{3 : Coupe stratigraphique}

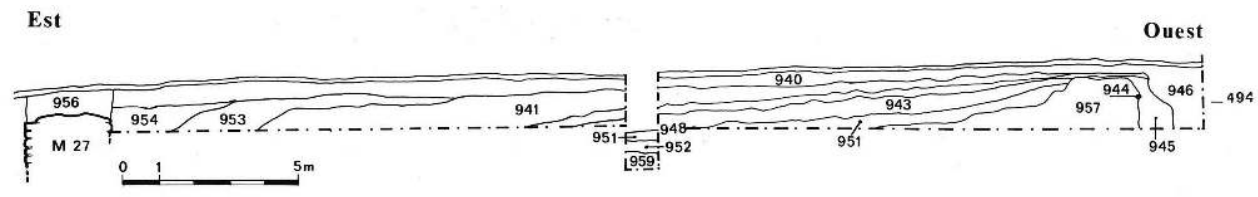




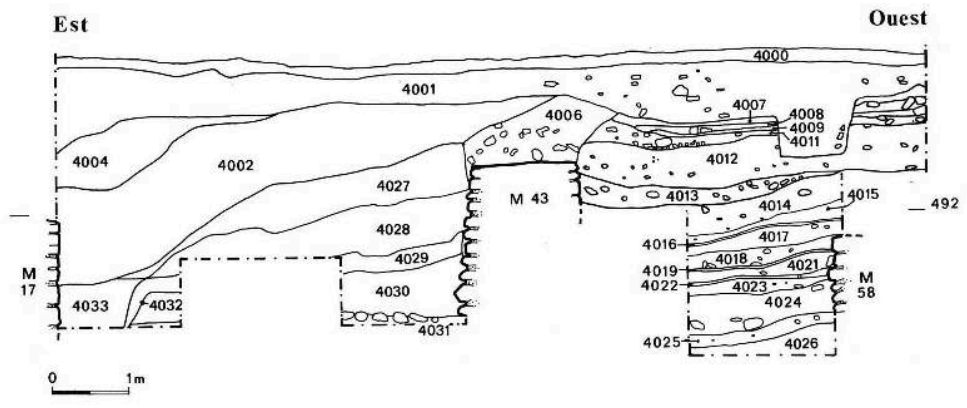

12 Ce niveau présente une importante dénivellation, axée sud-nord, parallèle au sens de la pente du versant de la montagne, entre les niveaux repérés à l'ouest $(492,94 \mathrm{~m}$ maximum) et ceux dégagés à l'est (489,50 m minimum). Il a été exhaussé localement par plusieurs couches de remblais, uniquement retrouvées dans la tranchée IV (C. 4025, zone 6, couche d'argile brune contenant de petits galets, épaisse de $20 \mathrm{~cm}$, recouverte par une couche d'argile jaune et de gros galets ; C. 4024, zone 6 (fig. 34) et C. 4031, zone 9, épaisse de $50 \mathrm{~cm}$ en moyenne).

13 Les sondages à l'ouest ont révélé la présence d'une levée de terre, d'une hauteur de $2 \mathrm{~m}$ au-dessus du sol intérieur, large de plus de $4 \mathrm{~m}$ à sa base et de 1,50 $\mathrm{m}$ au sommet. Elle est façonnée avec une argile limoneuse dans laquelle sont inclus de nombreux petits galets et petits éclats de molasse (C. 909, (fig. 35) ; C. 957 (fig. 33) ; C. 927, pièce 1 (fig-55). 


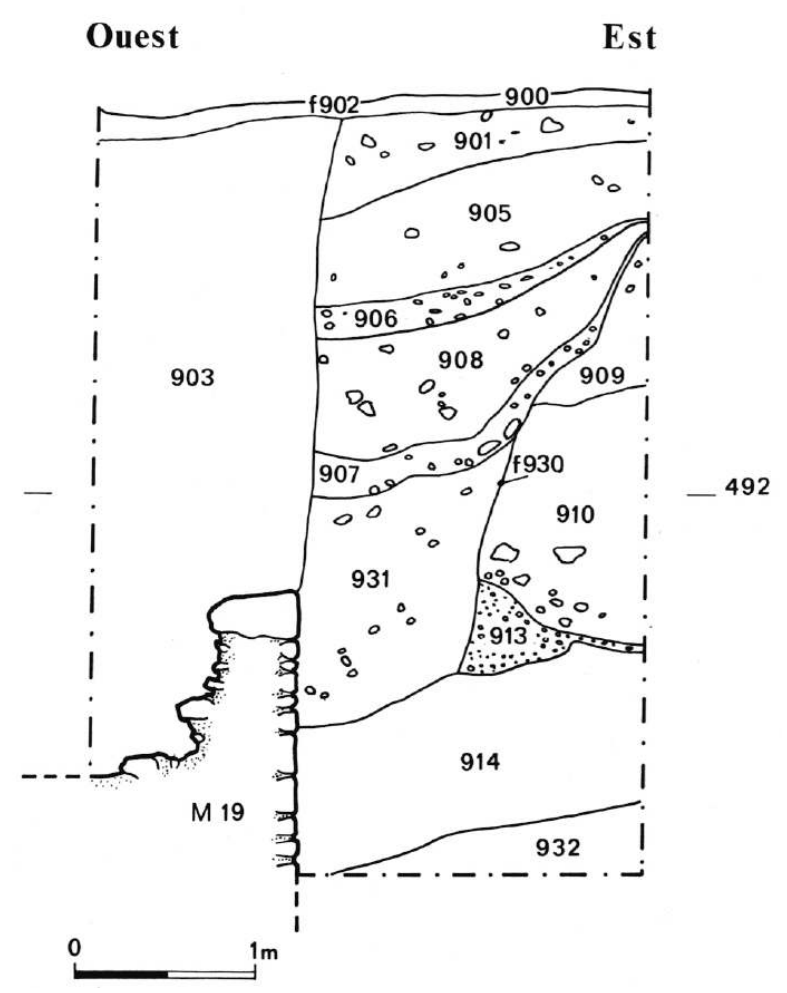

14 Retrouvé sur une longueur de $20 \mathrm{~m}$, suivant un tracé qui se révèle très légèrement courbe, ce talus pourrait correspondre à une enceinte de terre, limitant l'espace à l'ouest. La courbure laisse présumer une structure d'un diamètre très vaste. Le sommet de cette levée de terre, émergeant au pied du mur de courtine ouest, probablement érodé, présenteun dénivellé dans le sens sud-nord de $6 \mathrm{~cm}$ par mètre.

15 À l'est et au nord, le sol intérieur était bordé par un fossé. Nous ignorons cependant, s'il s'agit effectivement d'un fossé volontairement creusé ou du bord du thalweg dû au cours d'eau repéré en amont. Dans ces deux cas, nous ne savons pas s'il correspondait à la limite est de cet état ou s'il traversait une installation plus étendue. L'implantation à cet endroit des murs de courtines de l'état postérieur n'a pas permis une investigation poussée de cette structure dont nous ne connaissons que le sommet d'un des côtés : (F. 4032 (fig. 34).

Deux murs, en relation avec cet état, ont été partiellement reconnus, trop ponctuellement pour que nous puissions les rattacher à un type d'édifice.

17 Seulement connu par son niveau d'arasement (fig. 36), le mur M 59 (pièce V, tranchée V) est orienté nord-sud ; large de 1,40 m et repéré sur 1,50 m de long, il est constitué de deux parements en blocs de molasse et d'un blocage de galets et d'éclats de molasse, noyés dans du mortier de chaux. Le parement est du mur M 58 a été dégagé sur $1 \mathrm{~m}$ de large, en limite de la tranchée IV (fig. 34). Sa fondation est constituée de trois assises de galets liées au mortier de chaux, installées dans une tranchée étroite (F. 4020), de 40 $\mathrm{cm}$ de profondeur; seules trois assises de blocs de molasse formant la base de l'élévation ont été conservées. La première rangée de blocs au-dessus de la fondation, est légèrement saillante par rapport à l'aplomb de l'élévation et de la fondation. 


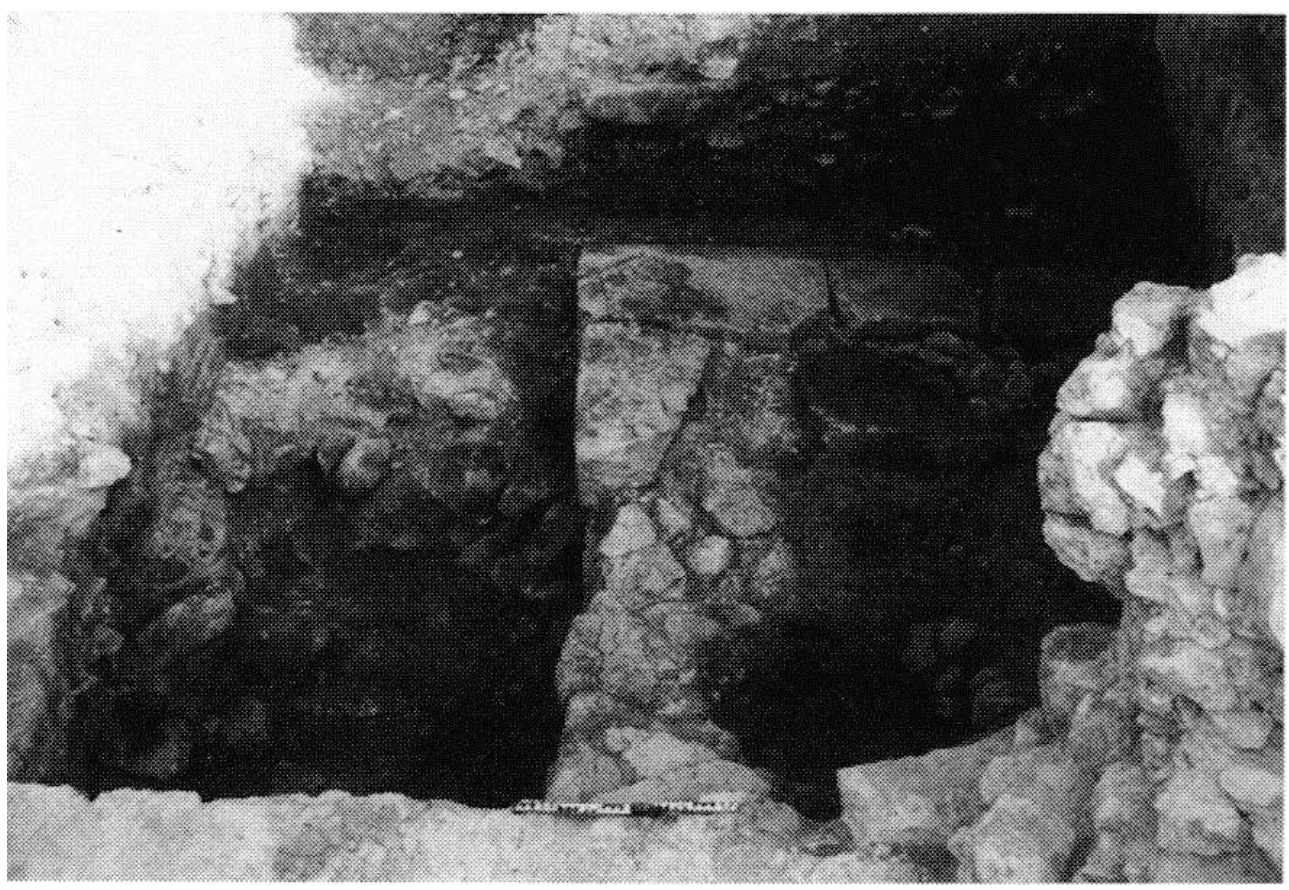

Une série de couches archéologiques en relation avec ce mur a pu être observée (fig. 34). La tranchée de fondation du mur M 58 a été creusée dans la couche de remblai $C$. 4024 ; les déblais de cette excavation ont été étalés pour niveler l'ancien sol (C. 4023); ce niveau est recouvert par un lit de sable, épais de 2 à $8 \mathrm{~cm}$ (C. 4022) et par une couche formée de sable, d'argile et de fragments de blocs de molasse (C. 4021). Cette séquence stratigraphique se répète une seconde fois : couche de sable pur (C. 4019) et couche hétérogène de sable, argile et fragments de molasse (C. 4018). Ces niveaux paraissent correspondre à des dépôts accumulés lors de la construction du bâtiment. Ils sont recouverts par une couche d'argile jaune, très compacte (C. 4017); elle constitue le remblai d'aménagement d'un sol intérieur en terre battue.

La limite est de ce bâtiment n'a pas été repérée, un remblai d'argile jaune homogène a été accumulé au-dessus de ces vestiges et jusqu'au mur d'enceinte (C. 4030).

20 A l'exception du talus et du sommet de la levée de terre, les niveaux de cette époque sont scellés de façon homogène par une couche de limon argileux gris foncé, mêlé de cendres et contenant des nombreux charbons de bois, des éléments rejetés de la démolition et quelques ossements de boeuf et de porc ou de sanglier. Ce niveau procède de la destruction de ce premier aménagement du site (C. 128 (fig. 58); C. 164 (fig. 37-72) ; C. 217, pièce II (fig. 56) ; C. 952 (fig. 33) ; C. 4015, zone 6, ; C. 4029, zone 9 (fig. 34) ; C. 6011 et C. 6024, pièces I et II (fig. 48). 
37 : Niveau de sol de l'état primitif (pièce IV, sond. 4)

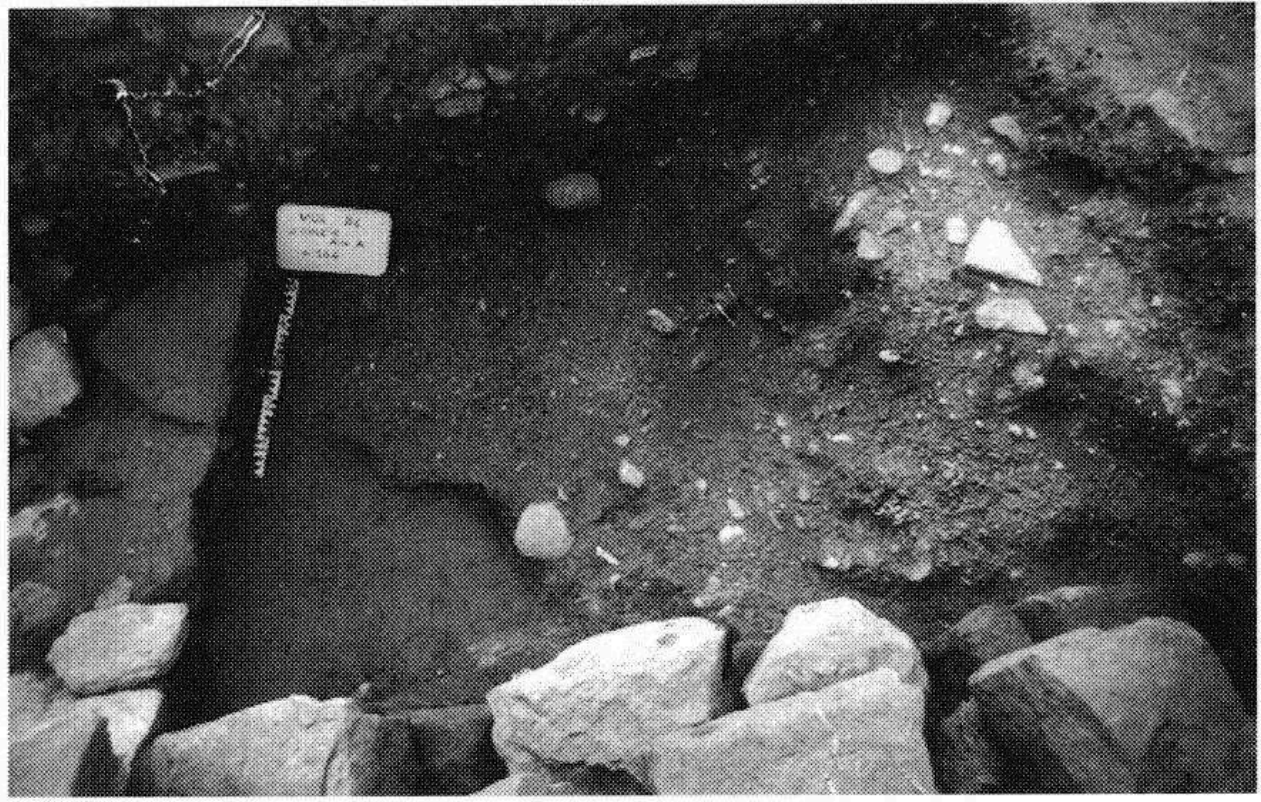

21 Très peu de matériel a été retrouvé dans ces niveaux. Seule la couche de démolition $C$. 4029 a livré une clé forée, quatre blocs hémisphériques constitués de concrétions et de déchets de fonderie, quelques tessons de céramique grise et un bougeoir zoomorphe représentant un cerf, en bronze ou en laiton (fig. 38). Cette pièce de dinanderie, remarquable par la simplicité de son décor et le sujet représenté, est datable du XIIe s. ou du début XIIIe s. (cf annexe 3).

\section{8 : Bougeoir zoomorphe, XIle siècle}

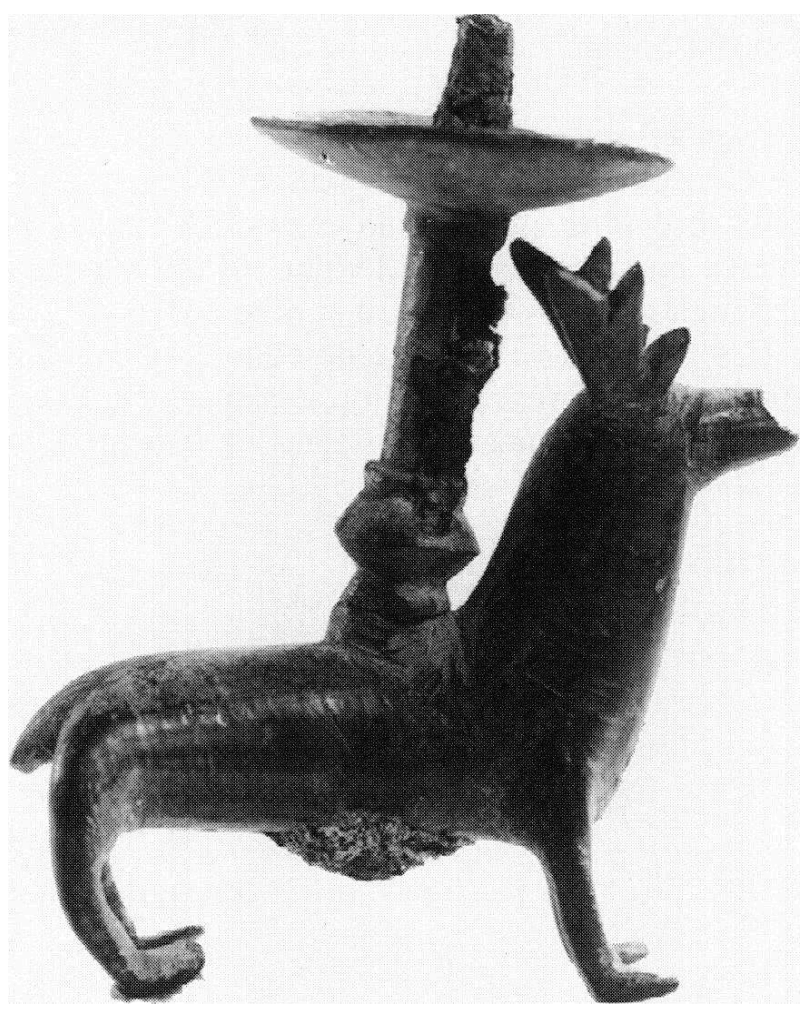


22 La première occupation du site est donc antérieure à la construction du château de pierre datable du milieu du XIIIe s. ; aucun des éléments et objets recueillis ne permet de dater cette première occupation avec plus de précision.

Les vestiges observés appartiennent à une structure dont la plus grande partie nous échappe du fait du profond remaniement occasionné par l'aménagement du château. Elle se caractérise essentiellement par la présence d'une enceinte de terre courbe et d'un fossé. Ces éléments, ainsi que l'objet de valeur qu'est le bougeoir, incitent à penser que nous sommes en présence d'un édifice castrai de terre ou du moins d'une partie de ce type de construction (basse-cour ou rempart de barrage ?).

Un chevalier, Pierre de Vulbens, vassal de Hugues de Sallenoves est mentionné dans des textes du début du XIIIe s. Ce premier état de construction pourrait correspondre au site castrai, lieu de sa résidence et siège de son pouvoir.

25 Le statut particulier qui en découlerait pour le terrain pourrait, en partie, expliquer le fait que le site fut choisi pour l'édification du château de pierre.

\section{Le château de pierre}

\section{État 1}

Les aménagements de la première occupation, décrits plus haut, servent de base à la construction du château de pierre, lui assurant une assiette hors du niveau de l'eau des fossés, et conditionnant son implantation et son architecture.

Les vestiges conservés permettent d'observer, au moins pour les parties basses, que le travail de construction s'est déroulé en deux étapes: tout d'abord l'érection de la muraille d'enceinte et des tours, puis l'organisation de l'espace ainsi délimité par la construction du logis et d'un bâtiment indépendant implanté dans la cour (fig. 39). 


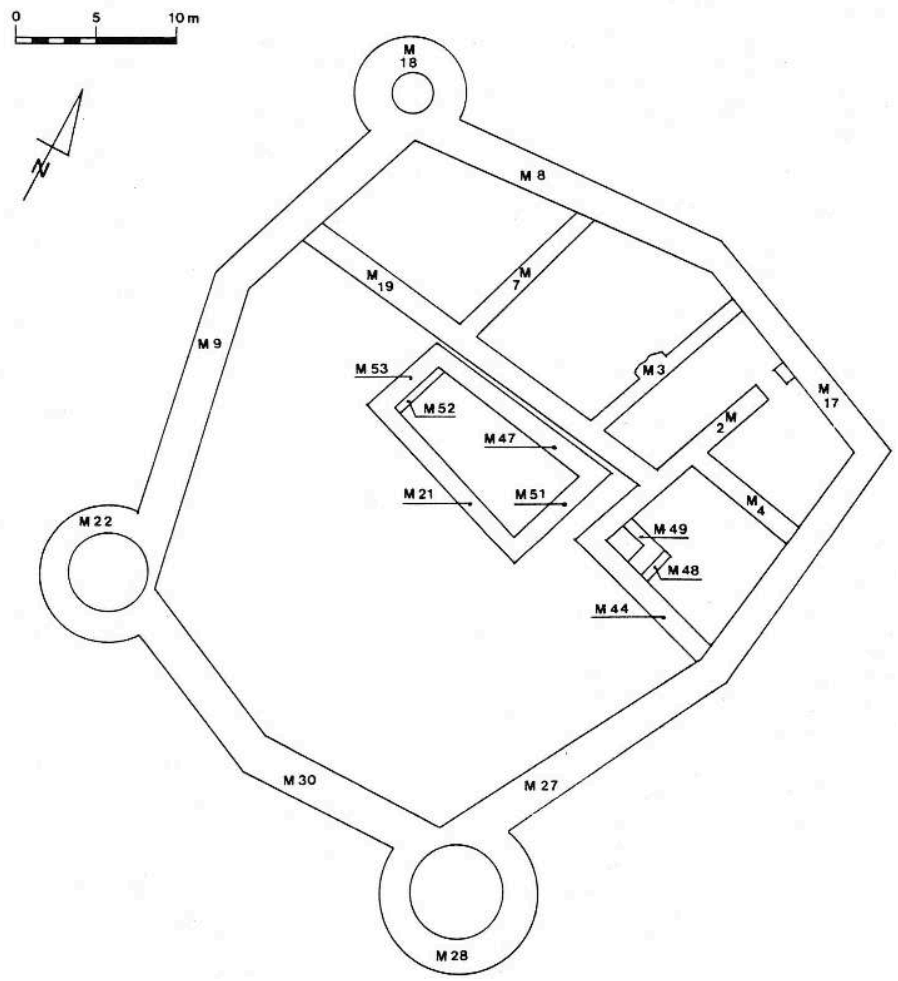

\section{L'enceinte}

de superficie, était directement menacée par la construction d'un immeuble. Le mur de cette tour (M 18) est large de 2,30 m et conservé sur une élévation de plus de 2,50 m de hauteur; il entoure un espace intérieur de 2,50 $\mathrm{m}$ de diamètre. Il est bâti en blocs de molasse dont la face extérieure est taillée de manière concave; travail qui fut sans doute effectué sur place, comme l'indiquent les éclats de taille que l'on retrouve dans la couche recouvrant le fond de l'espace intérieur (C. 807). circulaires, fortement en saillie vers l'extérieur, en flanquement des angles sud-est, sud-ouest et nord-ouest.

Le périmètre extérieur de l'enceinte mesure $198 \mathrm{~m}$, circonférences des tours incluses ; l'espace intérieur couvre une superficie de $1020 \mathrm{~m}^{2}$. Les murs de courtine, formant les côtés de l'octogone, mesurent entre 10 et $18 \mathrm{~m}$ de long et entre 2,40 et 2,50 $\mathrm{m}$ de large.

Les tours et la courtine sont construites en même temps; leurs assises sont en effet liées. La tour sud-est est la plus importante par ses dimensions :10 $\mathrm{m}$ de diamètre, soit une circonférence de $31,40 \mathrm{~m}$ et une superficie de $78,50 \mathrm{~m}^{2}$. Hors de l'emprise des constructions du lotissement, cette tour n'a pas été entièrement dégagée, seule une partie de l'arasement de cette structure a été mise au jour, à l'intersection qu'elle formait avec le mur de l'enceinte est.

circonférence et couvre une superficie de $63 \mathrm{~m}^{2}$. Egalement épargnée par l'aménagement moderne, elle n'a pas fait l'objet de recherches approfondies. 
Les deux tours sud ont été probablement conservées sur une grande élévation. En comparant le niveau d'arasement de ces tours avec le niveau supérieur des fondations du mur de courtine sud, qui les relie, on peut estimer qu'elles présenteraient plus de 5 $m$ de hauteur.

Les fondations de ces maçonneries sont implantées très profondément. A l'ouest, nous n'avons pas retrouvé la base de celle du mur $M 9$, ceci à plus de 4,50 m en dessous du niveau du sol actuel. Au sud, le sommet des fondations de M 30 se situe à $490 \mathrm{~m}$ d'altitude, alors qu'au nord, les élévations des murs M 18 et M 17 descendent respectivement au moins jusqu'à 489,50 m et $489 \mathrm{~m}$.

Les fondations que nous avons pu observer sont construites à l'intérieur de tranchées étroites, creusées dans le terrain naturel, par exemple F. 933 (fig. 40) pièce I ; F. 926 (fig. 55) et F. 467, pour le mur M 30 (fig. 67)). Le mur de courtine oriental est implanté dans le fossé appartenant à l'état antérieur (F. 4032), qui a été comblé après la construction du mur par un remblai d'argile jaune pure (C. 4033) (fig. 34).

40 : Coupe stratigraphique zone 9 et pièce I, sond. 9

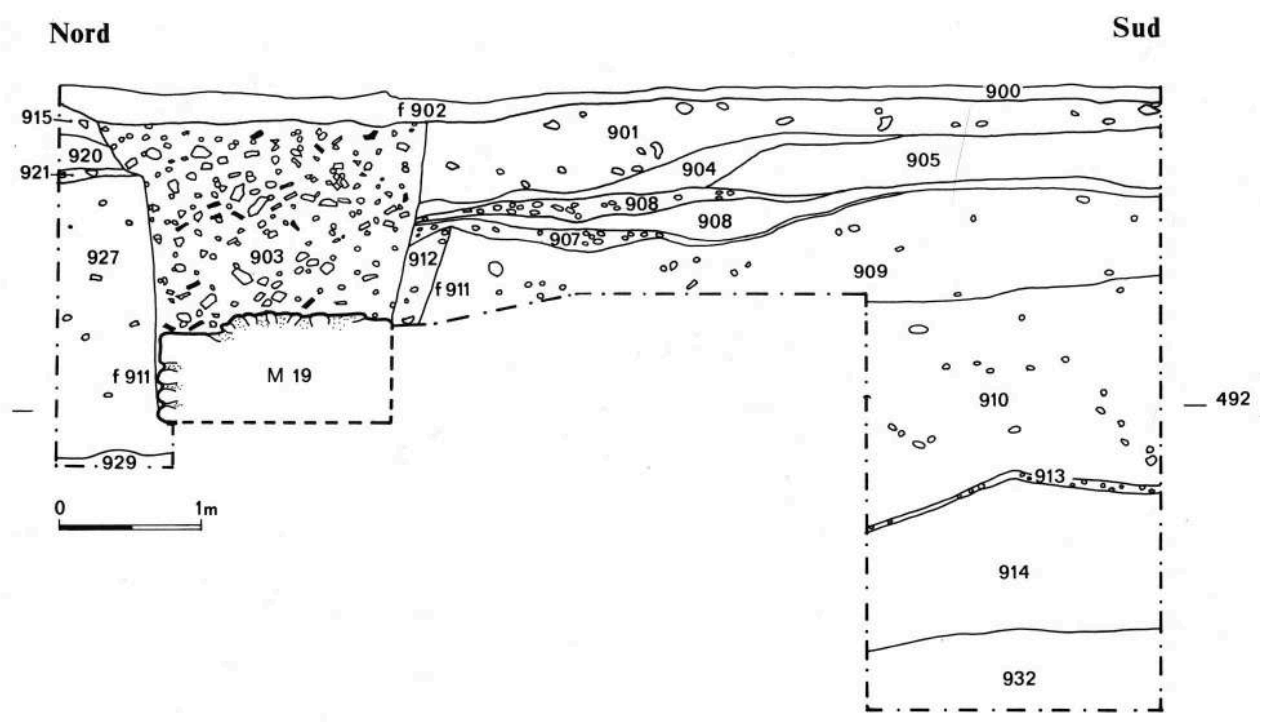

38 A l'ouest, le talus externe de la levée de terre, contre lequel est érigé le mur, a été taillé verticalement. Ce fait a été repéré tout le long de ce secteur ainsi par exemple F. 944 (fig. 33). L'espace entre le talus et la maçonnerie, large de $1 \mathrm{~m}$, est remblayé par un apport homogène de limon argileux brun, mêlé de galets et de cailloutis, ainsi C. 931 comblant F. 930 (fig. 35) ; C. 945 comblant. F. 944 (fig. 33).

39 A l'intérieur de ces tranchées, les maçonneries de fondation se composent d'assises de gros galets et de blocs de molasse, soigneusement alignés en parements et d'un blocage de galets et d'éclats de molasse, noyés dans du mortier de chaux (fig. 41). La différence entre le niveau du sol intérieur et celui du fossé extérieur entraîne une différence de niveaux entre les sommets des fondations interne et externe des murs. 
41 : Détail des fondations internes du mur de courtine ouest (sond. 9)

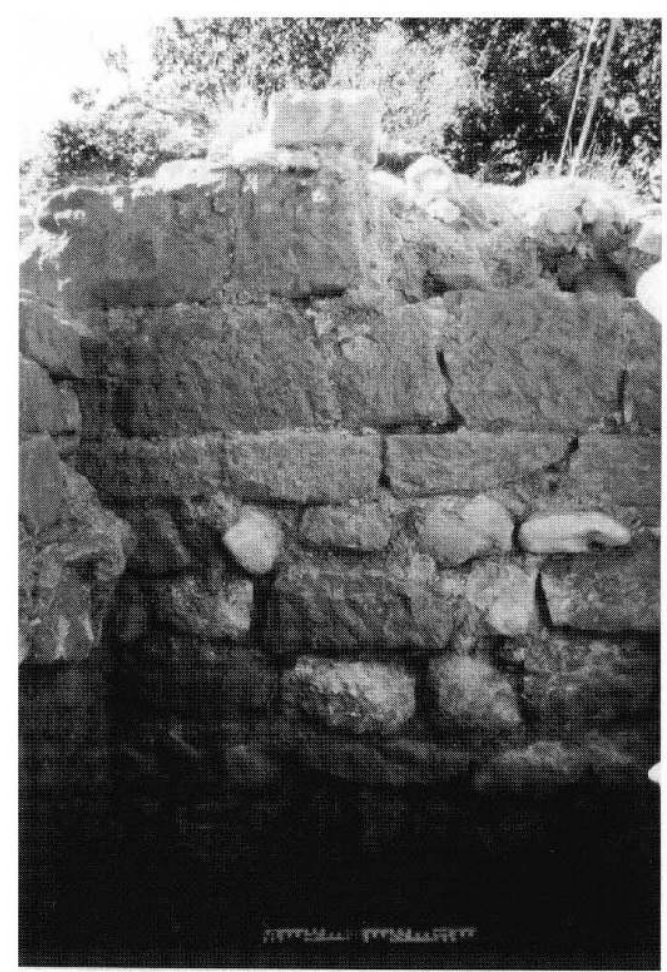

L'élévation externe du mur sud de l'enceinte, conservée sur $5 \mathrm{~m}$ de haut a été observée sur une longueur de 11,60 m (zone 4, sondage 3) (fig. 42-43). Il présente un moyen appareil mixte d'assises de blocs et de dalles de molasse, liées à joints fins avec du mortier de chaux.

\section{2 : Relevé de l'élévation du mur de courtine sud M 30}

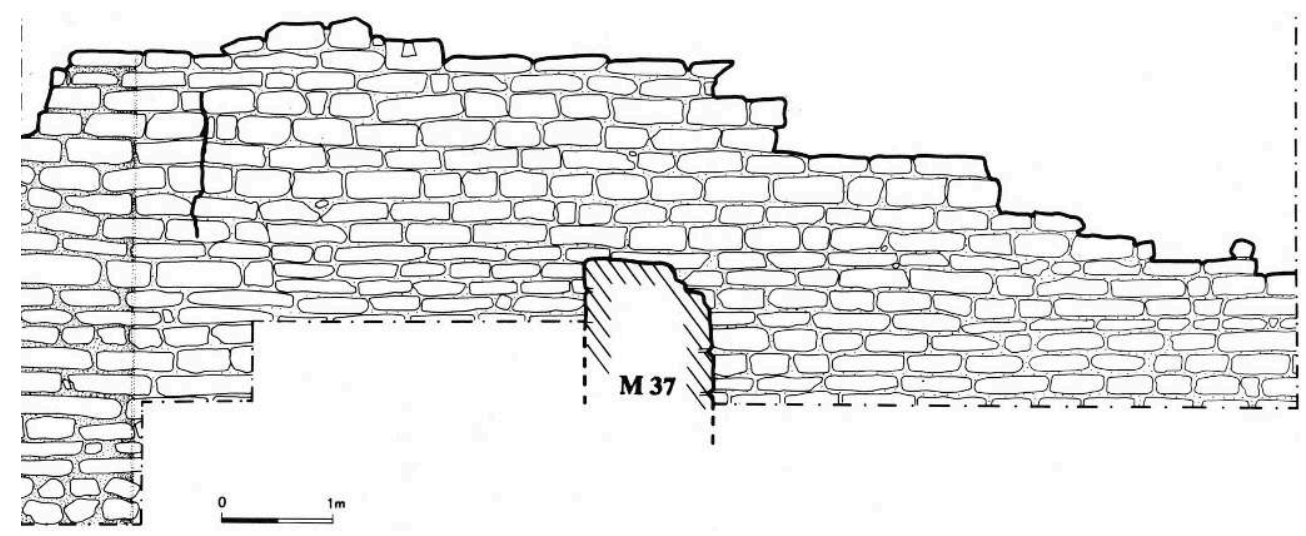




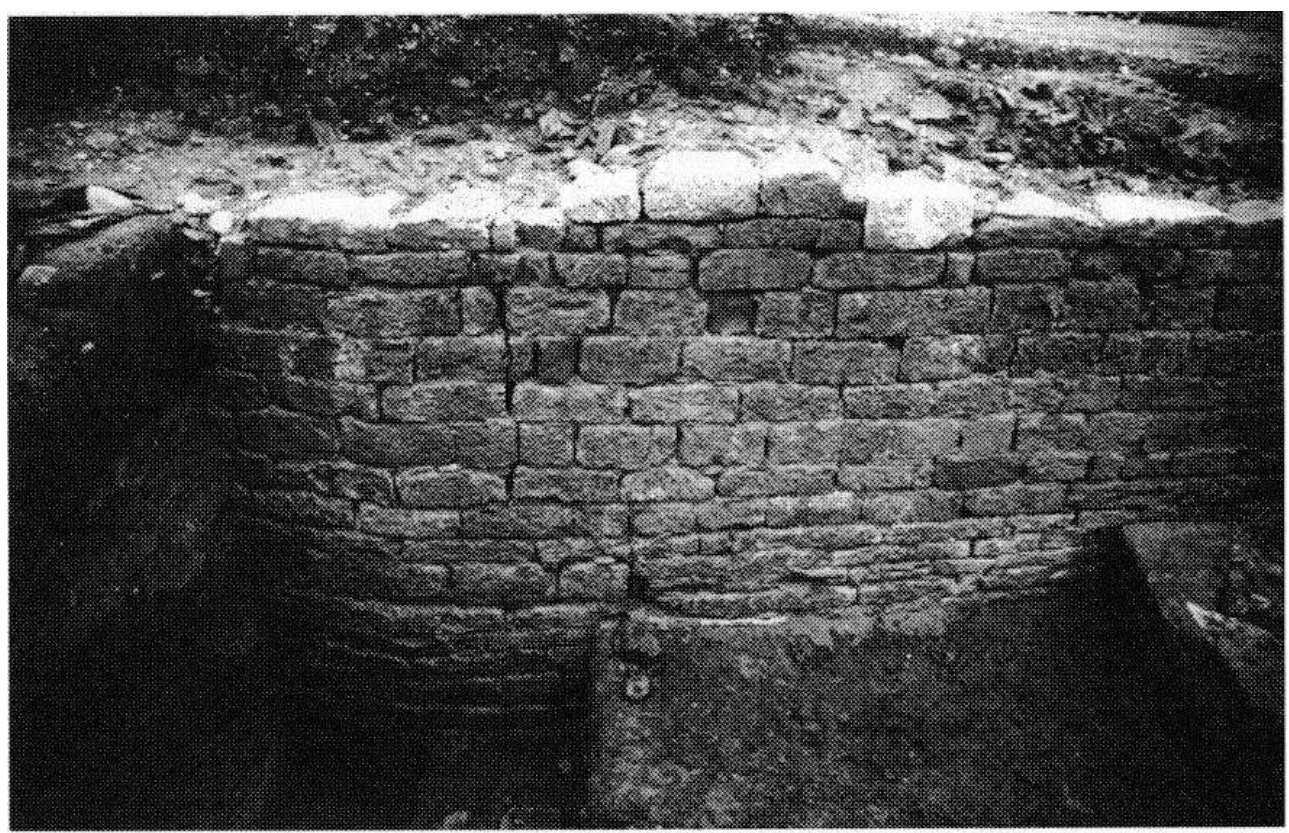

41 Les blocs, de forme trapézoïdale ou parfois presque triangulaire, profonds de 0,40 à 0,60 $\mathrm{m}$, présentent en parement une face rectangulaire de 0,60 à $0,80 \mathrm{~m}$ de large sur $0,40 \mathrm{~m}$ de haut ; les dalles, de forme quadrangulaire de 0,80 à $1 \mathrm{~m}$ de côté, n'ont que 0,10 à 0,20 $\mathrm{m}$ d'épaisseur. Elles constituent les assises des deux premiers mètres de l'élévation, puis viennent interrompre régulièrement la maçonnerie de blocs, d'une ou deux assises, ayant pour fonction de régler l'horizontalité de la construction. Comme en fondation, un blocage, constitué de galets et d'éclats de molasse noyés dans du mortier de chaux, s'insère entre les deux parements.

Les faces externes des dalles et des blocs sont soigneusement taillées, et portent les traces des outils utilisés pour ce travail. Il s'agit soit de profondes rainures, larges de 1 $\mathrm{mm}$, correspondant à l'impact d'une broche ou d'un pic frappant le bloc de manière oblique, le résultat recherché étant obtenu par enlèvement de fines lames de pierres (fig. 44) ; soit d'une taille systématique de la face externe par petits coups de brettelure (3 ou 4 dents de $2 \mathrm{~mm}$ de large) (fig. 45-46). Certaines pierres portent les traces de l'emploi de ces deux outils (fig. 47) ce qui pourrait correspondre à l'équarissage et à la taille des blocs. 
44 : M 30 bloc taillé au pic ou à la broche

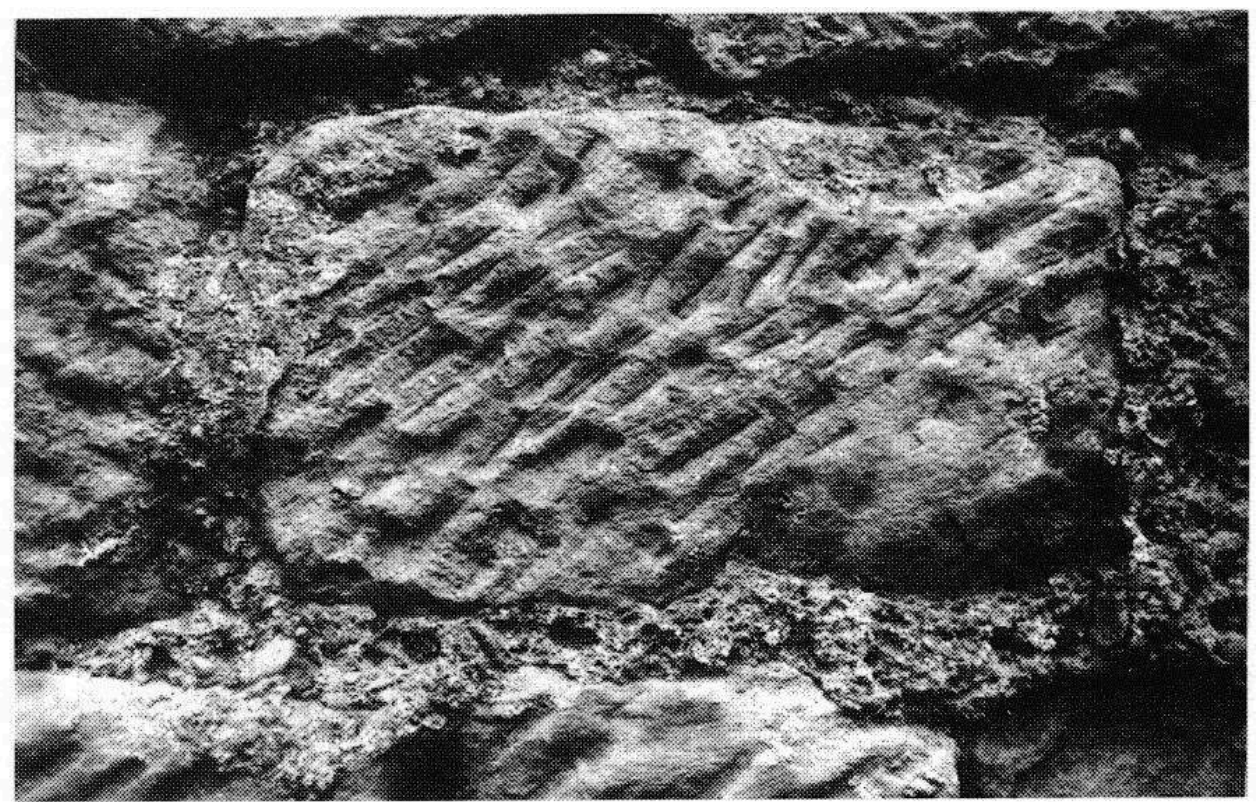

45- 46 : M 30 bloc taillé à la brettelure
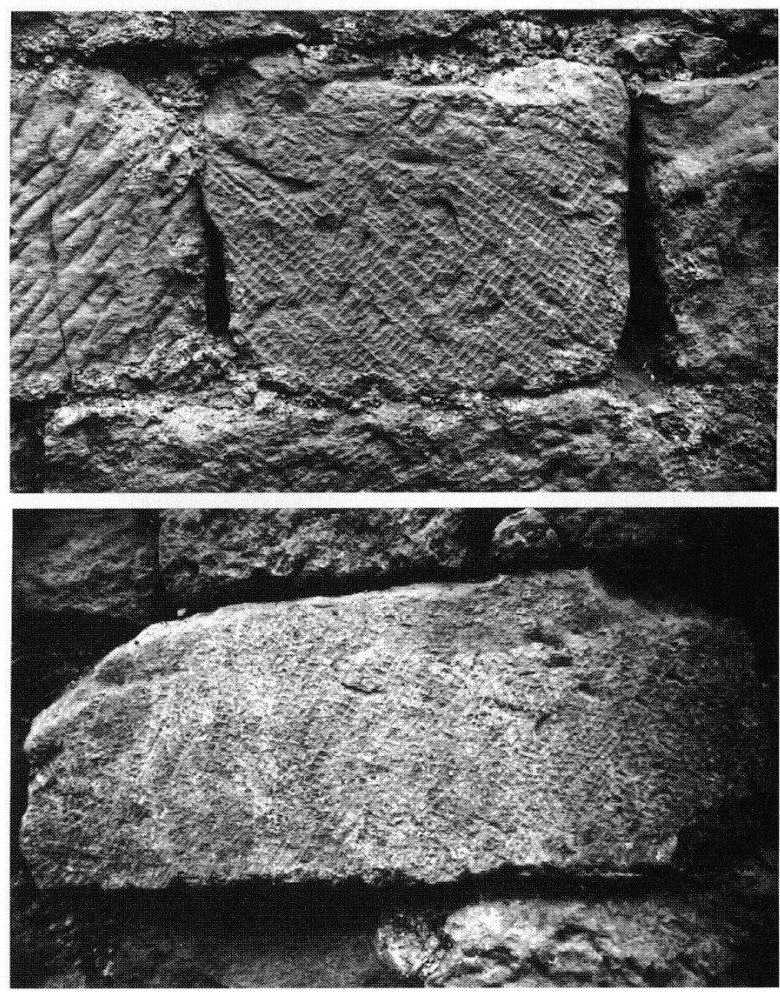


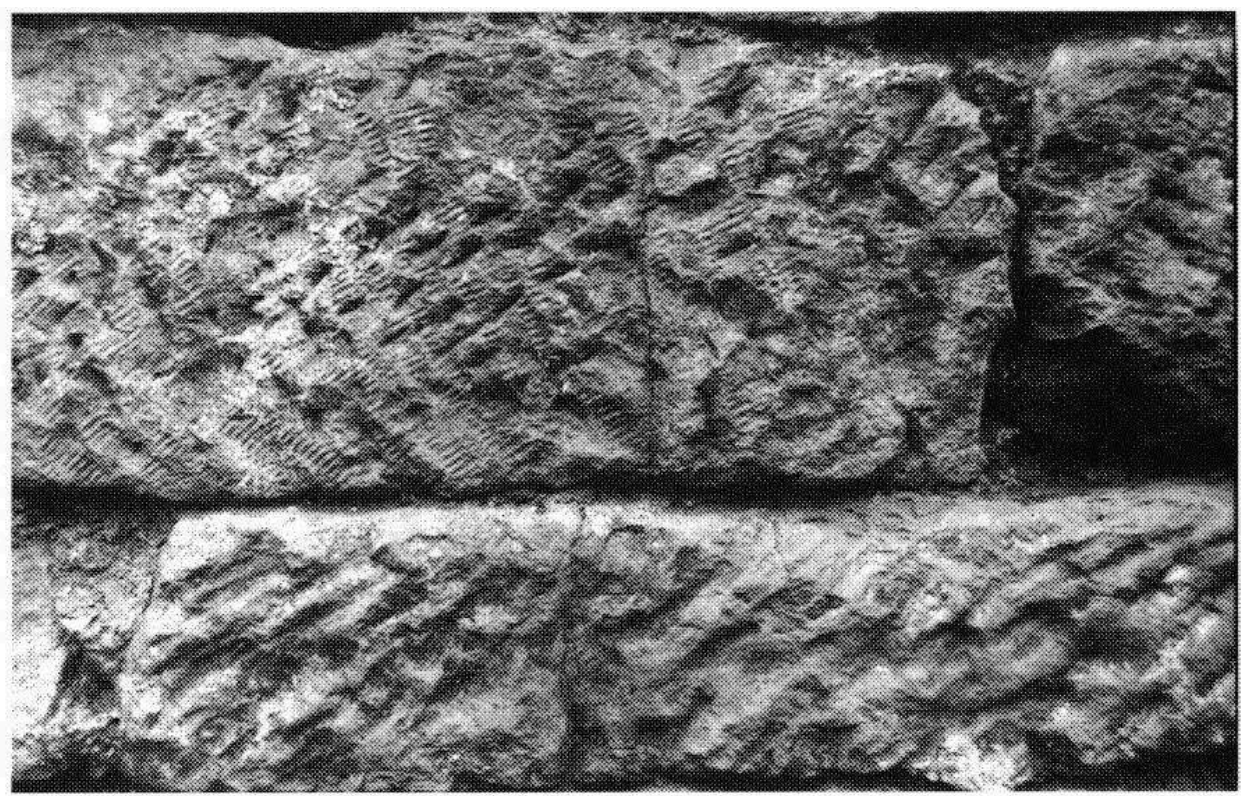

\section{Le logis}

43 Sur la partie nord de l'enceinte, côté village, un corps de logis est aménagé suivant un plan grossièrement polygonal. Il est subdivisé en plusieurs pièces par des murs de refend. Les intersections sont liées avec les murs de façade M 19 et M 44, en revanche leurs extrémités s'appuient contre le parement interne des courtines. Ce bâtiment occupe la superficie de $410 \mathrm{~m} 2$ et se décompose en deux parties architecturalement différentes : à l'ouest, deux grandes pièces I et II, et à l'est, trois pièces III, IV et V, plus petites et aux sols plus bas de $2 \mathrm{~m}$ environ. Cette différence de niveaux incite à voir dans les pièces de la partie orientale, les caves décrites dans l'inventaire de 1612 (A.D.H.S., 7J 493).

44 La partie ouest est limitée par le mur de façade M 19, long de $26 \mathrm{~m}$ et large de 1,50 m, orienté estouest; ce mur n'a pas été dégagé sur toute sa longueur, mais a pu être observé grâce à trois sondages : sondage 13 à l'est, sondage 8 au centre et sondage 9 à l'ouest.

45 La base du mur de façade M 19 est implantée dans une tranchée étroite F. 6023 (fig. 48) et F. 911 (fig. 40), creusée dans les niveaux de l'état antérieur. Les trois premières assises sont constituées de galets et de blocs de molasse non taillés, sur lesquelles reposent des dalles de molasse, formant les assises supérieures des fondations (fig. 49) ; ce mur avait déjà été partiellement détruit lors de la construction de l'état 3 et les matériaux récupérés très profondément après abandon du site; aucun vestige de l'élévation n'a donc pu être observé. 


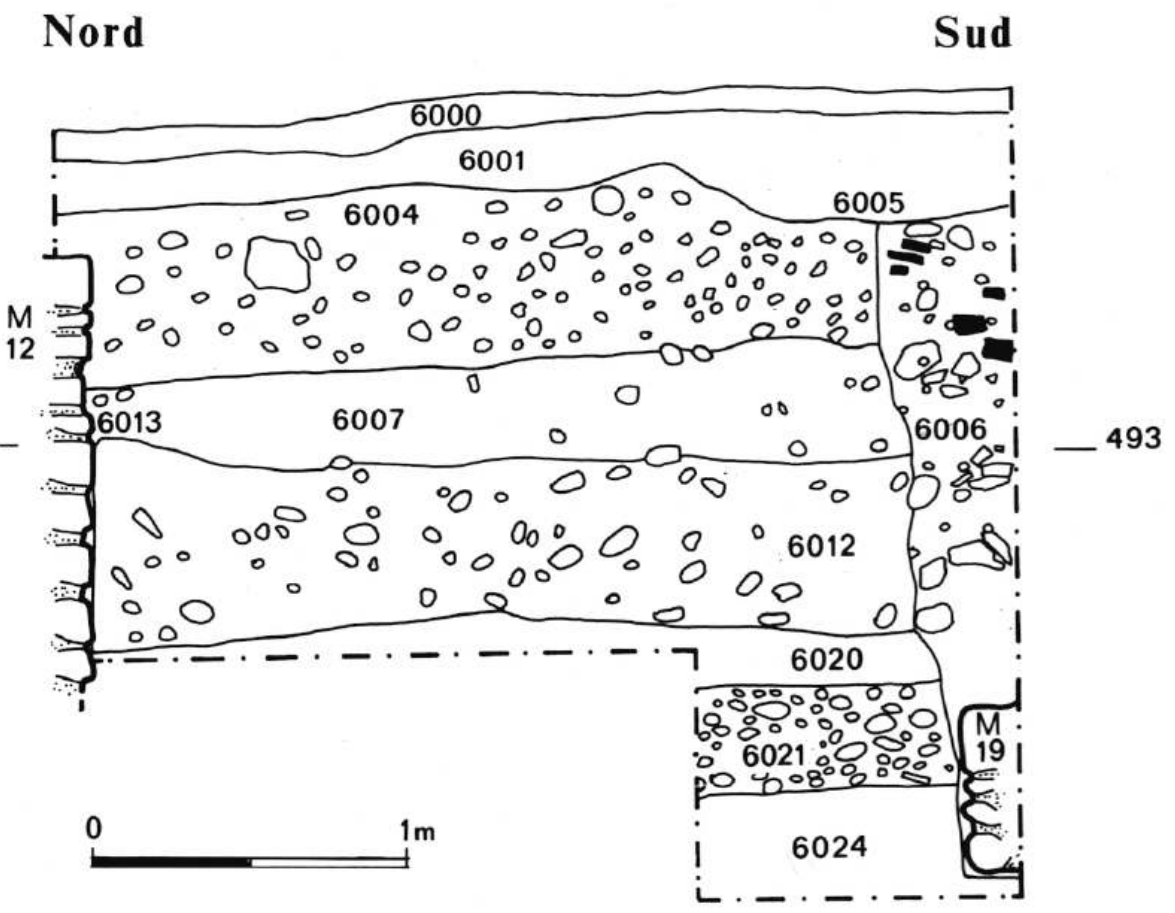

49 : Détail de l'assise de fondation du mur de façade du logis $M 19$

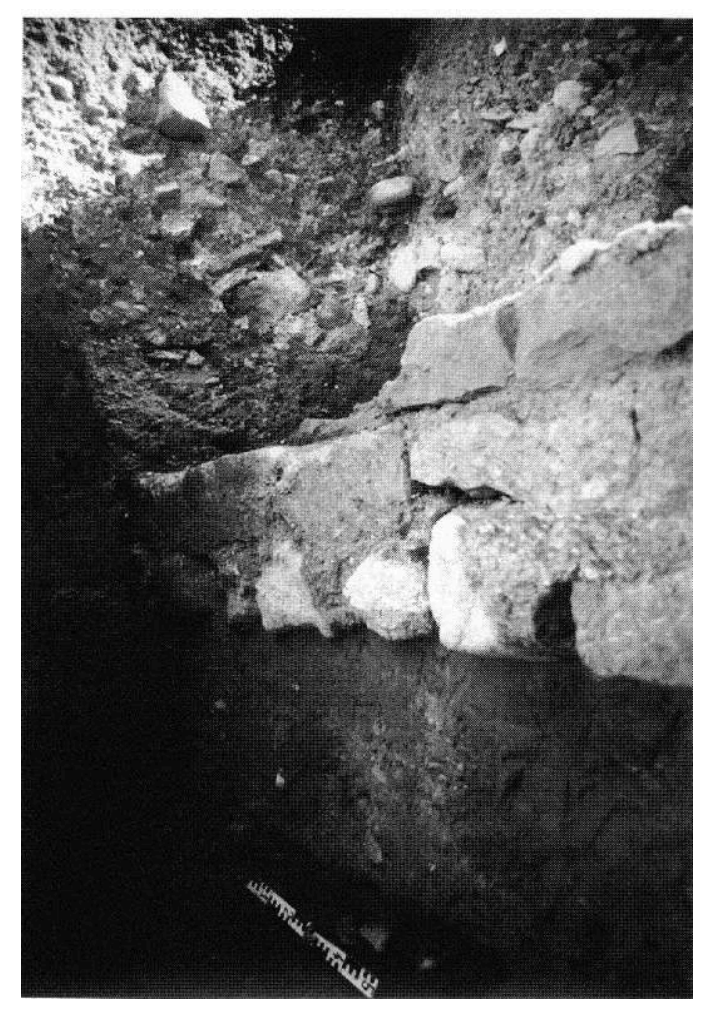

La maçonnerie est appuyée contre le bord septentrional de la tranchée de fondation ; l'espace, laissé libre du côté sud, a été comblé par un remblai de cailloutis et d'argile. 

creusée dans la couche d'argile compacte, jaune et sans inclusion (C 607 sondage 6 et C. 6024 sondage 8), premier niveau rencontré appartenant au substrat géologique. Long de $10 \mathrm{~m}$ et large de $1,10 \mathrm{~m}$, ce mur, partiellement conservé sur $1,50 \mathrm{~m}$ de haut, présente en fondation une maçonnerie de galets liés au mortier de chaux occupant toute la largeur de la tranchée; au-dessus se superposent les assises de blocs en molasse, constituant l'élévation (fig. 50). Probablement à cause de la pente naturelle du terrain, le niveau supérieur des assises de fondation est plus bas sur le parement est $(491,40 \mathrm{~m}$ pour 492,20 m à l'ouest).

50 : Structure du mur de refend $M 7$

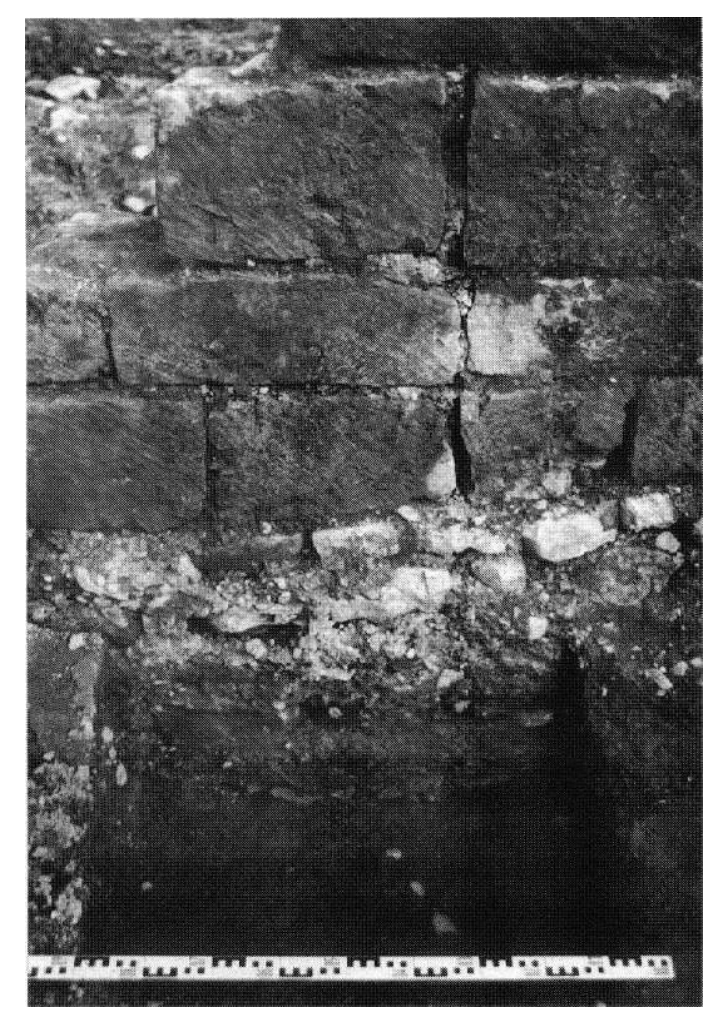

Le mur de refend M 3, long de 11,40 m et large de $1 \mathrm{~m}$, est appuyé à l'ouest contre une rupture verticale du terrain peut-être aménagée lors de la construction du logis. Le parement est présente une assise de gros galets, constituant la base du mur sur laquelle s'élèvent des assises de blocs de molasse. Le parement ouest comporte un massif quadrangulaire de 1,80 m de côté, construit de blocs de molasse que nous interprétons comme le vestige d'un contrefort. De part et d'autre de cette maçonnerie, le parement ouest du mur est constitué d'assises non réglées de galets et de blocs de molasse noyés dans du mortier de chaux. D'après l'observation de la partie conservée, cette maçonnerie se présente donc comme un mur de soutènement bordant, à l'est, une terrasse aménagée dans le terrain naturel.

La présence d'un contrefort au centre de ce mur s'explique peut-être par une différence des niveaux supérieurs entre les deux parties du logis. 
51 La partie orientale du bâtiment correspond à un espace de plan trapézoïdal, couvrant une surface de $145 \mathrm{~m}^{2}$, limité à l'est et au nord par les murs de courtine M 1 et M 17, au sud par le mur de façade M 44 et à l'ouest par M 2. L'ensemble est divisé en deux pièces par le mur de refend M 4, orienté estouest. Les fondations de ces murs sont implantées très profondément: aucun des sondages pratiqués dans ce secteur n'a permis d'atteindre la base de celles-ci.

52 Le mur M 44, long de 10,40 m et large de 1,20 m, présente en élévation deux parements de blocs de molasse avec un blocage de galets et d'éclats de blocs de molasse noyés dans du mortier de chaux. Il limite l'espace au sud et correspond, sans doute, à son mur de façade.

53 Le mur M 2, orienté nord-sud (fig. 51), est parallèle au mur M 3, long de $17 \mathrm{~m}$ et large de 1,10 m. Il est lié, au tiers de sa longueur, avec le mur de façade du bâtiment ouest, la façade de la partie est du logis étant ainsi en saillie par rapport à celle de la partie ouest.

\section{1 : Elévation du mur de refend M 2 (pièce IV)}

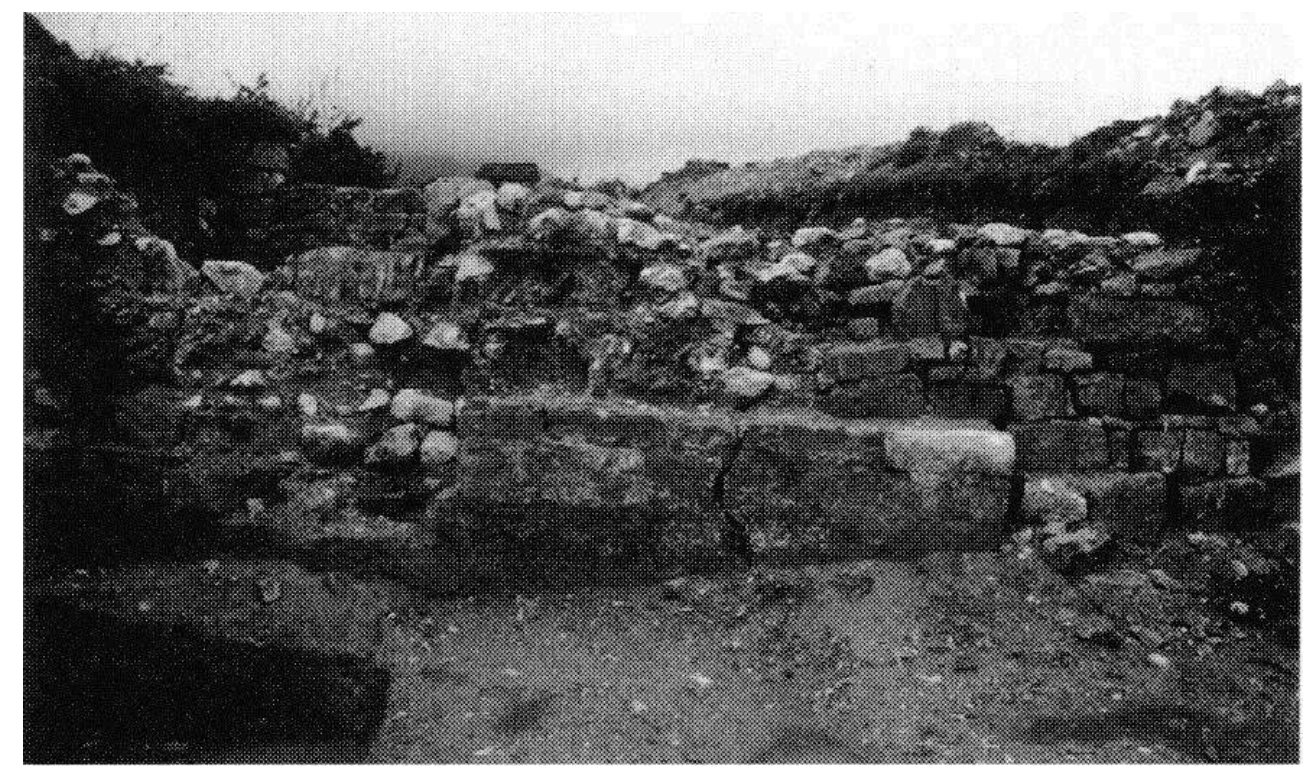

L'élévation de ce mur présente le même mode de construction que le mur M 44. Dans l'angle sud-ouest, formé par ces deux murs M 44 et M 2, trois assises de blocs de molasse, taillés en forme de voussoirs, sont partiellement conservées et permettent de restituer une voûte couvrant cet espace (fig. 52). 
52 : Départ de la voûte de couverture de la pièce $V$

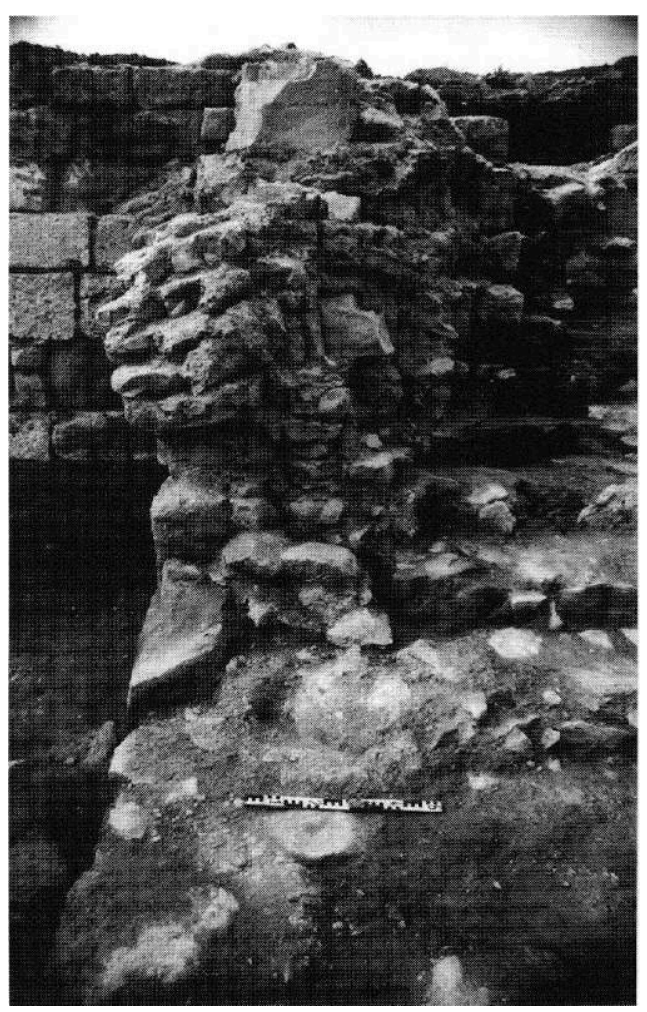

Dans l'angle nord-ouest, à $0,60 \mathrm{~m}$ du mur de l'enceinte, une porte est aménagée dans le mur M 2 ; elle permettait le passage entre la pièce IV et la pièce III. Les jambages de cette ouverture sont maçonnés en blocs de molasse. Large de 1,40 m, elle devait être surmontée par une arcade dont les claveaux auraient été récupérés à l'état 2.

Deux marques de tâcheron identiques, hautes de $8 \mathrm{~cm}$, représentent la lettre $\mathrm{V}$ gravée sur un bloc de chaque côté du piédroit sud (fig. 53).

Le mur de refend, M 4, axé est-ouest (fig. 54) est approximativement parallèle au mur de façade, long de 7,50 m et large de 1,20 m; il divise cette partie du logis en deux pièces. Seul le parement nord de ce mur a pu être dégagé. Il présente à sa base deux ressauts successifs de 0,20 m de large et de 0,60 m de haut, formés par des assises de blocs de molasse en saillie par rapport à l'aplomb du mur. Le piédroit d'une ouverture parementé en blocs de molasse a pu être mis au jour. Cette porte, permettant le passage entre la pièce $V$ et la pièce $I V$, se situait au milieu du mur de refend. 
53 : Mur M 2, marque de tâcheron (pièce IV)

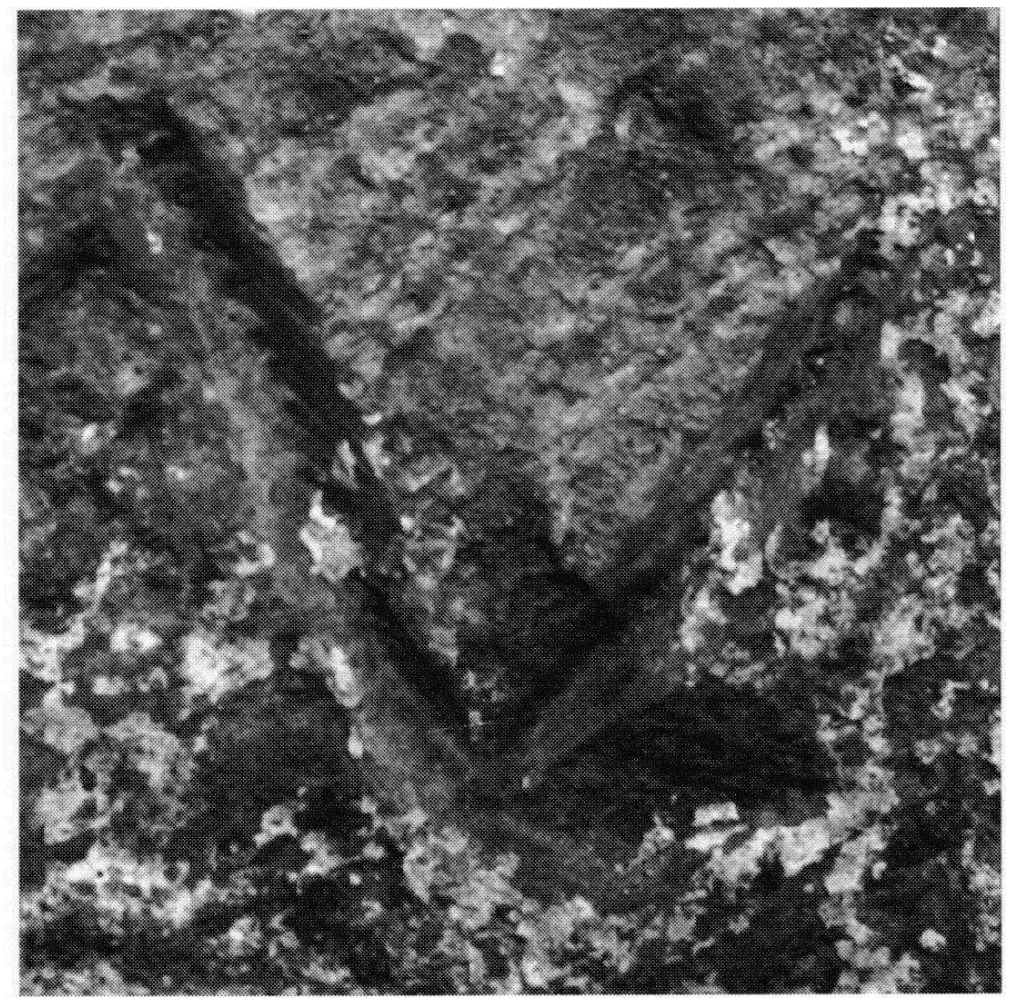

54 : Détail de l'élévation et de l'ouverture du mur M 4 (pièce IV)

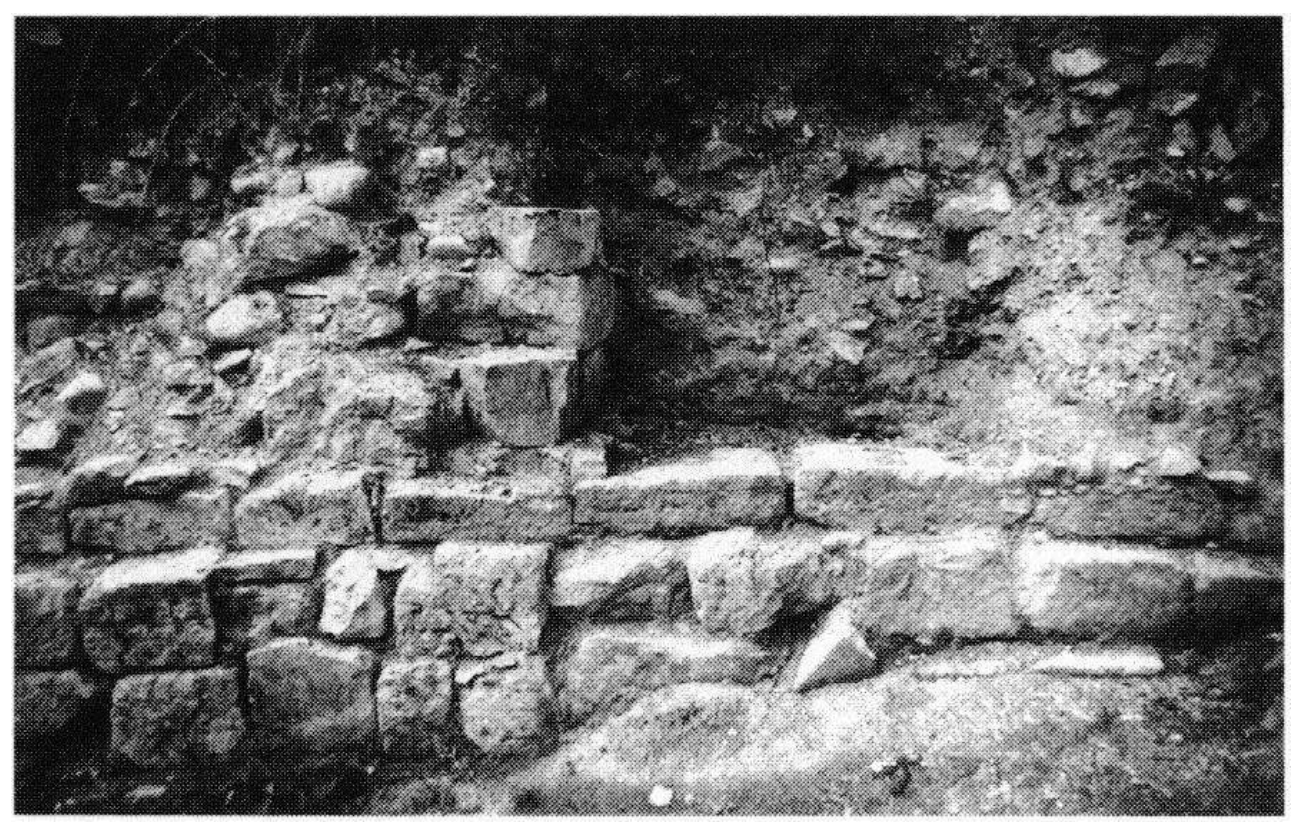

58 A l'intérieur des différentes pièces du logis, des sols sont aménagés sur des remblais. Surplombant le niveau extérieur, la moitié septentrionale des pièces I et II a été arasée en dessous du niveau des sols. Au contraire, nous avons pu repérer ceux-ci, dans des sondages pratiqués dans la partie sud. De même les pièces à l'est du logis (pièces III, IV et V) ont conservé leur sols profondément enfouis. 


\section{Pièce I}

59 A l'ouest, la pièce I, de plan trapézoïdal, couvre une superficie de $91 \mathrm{~m}^{2}$. Le remblai d'aménagement du sol de cette pièce a été repéré dans l'angle sud-ouest, sur une longueur de $3 \mathrm{~m}$ (C. 923) (fig. 55). Recouvrant l'ancienne levée de terre de l'état antérieur et les remblais de la tranchée de fondation du mur d'enceinte, il est constitué d'argile jaune, contenant des petits galets, amassée sur une épaisseur de 0,20 $\mathrm{m}$; son niveau supérieur se situe à 493,60 m d'altitude.

55 : Coupe stratigraphique pièce $I$, sond. 9

Ouest

Est

\section{Pièce II} superficie de $94,60 \mathrm{~m}^{2}$. L'aménagement du sol de cet espace nous est connu grâce à deux sondages: le sondage 8, effectué dans l'angle sud-ouest et le sondage 5, dans l'angle nord-est, où seuls les niveaux inférieurs ont été conservés.

61 Au nord, le bord du fossé de l'état antérieur, laissé en partie apparent lors de la construction de l'enceinte, est remblayé par un apport d'argile jaune, contenant des petits galets (C. 217) (fig. 56) ; au sud, le sol est rehaussé par trois remblais successifs d'argile et de cailloutis, sur $1 \mathrm{~m}$ d'épaisseur (C. 6021, cailloutis, C. 6020, argile jaune et C. 6012, argile contenant de nombreux petits galets) (fig. 48), seule la surface de celle-ci est suffisamment uniforme et compacte pour être interprétée comme le niveau de sol de cette pièce. L'importance de la surface à couvrir pourrait expliquer la nature hétérogène de ce remblai. Son niveau supérieur se situe à $493 \mathrm{~m}$ d'altitude, soit environ à $0,50 \mathrm{~m}$ en dessous du sol de la pièce $\mathrm{I}$. 


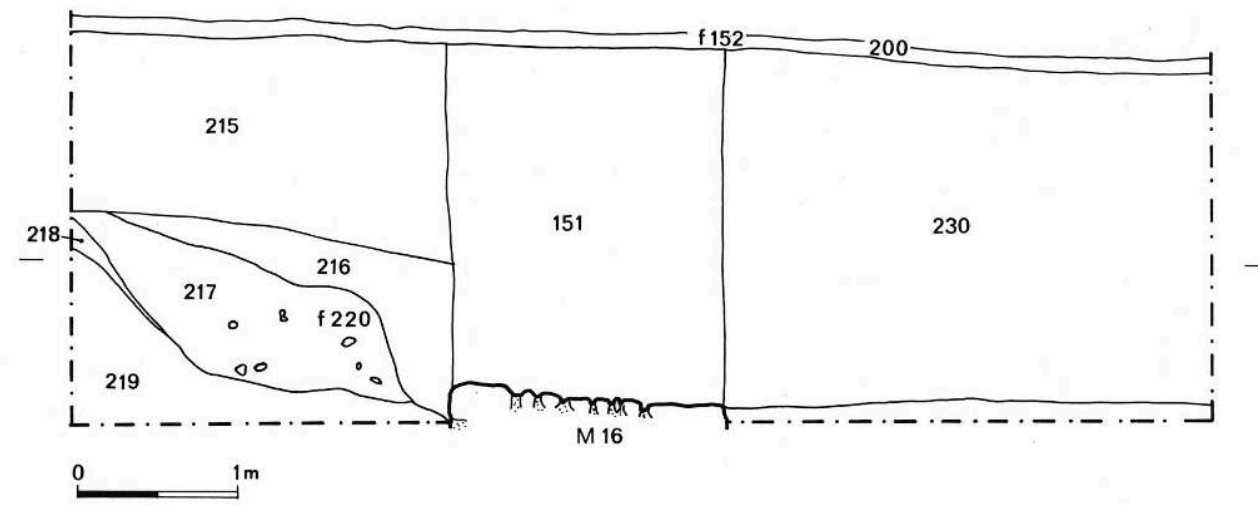

\section{Pièce III}

Formant la transition entre les deux parties du logis, la pièce III est, comme les deux précé- dentes, de forme trapézoïdale, elle couvre une superficie de $43,60 \mathrm{~m}^{2}$. Son sol est constitué d'un remblai d'argile jaune contenant des petits galets (C. 162) de faible épaisseur (0,15 $\mathrm{m}$ en moyenne) recouvrant le sol de l'état antérieur (fig. 57). Son niveau est à la cote d'altitude $491 \mathrm{~m}$, soit $2 \mathrm{~m}$ en dessous de celui de la pièce II.

\section{7 : Vue d'ensemble de la pièce III}

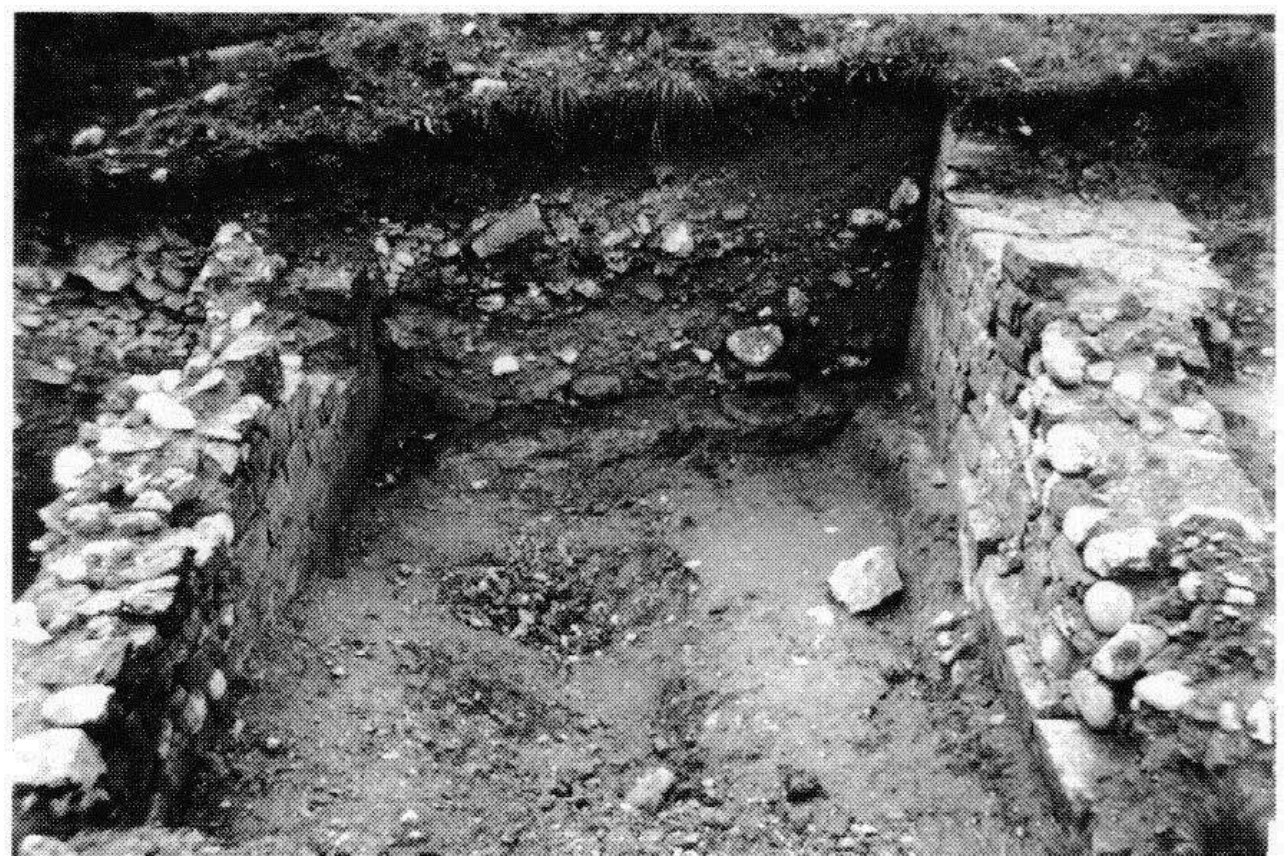

\section{Pièce IV}

Dans la partie est du logis, la pièce IV, de plan trapézoïdal, couvre une superficie de 36 $\mathrm{m}^{2}$. Le sol de cette pièce nous est connu grâce à deux sondages : le sondage 4 implanté dans l'angle nord-ouest et le sondage 1, ouvert sur toute la largeur de la pièce, 
parallèlement au mur M 4. Il est constitué d'un remblai d'argile jaune pure, ainsi C. 116, (fig. 58-59), et présente une légère pente vers le nord; son altitude moyenne est de $490,50 \mathrm{~m}$.

58 : Coupe stratigraphique de la pièce IV, sond. 1

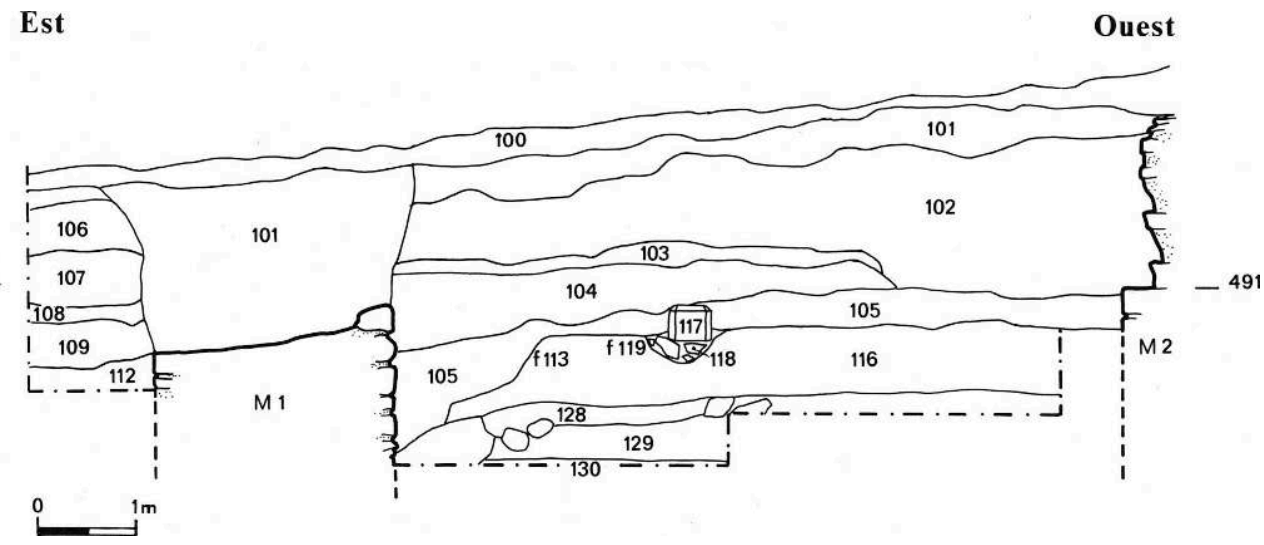

59 : Niveau de sol de la pièce IV

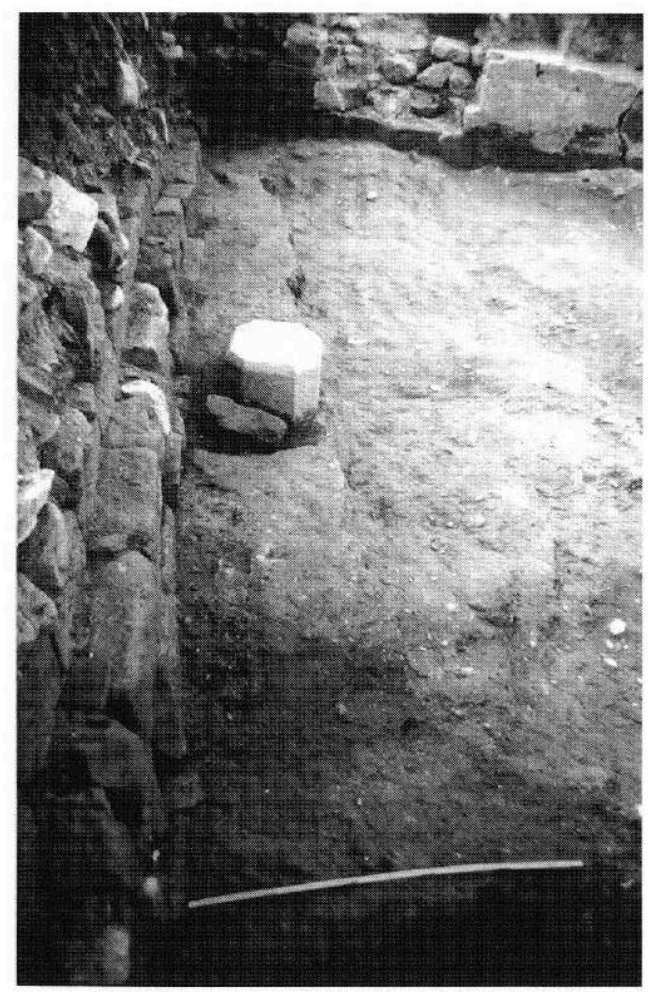

64 Au sud de cette pièce, à $0,50 \mathrm{~m}$ du parement du mur de refend $\mathrm{M} 4$ et à égale distance des murs $M 1$ et $M 2(3,20 \mathrm{~m})$, une petite fosse circulaire, de $0,70 \mathrm{~m}$ de diamètre, (F. 119) est creusée sur $0,30 \mathrm{~m}$ de profondeur dans le remblai du sol. Les petites pierres disposées au fond de l'excavation (C. 118) (fig. 58) servent de fondation à un bloc de calcaire (F. 117), placé à l'aplomb du jambage de la porte repérée dans le mur de refend dont le seuil est à 0,60 m au-dessus du niveau du sol (fig. 60). 


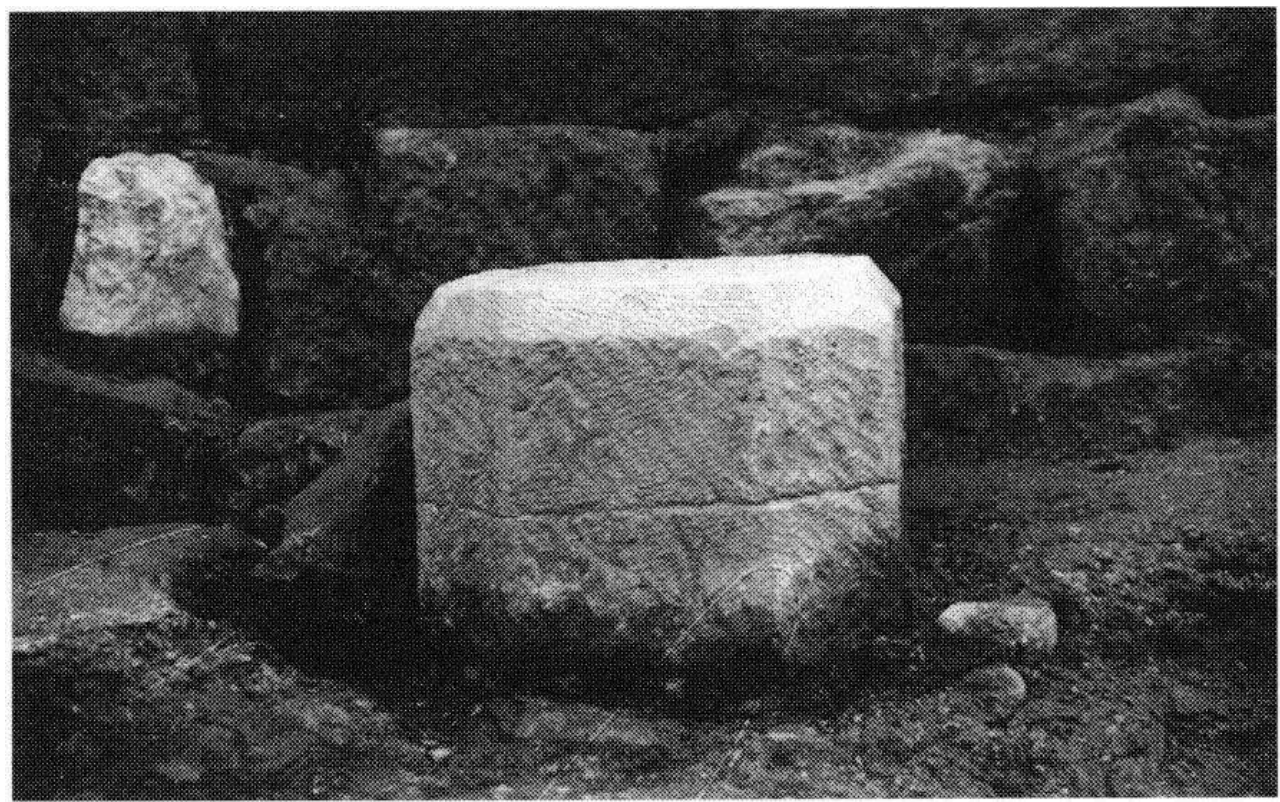

BLOC CALCAIRE, HAUTEUR DE 0,32 M, SECTION OCTOgONALE IRRÉgULIÈRE, LES CôTÉS OPPOSÉS FONT 0,28 M ET CEUX DIAgONALEMENT OPPOSÉS, 0,20 M. BLOC SOIgNEUSEMENT TAILLÉ À LA BRETTELURE, SON ARÊTE SUPÉRIEURE EST TAILLÉE EN BISEAU SUR 4 CM DE HAUT, UNE RAINURE MARQUE HORIZONTALEMENT LE MILIEU. CETTE PIERRE POURRAIT ÉVENTUELLEMENT CORRESPONDRE AU SUPPORT D'UN PILIER D'ESCALIER EN BOIS.

Il est soigneusement taillé à la brettelure, son arête supérieure est taillée en biseau sur $4 \mathrm{~cm}$ de haut, une rainure marque horizontalement le milieu. Cette pierre pourrait correspondre au support d'un pilier d'escalier en bois.

\section{Pièce V}

66 L'ouverture dans le mur de refend permettait le passage vers la pièce $\mathrm{V}$ dont seul l'angle sud-est a pu être partiellement dégagé (sondage 10). De plan trapézoïdal, elle couvre une superficie de $56 \mathrm{~m}^{2}$.

67 Le sol de cet espace nous est uniquement connu en surface. Il a été formé sur un remblai d'argile jaune C. 5010 ; son niveau supérieur est à $491,10 \mathrm{~m}$, soit environ $0,60 \mathrm{~m}$ au-dessus du niveau de sol de la pièce IV.

68 Dans l'angle sud-ouest de la pièce $\mathrm{V}$, un petit podium rectangulaire est aménagé audessus de ce sol. Long de $3 \mathrm{~m}$ el large de $2 \mathrm{~m}$, il est constitué d'une maçonnerie en équerre, s'appuyant sur les parements intérieurs des murs M 44 et M 2. La branche nord présente deux assises de moellons de molasse, sur 0,40 $\mathrm{m}$ de haut et $0,60 \mathrm{~m}$ de large. La branche est, large de $1 \mathrm{~m}$, est formée de deux assises de blocs de molasse, hauts de $0,20 \mathrm{~m}$, disposés de manière à former un ressaut extérieur de 0,40 $\mathrm{m}$ de large ; l'espace intérieur est remblayé par une couche d'argile jaune (C. 5009) dont le niveau supérieur est à $491,40 \mathrm{~m}$ d'altitude, soit $0,80 \mathrm{~m}$ en dessous de la base de la voûte (fig. 61). La destination de cette construction, est difficile à interpréter. 
61 : Podium dans l'angle sud-ouest de la pièce $\mathrm{V}$

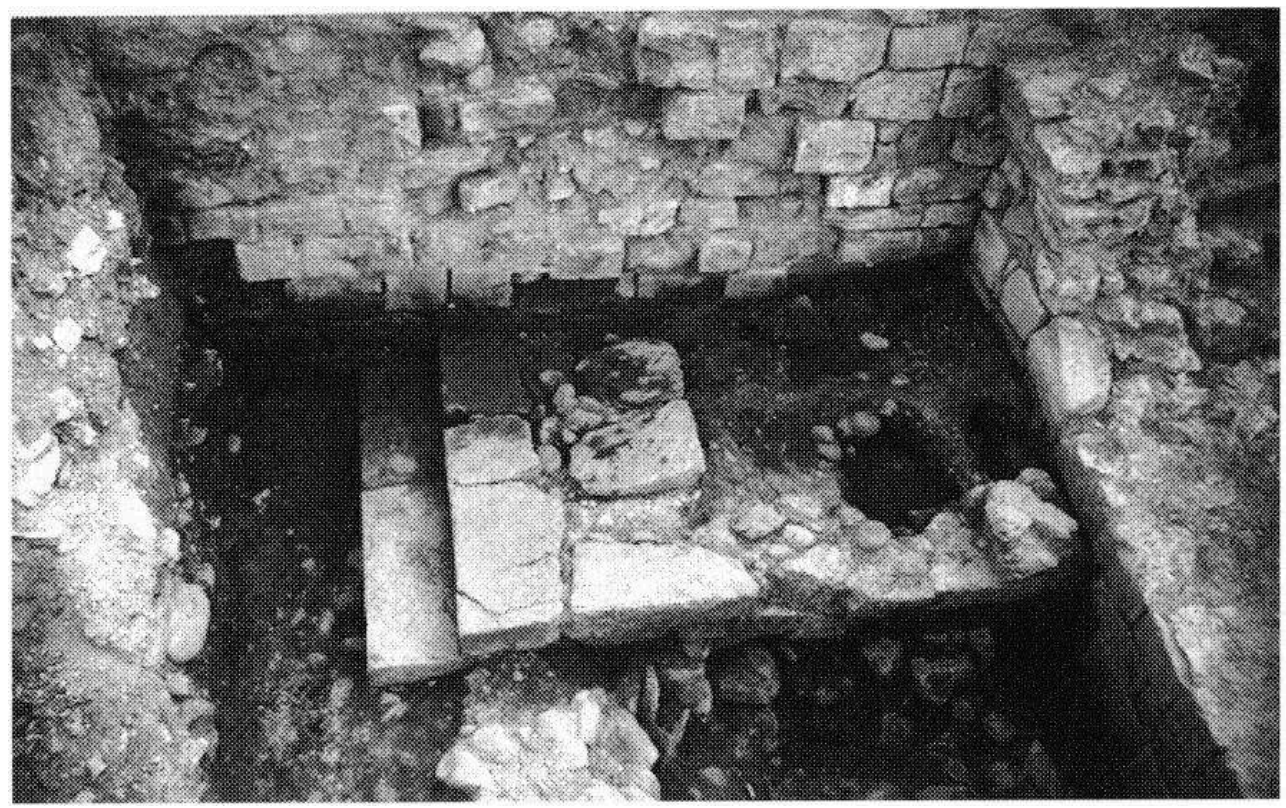

\section{Tour nord-ouest}

69 A l'intérieur de la tour nord-ouest (zone 8), un sol est aménagé sur un petit niveau de cailloutis (C. 806) (fig. 62-63), épais de 0,4 m. Son niveau supérieur est à $490 \mathrm{~m}$, soit 3,50 $\mathrm{m}$ en dessous du niveau du sol de la pièce voisine (pièce $\mathrm{I}$ ) ; l'accès à cet espace pouvait éventuellement se faire par une échelle, depuis l'étage supérieur.

\section{2 : Tour nord-ouest, niveau de sol}

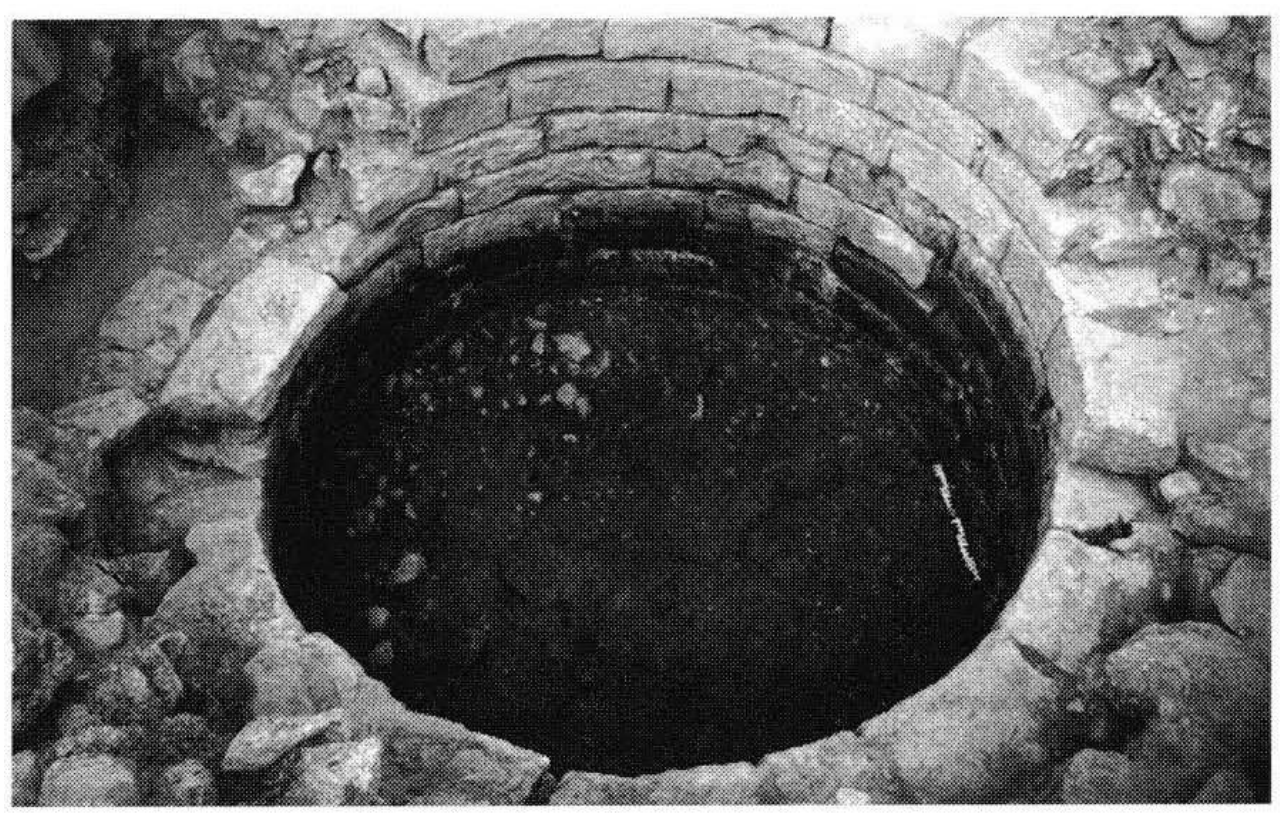


63 : Coupe stratigraphique de la tour nord-ouest (zone 8)

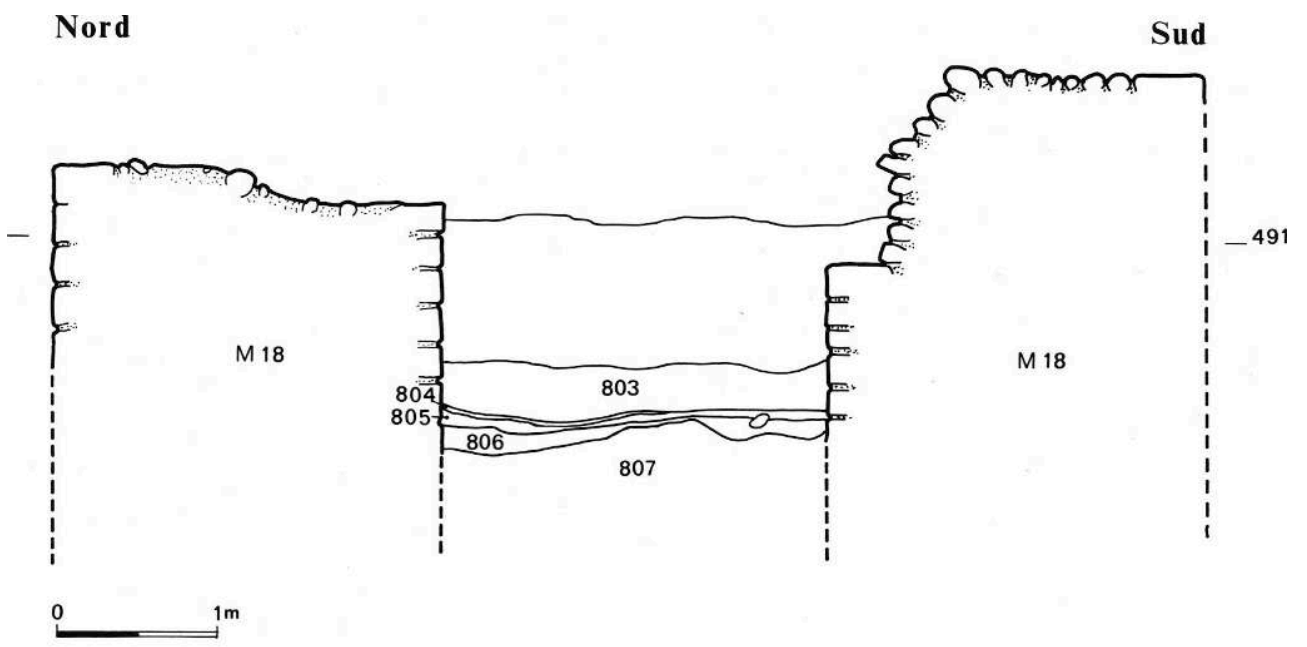

70 La surface de ce sol était recouverte par une couche de limon argileux gris (C. 805), contenant des éclats de molasse, des galets et de nombreux charbons de bois, ainsi qu'un abondant matériel résiduel : tessons de céramique, de verre datables du XIVe ou XVe s., des objets métalliques et des restes osseux de deux porcs, d'un boeuf et d'un mouton ainsi que de gallinacés et d'un pigeon.

71 Cet espace, de par son exiguïté se prête mal à une occupation. Par contre la très grande quantité d'os, déchets de consommation alimentaire, accumulée sur une très faible épaisseur de remblai $(5 \mathrm{~cm})$ incite plutôt à y voir un dépotoir temporaire. La présence d'un fémur de rat noir renforce cette hypothèse.

\section{La cour intérieure}

La partie méridionale de l'enceinte, côté montagne, délimite une cour intérieure (zone 9), de $265 \mathrm{~m}^{2}$ de surface.

Son sol se présente sous forme de quart de cuvette ; il a été aménagé par un important remblai d'argile jaune, contenant des petits galets (C. 951) (fig. 33), C. 4014, zone 6 et C. 4028, zone 9) (fig. 34), recouvrant partiellement les niveaux correspondant à l'état antérieur ; en son point le plus bas, dans l'angle nord-est de la cour, le niveau du sol est à $493 \mathrm{~m}$, soit $2 \mathrm{~m}$ au-dessus du niveau du sol de la pièce $\mathrm{V}$.

74 A l'ouest, l'ancienne levée de terre n'est pas complètement remblayée mais forme une sorte de terre-plein semi-circulaire au pied du mur de courtine M 9. Son niveau supérieur se situe à 494,80 m d'altitude, à proximité de l'angle de la tour sudouest.

$\mathrm{Au}$ nord-ouest, l'enceinte de terre et les couches de remplissage de la tranchée de fondation de M 9 sont partiellement recouvertes par une couche d'occupation (C. 907) (fig. 40) (C. 924) (fig. 55), constituée de limon gris contenant des cendres, des charbons de bois et un tesson de céramique du XIIIe s. (cf. annexe 2). Cette couche coupée par la tranchée de fondation du mur de façade sud du logis, M 19, est sans doute consécutive à l'occupation du chantier par les ouvriers au moment de la construction de la courtine.

L'argile du sol de la cour est rubéfiée par endroits: traces de foyers temporaires, allumés au milieu de la cour; aucune structure n'indique un usage prolongé de ces foyers. Le sol, aux alentours, est recouvert par une fine couche d'occupation, contenant des cendres, épaisse de $2 \mathrm{~cm}$ (C. 948) (fig. 33). 


\section{Le bâtiment central}

$77 \mathrm{Au}$ centre de l'enceinte, un bâtiment annexe de plan trapézoïdal, couvrant une superficie de $91 \mathrm{~m} 2$ est construit dans l'angle formé par les murs du logis M 19 et M 2 . Le mur nord de ce bâtiment est distant seulement de 0,20 m du mur de façade $\mathrm{M} 19$ et le mur oriental est séparé du mur M 2 par un espace de 1, 60 m (fig. 32).

Ce bâtiment est limité au nord par le mur M 47, long de 13,60 m et large de 1,20 m, à l'est, par le mur M 51, long de $8 \mathrm{~m}$ et large de 1,20 m, au sud, par le mur M 21, long de 13,40 m et large de $1 \mathrm{~m}$ et à l'ouest, par le mur M 53, long de 5,80 m et large de 1,20 m.

79 Ces murs sont construits en moellons de molasse, de 0,15 $\mathrm{m}$ de haut en moyenne et en galets, disposés en parements avec un blocage d'éclats de molasse et de galets noyés dans du mortier de chaux. Ce mode de construction a été utilisé pour les fondations comme pour l'élévation. Le mur ouest M 53 a été doublé intérieurement par une maçonnerie ne présentant de parement que sur sa face externe: M 52; sa fonction reste inconnue.

80 Un petit sondage implanté contre le mur est, a permis de retrouver le sol d'origine de cette pièce, formé sur un remblai d'argile jaune pure (C. 1110), épais de $0,40 \mathrm{~m}$ et à 492,40 m d'altitude; il est recouvert par une couche d'occupation cendreuse C. 1109, épaisse de $2 \mathrm{~cm}$ (fig. 77).

\section{État 2}

81 Dès le XIVe s., les comptes de châtellenies attestent certaines restructurations de l'édifice et constructions annexes. Nous regroupons dans l'état 2 (fig. 64) 1'ensemble des transformations que nous avons pu observer. Elles ne sont datables que par chronologie relative, postérieures à l'en ceinte sur laquelle elles s'appuient. Celle-ci forme une barrière empêchant de mettre en relation les séquences stratigraphiques. La description du château faite dans l'inventaire de 1612 correspond à cet état de la construction. 
64 : Château du Vuache, plan de l'état 2

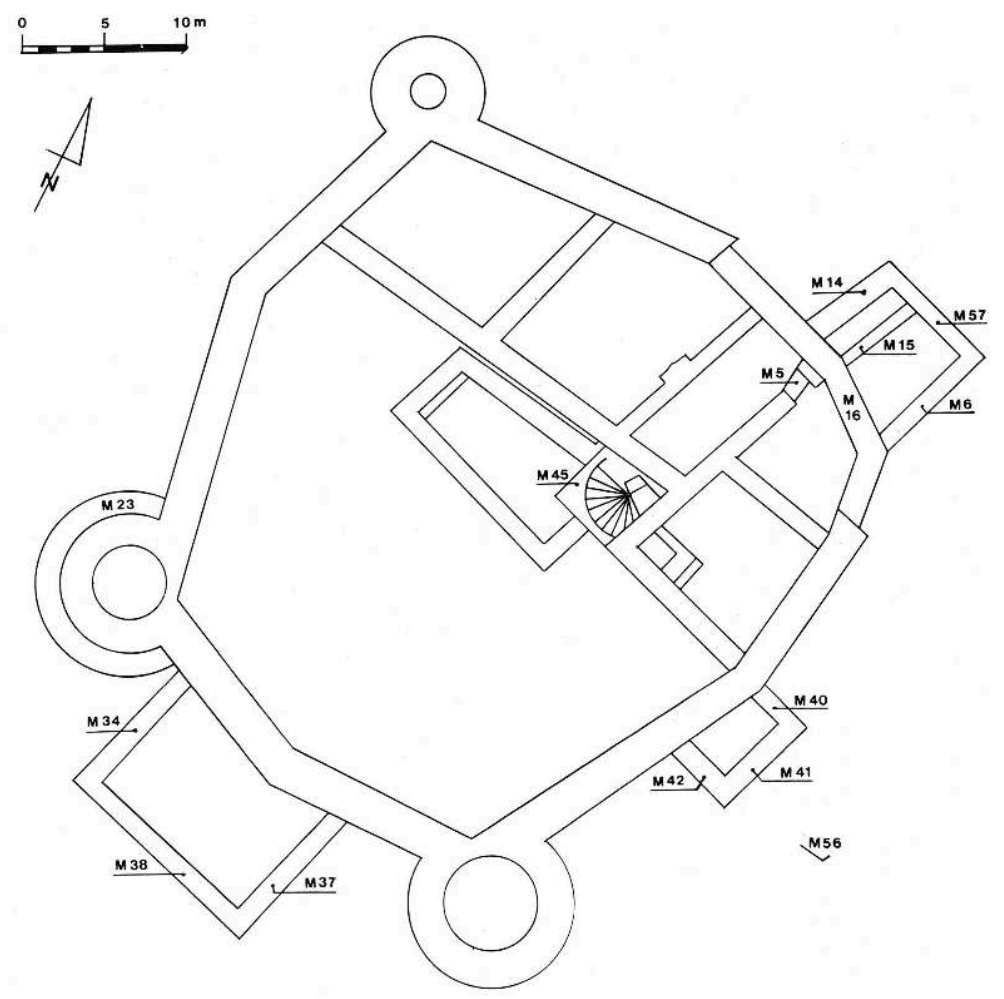

Une porte à l'est?

Un petit bâtiment rectangulaire (zone 7), large de $4,60 \mathrm{~m}$ sur $7 \mathrm{~m}$ de long, est appuyé au centre du mur de courtine est $\mathrm{M} 1$, à proximité de la partie est du logis. Les murs font $1,40 \mathrm{~m}$ de large et s'appuient sur le parement externe de la courtine.

Une tranchée de $1 \mathrm{~m}$ de large a été pratiquée dans la longueur de cet espace ; elle n'a révélé qu'une succession de remblais hétérogènes. En raison du peu de temps et de moyens impartis pour la fouille, cette coupe n'a pas fait l'objet d'une analyse détaillée. Ce bâtiment pourrait correspondre à la porte dont la construction est mentionnée en 1327. Dans ce cas, il était surmonté d'un chaffal, petite construction de bois en encorbellement. Une tranchée a été ouverte suivant un axe perpendiculaire à cet édifice mais l'importance du remblai accumulé pour combler le fossé et la présence de la nappe phréatique rendaient difficile l'exploration de ce secteur. Seul l'angle d'une maçonnerie correspondant à une des piles du pont a pu être repéré sous le niveau de la nappe. Ce pont constitué d'arches maçonnées et d'un tablier de bois, est également mentionné dans les comptes pour l'année 1326, date de sa construction.

\section{Un bâtiment annexe au sud}

$\mathrm{Au}$ sud de l'enceinte, un bâtiment annexe (zone 4) est aménagé contre le parement externe du mur M 30. Construit suivant un plan approximativement rectangulaire, de $14,20 \mathrm{~m}$ de long sur 9,40 m de large, il couvre une superficie de $133,50 \mathrm{~m}^{2}$.

Cet espace est limité à l'ouest par le mur M 34, long de $9 \mathrm{~m}$, au sud, par le mur M 38, long de $14 \mathrm{~m}$ et à l'est, par le mur M 37, long de 9,40 m; tous ces murs sont larges de 
1,25 m. L'angle sud-ouest présente un chaînage de blocs de molasse, disposés en carreaux et en boutisses. Le quatrième côté est constitué par le mur de courtine M 30 .

Les tranchées de fondation des murs sont creusées dans une couche d'argile grise, très plastique, d'origine alluvionnaire (C. 451) (fig. 65) accumulée contre le mur de courtine sud qui forme barrage à l'écoulement des eaux de ruissellement sur la pente de la montagne.

\section{5 : Coupe stratigraphique zone 4 , sond. 3}

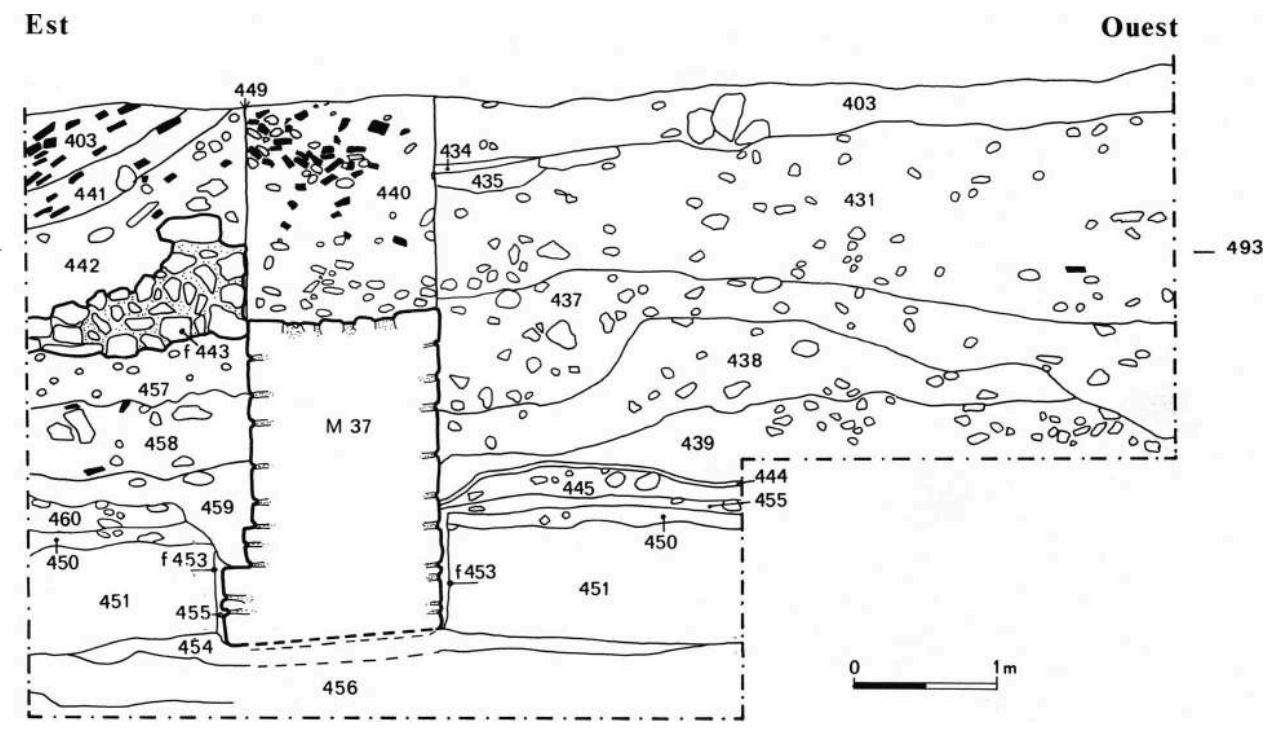

Celle-ci est recouverte par une couche de couleur brune très foncée, d'aspect et d'odeur comparables à de la tourbe (fig. 66). Elle contenait de nombreux petits fragments de bois et pourrait résulter de dépôts d'origine naturelle accumulés au fond du fossé (C. 450). Ces deux couches contenaient également quelques ossements d'animaux.

\section{6 : Zone 4, sond. 3 niveaux accumulés dans le fossé}

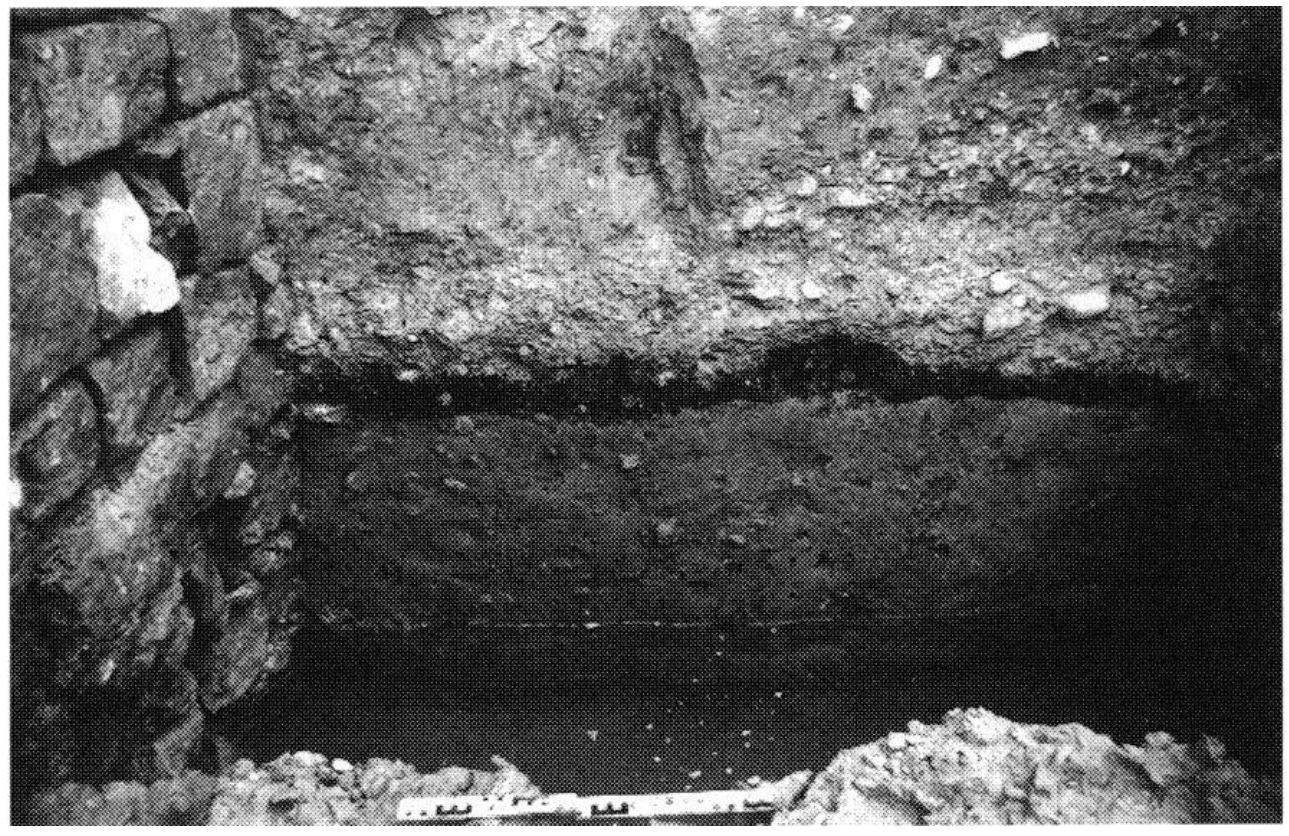


$88 \mathrm{Au}$ pied du mur d'enceinte, ces couches ont été recoupées par des tranchées successives, suivant l'alignement de son parement : F 465, F 464 et F 467 (fig. 67). Dues au dégagement de la base du mur de courtine, ces tranchées pourraient être consécutives aux curages du fossé : la tranchée F 465 a été comblée sur $0,80 \mathrm{~m}$ de profondeur par une couche d'argile jaune, pure (C. 466). Le sommet de ce comblement a été recreusé sur un mètre de large par la tranchée F 467, comblée par l'argile ocre, contenant des petits galets (C. 463), dont le sommet est partiellement recreusé sur 0,15 $\mathrm{m}$ de large par la tranchée $\mathrm{F} 464$ et recouvert par une couche d'argile jaune pure (C. 462).

67 : Coupe stratigraphique zone 4 , sond. 3

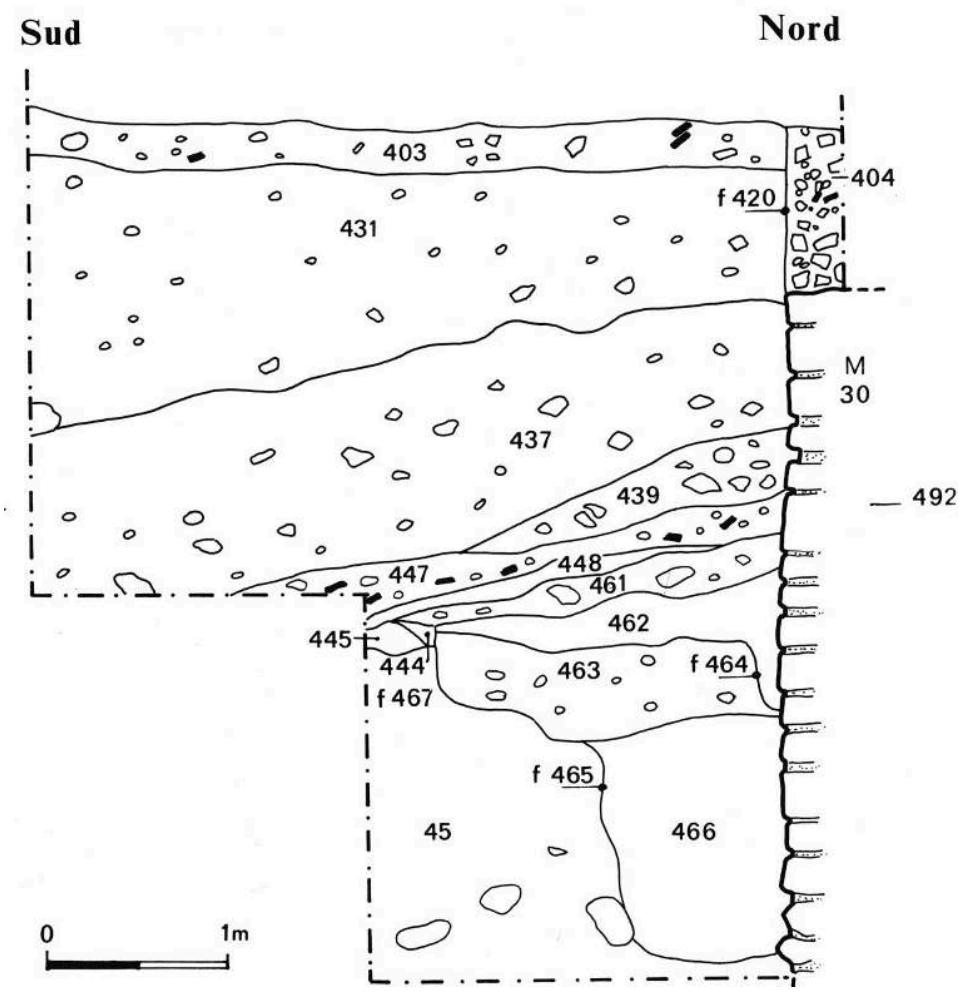

89 La construction et la stratigraphie de ce bâtiment ont pu être observés par un sondage implanté à cheval sur le mur limitant ce secteur à l'est, (fig. 67). La tranchée de fondation (F 453) (fig. 65) du mur M 37 a été creusée dans les couches d'origine naturelle (C. 450 et C. 451), sur une largeur de 1,46 m pour une profondeur de $0,70 \mathrm{~m}$.

90 A l'intérieur de cette tranchée, la maçonnerie a été appuyée contre le bord ouest, sous la forme d'un parement vertical de moellons de molasse et de galets disposés sur trois assises, alors qu'à l'est, elle est constituée de deux ressauts de blocs de molasse se chevauchant; large de 0,25 $\mathrm{m}$ à trois mètres de l'angle nord-est, ce ressaut s'amenuise vers le nord, pour finalement se confondre avec l'élévation du mur, $1 \mathrm{~m}$ avant l'intersection avec la courtine.

91 Le sommet de la maçonnerie de fondation de ce mur est à $491,30 \mathrm{~m}$ d'altitude, environ 3 $m$ en dessous du niveau du sol contemporain de la cour interne.

92 Les élévations des murs de ce bâtiment présentent, en parements, un appareil irrégulier de blocs de molasse et un blocage d'éclats de molasse et de galets noyés dans du mortier de chaux (fig. 68). 


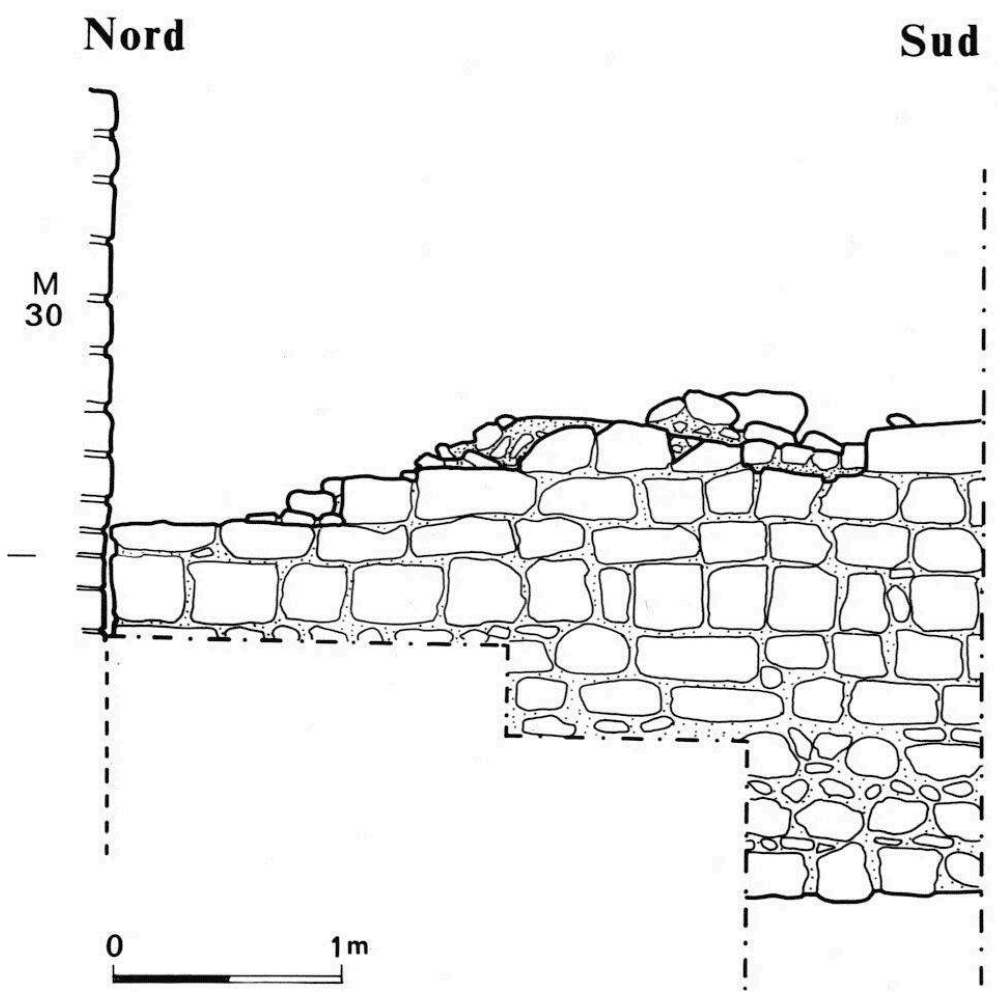

A l'intérieur du bâtiment, à partir du niveau correspondant au sommet des fondations, les paléosols antérieurs à cette construction sont recouverts par un lit de cailloutis, de sable et de particules de mortier, déposé pendant la construction et marquant le sol de travail (C. 445, C. 461) (fig. 65-67). Ce niveau est recouvert par une fine couche de cendres et de charbons de bois, contenant des restes osseux d'animaux complétant ceux trouvés dans les couches inférieures (C. 444 et C. 448), et localement, contre le mur nord, par un remblai d'argile brune, mêlée de cendres et de charbons de bois (C. 447). Ces couches correspondent probablement à la période de construction du bâtiment et se seraient déposées pendant l'occupation du chantier par les ouvriers.

Les ossements d'animaux (porcs, boeuf, un mouton dont l'ensemble du squelette est à peu près représenté, poules et ceux d'un ours brun) correspondent à une période de rejet dans le fossé, antérieurement à la construction de bâtiment annexe.

A l'extérieur du bâtiment, une couche d'argile grise (C. 459) (fig. 65) contenant également des cendres, recouvre les niveaux antérieurs à la construction. La base du mur M 37 est occultée par des dépôts alluviaux, dus au ruissellement des eaux de pluie (C. 458 et C. 457) (fig. 74).

Dans la coupe stratigraphique, au sud du sondage, nous avons partiellement dégagé un parement de mur semi-circulaire $\mathrm{F} 443$, dont la base est à 492,20 m d'altitude et qui s'appuie à l'ouest sur le parement externe du mur M 37 (fig. 65).

L'intérieur de cet édifice est comblé postérieurement par trois importantes couches de remblais : C. 439 , remblai de sable et de limon gris, contenant des cailloux, C. 437, remblai d'argile jaune compacte, incluant des éclats de molasse et de nombreux cailloux de calibre très varié et $C$. 431, remblai d'argile jaune compacte, contenant des galets et des éclats de molasse. Seule la surface de ce dernier porte des traces 
d'utilisation comme sol intérieur de la zone 4. Contre le mur M 37, un foyer, limité à l'ouest par une lauze de molasse, se signale par la rubéfaction de l'argile (C. 435) et une fine couche de cendres (C. 434) le recouvrant.

Après ces aménagements, le niveau du sol du bâtiment annexe se trouve au même niveau que le sol intérieur de l'enceinte. Il est probable que ce rehaussement soit conçu dès l'origine et que l'accès à cette pièce se faisait depuis la cour intérieure.

\section{La tour sud-ouest}

99 Elle est renforcée par un chemisage (zone 10, M 23), appuyé contre le parement extérieur du mur en blocs de molasse (fig. 69). Cette maçonnerie présente un blocage de galets noyés dans du mortier de chaux qui s'appuie contre le parement vertical du mur primitif et, à l'extérieur, un parement de gros blocs de calcaire, quadrangulaires, de $0,60 \mathrm{~m}$ à $0,70 \mathrm{~m}$ de coté ; les faces de ceux constituant les assises supérieures sont taillées en biais pour former un glacis. Ce revêtement est large de $2 \mathrm{~m}$ pour les assises inférieures et seulement de $1,50 \mathrm{~m}$ au niveau d'arasement. Il ne couvrait probablement que la base de la tour et témoigne d'un renforçement du caractère défensif du château.

69 : Tour sud-ouest, parement externe du chemisage

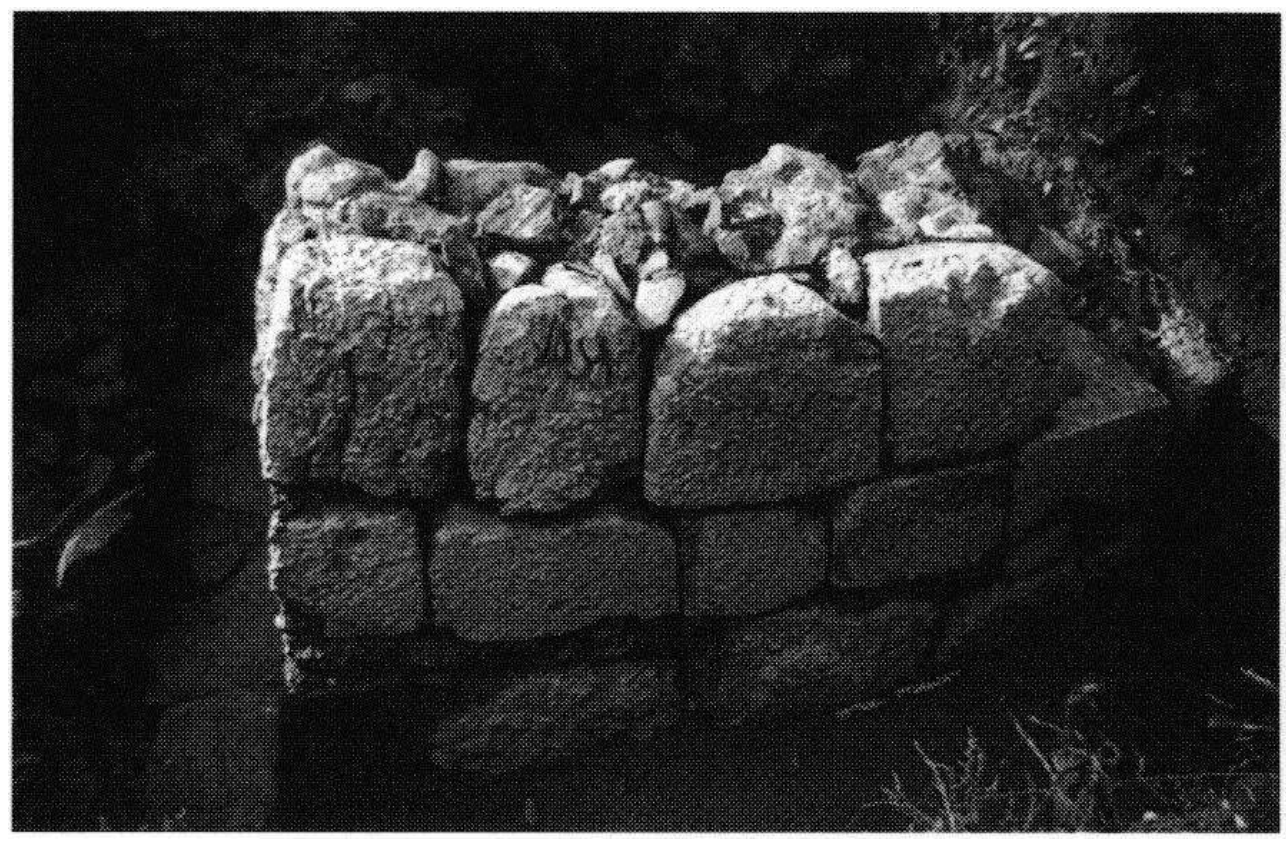

\section{Remaniement de l'enceinte}

L'angle nord-est de l'enceinte, formé par les murs M 17 et M 27 est arasé jusqu'à la côte d'altitude $489 \mathrm{~m}$. Un nouveau mur de courtine M 16 est construit à leur emplacement (fig. 70), large de 1,60 m, il présente, d'ouest en est, trois pans longs, respectivement, de $10 \mathrm{~m}, 6 \mathrm{~m}$ et $5 \mathrm{~m}$; il est fondé sur une assise de gros blocs morainiques, hauts de 0,30 $m$ (fig. 71) et recouvrant en partie l'arasement des murs de l'état I qui étaient plus larges. Son élévation est construite en blocs de molasse, dont la plupart paraissent être des remplois de l'état I, disposés en parement avec un blocage composé de galets et 
d'éclats de molasse noyés dans du mortier de chaux; le parement interne est appuyé contre les extrémités des murs de refend.

70 : Coupe stratigraphique zone V, pièce VII

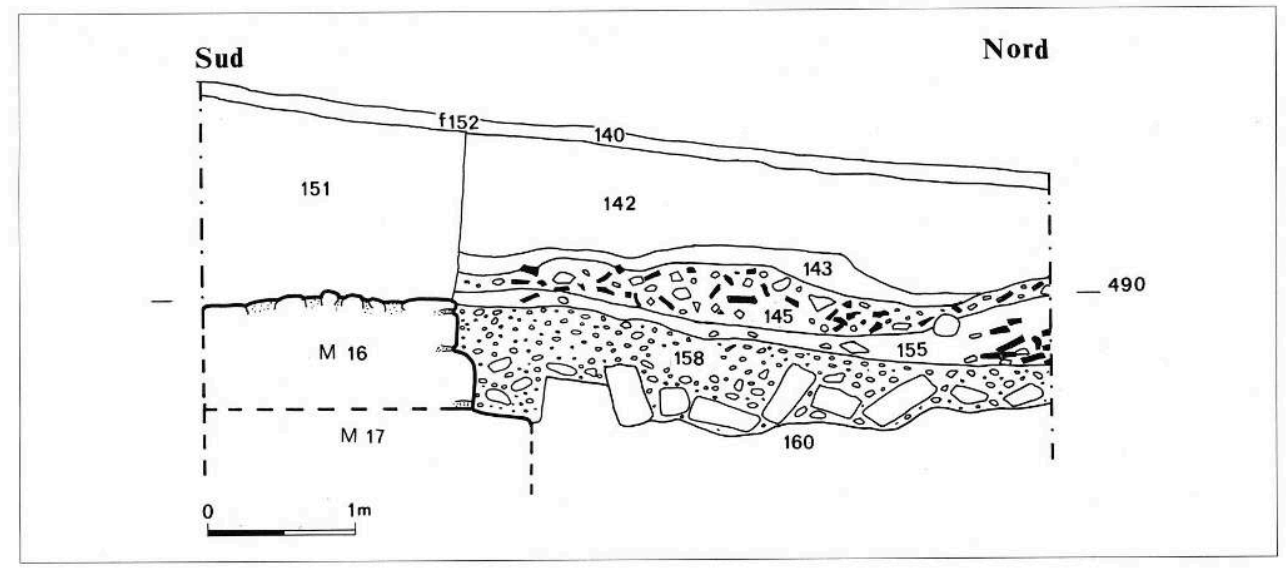

Pour l'installation de cette construction, une tranchée a dû être creusée dans les niveaux intérieurs du logis (F 113, pièce IV et F 220, pièce III).

\section{1 : Assise de fondation du mur M 16}

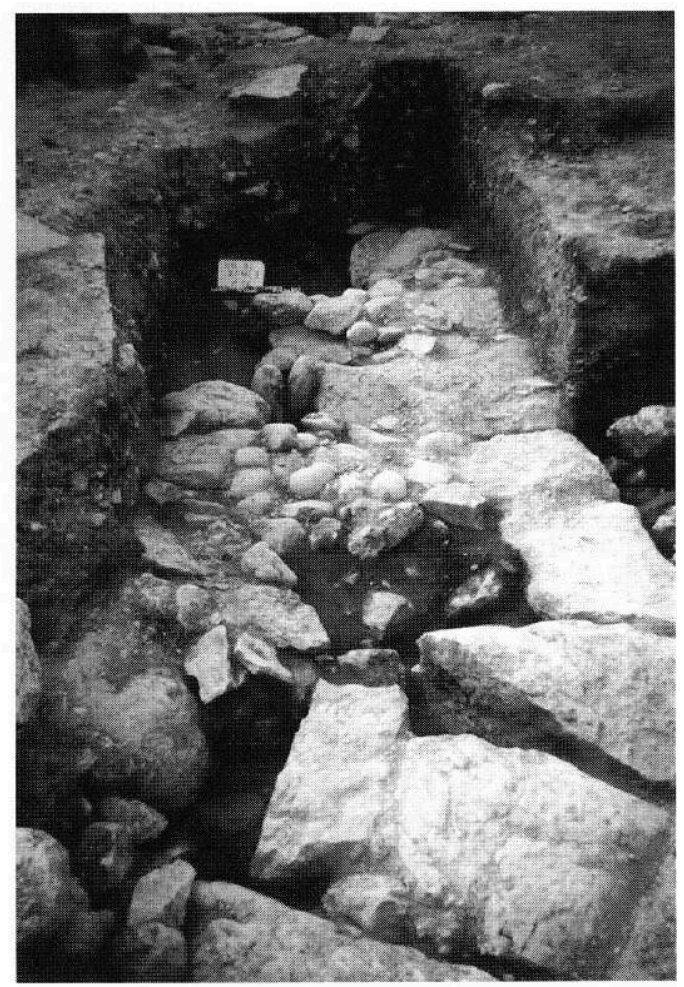

Ainsi, dans la pièce IV, cette tranchée est comblée par un remblai C. 105, (fig. 60) constitué par de l'argile jaune compacte, recouvrant également le sol de l'état 1 de cette pièce sur une épaisseur moyenne de $0,50 \mathrm{~m}$. Il est lui-même recouvert partiellement par un remblai d'argile grise C. 104 (fig. 60). Ce double apport de remblais rehausse le sol jusqu'au niveau du seuil de la porte du mur de refend M 4. 
103 La porte reliant les pièces III et IV est condamnée par une maçonnerie de blocs de molasse remployés M 5, implantée dans une tranchée étroite F 167, creusée dans les sols de ces deux pièces (fig. 72-73).

72 : Coupe stratigraphique pièces II et III, sond. 4
Est
Ouest

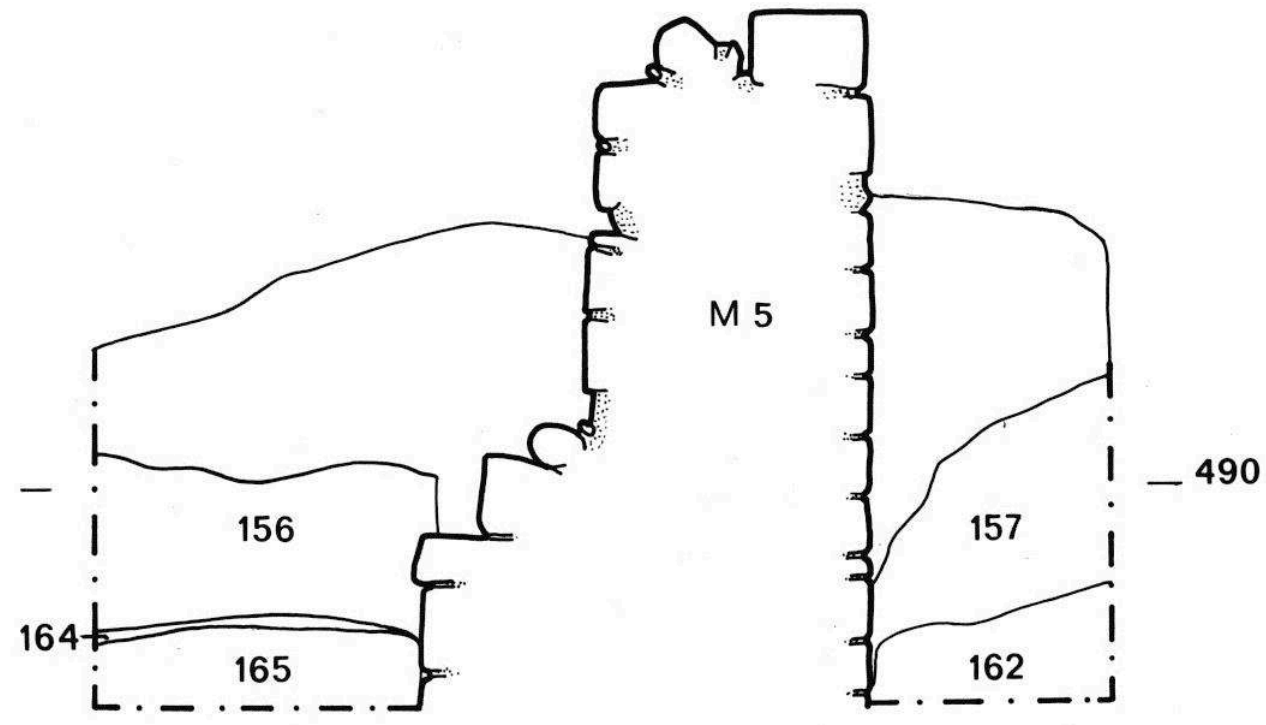

73 : Maçonnerie condamnant la porte de la pièce IV

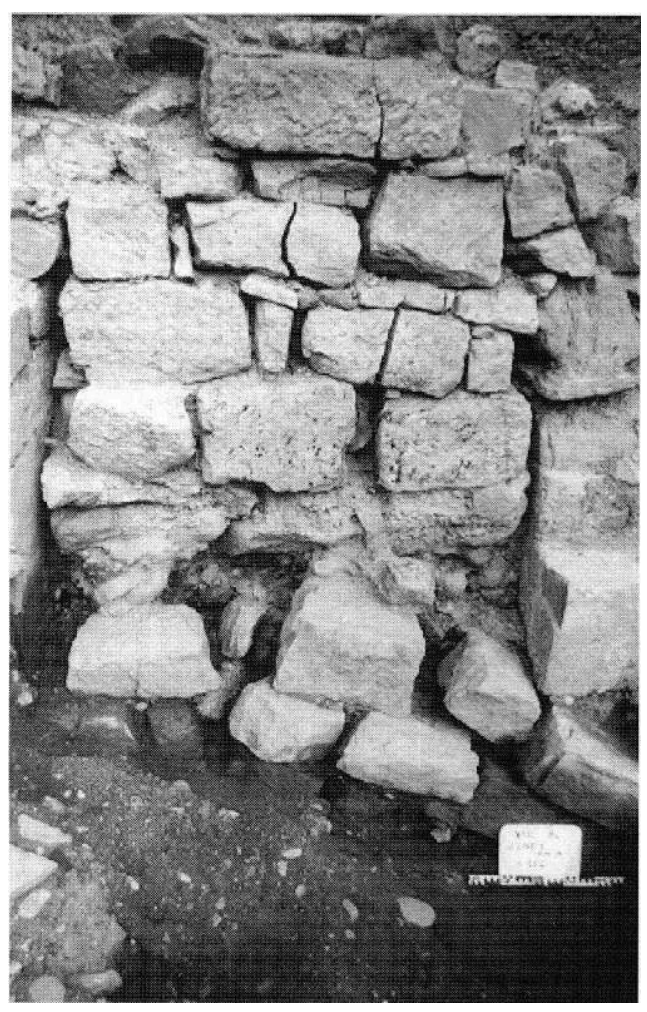


104 Cette réfection intervient après un affaissement du terrain ayant entraîné une fissuration des murs particulièrement remarquable sur le parement est du mur $\mathrm{M} 3$ où les brèches ont été bouchées par des galets (fig. 74).

74 : Fissures et réparations du mur $M 3$, pièce III

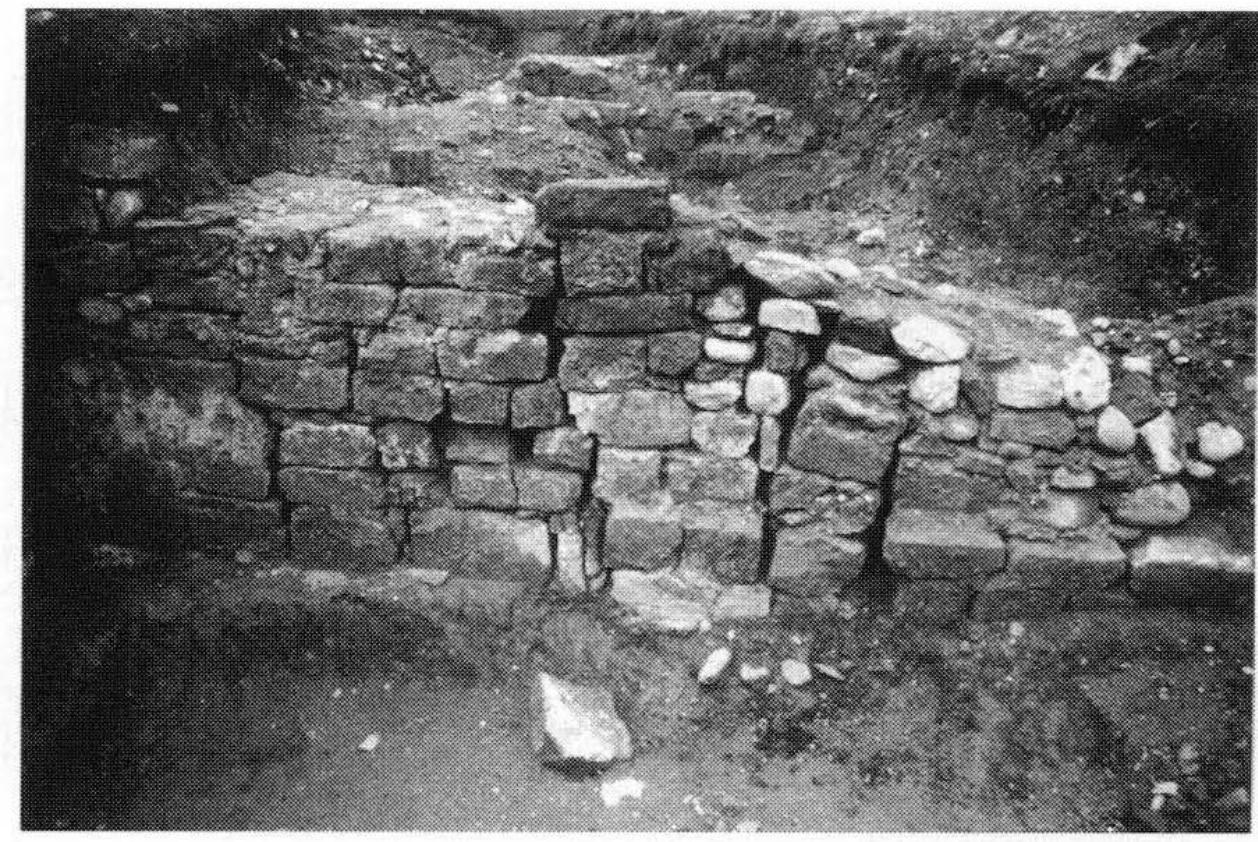

La pièce III est entièrement remblayée par une série de couches contenant des débris de démolition : blocs de molasse, briques et tuiles plates (C. 204, C. 203 et C. 202) (fig. 59).

\section{Un batiment annexe au nord}

106 Au nord, à l'extérieur de la courtine (zone 5), un bâtiment rectangulaire est appuyé sur le parement du nouveau mur M 16 (L: $9 \mathrm{~m}, 1: 7 \mathrm{~m}$ ), il est limité à l'ouest par le mur M 14, (L : 6,50 m, 1:1,40 m), à l'est, par le mur M 6, (L: $7 \mathrm{~m} \mathrm{1:1,20} \mathrm{m} \mathrm{et} \mathrm{au} \mathrm{nord} \mathrm{par} \mathrm{le} \mathrm{mur}$ M 57, (L : 8,20 m, 1:1,20 m). Ces murs sont construits en blocs de molasse appareillés en parements avec un blocage de galets et de molasse noyés dans du mortier de chaux (fig. 75). 


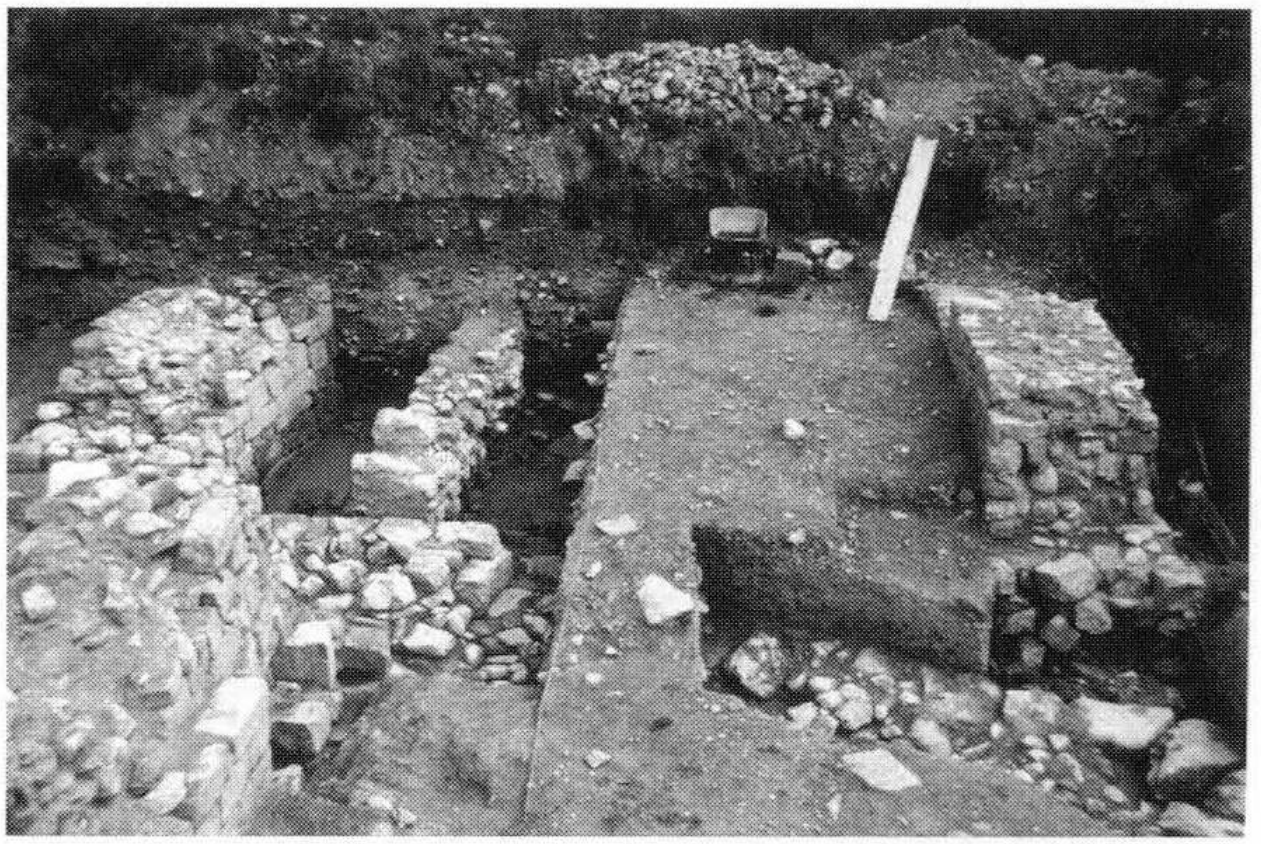

La maçonnerie de fondation a pu être observée sur le parement interne du mur M 14. Concrétisée par un léger ressaut saillant de $4 \mathrm{~cm}$ de l'aplomb du parement du mur, elle est implantée dans une tranchée étroite F 159 qui est creusée dans la couche de démolition du mur M 17 (fig. 70) caractérisée par l'accumulation d'un sable jaune contenant des blocs de molasse, des galets, du gravier et des nodules de mortier provenant de l'arasement du mur primitif de l'enceinte et dans la couche sous-jacente, constituée d'argile grise pure, peutêtre d'origine alluvionnaire (c. 160). Celle-ci contenait quelques petits morceaux de bois, conservés dans la nappe phréatique et s'appuyait contre le parement externe de M 17, mur de courtine de l'état 1.

L'espace intérieur est divisé en deux par un petit mur de refend, M 15, large de 0,80 m et repéré sur $5 \mathrm{~m}$ de long. La base de ce mur est constituée de deux assises de fondation en galets et en blocs de molasse, posée sur la couche d'argile C. 160, sur une hauteur de $0,40 \mathrm{~m}$; son élévation est faite en blocs de molasse dont certains sont des éléments remployés. Parmi ceux-ci, deux blocs sont décorés, ils font certainement partie d'un même ensemble qui pourrait correspondre à un piédroit de cheminée engagée (fig. 76). 


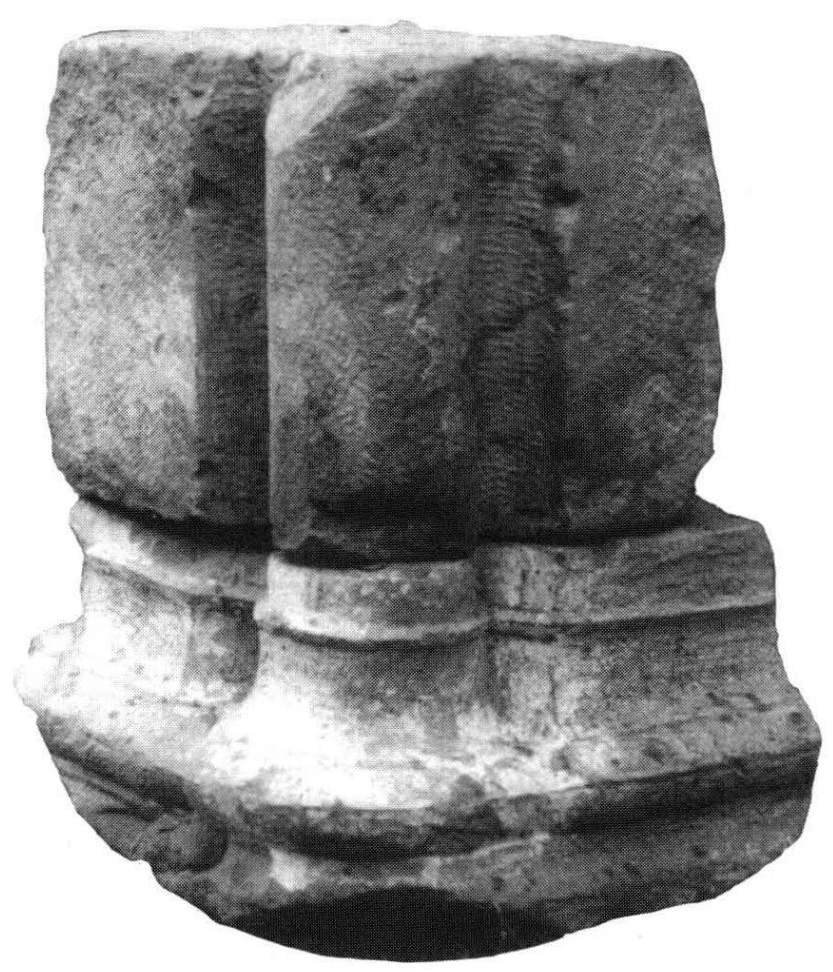

MOULURE D'ANgLE ET COLONNETTE ENgAgÉE. MOLASSE, COMPOSITION À PARTIR DE DEUX BLOCS : UN BLOC CUBIQUE DE 0,45 M DE CôTÉ, PRÉSENTANT UNE COLONNETTE DE 0,15 M DE DIAMÈTRE, ENgAgÉE DANS UN DES ANgLES, UN AUTRE BLOC APPROXIMATIVEMENT CUBIQUE DE 0,40 M DE HAUT ET 0,45 M DE CÔTÉ SCULPTÉ SUR DEUX FACES D'UNE MOULURE LÉgÈREMENT CONCAVE MARQUÉE AU TIERS INFÉRIEUR D'UN CHANFREIN DOUBLE (H : 0,02 M), SURMONTÉE D'UN TORE À SECTION OgIVALE (H : 0,08 M) L'ANgLE EST TRAITÉ POUR FORMER UN CHAPITEAU CAMPANIFORME À CORBEILLE NUE (D : 0,15 M À LA BASE).

L'espace est de ce bâtiment, pièce VI, couvre une superficie de $24 \mathrm{~m} 2$ et la pièce VII, à l'ouest, une surface de 7,50 m2 (fig. 30).

Le sol de ces pièces est formé sur la surface du remblai de démolition de l'enceinte primitive (C 158) dont le niveau supérieur est à $489,90 \mathrm{~m}$ d'altitude. A ce niveau est associée la découverte de nombreux ossements d'animaux domestiques (porc, boeuf et mouton, poule et oie) et de gibier (petit oiseau et lièvre commun). La profondeur de ces sols, par rapport à ceux du logis, permet de supposer que la partie inférieure de ce bâtiment, avait probablement une fonction de caves qui auraient été surmontées par un étage dont il ne reste aucun vestige.

\section{Le bâtiment central}

111 Après la construction d'une nouvelle cuisine, celle de l'état 1 est transformée en grenier à grain, en septembre de l'année 1339: "In uno granerio facto de novo... infra castrum de Vuache in loco in quo quoquina esse solebat "(A.D.H.S., inv. 58, fol. 387, c. 126). Cette référence pourrait correspondre au remblaiement du bâtiment annexe (zone 12) sur une épaisseur de 1,60 m par une couche d'argile jaune pure (C. 1102) (fig. 77). 


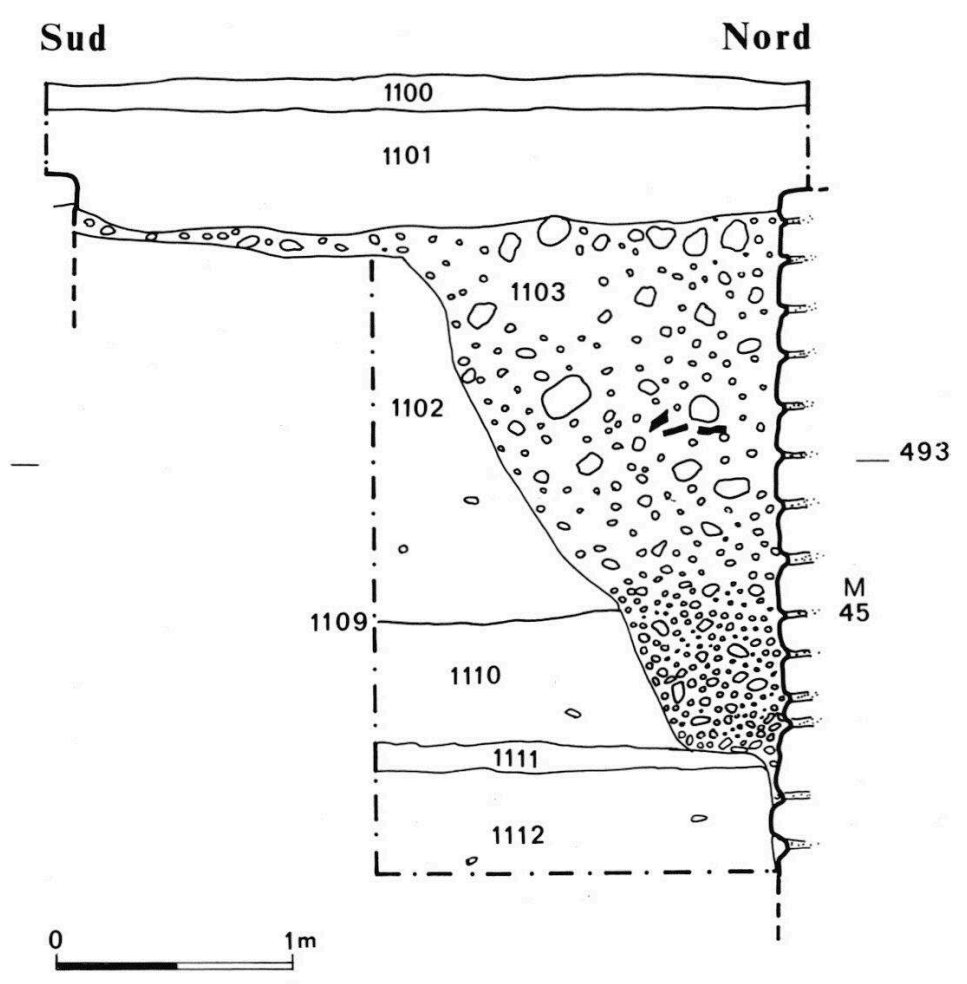

112 C'est certainement à la même époque ou légèrement plus tard que les murs de cet édifice ont été arasés, ne dépassant plus que d'une seule assise du niveau supérieur du sol intérieur, à $494 \mathrm{~m}$ d'altitude et formant ainsi une petite terrasse au-dessus du sol de la cour intérieure.

\section{L'escalier à vis}

L'angle nord-est de la zone 12 a été démoli lors de la construction d'un escalier à vis, appuyé sur l'angle du logis formé par le mur de façade M 19 et le mur M 2.

Permettant une circulation verticale vers les étages (zone 13) la tourelle d'escalier, de forme trapézoïdale, présentait deux côtés de $4,80 \mathrm{~m}$ au sud et à l'ouest, un côté de 4,90 $\mathrm{m}$ au nord et un côté de $5 \mathrm{~m}$ à l'est. Elle a été implantée dans une fosse de fondation quadrangulaire $\mathrm{F}$ 1104. L'espace laissé libre après la construction de l'escalier est comblé par un remblai de gravier contenant des galets, des éclats de molasse, des fragments de tuiles et des tessons de verre et de céramique (C. 1103) (fig. 77).

115 Ces tessons correspondent à deux albarelles en céramique glaçurée et à des gobelets côtelés ou non décorés, des bouteilles aplaties et des fioles à long col, en verre et dont la datation est à situer entre l'extrême fin du XVe s. et le début du XVIe s.

116 La structure de l'escalier se présente sous la forme d'une importante maçonnerie de moellons de molasse et de galets, liés au mortier de chaux, composant la cage et supportant la première volée de marches (fig. 78). Un tronçon de colonne est remployé dans cette maçonnerie. La base de l'escalier est faite d'une maçonnerie servant de sol au palier inférieur à $492 \mathrm{~m}$ d'altitude; ce palier comportait une porte donnant accès à la cave sud, mentionnée dans l'inventaire de 1612, et dont aucun vestige n'a été conservé. 


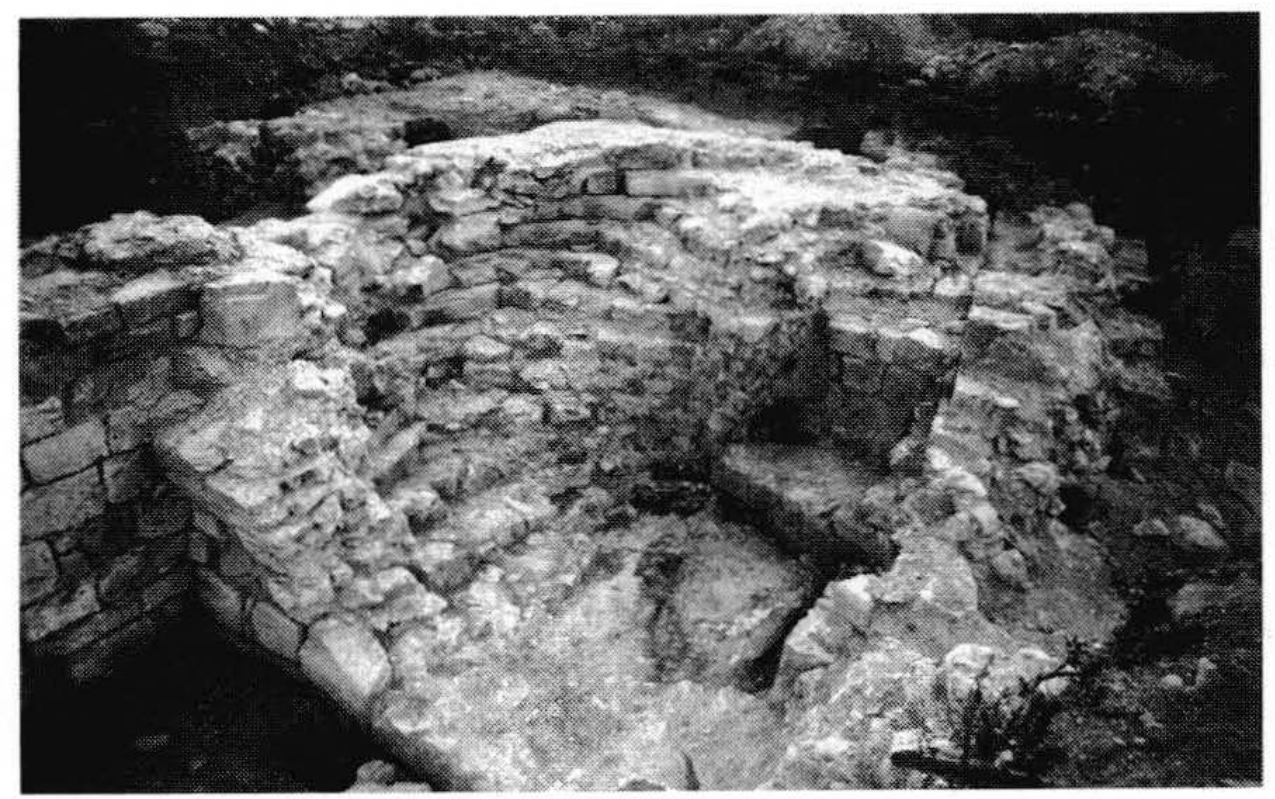

Les degrés de l'escalier à vis, taillés dans des blocs de molasse, étaient engagés dans le parement interne de la cage d'escalier et dans le parement du mur M 2. Ils ont été récupérés après l'abandon du château. Seules les extrémités engagées dans la maçonnerie sont conservées. Elles présentent une hauteur de $0,12 \mathrm{~m}$ et une profondeur de $0,60 \mathrm{~m}$ sur la circonférence; longues de 2,40 m, elles se superposaient autour d'un noyau central de $0,20 \mathrm{~m}$ de diamètre, dont l'empreinte a été imprimée dans le mortier du massif de fondation soutenant les premières marches (fig. 79). 


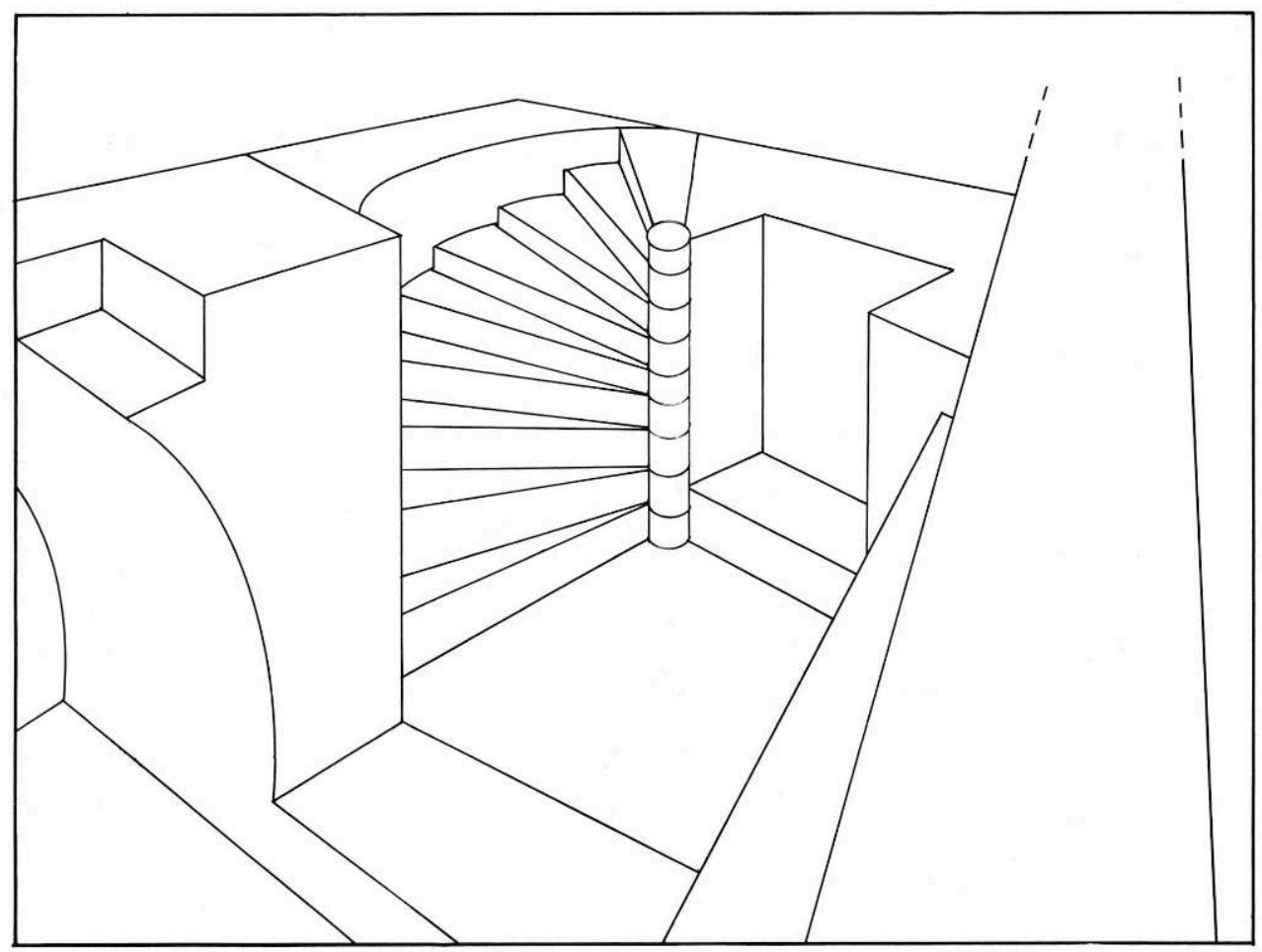

118 Au pied de cet escalier, une niche a été aménagée sous la seconde volée de marches. Sa partie supérieure a été arasée. Elle se trouvait sous lesmarches 11 à 15 . De plan trapézoïdal, le fond mesure $1 \mathrm{~m}$ de large, l'ouverture, $1,20 \mathrm{~m}$ et les côtés, $0,80 \mathrm{~m}$ de profondeur. La partie inférieure a été surélevée sur 0,40 $\mathrm{m}$ de hauteur au-dessus du sol du palier, par une maçonnerie présentant un parement extérieur de deux assises de petits moellons de molasse. L'intérieur est rempli par un blocage de galets et d'éclats de molasse noyés dans du mortier de chaux.

119 L'inventaire de 1612 décrit ainsi la base de l'escalier : «Plus au pied de la Viorbe une armoyre ayant sa porte bois de sappin avecq ses esparres et verroil serrure... Plus la première porte de cave ». Le terme de "Viorbe » désigne précisement un escalier à vis (Desormaux $\mathrm{J}, 1902)$.

120 L'état de conservation de cette construction ne permet ni de proposer un essai de restitution cohérent pour la superstructure, ni de préciser la datation de celle-ci. Dans son élévation, l'escalier donnait au moins accès au premier étage à la grandesalle et à la cuisine et au deuxième étage à une des chambres.

\section{Cantonnement d'une garnison}

Les stratigraphies observées dans la partie orientale du logis, la tour nord-ouest et la zone 5 comportent une séquence de dépôts de nature identique. Elle se caractérise par des couches de couleur noire, accumulées sur les niveaux de sols et contenant des cendres et des charbons de bois ainsi qu'une grande quantité de matériel archéologique, elles sont recouvertes par des couches de démolition plus ou moins importantes :

En zone 5, les couches C. 147 et C. 155 recouvrent les sols des pièces VI et VII, épaisses de $0,15 \mathrm{~m}$ en moyenne, de couleur noire, elles sont constituées de limon très chargé de 
cendres et de charbons de bois et d'éclats de molasse rubéifiés résultant probablement d'un incendie (fig. 70).

Un abondant matériel a été enfoui dans ces couches: il se compose d'une grande quantité d'os d'animaux sauvages et domestiques, de nombreux tessons de verres (plus de 2000 , trouvés dans ce secteur), de quelques tessons de poteries, d'objets en fer: clous, armature de volet, sertis de vitraux, objets en bronze : ciseaux, épingles à tête ronde, anneaux; une bague en or sertie d'un rubis et d'un saphir et deux pièces de monnaies soudées par leurs droits, trop dégradées pour être identifiables.

Ces couches sont recouvertes par d'importants dépôts consécutifs à la démolition du bâtiment, comportant des fragments de tuiles, des pierres de la maçonnerie et du mortier désagrégé ainsi C. 145 (fig. 70). La couche 144 a livré une pièce de monnaie (fig. 118, p. 11), de Charles Emmanuel I frappée entre la fin du XVIe s. et le début du XVIIe s.

L'importance des couches de démolition de ce bâtiment annexe et l'absence de niveau de sol postérieur incitent à penser qu'il a été démoli peu de temps aprés l'incendie.

Les sols des deux pièces de la partie orientale du logis sont recouverts par des couches de nature identique, d'une épaisseur de $12 \mathrm{~cm}$ en moyenne (C. 103) (fig. 60). Constituées par un limon brun, mêlé de cendres et de charbons de bois, elles sont cependant moins cendreuses que dans les deux pièces précédemment décrites, mais contiennent également un important matériel ostéologique, des tessons du même type de céramique blanche à glaçure verte, des fragments de verre, des objets en fer en bronze et deux monnaies (fig. 118, p. 3).

127 Une couche comparable recouvre, sur 0,30 $\mathrm{m}$ d'épaisseur, le sol de la tour nord-ouest (C. 803) (fig. 57) ; elle est constituée de limon brun, de cendres et de charbons de bois, sur $0,50 \mathrm{~m}$ d'épaisseur et contient également des fragments d'os d'animaux et en particulier de volaille, des tessons de céramique et de verre et des objets de fer et de bronze.

Cette séquence stratigraphique est en relation avec une dégradation du bâtiment très importante en particulier pour la zone 5 qui semble avoir été entièrement démolie. Elle pourrait correspondre au démantèlement du château par les Bernois en 1536 et à son occupation par les troupes françaises de 1536 à 1564, époque pendant laquelle pourraient s'être déposées ces couches consécutivement à l'occupation et au bivouac de militaires.

Dans l'inventaire de 1612 il est mentionné une tour en la qualifiant de « casée », un seul niveau est indiqué. Cette tour était probablement en partie arasée. Le châtelain fait état des nombreuses réparations, en particulier celles des portes, qu'il a effectuées durant son mandat. La zone 5 , au nord de l'enceinte ne semble pas mentionnée dans ce texte. Une porte de cave donnait accès à la cour, elle ne pouvait se trouver que de ce côté puisque sur les autres, des remblais dont le niveau est nettement supérieur aux niveaux des sols des caves et le fossé ne permettaient pas d'ouverture; à l'origine, cette porte donnait probablement accès au sous-sol de la zone 5 ; une fois ce bâtiment arasé, elle pouvait permettre de passer dans la " grand cour ", c'est à dire la basse-cour.

\section{État 3}

130 La troisième étape architecturale du château du Vuache se manifeste essentiellement par l'aménagement d'une importante structure, construite au centre de l'enceinte 
castrale (fig. 80). Elle est constituée au sud par le mur M 20, (L:23 m, 1:1,15 m), à l'est, par le mur M 43, (L: $8 \mathrm{~m}, 1: 1,10 \mathrm{~m}$ ), s'appuyant sur le mur de façade M 44, à $6 \mathrm{~m}$ du mur de courtine est, à l'ouest, par le mur M 13, (L:16 m, 1:1,10 m), distant de $6 \mathrm{~m}$ au nord et de $4 \mathrm{~m}$ au sud du mur de courtine ouest M 9 et au nord, par M 12 (L : $15 \mathrm{~m}, 1$ : $1,10 \mathrm{~m})$.

80 : Château du Vuache, plan de l'état 3

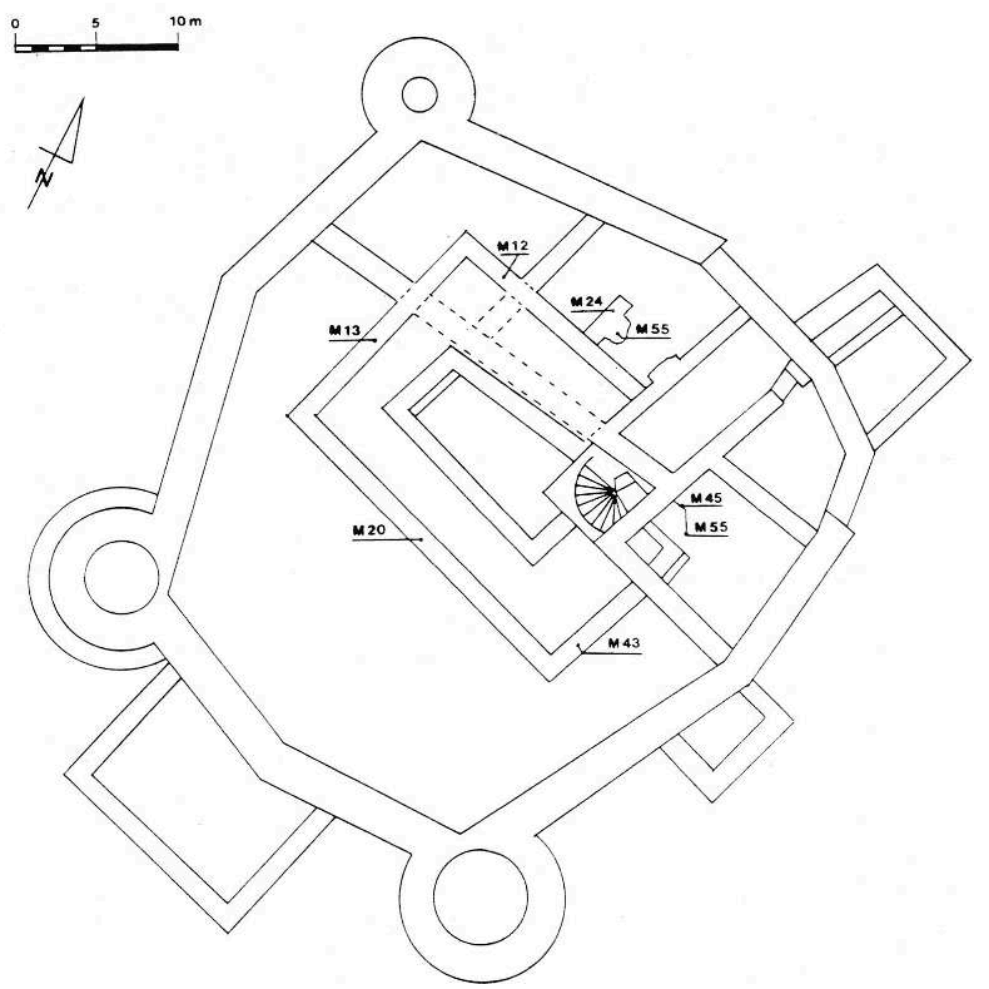

131 Ces murs sont construits sur des fondations en gros galets et en blocs morainiques profondément implantées dans des tranchées, par exemple F 958, F 707, (fig. 81). La base de ces fondations est à $492,40 \mathrm{~m}$ pour le mur sud et à $491 \mathrm{~m}$ pour le mur est; à 494 $\mathrm{m}$ pour le mur ouest et à $492,40 \mathrm{~m}$ pour le mur nord; le sommet des fondations est marqué par un léger ressaut sur le parement nord des murs, orientés est-ouest.

81 :Coupe stratigraphique zones 9 et 6

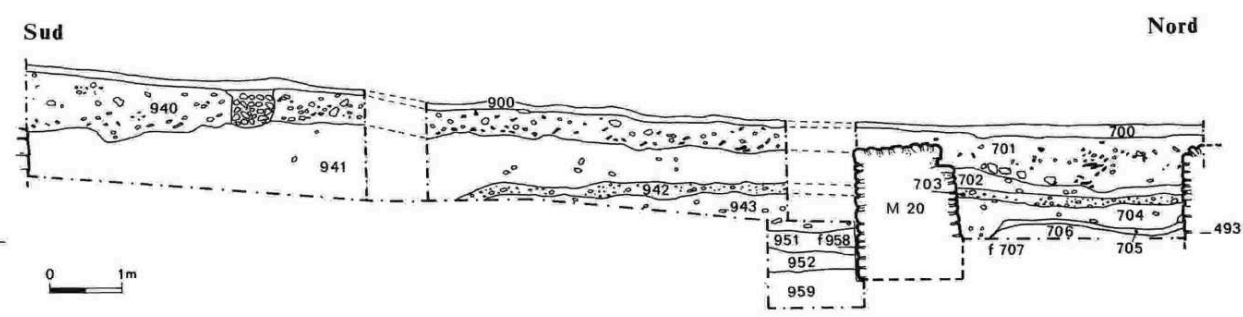

Les élévations sont construites avec des assises de galets en parements et un blocage interne de galets et d'éclats de molasse noyés dans du mortier de chaux (fig. 82). 


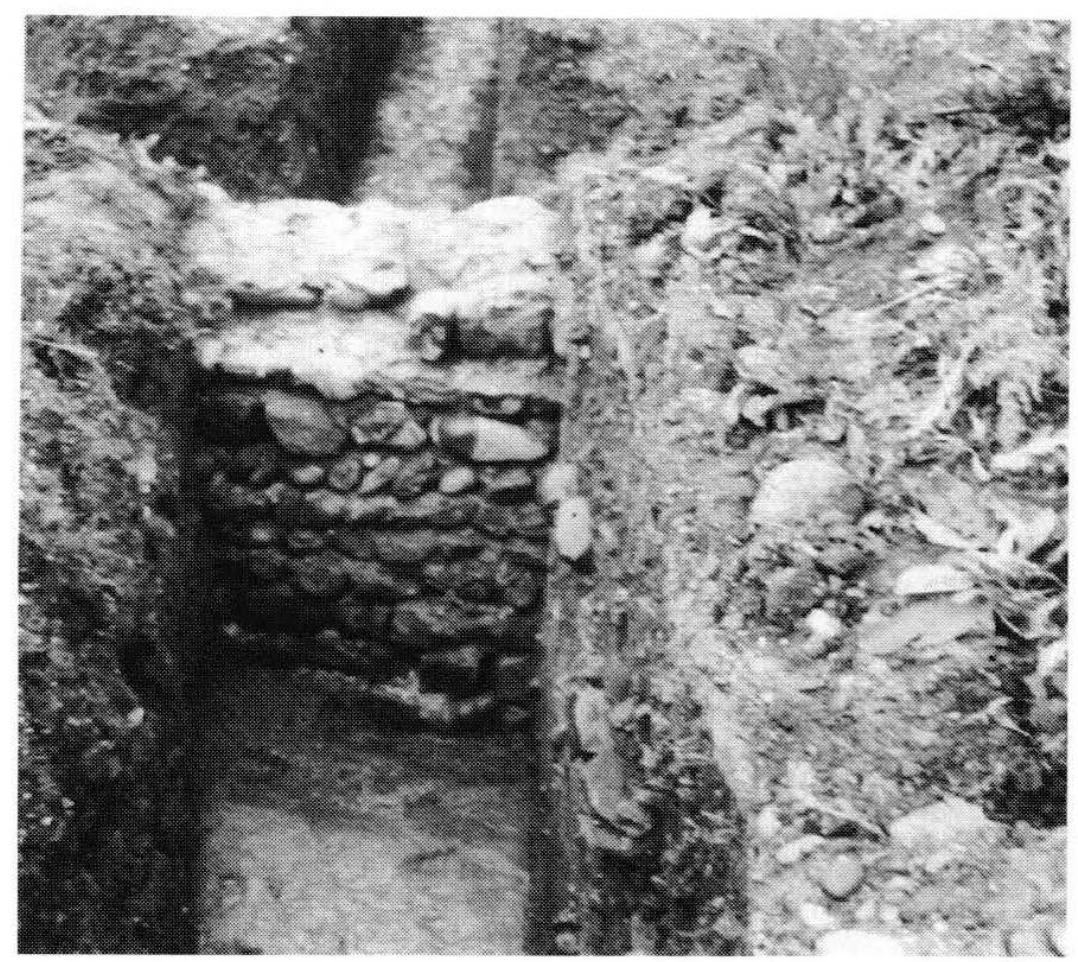

La partie nord de cette structure englobe la terrasse de l'état 2 et recouvre partiellement le mur de façade M 19 et le mur de refend M 7, arasés lors de la construction ce qui entraîne obligatoirement la restructuration de l'aile ouest du logis.

Consécutivement à cette construction, une série de remblais viennent niveler les sols à l'extérieur et à l'intérieur de cette structure : le premier apport est constitué d'argile jaune contenant des petits galets (C. 943) (fig. 33), C. 704 (fig. 81), sur une épaisseur moyenne de $0,20 \mathrm{~m}$ il est recouvert par un remblai d'argile grise mêlée de petits galets et de cendres C. 942, C. 703 (fig. 81) et C. 4013 (fig. 34), épais de 0,10 m en moyenne et lui-même recouvert par une couche d'argile brune incluant de rares galets C. 941, C. 702 (fig. 81), C. 6007 (fig. 48), C. 4012, C. 4027 (fig. 34), d'une épaisseur moyenne de $0,50 \mathrm{~m}$.

Ce remblai est complété, à l'est, où il forme une pente perpendiculaire au mur de courtine, par deux couches de remblais: C. 953, argile jaune et C. 954, argile ocre, repérées à l'est de la tranchée II. A l'ouest, cette série de remblais recouvre le talus de l'ancienne levée de terre.

136 A l'intérieur de cette structure, le sol se situe à 493,30 m d'altitude en moyenne, le niveau du sol extérieur est compris entre 494,50 m à l'ouest et $493 \mathrm{~m}$ au nord-est. Aucun aménagement autre que ce nouveau sol n'a été repéré autour de cette construction, dans les zones l'entourant au sud, à l'ouest et à l'est.

137 Le sol originel de la pièce I est enseveli sous une couche de limon brun, contenant des éléments de démolition: cailloutis, galets, éclats de molasse, fragments de tuiles et petits blocs de mortier (C. 921, sondage 9). Epaisse de 0,10 m, elle est recouverte par une couche d'argile jaune, pure et compacte C. 920 (fig. 55), épaisse de 0,15 m. Elle constitue le remblai d'aménagement d'un nouveau sol de terre battue. 
Dans la pièce II, un petit mur de galets (M 24) est construit perpendiculairement au nouveau mur de façade $M 12$ et parallèlement au mur de refend $M 7$. Large de 1,20 m et long de 3,20 m, il est construit en galets disposés en parements avec un blocage de galets noyés dans du mortier de chaux. Il divise la partie sud de la pièce II en deux aires égales, de 3,40 m de large (fig. 80).

Contre le parement est de M 23 s'appuie une maçonnerie de forme senti-circulaire, de 2 $\mathrm{m}$ de diamètre, construite en galets liés au mortier de chaux.

Une monnaie était incluse dans le mortier de cette maçonnerie; il s'agit d'un denier de l'évêché de Genève, frappé, probablement, au XIIIe s. (fig. 118, p. 1). Ne pouvant correspondre à l'époque de construction de l'état 3, elle provient, sans doute, du creusement de la tranchée de fondation de ce mur.

141 Entre les murs M 3 et M 24, un niveau de sol, constitué sur un remblai d'argile (C. 260) a seulement été repéré en surface, son niveau supérieur est à $493 \mathrm{~m}$ et pourrait correspondre au sol de la pièce II, dès l'état 1.

\section{Abandon}

142 Le château du Vuache a été par la suite entièrement démoli, servant peut-être de carrière pour la construction du nouveau château de Faramans où s'installe le siège de la seigneurie dès la première moitié du XVIIe s. Il est qualifié de mazure en 1701 et en 1730 ; il disparaît certainement au cours des années qui suivent.

143 Cette démolition entraîne le remblaiement des niveaux antérieurs sous d'importants dépôts de déchets et de matériaux de construction, non récupérés : gravier, blocs de molasse, galets, mortier et tuiles; ces couches contenaient quelques objets archéologiques.

144 Les blocs de parement des murs sont récupérés très profondément, ce qui entraîne la formation de tranchées suivant l'alignement des murs, comblées par la suite avec des déblais de démolition.

145 Parmi les matériaux rejetés lors de la démolition des superstructures du bâtiment castrai, ont été retrouvés quelques éléments de pierre (fig. 83) ou de terre cuite (fig. 84), témoins du décor architectural de l'édifice disparu ${ }^{17}$; certains peuvent être rapprochés de mentions faites dans les textes: parmi toutes les fenêtres minutieusement détaillées par l'inventaire de 1612 (A.D.H.S., série J, 7J 493), une seule, située dans la chambre des chambrières, est qualifiée de "fenestre croisée », c'est-à-dire de fenêtre à meneau, "croisée » désignant une croix formée dans une fenêtre par un montant et une traverse de pierre (Huguet, 1929) « lesdites fenestres garnies de leurs portes esparres et verroilz saufz en celle dessus ou il ny a aulcung verroilz». Parmi les dépenses faites en 1336, malheureusement sur le plus abîmé des rouleaux de comptes de châtellenie (A.D.H.S., inv. 58, F.387, c. 126), est signalé le travail d'un tailleur de pierre pour la fabrication d'une cheminée "chiminata", peut-être dans le cadre de la construction d'une nouvelle cuisine mentionnée dans le même document. 
83 : Eléments architectoniques en pierre

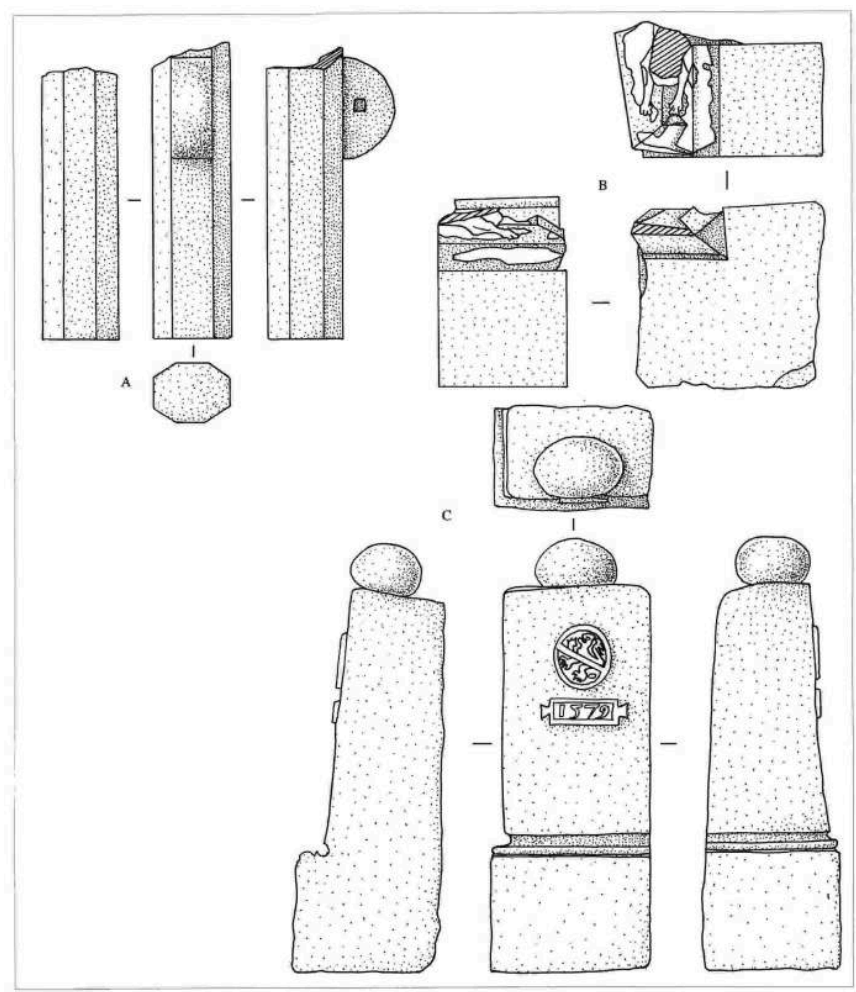

MENEAU (fig. 83, A)

molasse, $\mathrm{H}$ : : 0,60 $\mathrm{m}$, section octogonale :

$0,17 \mathrm{~m} /$ 0,17 m, largueur des faces : 0,07m

CHAMBRANLE de FENÊTRE (fig. 83, B)

molasse, H. : 0,30 m, l. : 0,45 m ép. : 0,41 m

BORNE ARMOIRIÉE (fig. 83, c) EN CALCAIRE

$\mathrm{H}$. : $0,95 \mathrm{~m}$, section rectangulaire :

corps : 0,32 m / 0,20 m, base : 0,35 m / 0,25m,

ép. : 0,41 m

La toiture des bâtiments, fréquemment restaurée, est souvent citée dans les comptes du XIVe s., la couverture des tours étant faites de tavaillons (terme régional désignant des bardeaux), le toit de la "magne aule» est, en 1329, réparé avec des tuiles neuves, des tuiles anciennes et des tavaillons, puis finalement entièrement refait en tuiles en 1341 . Les éléments de terre cuite retrouvés dans les couches de démolition de l'édifice appartiennent probablement à un état tardif de la construction, en particulier, les tuiles émaillées connues en Bourgogne et en Forez à partir du milieu du XVe s. 
84 : Eléments architectoniques en terre cuite

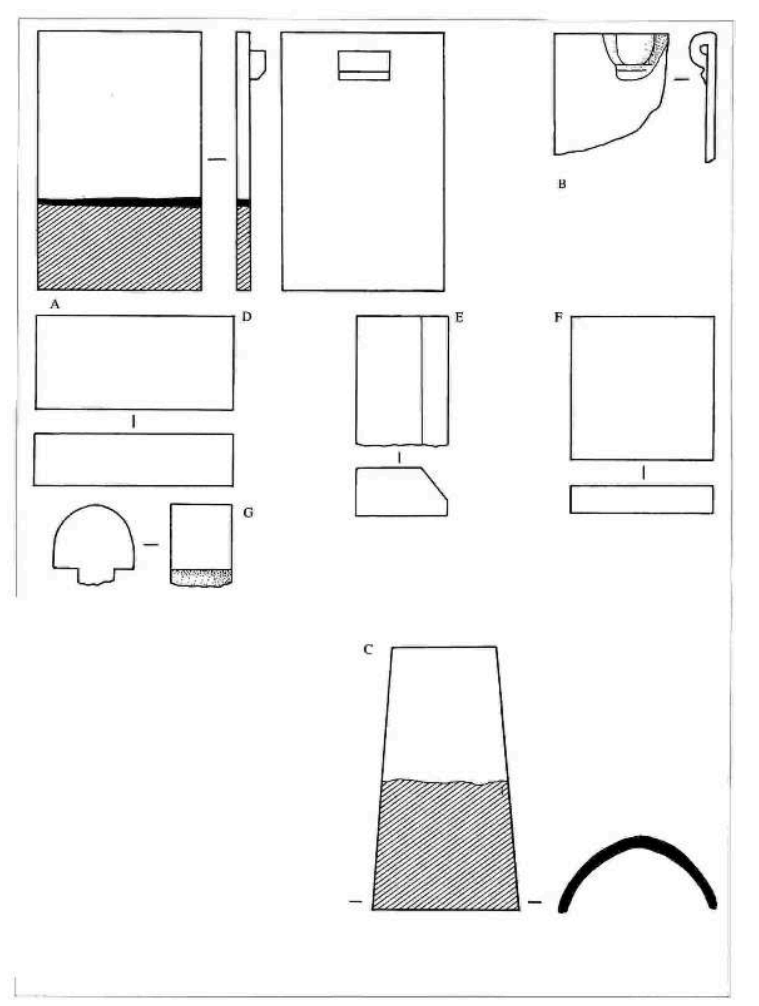

TUILES PLATES (fig. 84, A-B)

terre cuite, $L: 0,30$ m, 1: 0,19 m, ép. : 0,015 m.

tuile plate rectangulaire

TUILES CREUSES (fig. 84, c)

terre cuite, $L: 0,30$ m, 0,12 m, 0,17 m, ép. : 1 cm

BRIQUES(fig. 84, D)

terre cuite, $L: 0,23 \mathrm{~m}, 1: 0,11$ m, ép. : $6 \mathrm{~cm}$

brique rectangulaire de construction

BRIQUES CHANFREINÉES (fig. 84, E)

terre cuite, $L: 0,15 \mathrm{~m}, 1: 0,10,5 \mathrm{~cm}, 2 \mathrm{~cm}$

brique rectangulaire dont une des arêtes présente un chanfrein

de 2,5 $\mathrm{cm}$ de hauteur et de largeur.

CARREAU (fig. 84, .F)

terre cuite, côté : 0,165 m, ép.: 3,5 cm, carreau de pavement?

FRAgMENT DE BRIQUE MOULÉE (fig. 84, G)

terre cuite, $L: 0,10 \mathrm{~m}, 1: 0,10 \mathrm{~m}$, ép. : $7 \mathrm{~cm}$

fragment de brique moulée présentant une partie hémisphérique

de $5 \mathrm{~cm}$ de diamètre se rattachant à une partie centrale rectangulaire

large de $4 \mathrm{~cm}$.

\section{Données historiques}

D'après les documents analysés, le château apparaît comme premier point d'ancrage de la seigneurie. Le bâtiment castrai n'était cependant que la partie résidentielle et défensive d'un ensemble d'édifices constituant le patrimoine immobilier de la châtellenie et de la seigneurie médiévales. Dans certains textes apparaissent des constructions qui s'élevaient à proximité du château, à fonctions diverses. Les constructions abritant, four, moulin et pressoir, matérialisent les droits banaux. D'autres, à fonctions économique et agricole sont liés à la seigneurie foncière : grange, étable, colombier et un second pressoir ou cellier, sans oublier la chapelle seigneuriale 
aménagée dans l'église paroissiale de Vulbens. En raison de la disparition ou de l'état très médiocre des vestiges de ces édifices, nous ne pouvons qu'avoir recours aux archives conservées pour essayer de restituer l'organisation et le fonctionnement de ce que nous pourrions appeler le complexe castral.

Dans les textes présentés au début du chapitre II quelques mentions sont faites de l'édifice castrai et des travaux de construction qui y sont faits. Elles permettent une interprétation plus fiable des vestiges découverts.

Le terme de castrum est utilisé dans tous les documents à l'exception de l'acte de donation par le comte Amédée à sa nièce Jeanne de Genève, en 1296, dans lequel le rédacteur hésite entre : «Castro sen domus fortem » ceci pourrait s'expliquer par le fait que le comte conserve le droit de ban et n'accorde à sa nièce que le domaine foncier.

\section{La grand-cour}

Les bâtiments annexes et les cultures pratiquées par les seigneurs sont mentionnés dès le XIVe s., dans les comptes de châtellenie; le colombier est réparé avec d'anciennes portes du château, en 1326 ; la treille en 1331, 1335, 1336, 1339 et la clôture du jardin en 1332 et 1333, font l'objet de dépenses d'entretien; la grange, où était entreposé le foin provenant des dîmes seigneuriales, était couverte par une toiture en tavaillons (bardeaux) réparée en 1329, 1331, 1332, 1334, 1337, 1339 et 1342 ; au moins un de ses côtés était clos par un mur fait de "vergis et rama ». Ces deux termes désignent des tiges et des branches entrelacées et font penser à ces parois de granges en branches d'aulne vert tressées comme une vannerie, connues dans l'architecture vernaculaire Savoyarde, dans la basse vallée de l'Arc et des vallées voisines (Cuisenier, 1979, p. 103). L'étable n'est mentionnée qu'à l'occasion de la construction d'un nouveau ratelier. Le fait que son toit ne soit jamais mentionné alors que celui de la grange était réparé fréquemment permet de penser que ces deux locaux étaient peut-être associés sous la même toiture, comme c'est le cas en 1612 ; cependant, à cause de la fragilité des matériaux de construction de cet édifice et à cause de l'évolution de la châtellenie, ce bâtiment a pu être plusieurs fois réparé, agrandi ou rebâti, aussi est-il difficile de comparer la grange du XIVe s. à celle du XVIIe s.

Le cellier qui abritait un pressoir à vis, une cuve et des tonneaux, "dolia» est mentionné en 1328, mais sa localisation n'est pas précisée. Etaitil dans la basse-cour ou à l'extérieur de celle-ci ? En 1337, un nouveau cellier est construit « infra castrum ».

Le reste de l'espace était probablement utilisé pour le pâturage des montures des hôtes du château et des troupeaux de chevaux du comte, lors de leurs séjours occasionnels au Vuache et qui, en raison de leur valeur, nécessitaient une surveillance étroite; c'est peut-être également une des raisons de la clôture du jardin.

Dans les sommaires des titres de fief dressés lors de l'investiture des seigneurs du Vuache, au château avec ses courtines, son pont et ses fossés est associé «l'ale du dit (château) située autour » avec ses étables, grange, jardin; ce terme dont nous n'avons retrouvé aucune mention dans les dictionnaires d'ancien français ni dans les glossaires régionaux, se rapporte sans équivoque à la basse-cour ; s'agit-il d'une forme locale de bayle? 
155 En 1612, la basse-cour ou " grand cour » du château était clôturée par une palissade, s'ouvrant sur le chemin public par un portail couvert, élément d'architecture typique de l'Avant-Pays savoyard,

«la porte d'entrée de la cour d'une maison importante, est protégée par un portique ou un arc surmonté par une petite toiture à deux pans, recouverte d'ardoises ou de tuiles plates » (Dufournet, 1978, p. 103).

156 A l'intérieur de cette enceinte, se trouvaient le colombier, peint en blanc et couvert d'un toit de chaume, un bâtiment réunissant la grange et l'étable, situé au nord du château et abritant un lit, certainement pour le logement des domestiques s'occupant des animaux, un édifice élevé par le châtelain du Vuache, avant 1612, dont la fonction n'est pas précisée et également un jardin, «clos à palissade» et une vigne cultivée sur " hutins» Les hautins sont des:

" arbres ou grands échallas sur lesquelles les ceps croissent en hauteur"

(Cuisenier, 1979, p. 139).

157 Après l'abandon du site, la basse-cour est divisée en parcelles et mise en culture. C'est cet état qui apparaît sur la Mappe Sarde de 1730. Le seigneur conserve les parcelles entourant les ruines du château: on y voit une grande maison et le four à pain appartenant au seigneur, qui a donc conservé l'un de ses privilèges banaux. Les vestiges de ces bâtiments sont actuellement intégrés dans des constructions modernes. L'espace entourant le château est limité au nord par la route principale traversant la seigneurie depuis Dingy jusqu'à Chevrier où elle se divise en deux branches, l'une allant vers la Semine, par le défilé de l'Ecluse et l'autre vers Cologny et le gué traversant le Rhône ; deux chemins perpendiculaires à l'axe principal se dirigeant vers le sommet de la montagne limitent cet espace à l'ouest et au nord-est ; au sud et au sud-est les parcelles limitrophes appartiennent à des paysans. Certaines ont sans doute été gagnées sur l'ancienne basse-cour car vendues par le seigneur.

158 Ne présentant aucun caractère militaire ou simplement défensif, la basse-cour du château du Vuache ne semble pas avoir été aménagée pour servir de refuge à la population. Elle paraît essentiellement être liée au caractère domanial de cet édifice et au système économique seigneurial: l'espace réservé aux pâturages, le colombier, l'étable et le jardin sont prévus pour les besoins des habitants du château; la grange est destinée au stockage des produits de la dîme et de la réserve seigneuriale, le four et le pressoir banaux sont les moyens de transformation mécanique des produits des récoltes, par lesquels le seigneur contraignait les habitants de son mandement à lui verser des redevances.

\section{Le château}

159 L'architecture du château du Vuache est assez peu documentée. Il est par ailleurs assez difficile, étant donné l'état de conservation de celui-ci, de confronter les quelques indications réunies avec les vestiges mis au jour. Quelques mentions de constructions et de réparations apparaissent dans les comptes de châtellenie du XIVe s. (fig. 85); l'inventaire dressé en 1612 présente une descrip tion du château, pièce par pièce, détaillant principalement les portes, les fenêtres et le mobilier. 
85 : Détail des comptes de châtellenie

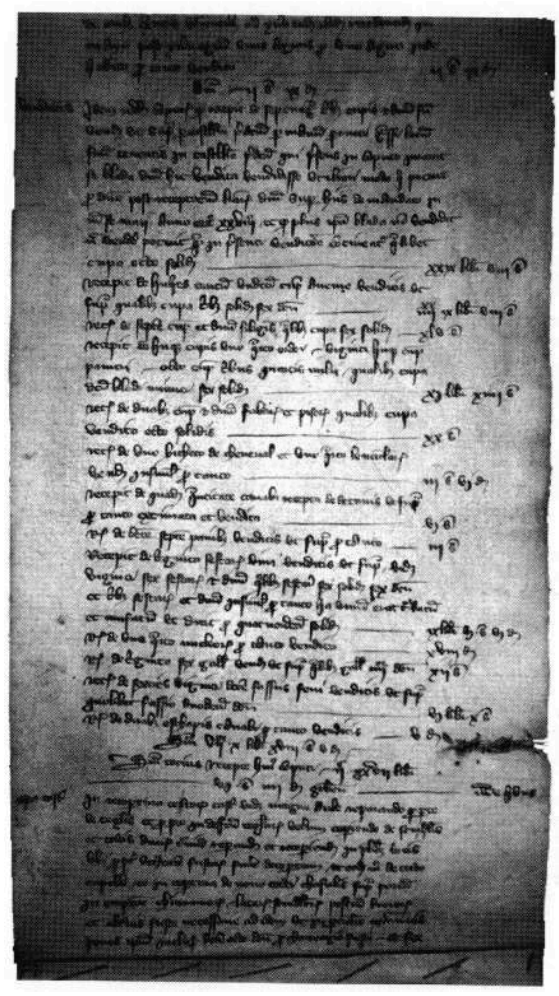

\section{L'enceinte}

160 En l'absence de moyens de défense naturels autre que le petit cours d'eau alimentant le fossé, le rempart de maçonnerie était destiné à assurer, à lui seul, la capacité de résistance et la protection de l'édifice. Les documents soulignent l'importance des tours et révèlent les aménagements de bois couronnant le sommet des constructions.

En 1329, les toits de deux tours, recouverts de tavaillons, sont réparés en plusieurs endroits.

En 1333, une tour est désignée sous le nom de Villaret ou Villoret.

En 1335, la porte d'une tour est refaite à neuf et munie d'une serrure.

Ce sont les seules mentions directes des tours faites dans les comptes de châtellenie. Aucun détail n'est donné de leur aménagement intérieur. Il est intéressant de noter que leurs toits étaient, au XIVe s., couverts de bardeaux alors que le toit du logis, certainement pour des raisons de prestige, utilisait déjà des tuiles. Au XVIIe s., toutes les toitures de l'édifice castrai, tours et logis, étaient en tuiles plates.

En 1612, les tours sont très rapidement décrites, mais leurs portes sont cependant détaillées; cela nous permet de suivre ainsi le cheminement du rédacteur; dans la première tour : après la porte d'entrée, munie d'une serrure neuve, il passe devant la porte de prison, fermant par une serrure et un verrou et percée d'un regard pourvu d'une grille, puis la porte de la pièce audessus de la prison, sans serrure, "et au donjon de la tour ny a aulcunne porte", l'emploi du terme donjon est difficilement compréhensible. Il semble désigner le dernier étage de la tour, directement sous la toiture qui est en assez bon état, sauf quelques tuiles qui ont été emportées par le vent. 
La seconde tour mentionnée a été en partie arasée, " cassée » et se réduit à un seul étage étant donné que l'inventaire ne présente qu'une seule porte.

En 1333, le château du Vuache est restauré à la demande du comte de Genève Amédée III. Les travaux sont effectués en plusieurs endroits non précisés de l'édifice castrai, excepté ceux de charpenterie intervenant sur le platelage du pont et surtout ceux engagés sur les structures en bois couronnant l'enceinte : coursières " curseriarum super muros ", trois "eschifarum ", également désignées par le mot "garites». Le terme technique, en poliorcétique médiévale, d'échiffe désigne habituellement en idiome savoyard, une guérite. Il s'agit, probablement dans ce cas, d'aménagements particuliers des coursières ou peut-être de hourds, construits au sommet des trois tours. Enfin un " chafalli » ou édicule construit en encorbellement au-dessus de la porte d'entrée.

Les vestiges de la porte d'entrée de l'enceinte ont été retrouvés; il s'agit d'un petit bâtiment rectangulaire, appuyé contre le parement externe de la courtine orientale, précédé par un pont maçonné, établi sur le fossé dont la construction est mentionnée dans le compte de l'année 1327. Fait d'arches maçonnées en blocs de molasse et de chevalets de bois (dont l'un est refait en 1339) supportant un manteau de bois de chêne provenant du bois du seigneur, le pont mesurait « 4 toyses et plus» de longueur et « $I$ toyse» de largeur (7,80 m sur 1,95 m). Il aboutissait dans le porche originellement surmonté par un chaffal.

\section{Le logis}

D'après les observations archéologiques, le logis du château du Vuache se présente comme un bâtiment où l'espace habitable est très développé, occupant tout le côté nord de l'enceinte. Dans les comptes de châtellenie du XIVe s., le logis apparaît spécifiquement désigné soit par le terme "aula», ou "magne aula» soit par le terme «sala » ou « magna sala» Il est probable que ces mots désignent plus particulièrement la grande salle du château, lieu essentiel du pouvoir seigneurial ; le terme de "sala» est occasionnellement associé aux « came ris ».

La cuisine a fait l'objet de nombreuses restructurations : originellement construite hors du logis, elle sera intégrée à celui-ci avant le XVIIe s.

Il ne nous est pas parvenu de descriptions détaillées du château du XIVe s. mais le bâtiment résidentiel et les pièces qui le composent sont mentionnés à l'occasion de travaux de réparation et d'aménagement.

En 1326, les menuiseries de portes et de fenêtres sont refaites à neuf. En 1328, le toit du château est réparé en plusieurs endroits; deux portes et deux fenêtres de la salle «sale » sont refaites. En 1329, la couverture de la grande salle « magne aule » est réparée avec des tuiles neuves, des tuiles anciennes et des tavaillons; cinq portes de la salle et de chambres sont refaites à neuf "sala et cameris ». En 1334, une fenêtre est ouverte dans un des murs de la grande salle "magna sala». Elle avait une fonction militaire mais les termes de la description sont certainement régionaux et nous n'en avons pas retrouvé la signification: "unam fenestram videlicet charmutanam propter guerram in magna sala et charmutanas internas». En 1335, deux charpentiers réparent le toit audessus de la salle "super salam» et refont les fenêtres d'une chambre "camera supra sutteranum ». Le terme de souterrain désigne ici, sans aucun doute, une des caves semienterrées de la partie est du logis. 
173 En 1337, la loge de l'aula qui était en ruine « aula domini castri de Vuachio cum logia » est restaurée; six chênes, abattus dans le bois du seigneur sont nécessaires pour cette réfection. Il est difficile de déterminer exactement ce que désigne le terme de "logia». Il semblerait qu'il s'agisse d'une galerie extérieure sur la façade du corps du logis ou d'un hourd couronnant ce bâtiment. En 1341, le toit de la grande salle " tecti aule maioris castri » est entièrement refait et recouvert de tuiles, sur des murs surélevés "expondis muri remergerunt ».

174 L'inventaire dressé en 1612, près de 400 ans après l'édification du château offre une description qui, bien que peu détaillée, présente l'avantage d'énumérer les bâtiments annexes et les pièces du logis dans l'ordre de la visite des rédacteurs. Il paraît correspondre à l'état 2 et permet de proposer un essai de reconstitution des masses architecturales et d'identifer les vestiges découverts.

A cette époque, le logis seigneurial présentait quatre niveaux. Au rez-de-chaussée, sont d'abord cités deux cabinets s'ouvrant sur la cour, qui pourraient avoir une fonction d'entrepôts ou de réserves, puis deux caves voûtées dont l'accès se faisait au bas de l'escalier à vis. Une seconde porte permettait d'accéder à la grande cour.

Au premier étage, se trouvaient les pièces principales du logis dont la disposition n'est pas précisée, cependant l'escalier donnait accès à la cuisine et à la grande salle. Celle-ci, éclairée par quatre fenêtres dont deux dans le mur nord, était en communication avec la cuisine. Elle apparaît vide de meubles, à l'exception d'un châlit à piliers en noyer. La cuisine, équipée d'une grande cheminée était pourvue de deux fenêtres munies de barreaux. Elle était séparée, peut-être simplement par une cloison légère, de la "despence » où étaient conservées les réserves alimentaires. Le mobilier de cette pièce consistait en une table sur tréteaux en noyer et un petit buffet à deux portes. Un placard était aménagé dans un mur. La cheminée était pourvue de deux landiers et d'une crémaillière de fer.

177 Au même étage, se trouvaient deux chambres; la première : "chambre de Madame », est éclairée par une fenêtre vitrée, meublée par un lit à colonnes torsadés, «tournoyé » en noyer avec un ciel en toile peinte, un autre lit dont le fond sert de coffre, une table, un buffet et une armoire ; la seconde, qualifiée plus loin de "chambre des chambrières", s'ouvrant par deux portes et éclairée par deux fenêtres, l'une à meneau, l'autre qualifiée de «derveilletz »(l), comportait un lit à colonnes en noyer, dont le fond est en sapin et le ciel en toile peinte, une garde-robe à quatre portes en noyer, un coffre, un lit bas en noyer et sapin, une table et ses tréteaux en noyer et une armoire en bois de sapin ; sur l'un des murs de cette pièce, est accroché un ratelier en noyer, destiné aux armes; cette chambre communique avec une petite pièce "cabinet" où se trouve seulement une petite table.

$178 \mathrm{Au}$ second étage, sont décrites quatre chambres, localisées par rapport au niveau inférieur. La première chambre mentionnée, située audessus de celle des chambrières, est munie de deux fenêtres et vide de tous meubles; la seconde, au-dessus de la chambre de Madame, est éclairée par une fenêtre vitrée et uniquement meublée d'un lit en noyer dont le fond était en sapin ; la troisième, également vide, se trouve entre la chambre précédente et l'escalier, la quatrième, au-dessus de la cuisine, abritant un petit buffet de sapin, est close sur deux côtés par deux parois en chêne et communique avec le "grand grenyer » qui se trouve probablement au-dessus de la grande salle. Ces quatre chambres forment un étage situé sous un autre grenier : le "grenyer dessus". 
179 La base de l'escalier à vis "viorbe », desservant les étages, a été mise au jour lors des fouilles. Il s'agit d'une construction postérieure au gros oeuvre de l'édifice. Au pied de l'escalier, est signalée une "armoyre ayant sa porte bois de sappin" correspondant probablement au placard aménagé sous la seconde volée de marches.

\section{Les bâtiments annexes à l'intérieur de l'enceinte}

Des constructions à caractère utilitaire se trouvent à proximité du château. Il s'agit de bâtiments ayant une fonction spécifique: cuisine, cellier et qui pourraient correspondre, aux édifices accolés postérieurement à l'enceinte (zones 4 et 5).

Si en 1612, la cuisine se trouvait à l'intérieur du logis, elle est mentionnée en 1331, lors de travaux de réfection de son toit, à l'extérieur de celuici : "coquina domini infra castrum ». En 1336, une nouvelle cuisine est construite, pourvue d'une cheminée faite par un tailleur de pierre, et placée sous un toit qui est construit spécialement donc toujours à l'extérieur. Le mauvais état de conservation de ce rouleau de comptes rend la description très lacunaire,

« Deux ouvriers qui ont coupé du bois dans le bois du seigneur....et ont fait cette cuisine..., travail d'un tailleur de pierre pour la fabrication d'une cheminée ».

En 1334, un grenier « solarii » est érigé sous la tour dite Villaret.

En 1337, un nouveau cellier "in factura de novo edificii domus torcularis Domini infra castrum » est construit à proximité du château. Un bâtiment, ayant fonction de cellier, "appelle pressoir » et abritant un four, est mentionné dans l'inventaire de 1612. Il se situe à l'extérieur du logis. En effet, il est désigné par le terme de «membre »ce qui indiquerait un édifice séparé de l'ensemble plutôt qu'une simple pièce. Sa description est faite après celle des deux cabinets (pièces I et II) et avant celle de l'escalier.

En 1339, un grenier est construit à l'ancienne place de la cuisine "granerio facto de novo...infra castrum de Vuachio in loco in quo quoquina esse solebat ".

\section{Les bâtiments annexes à l'extérieur de l'enceinte}

Le seigneur du Vuache détenait également des édifices à l'extérieur de l'enceinte de la grand-cour ou basse-cour.

186 Le cellier de Tary, mentionné dès 1447 , est au centre d'une grande vigne appartenant au domaine seigneurial, à environ $200 \mathrm{~m}$ à l'ouest du château. Cette situation, au milieu de culture délicate, rend peu probable l'interprétation de pressoir banal. De plus il est contemporain de celui situé à proximité immédiate du château.

Le moulin de Lavandier, à $200 \mathrm{~m}$ du château avait lui une fonction banale attestée depuis 1326 ; ce moulin, utilisant l'énergie hydraulique, était installé sur un bief dérivé de la rivière de Fontaine Froide.

En 1447, le seigneur Richard de Montchenu a des droits sur un moulin par indivision avec l'Hospice de Cologny ; son petit-fils Antoine de Montchenu a acquis avant 1498 un autre moulin qualifié de raisse au lieu-dit "Coppier ». Comme nous l'avons déjà vu, il s'agit peut-être d'une scierie (A.D.S., série SA, 136). En 1730, le seigneur de Blancheville est propriétaire d'une tuilerie située à l'emplacement de l'ancien village de Moissel, à l'est de Bans (A.D.H.S., 1730, tabelles). 
189 Nous n'avons retrouvé ni document ni vestige archéologique attestant de la présence d'une chapelle castrale à l'intérieur du château. Le chapelain du seigneur est cependant mentionné dans le plus ancien rouleau de comptes, en 1326. En 1484, la chapelle du seigneur du Vuache, sous le vocable de Sainte-Catherine se situait à l'intérieur de l'église paroissiale (A.D.H.S., série G., doc. IG 18).

\section{La vie vu château}

190 Le comte Amédée II de Genève semble avoir particulièrement apprécié séjourner à Vulbens. Après avoir cédé la seigneurie foncière à sa nièce en 1296 , il continua d'y venir à plusieurs reprises (cf. supra chap. 2.1).

191 Pour les comtes de Genève, des XIIIe et XIVe s., le château du Vuache revêtait une importance militaire et stratégique indéniable car il permettait de surveiller le Rhône dont la rive droite était devenue territoire savoyard à cette époque. Résidant à Annecy, le comte a éprouvé la nécessité d'une protection militaire de la rive gauche entre Genève et le mont Vuache, car le fleuve était ici facilement traversable par des troupes ennemies. En 1333, les éléments défensifs du château sont restaurés sur ordre du comte. De par son droit banal il délègue deux commissaires chargés de vérifier si les travaux ont été effectués et si la défense est assurée par des hommes d'armes; le château a donc joué un rôle stratégique au début du XIVe s., durant les luttes qui opposèrent le comte de Savoie au Dauphin de Faucigny allié du comte de Genève.

192 Cependant les documents nous renseignent essentiellement sur le rôle secondaire joué par le château durant ce conflit : protection et gîte d'étape des envoyés du comte, des troupes de passage et lieu d'approvisionnement.

\section{Le château, gîte d'étape}

193 En 1329, le prince Jean de Savoie passe une nuit au château ; deux lieutenants du comte y séjournent avec des armes.

194 En 1332, deux clercs du comte avec leurs chevaux et leurs valets résident pendant quatre jours au Vuache.

195 En 1333, en plus des commissaires délégués à la surveillance des travaux, trois chevaliers et leurs valets séjournent au château, de la Toussaint 1333 à janvier 1334 ; plusieurs bouchers et hommes d'armes, accompagnant un troupeau (vaches et moutons) jusqu'à l'armée du comte, y font étape et une troupe de 1692 hommes d'armes «clientium » y stationne.

196 En 1336, plusieurs valets du comte séjournent au Vuache «pro tempore de g... (guerra ?).

197 En 1337, le châtelain note les séjours de Bastien de Monte Jocerto et du notaire Perret de Pererea pendant trois jours, de Jacquemet de Chyedes Morelletti pendant cinq jours et ceux de trois valets de la maison de la comtesse venus prendre livraison de blé et d'autres gardant par intervalles les chevaux du comte.

198 En 1339, des chevaux du comte sont à nouveau gardés au Vuache et un envoyé du comte vient prendre livraison de douze charrois de vin.

199 En 1341, vingt-quatre "chevaux lyards» (gris pommelé) sont gardés par des valets du comte. 


\section{Le château, lieu de détention} 1612, le château est décrit dans un état de vétusté débutante qui permet d'émettre des doutes quant à son occupation permanente. Même le châtelain, chargé par le seigneur de la gestion du domaine, ne signale pas d'espace qui lui soit réservé et devait résider à l'extérieur.

\section{Restitution et datation}

En confrontant les données de l'étude archéologique (plan des infrastructures) avec les quelques indications sur l'usage des pièces et des bâtiments annexes, l'aménagement 
des étages et les travaux de transformations, fournies par les textes postérieurs à la construction du château, il est possible de proposer une hypothèse de restitution des masses architecturales du château du Vuache et d'en préciser la chronologie.

Si les comptes de châtellenies ne fournissent que très peu d'informations sur le bâtiment castrai, l'inventaire de 1612 présente en détail, les différentes parties du château et permet l'identification des pièces du niveau inférieur dont les vestiges ont été mis au jour; cependant dans l'espace clos que formait l'enceinte, l'évolution de l'habitat a pu porter sur les niveaux supérieurs dans une mesure plus importante que celle que nous percevons.

213 Le bâtiment castrai se présente, à l'Etat 1, comme une structure ramassée sur ellemême, suivant un plan complexe et n'occupant qu'une surface réduite (fig. 86 A). Un vaste logis occupe tout le côté nord de l'enceinte, les courtines et les tours circulaires sont destinées à assurer la capacité de résistance de l'édifice.

86 : Vue isométrique

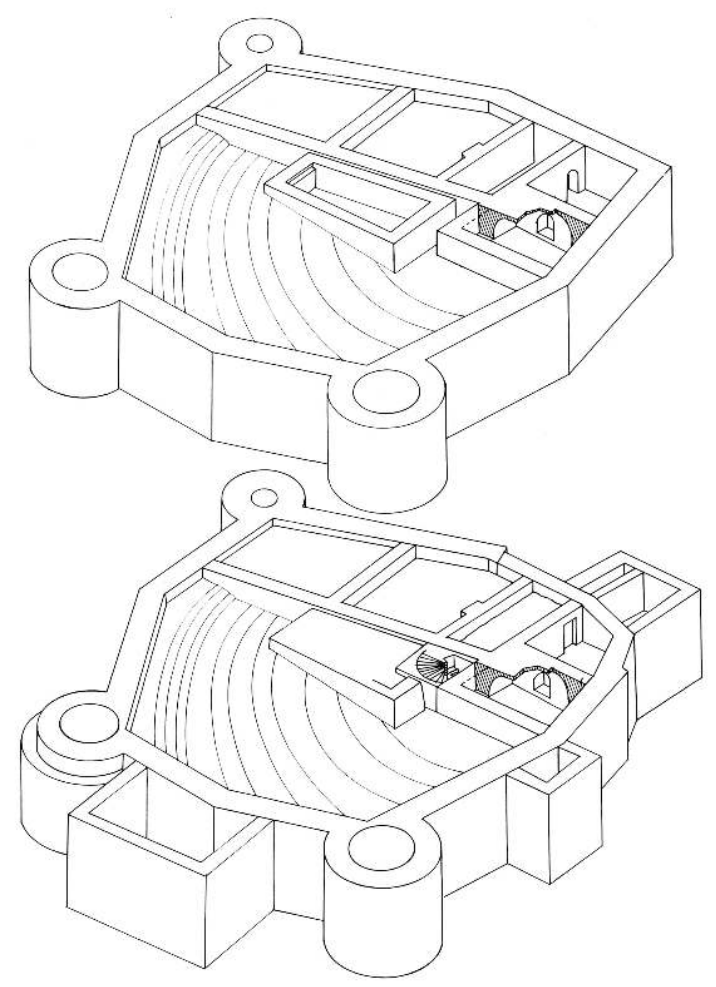

A. de l'état 1

B. de l'état 2 


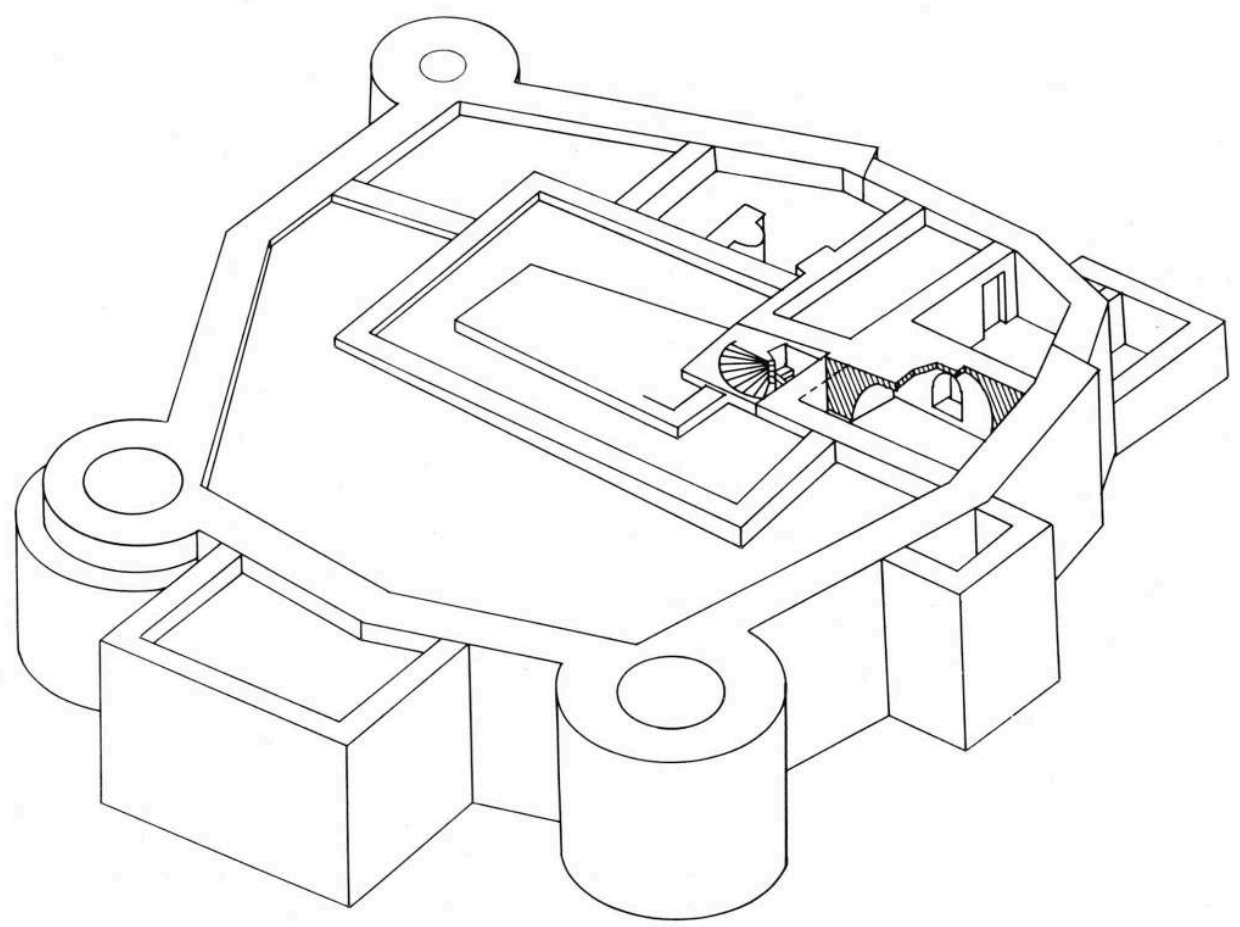

\section{DE L'ÉTAT 3}

Larges de 2,50 m en moyenne, les murs de l'enceinte pouvaient s'élever entre 10 et 20 $\mathrm{m}$; la tour sud-est, de $10 \mathrm{~m}$ de diamètre, comportant trois étages, avait entre 20 et $30 \mathrm{~m}$ de hauteur ; les deux tours ouest, de diamètre inférieur, devaient être plus petites.

Ayant un plan polygonal irrégulier, le logis seigneurial se compose de deux corps de bâtiment; à l'ouest, les deux grands espaces (pièces I et II) dont les niveaux de sols correspondent avec celui du sol de la cour sont certainement les deux qualifiés de "cabinet", pièces indépendantes servant d'entrepôts ou de resserres; à l'est, la construction est profondément implantée, l'espace est divisé en trois pièces par des murs de refend (pièces III, IV, V) qui correspondent aux deux caves voûtées mentionnées en 1612 ; la pièce III remblayée antérieurement, n'apparaît pas dans ce document.

$216 \mathrm{Au}$ XIVe s., le secteur habitation de l'édifice se compose de deux parties : la grande salle et des chambres "sala et cameris ». Le toit de la salle était, semble-t-il, individualisé. Une des chambres était située au-dessus d'un souterrain «supra sutteranum ", sans doute une des caves. Cette organisation se retrouve en 1612 ; au premier étage, la grande salle est éclairée par quatre fenêtres et communique avec deux chambres importantes ; celles-ci sont surmontées d'un étage aménagé également en chambres alors que la salle se situe sous "le grand grenyer». Un autre grenier surmontant le second étage de chambres indique un décrochement du toit entre les deux corps du bâtiment.

217 Si l'on admet que la disposition des pièces n'a pas varié entre le XIVe et le XVIIe s., la grande salle devait se trouver dans la partie ouest, au-dessus des pièces I et II et les chambres se superpo sant sur deux étages, dans la partie est, au-dessus des caves, pièces III, IV et V. La proéminence que forme le corps de logis oriental pourrait expliquer l'absence de tour dans l'angle nord-est de l'enceinte. Le petit bâtiment situé dans la cour pourrait correspondre à la cuisine, mentionnée en 1331, lors de la 
réfection de son toit. Elle a été détruite en 1336, lors de la construction d'une nouvelle cuisine.

218 De par sa conception initiale, le château du Vuache peut être rapproché de quelques exemples d'édifices castraux : son plan est voisin de celui de Yèvres-le-Châtel dans le Loiret, dont la construction est attribuée à Philippe-Auguste et remonte au début du XIIIe s. (Salch, 1977, p. 1261). Sa structure est similaire à celles de châteaux de Clermont-en-Morée (Oise) et de Boulogne-surMer (Pas-de-Calais), datés du début du XIIIe s. Ces exemples présentent également un plan très resserré, dans lequel l'importance des tours relativise celle du donjon qui ne conserve certainement pas la triple fonction de lieu d'habitation, de centre administratif et de point fort de la défense militaire (Fournier, 1978).

219 Dans un cadre plus régional, le château du Vuache correspond au type des châteaux construits dans le domaine de la maison de Savoie dès le milieu du XIIIe s. (Blondel, 1956). Par ailleurs, en raison de l'influence des architectes savoyards au service d'Edouard I, roi d'Angleterre, il peut être rapproché de ceux bâtis à la frontière anglogalloise, durant le dernier quart du XIIIe s. (Taylor, 1963 et 1985).

220 Ce type de fortifications, en grande majorité construites en plaine, est désigné par l'expression "carré savoyard». Il se caractérise par une enceinte quadrangulaire, pourvue de tours circulaires aux angles, et d'un bâtiment de logis aménagé contre l'une des courtines ; c'est le cas des châteaux savoyards de Cursinge-en-Chablais, d'Yverdon, de Coudray, de Les Marches et du château comtal de Saint-Georges-d'Espéranche (Isère) pour le domaine de Savoie et des châteaux de Conway, Flint, Harlech. Beaumaris et Caernarvon en pays de Galles; seul le château de Rolle (canton de Vaud, Suisse) présente un plan approximativement triangulaire.

221 Le plan du château du Vuache conditionné par l'aménagement antérieur du site, diffère de ce type par son plan octogonal. Il paraît donc possible de dater la construction du Vuache du second quart du XIIIe s., époque de la prise du pouvoir sur la seigneurie par le comte de Genève.

$222 \mathrm{Au}$ XIVe s., les comptes de châtellenie (fig. 85) font état d'une défense renforcée sur commandement du comte de Genève ; aménagement du fossé, construction d'un pont et d'une tourelle d'entrée surmontée d'un chaffal qui correspondrait au petit édifice (zone 7) appuyé sur la courtine orientale en 1327, restauration des hourds, des coursières sur la muraille et de l'étage de bois de l'entrée en 1333, fenêtre à fonction militaire ouverte dans la salle du château en 1334. Les bâtiments indépendants (cuisine, cellier et grenier) sont regroupés à proximité du centre défensif : une nouvelle cuisine est construite en 1336 et un cellier en 1337 «infra castrum " peut-être adossé aux courtines. Un grenier est construit à l'emplacement de l'ancienne cuisine qui se trouvait, comme nous l'avons vu plus haut, à l'intérieur de l'enceinte.

Cette phase de construction correspond à l'époque où le conflit entre le comte de Genève et le duc de Savoie se déroulait sur les rives du Rhône, en aval du Vuache. Le renforçement de la tour sud-ouest (zone 10) est peut-être à rattacher à cette période, cependant aucun indice ne permet de l'affirmer.

224 D'autres transformations interviennent entre le XVe et le début du XVIe s. : réfection de l'angle nord-est de l'enceinte, condamnation de la pièce III, construction de la zone 5 et de l'escalier à vis (fig. 86, B). L'ensemble de ces réfections entre le XIVe s. et le XVIIe s. ont été regroupées dans l'état 2. 
L'absence totale de matériel dans les niveaux correspondant à la construction du bâtiment annexe appuyé sur la courtine nord (zone 5) n'autorise pas d'en proposer une datation plus précise ni d'affirmer quelle soit contemporaine de la reconstruction de l'angle de l'enceinte ; le matériel recueilli dans la tranchée de fondation de l'escalier ne permet pas, dans l'état actuel de nos connaissances, d'en déduire sa date de construction.

Au début du XVIIe s., un certain état de vétusté transparait lors de l'inventaire : tour "cassée ", nombreux travaux de réfections qu'a dû effectuer le châtelain.

227 L'état 3 (fig. $86 \mathrm{C}$ ) correspond à une étape de construction qui peut être rapprochée du seul document iconographique dont nous disposons, le cadastre de 1730 (fig. 87). Le château y est sommairement relevé ; au centre du bâtiment castrai est représenté un espace quadrangulaire, correspondant approximativement à la construction de l'état 3. Il porte le numéro de parcelle 12, se rapportant à une cour.

87 : Représentation du château du Vuache en 1730

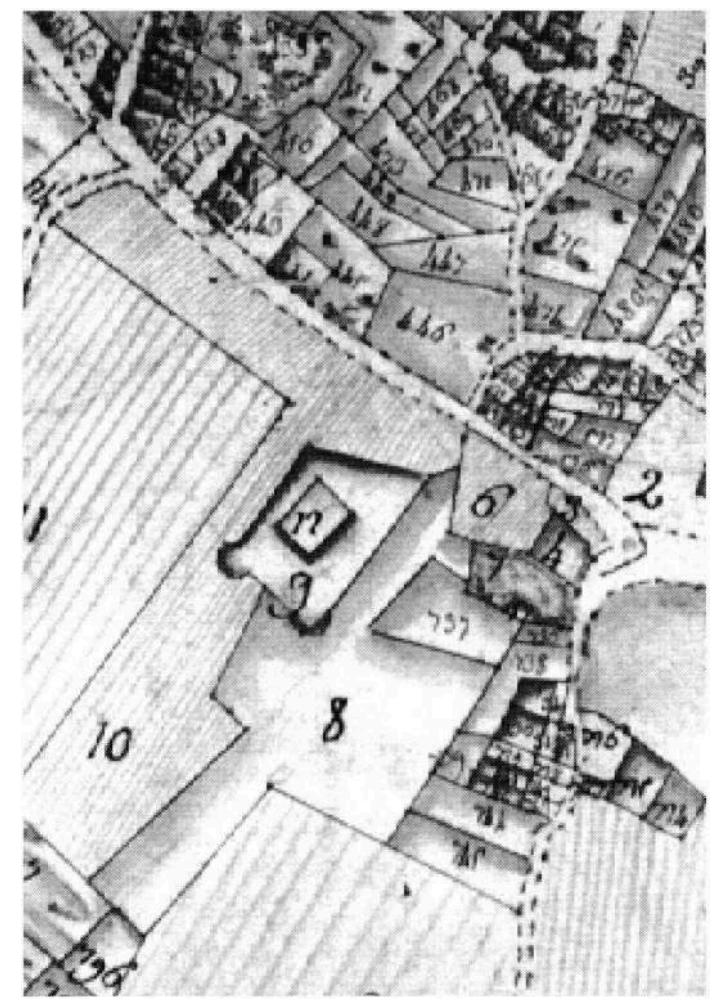

Cette construction est postérieure à 1612, époque à laquelle l'inventaire décrit le château dans son état 2 et certainement antérieure à l'édification du nouveau château seigneurial, datée par une inscription sur un linteau de porte, de 1640. L'état 3 apparaît comme une restructuration générale du château, effectuée au début du XVIIe s.; malgré les toits aquarellés en rouge sur la Mappe Sarde, l'absence de vestiges de structures maçonnées, autour de cette cour, nous amène à supposer que cette réfection n'a peut-être pas été achevée avant l'abandon du site. 


\section{NOTES}

17. Parmi les éléments architectoniques en pierre, on a retrouvé une partie d'un meneau (fig. 83, A), colonnette octogonale dont la partie supérieure est cassée, un des côtés présente un ressaut semi-circulaire (diam. : $22 \mathrm{~cm}$ ) percé d'un trou carré de $2 \mathrm{~cm}$ de côté servant au passage d'une barre assurant la fermeture de la fenêtre (pièce II, C. 201).Ainsi qu'un bloc de molasse dont une arête est décorée d'une large moulure à double chanfrein, s'évasant vers le haut et formant un angle vers le bas et surmontée par un lion couché dont subsistent les membres antérieurs et le poitrail. Un enduit blanc est partiellement conservé. Cet élément pourrait correspondre au décor d'un chambranle de fenêtre ou de porte (pièce IV, C. 102) (fig. 83, B).

La borne armoiriée, (fig. 83, C) est un monolithe sculpté sur deux faces, face antérieure et côté droit ; la base du bloc, débordant sur ces deux côtés, haute de 0,25 m, est reliée au corps par une moulure complexe, demi-circulaire au bord extérieur et en gorge à profil circulaire à l'intérieur ; la moitié supérieure de la face antérieure porte un décor traité en relief: blason ovale de la famille de Menthon Lornay (de gueules au lion d'argent à la bande d'azur brochant sur le tout) surmontant un cartouche en forme de tessère dans lequel est inscrit la date de 1579 ; une sphère ovoïde ( $\mathrm{L}: 0,28 \mathrm{~m}, \mathrm{H}: 0,10 \mathrm{~m}, 1: 0,23 \mathrm{~m}$ ) traitée en ronde-bosse surmonte le corps, alignée sur le bord antérieur. L'absence de traitement des autres faces indique que ce bloc formait probablement l'angle d'un muret dont la hauteur ne devait pas dépasser celle du monolithe. Cette pierre a été retrouvée à l'extérieur du bâtiment castrai dans le remblai de la tranchée de canalisation du cours d'eau alimentant originellement les fossés du château à l'est.

Parmi les éléments architectoniques en terre cuite, on a retrouvé des tuiles plates (fig. 84, A et B). Soit rectangulaires : tuile munie sur le revers d'un tenon de fixation, la partie inférieure du côté extérieur, sur $0,10 \mathrm{~m}$, soit le tiers de la longueur totale, est recouverte d'émail coloré (jaune, ocre brun, vert ou noir), un trait plus; foncé d'alumine16 évitait les coulures d'émail lors de la cuisson. Deux types de tenons ont été retrouvés : le plus fréquent est un tenon moulé sur le dos de la tuile à $2 \mathrm{~cm}$ du bord supérieur, épais de $2 \mathrm{~cm}$, large de $6 \mathrm{~cm}$, haut de $3 \mathrm{~cm}$ et donc l'arête inférieure est chanfreinée sur $1 \mathrm{~cm}$ de haut ; le second type retrouvé en un seul exemplaire est un appendice approximativement carré de $4 \mathrm{~cm}$ de côté, situé au milieu de la partie supérieure de la tuile, rabattu après moulage sur le revers de la tuile auquel il est soudé par écrasement des bords. Soit des tuiles creuses (fig. 84, C) : tuile canal émaillée sur un peu plus de sa moitié servant probablement pour la couverture des arêtiers; les quelques fragments de ce type de tuiles sont tous émaillés de couleur verte. 


\section{Conclusion}

1 Par la mise en oeuvre et la confrontation de deux méthodes complémentaires: l'enquête historique dans la documentation scriptuaire et la fouille archéologique, tant par l'analyse des structures et des stratigraphies que par l'étude de l'ensemble du matériel recueilli, les recherches effectuées sur le château du Vuache attirent l'attention sur la complexité d'un édifice castrai et permettent l'évocation de l'histoire d'un des cadres essentiels de la vie rurale sous l'Ancien Régime, les seigneuries laïques.

2 En analysant les cinq siècles d'existence du château, nous survolons une période chronologique s'étendant du bas Moyen Age jusqu'à l'abolition des droits seigneuriaux correspondant à une étape fondamentale de l'évolution millénaire du paysage agraire dont j'ai essayé d'éclairer la genèse et l'évolution à travers les données historiques et toponymiques correspondant aux sites antiques, aux villae carolingiennes et aux créations des paroisses.

3 En ce qui concerne l'existence du château et de la seigneurie, malgré des aspects qui restent obscurs de par la discontinuité des sources historiques, trois époques principales se dégagent, suivant en cela l'évolution de l'environnement social et économique du monde rural.

4 Un site castrai et un domaine aristocratique précédaient probablement la construction du château de pierre. Nous pouvons le supposer grâce au fait qu'un chevalier, portant le nom du village de Vulbens, est connu par le testament du comte Hugues de Sallenoves rédigé en 1239 et grâce aux vestiges partiellement reconnus d'un aménagement essentiellement caractérisé par la présence d'un segment d'enceinte de terre circulaire et antérieur au XIIIe $s$.

\section{État 1}

5 La construction du château du Vuache est attribuable au comte Guillaume de Genève, soucieux de fortifier une zone de marche nouvelle créée au début du XIIIe s. entre le comté de Savoie sur la rive gauche du Rhône et celui de Genève sur la rive droite. La conception architecturale de cet édifice: enceinte maçonnée enfermant une surface réduite et flanquée de tours circulaires fortement saillantes permet de concentrer les moyens de défense passive afin d'assurer sa capacité de résistance, un guet efficace et 
révèle son importance stratégique. Cependant un vaste logis lui confère également un caractère résidentiel non négligeable. Aux chambres, servant de lieu d'habitation, est associée la grande salle ou aula, salle de réception et d'apparat et lieu d'exercice du pouvoir administratif du seigneur.

Jusqu'à la fin du XIVe s,, le Vuache dépendra des comtes de Genève, soit directement, soit par l'entremise de membres proches de leur famille. Constituant en 1252 une partie de l'apanage d'Henri, frère du comte Raoul, le château et le mandement seront successivement tenus par leurs frères, évêques de Genève et de Langres durant une vingtaine d'années jusqu'en 1290. Six ans plus tard, le château et le domaine foncier sont concédés à ses nièces Jeanne et Comtesson par le comte Amédée II de Genève qui conserve la seigneurie politique ou droit de ban. De ce fait, le comte continue à y exercer ses droits prééminents de justice, de perception économique, de résidence, d'approvisionnement et de commandement militaire. Le château sert, en particulier, de gîte d'étape pour les armées comtales et pour les convois de bétail qui leur sont destinés et c'est le comte qui ordonne les transformations et la restauration de ces organes de défense, au début du XIVe s. : porte d'entrée fortifiée, réaménagement du fossé et du pont le traversant, restauration des coursières.

\section{État 2}

7 C'est en usant du caractère monumental du château et, probablement, par spoliation de certains domaines ecclésiastiques voisins, que les comtes procéderont à la création de la circonscription géographique correspondant à la seigneurie telle que nous la saisissons dans les documents plus récents et dont ils revendiquent la domination.

La réserve seigneuriale paraît, pour cette première époque et outre la basse-cour et les bois, limitée à quelques vignes et prés, occupant un espace très restreint par rapport aux tenures paysannes.

9 En 1366, le comte autorise la vente du Vuache; mais il ne s'agit certainement que du domaine foncier, à Marguerite de Banains dont le second époux Girard de Ternier qui, après la disparition de la famille de Genève, semble regrouper la seigneurie foncière et la seigneurie banale et rend hommage au comte de Savoie en 1397. A partir de cette époque, commence une mutation de l'économie seigneuriale, sous l'impulsion de la famille de Montchenu. En règle générale, les domaines aristocratiques ont connu, à la fin du XIVe s. et au début du XVe s., un appauvrissement économique du fait des difficultés conjoncturelles auxquelles le monde rural a affaire mais aussi à cause de la codification des usages, aux mouvements communautaires des habitants des villages et au développement progressif des pouvoirs du roi et des grands féodaux.

Pour remédier à ces difficultés, les seigneurs du Vuache ont recours à deux stratégies : l'acquisition de parcelles à vocation agricole et exploitées en faire-valoir direct et vouées à des activités spéculatives : culture de la vigne et élevage, donc rémunératices, mais nécessitant une main-d'oeuvre salariée et l'affermage périodique d'une partie du domaine qui conduira à la construction de la maison-forte de Reclaz, ce mode de gestion décentralisée d'une partie de la réserve assurant un revenu fixe. Durant cette période, le château ayant perdu son rôle stratégique, son évolution architecturale (Etat 2) vise à apporter un supplément de confort aux habitants et à l'adapter à l'évolution du domaine utile : construction d'un escalier à vis et d'une nouvelle cuisine. 


\section{État 3}

11 À partir du milieu du XVIe s. et après vingttrois années d'occupation par une troupe militaire française, le mode de gestion du domaine est plus difficile à percevoir ; le château et le domaine du Vuache dépendent de la famille de MenthonLornay et sont, très probablement, périodiquement affermés comme le révèle l'inventaire de 1612 . Après la tentative de restructuration par l'aménagement d'une cour centrale, le château médiéval est abandonné au profit d'un nouveau bâtiment construit vers 1640, le château de Faramaz.

12 Au début du XVIIIe s., la seigneurie, indivise entre le comte de Menthon-Lornay et le marquis Millet de Challes et donc probablement affermée, est rachetée par le marquis de Lescheraine qui le laisse à son gendre de Coudrey de Blancheville qui semble, d'après la Mappe Sarde, exploiter le domaine en faire-valoir direct.

13 Le marquis Jacques de Lescheraine reçoit le Vuache en 1758 et le conserve jusqu'en 1792, date de l'abolition des droits seigneuriaux. Les recherches effectuées sur le château et la seigneurie du Vuache les font apparaître dans leurs différentes fonctions, à travers leurs aspects militaire, administratif, économique, résidentiel et politique autour desquels s'organise la vie quotidienne des villageois. Ils correspondent essentiellement à un ensemble de biens fonciers et immobiliers exploitables et accumulables, engageables ou vendables selon les conjonctures et les besoins économiques auxquels les différents seigneurs qui se sont succédé ont eu à faire face. 
Annexes 


\title{
Annexe 1. Les objets de la vie quotidienne
}

\author{
Michel Dhénin
}

\section{Les objets de métal et d'os}

1 De nombreux objets métalliques ou de tabletterie et quelques pièces de monnaies ont été collectés dans les contextes stratigraphiques bien datés du château du Vuache. Ils nous apportent d'importantes informations sur la charpente et l'aménagement des huisseries; ils illustrent l'ameublement et l'éclairage artificiel. Surtout, ils nous renseignent sur le mode de vie des occupants du château. Les pratiques domestiques sont largement représentées par les ustensiles de cuisine complémentaires des récipients de terre et de verre, par les outils et le matériel de couture, ainsi que par les objets de toilette et les accessoires du costume. Sont également représentées, les activités équestre, cynégétique ou guerrière, ludique, de piété, administrative et commerciale exercées dans le contexte castral.

Dans sa grande majorité, le matériel ferreux a subi une oxydation tellement importante qu'il nécessitera une restauration préalable à son analyse; par contre les objets d'alliage cuivreux nous sont parvenus très bien conservés. Le présent travail ne saurait donc être exhaustif, mais est volontairement limité à un répertoire des objets les plus facilement identifiables. En espérant qu'un complément pourra être rapporté après la restauration des objets. ${ }^{18}$

3 Trois périodes de l'occupation du site sont représentées, à part quelques éléments particuliers ou isolés :

- la première correspond au niveau de démolition de l'état antérieur à la construction du château de pierre, séquence stratigraphique malheureusement peu explorée et dont l'enfouissement est datable du 1er quart du XIIIe s.

- la seconde est représentée par les découvertes faites dans la couche 803, déposée au XIVe s., au fond de la tour nord-ouest et, comme l'a démontré l'analyse ostéologique, correspondant à un dépotoir temporaire. 
- la troisième regroupant le plus grand nombre d'objets correspond au niveau d'occupation réparti sur l'ensemble du logis et attribuable à l'occupation militaire du château par les Bernois puis par une compagnie française entre 1536 et 1564.

4 Les objets de la deuxième et de la troisième séries, illustrant la vie du château de pierre, sont présentés conjointement.

\section{Objets de l'occupation primitive}

5 La première occupation du site, antérieure à la construction du château de pierre, a livré une clef, une lame de couteau et un bougeoir zoomorphe, tous contenus dans la couche de démolition (C 4029, tranchée IV, zone 9) dont la datation se situe entre la fin XIIe et le 1er quart du XIIIe s. (fig. 88) La qualité exceptionnelle de ce luminaire indique probablement un niveau de vie assez élevé.

D'autre part, quatre blocs hémisphériques (D. : $16 \mathrm{~cm}$, ép. max. : $8 \mathrm{~cm}$ ) de minerai de fer en cours de transformation, sont révélateurs d'une activité liée à la métallurgie.

7 Clef forée (fig. 88, A)

fer forgé. L : 11,5 cm, $1: 3,7 \mathrm{~cm}$, ép. : $1 \mathrm{~cm}$

clé de porte à canon creux, anneau circulaire de section carrée, panneton rectangulaire de section plate et à découpe symétrique, ouvert perpendiculairement à la tige (Medieval catalogue, 1954 Type III, p. 137, Rieb-Salch, 1973 p. 66).

88 :-A : Clef forée

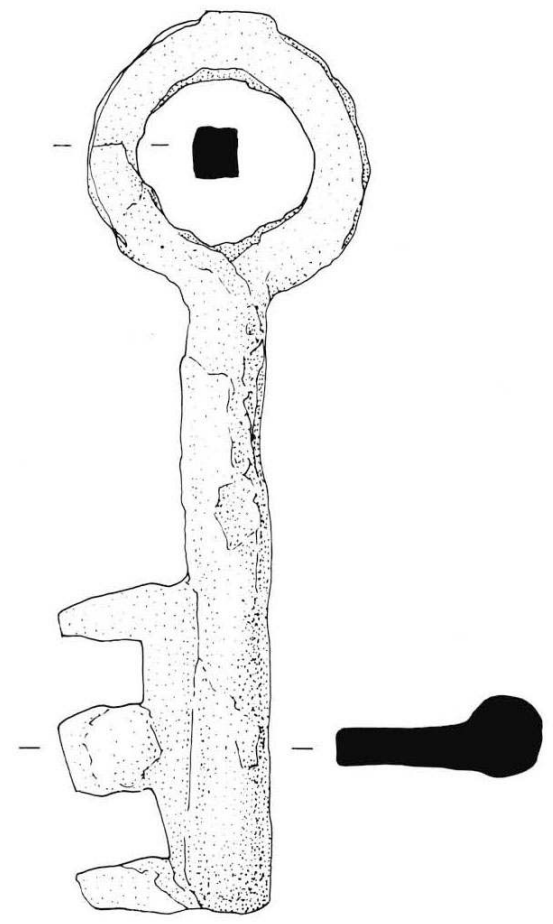

Lame (fig. 88, B)

fer. $\mathrm{L}: 7,8 \mathrm{~cm}, 1: 1 \mathrm{~cm}$, D de la soie : 0,6 cm, L de la lame : $3,2 \mathrm{~cm}$

petite lame de couteau à dos et tranchant symétriques s'arrondissant pour former une 
pointe arrondie. La soie de section circulaire, dans l'axe du dos, est plus grande que la lame, ce qui incite à y voir soit un cernoir (couteau à ouvrir les noix) soit un outil de précision : bistouri ou rasoir (Gay, 1887 t.1, p. 300).

- B : Lame

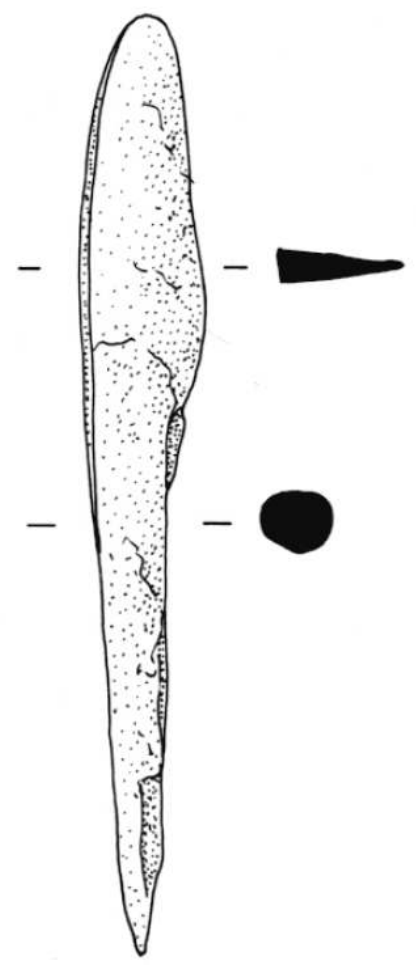

Chandelier zoomorphe (fig. 88, C) et (fig. 38)

bronze et fer. $\mathrm{L}: 9 \mathrm{~cm}, 1: 5 \mathrm{~cm}, \mathrm{H}: 12 \mathrm{~cm}$

pied massif figurant un cerf stylisé probablement obtenu par moulage à la cire perdue, retouché au burin pour situer l'emplacement des yeux et du museau et pour figurer les poils de la queue. Les cornes sont entaillées après moulage pour former trois andouillers, le nez creux est cassé, les pattes sont courtes et leurs extrémités repliées pour assurer la stabilité de l'objet, les membres postérieurs sont légèrement déformés ; sur le garrot s'adapte une tige cylindrique à base ornementale surmontée par une coupelle de $5 \mathrm{~cm}$ de diamètre et de $1 \mathrm{~cm}$ de profondeur. Ces trois parties indépendantes sont fixées par une tige de fer dont la pointe effilée (broche), servait à la fixation d'une chandelle.(d'Allemagne, 1891, p. 80-82). 


\section{- C : Chandelier zoomorphe}
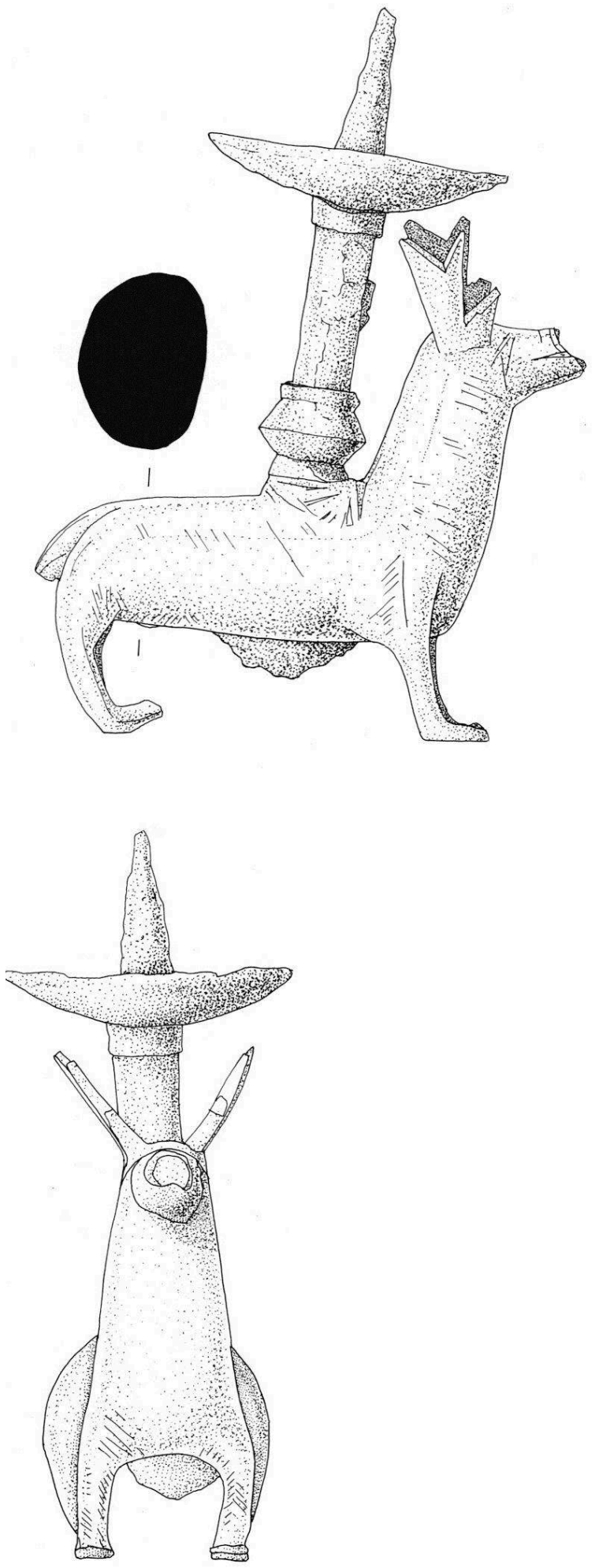


\section{Objets de l'occupation du château de pierre}

\section{Clouterie et huisserie}

Plusieurs séries d'objets en fer illustrent l'aménagement de la construction. Ils ont été exhumés dans des contextes datant des XVIe et XVIIe s. et résultant des démolitions partielles de l'édifice castrai. Il est cependant probable qu'ils appartiennent à toute la période d'occupation du site comprise entre le XIIIe et le XVIIe s. C'est le cas de la clouterie dont les plus grandes pièces provenant probablement de la charpente, mais également des éléments d'huisserie soit pour la rotation, poignées, gonds et paumelles, soit pour la fermeture, clés et fragments de serrure.

\section{Clouterie}

11 Plusieurs dizaines de clous ont été retrouvées. Malgré des dimensions variables dues au mode de fabrication artisanale, trois types principaux se rapportant à la charpente sont représentés :

Grands clous à tête plate et mince et tige de section carrée, longue et effilée (fig. 89, A).

Grands clous à tête rectangulaire ou pyramidale et tige massive de section carrée (fig. 89, B).

89 : Clous
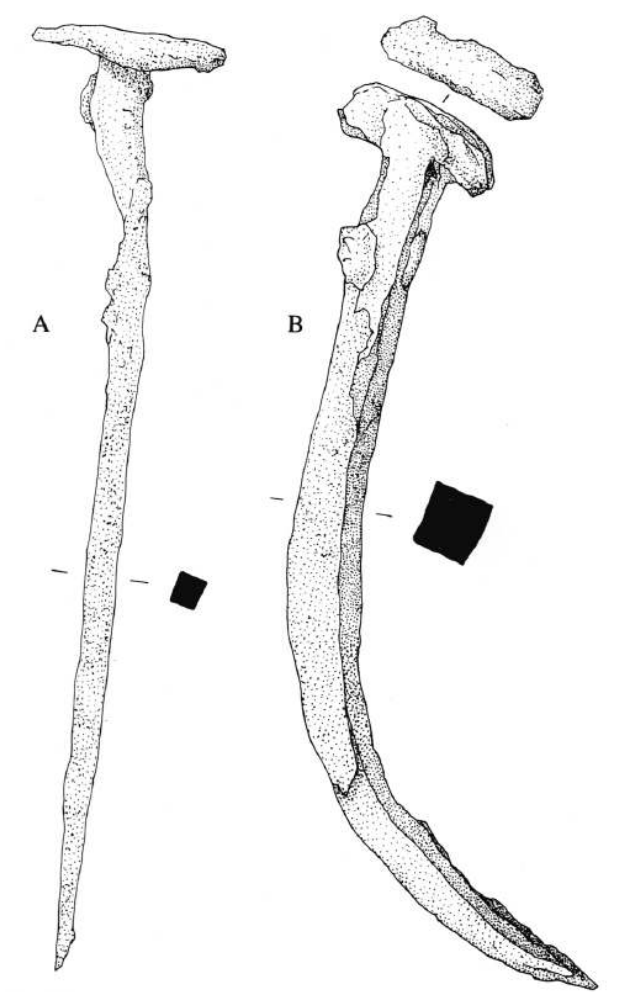

14 Petits clous à tête plate et tige de section carrée (fig. 89, C) (Démians d'Archimbaud, 1980, p. 480-481). 


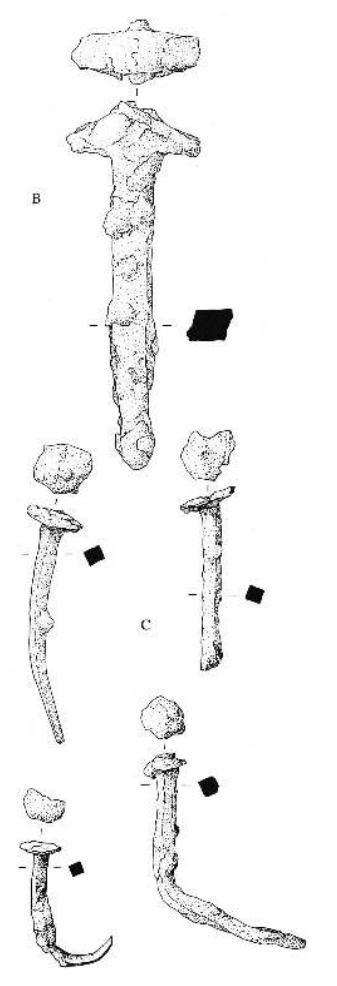

\section{Huisserie}

Les réfections des portes et fenêtres du château sont souvent mentionnées dans les comptes de châtellenie et dans les textes postérieurs, en particulier dans l'inventaire de 1612 où le châtelain rappelle qu'il $a$, durant son mandat, fait refaire la plupart d'entre elles. Les objets métalliques recueillis sont des éléments d'assemblages articulés, des poignées de portes, des serrures et des clefs :

16 - Gonds à fiches cylindriques

éléments scellés dans la maçonnerie, les trois exemples présentés ici se différencient par leurs pattes de scellement :

17 Gond à fiche (fig. 90, A)

fer. $\mathrm{L}: 10,4 \mathrm{~cm}, 1 .: 2,5 \mathrm{~cm}$, D de la fiche $: 1,5 \mathrm{~cm}$.

gond à patte de scellement de forme approximativement rectangulaire

18 Gond à fiche (fig. 90, B)

fer. $\mathrm{L}: 9 \mathrm{~cm}, 1: 3 \mathrm{~cm}$, D de la fiche $: 1,5 \mathrm{~cm}$.

gond à patte de scellement de forme trapézoïdale.

19 Gond à fiche (fig. 90, C)

fer. $\mathrm{L}: 10,2 \mathrm{~cm}, 1: 1,3 \mathrm{~cm}$, D de la fiche $: 1 \mathrm{~cm}$.

gond à patte de scellement de forme pyramidale et de section carrée (Démians d'Archimbaud. 1980, p. 466, C.A.N. $n^{\circ} 768$, p. 197). 
90 :Gonds

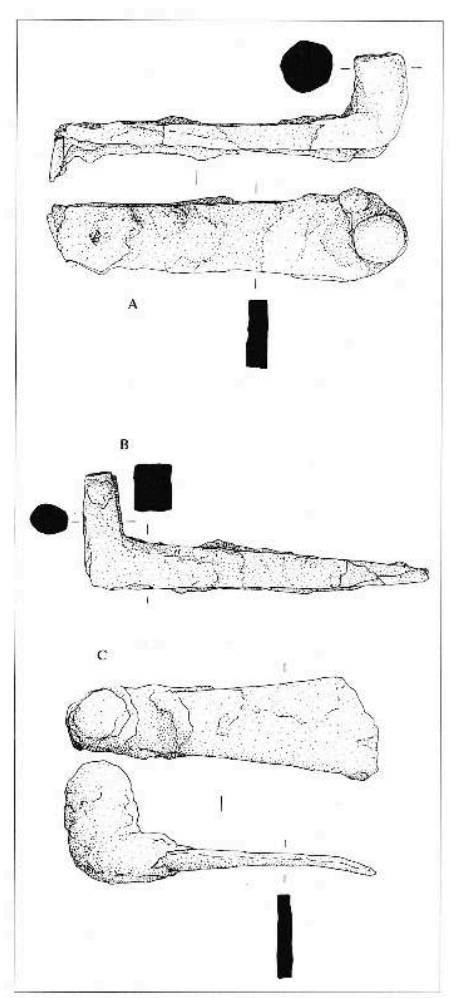

20 - Paumelles ou gonds goupilles

éléments complémentaires du gond ayant la forme d'un crampon à large collet à double branches rectilignes s'amincissant en pointes pour permettre sa fixation dans le support en bois.

21 Paumelle (fig. 91, A)

fer. $L:$ 7,6 cm, 1 max. : 1,9 cm, ép : 0,3 cm, D de la tête : $1,5 \mathrm{~cm}$.

Paumelle (fig. 91, B)

fer. $\mathrm{L}: 8,5 \mathrm{~cm}, 1$ max. : $1,9 \mathrm{~cm}$, ép : 0,5 cm, D de la tête : $1,8 \mathrm{~cm}$.

23 Paumelle (fig. 91, C)

fer. $L$ : $6,9 \mathrm{~cm}, 1$ max. : $1,4 \mathrm{~cm}$, ép : 0,4 cm, D de la tête : $1,4 \mathrm{~cm}$

(Démians d'Archimbaud, 1980, p. 466, C.A.N. 1987, nº 770 p. 198) 


\section{1 : Paumelles}

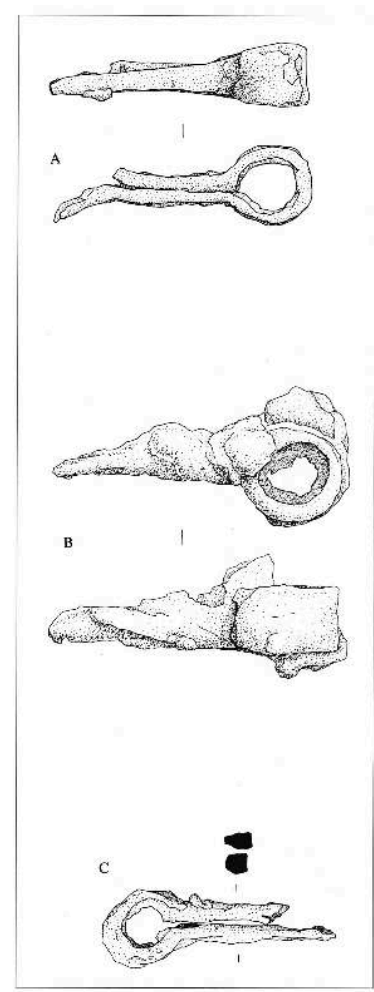

24 - Penture, un autre système de rotation est représenté par un élément isolé :

Penture droite (fig. 92)

fer. L : 19,5 cm, $1: 1 \mathrm{~cm}$, ép : 3,7 cm, D de la tête : $1 \mathrm{~cm}$.

penture droite de section rectangulaire, à tête cylindrique, dont l'axe médian est dans l'alignement de la face postérieure de la branche (Démians d'Archimbaud, 1980, p. 475,

C.A.N. $1987, \mathrm{n}^{\circ} 774$ p. 198)

\section{2 : Penture}

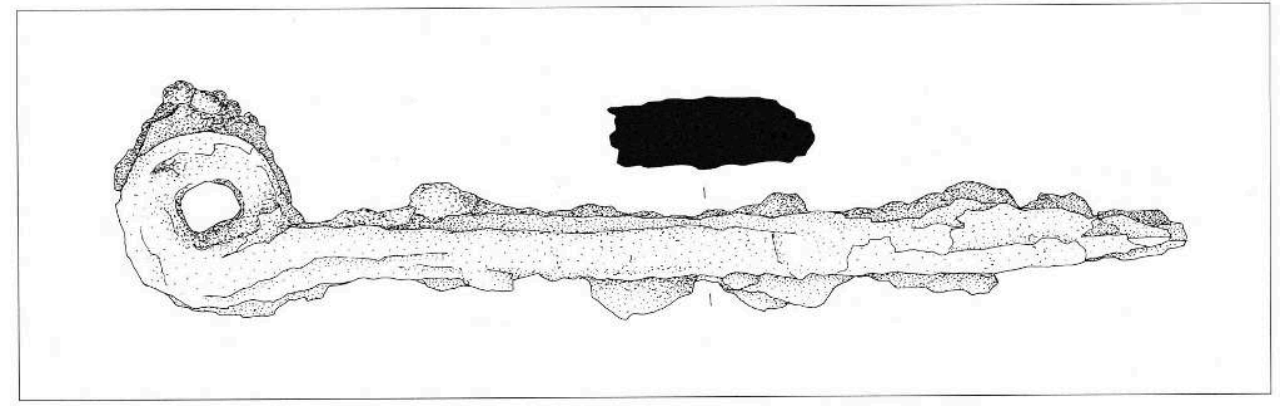

25 - Poignées de portes

Deux exemplaires de poignées de porte de même type ont été retrouvés; elles sont formées par une simple tige de fer dont les deux extrémités sont repliées à angle droit. Elles étaient probablement fixées verticalement par simple enfoncement dans le bois et permettaient de tirer ou de pousser le vantail.

fer. $\mathrm{L}: 11 \mathrm{~cm}, 1: 6,7 \mathrm{~cm}$, ép. : 0,5 cm.

poignée droite de section carrée, une des pointes est cassée. 
Poignée droite (fig. 93, B)

fer. $\mathrm{L}: 8,5 \mathrm{~cm}, 1: 4.5 \mathrm{~cm}$, ép : 0,3 cm. $1,1 \mathrm{~cm}$

poignée droite de section rectangulaire.

93 : Poignées

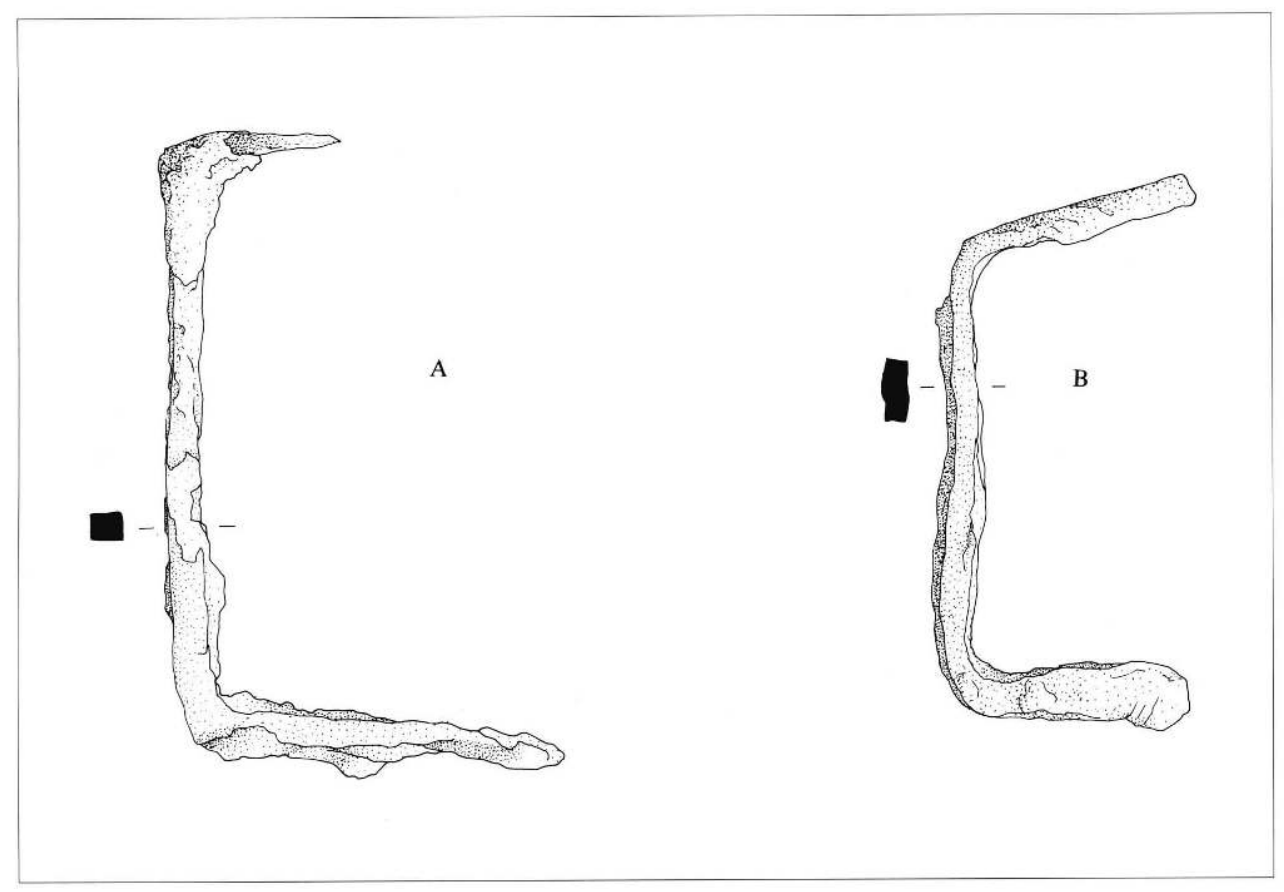

28 - Serrures et Clefs

Plusieurs fragments de serrures formées par emboutissage d'une plaque de fer forgé (type serrures à bosses) ont pu être observés mais leur état de conservation n'en permet pas l'analyse avant restauration. Les clefs sont au nombre de trois, il s'agit de grandes clefs bénardes.

Clef bénarde (fig.94, A)

fer. $\mathrm{L}: 14,8 \mathrm{~cm}, 1: 2,8 \mathrm{~cm}$.

grande clef à anneau circulaire, tige de section ronde se terminant en pointe, le panneton est trop oxydé pour être décrit.

Clef bénarde (fig. 94, B)

fer. $\mathrm{L}: 14,8 \mathrm{~cm}, 1: 3,2 \mathrm{~cm}$.

grande clef à anneau circulaire, tige de section ronde, panneton cassé présentant une bouterolle postérieure et un pertuis originellement ouvert en pleine croix.

31 Clef bénarde (fig. 94, C)

fer. $\mathrm{L}: 11,1 \mathrm{~cm}, \mathrm{I}: 2,9 \mathrm{~cm}$.

grande clef à anneau circulaire de section pentagonale, tige de section carrée, panneton découpé en arête de poisson. 


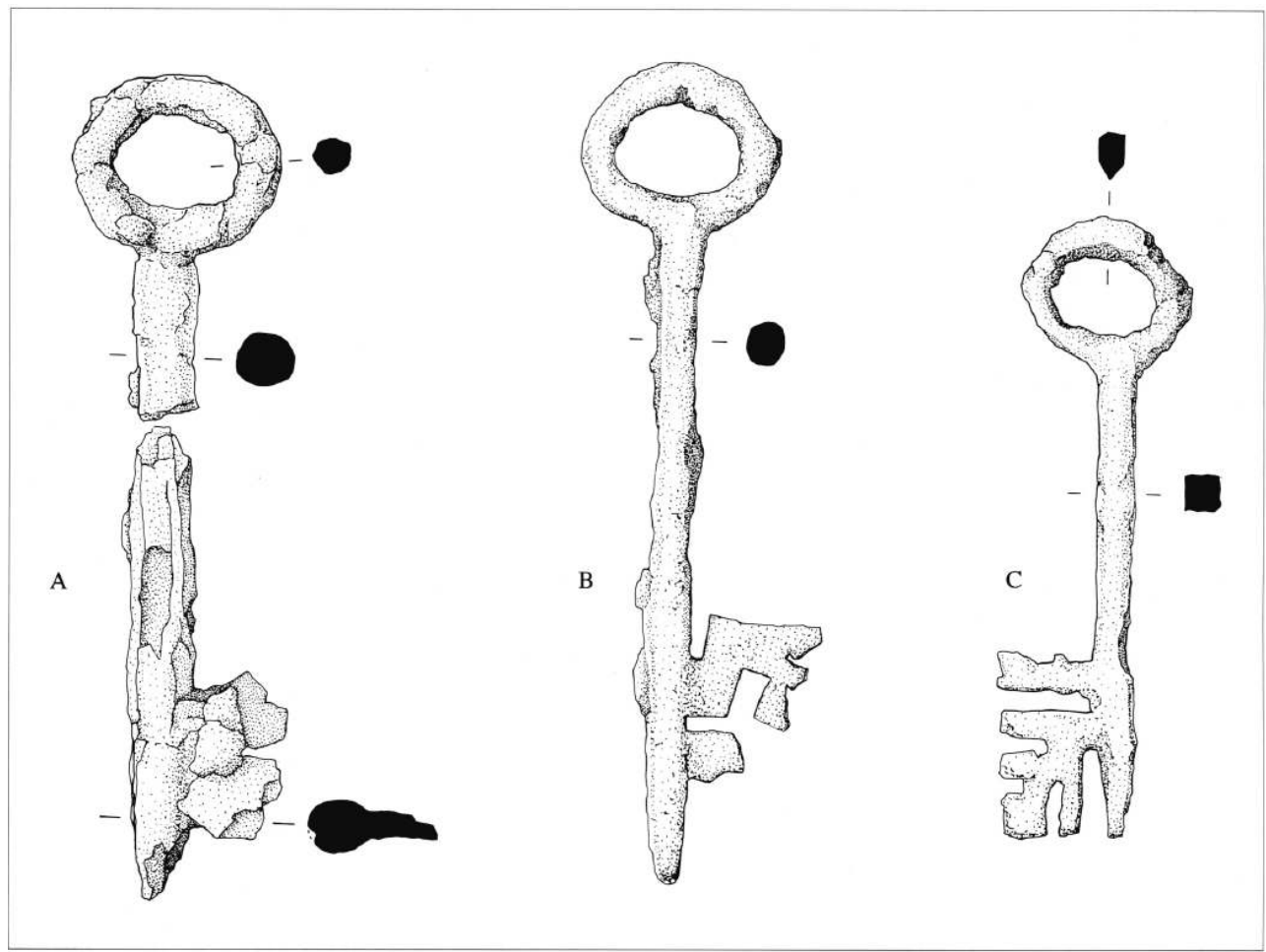

Serti de vitrail (fig. 95)

Conjointement aux fragments de verres à vitres très détériorés, décrits dans l'annexe 2 , une grande quantité d'éléments formant les résilles de sertissage de vitraux a également été retrouvée dans les contextes du XVIe s. En forme de double U, ils sont façonnés en plomb et permettent d'imaginer que les fenêtres étaient obturées par des vitrages de qualité.

95 : Serti de vitrail
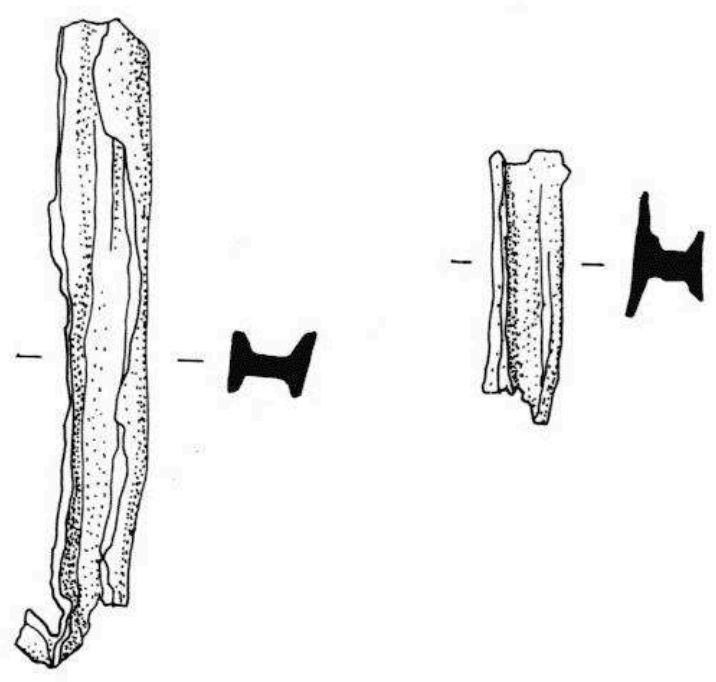


\section{Accessoires de meubles}

bronze. $\mathrm{L}: 3,2 \mathrm{~cm}, 2,4 \mathrm{~cm}, 3,6 \mathrm{~cm}, \mathrm{H}: 1,1 \mathrm{~cm}$, XVIe s.

petite serrure de coffret décorée et dont une partie du système mécanique est conservée (Rieb-Salch 1973, nº 439 p. 68)

\section{clous de menuiserie servant à fixer des panneaux et dont la tête était enfoncée grâce à} un chasse-clous.

96 : Accessoires du mobilier
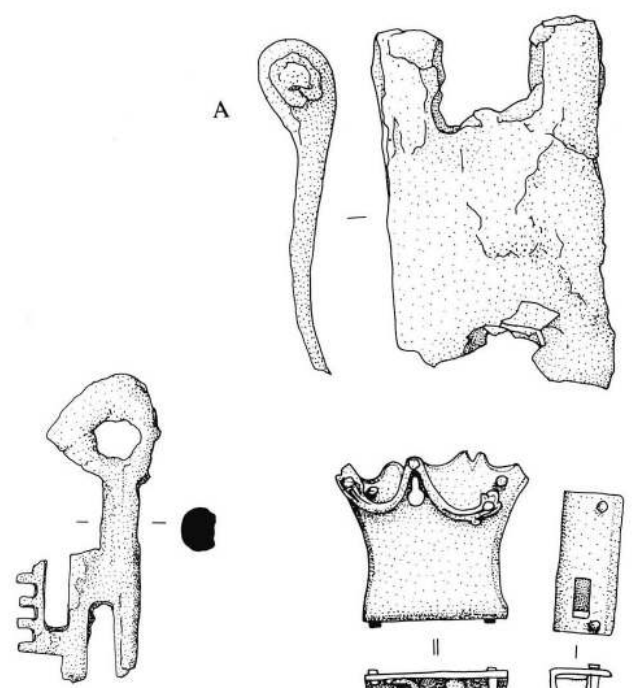
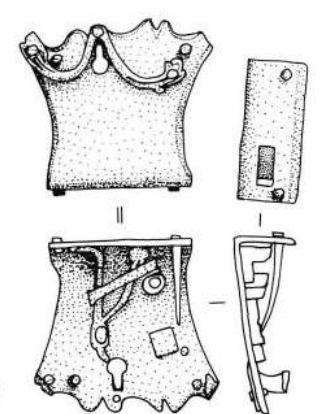

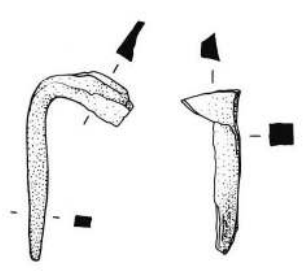

D

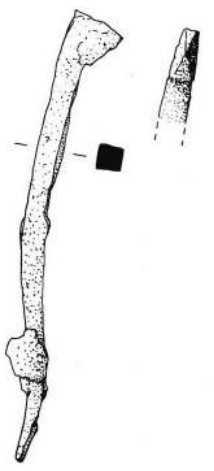




\section{Luminaire}

objet formé d'une douille cylindrique (D : $1,3 \mathrm{~cm}$, haut: $2 \mathrm{~cm}$ ) et d'une pointe dont l'extrémité est cassée ; il peut s'agir d'un chandelier à fiche dont la pointe se plantait dans un morceau de bois (C.A.N. $1987: \mathrm{n}^{\circ}$ 860, p. 215 ; Démians d'Archimbaud 1980, p. 477-478)

Douille ou binet de chandelier (fig. 97, C)

bronze. $\mathrm{H}: 3,5 \mathrm{~cm}, 1: 3,4 \mathrm{~cm}$, ép : $1 \mathrm{~mm}$ XVIe s.

douille originellement cylindrique $(\mathrm{D}: 2,5 \mathrm{~cm})$, présentant d'un côté, une entaille verticale (L. : 0,3 cm, 1.:1,7 cm) et de l'autre côté une rainure horizontale formée par huit paires d'ergots rectangulaires.

Couvercle de lampe à huile (fig. 97, D)

bronze. $\mathrm{L}: 4,2 \mathrm{~cm}, 1: 2,8 \mathrm{~cm}, \mathrm{H}: 2,1 \mathrm{~cm}$, XVIe s.

plaque découpée en forme de deux cercles accolés ; le plus petit (D : 1,6 cm) est traversé en son centre par un cylindre de $0,7 \mathrm{~cm}$ de diamètre et haut de $2 \mathrm{~cm}$ dans lequel devait être placée une extrémité de la mèche ; au centre du plus grand (D : 2,8 cm) est fixé un « robinet » dont la partie apparente est en forme de fleur de lys. La partie interne, fixée à un petit disque horizontal, était probablement destinée à recevoir la réserve de mèche. Ce type d'élément complétait une lampe à huile qui pouvait être en céramique, verre ou métal (d'Allemagne 1891, p. 237). 


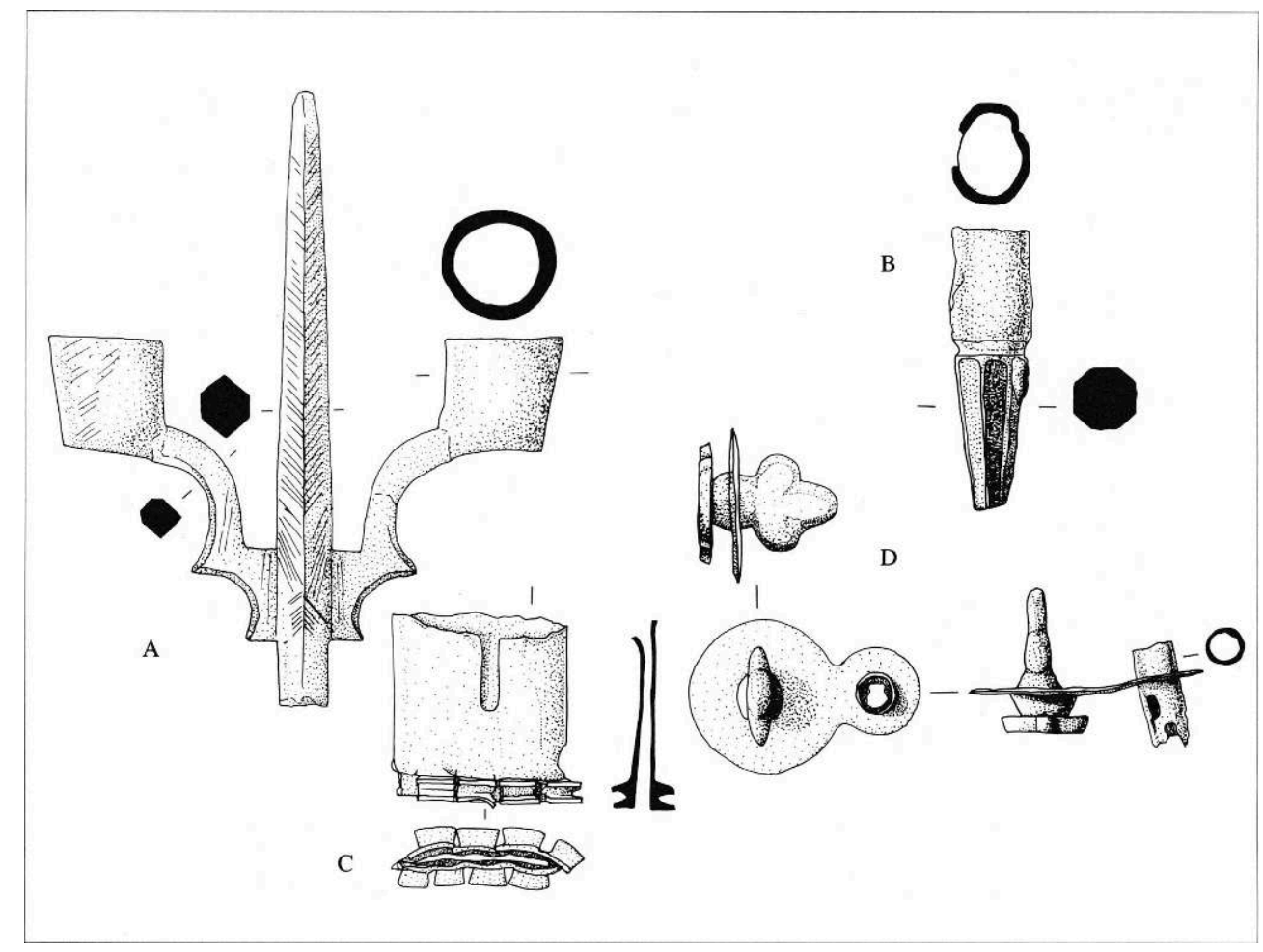

\section{Armement et équipement équestre}

Quelques objets caractéristiques de la société castrale, se rapportent aux activités militaire, cynégétique et équestre.

L'armement est très peu représenté. Six carreaux d'arbalète en fer, de deux types différents et un fragment de canon d'arquebuse en alliage cuivreux, sont les seuls éléments de cette catégorie.

L'équipement équestre est illustré par trois lots d'objets : un fer à cheval et un éperon datés de la fin du XVe s.; des éléments de décor, une boucle et un passant de lanière du début du XVIe s. se rapportent au harnachement ainsi qu'une moitié de fer et un clou de ferrure trouvés dans les niveaux d'abandon du XVIIe s.

Carreaux d'arbalète coniques (fig. 98, A)

fer. L moyenne : 7,5 cm, D de la base : $1 \mathrm{~cm}$.

le premier type de carreau représenté par trois exemplaires trouvés dans un contexte du début du XVIe s. se caractérise par sa forme conique et effilée de section ronde (Rieb-Salch 1973, n¹07 p. 25)

Carreaux d'arbalète à douilles étranglées (fig. 98, B)

fer. $7 \mathrm{~cm}<\mathrm{L}>; 10 \mathrm{~cm}$, D de la base : $1,5 \mathrm{~cm}$.

le second type, également représenté par trois exemplaires trouvés dans des contextes du XVIIe s., présente une pointe de section losangique, un étranglement central et une douille d'emmanchement conique de section ronde. Ce type paraît plus ancien que l'époque d'enfouissement (Démians d'Archimbaud 1980, p. 447 ; Medieval catalogue 1954, p. 65-73 ; Rieb-Salch 1973, n 103106 , p. 25).

Fragment de canon d'arquebuse (fig. 98, C)

bronze. $\mathrm{L}: 8 \mathrm{~cm}, 1: 3,6 \mathrm{~cm}$. 
fragment de tube à section octogonale avec une perforation centrale circulaire : calibre de $15 \mathrm{~mm}$. Trouvé dans un contexte du début du XVIe s., ce type d'arme à feu pouvait projeter des carreaux d'arbalète (Rieb-Salch 1973, n60-63, p. 22).

\section{8 : Armement}

A

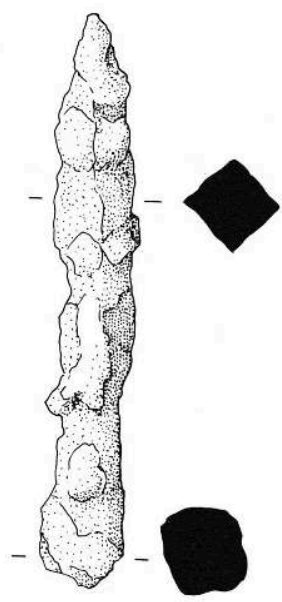

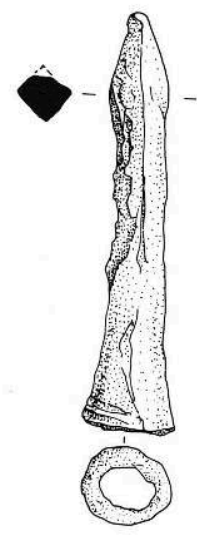

B

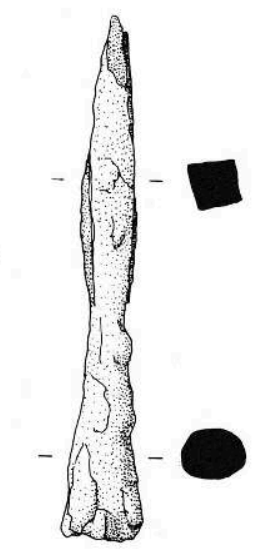

C
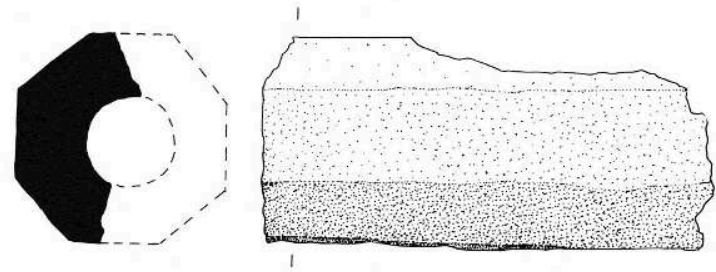

Eperon à pointe (fig. 99, A)

fer. $\mathrm{L}: 10,8 \mathrm{~cm}, 1: 10,6 \mathrm{~cm}$, ép des tiges : 0,7 cm

éperon à tiges incurvées dans le sens de la hauteur et de section quadrangulaire, s'épaississant pour former une talonnière plus large. Une des extrémités des branches est terminée par un rivet muni d'une tête carrée permettant de fixer la bride de cuir, l'autre, par un oeillet rectangulaire $(0,8 \mathrm{~cm}, 0,1 \mathrm{~cm})$. La pointe en bouton pyramidal dégagée par le reserrement d'un collet court, est reliée à la talonnière (long, totale de la pointe $: 2,5 \mathrm{~cm}$ ).

Nous n'avons pas retrouvé d'exemples d'éperons semblables datant de cette époque ; celui du Vuache se différencie des éperons connus par la taille réduite de sa pointe et par son système de fixation présentant deux attaches différentes (Medieval Catalogue 1954, p. 94-112 ; Démians d'Archimbaud 1980, p. 449).

Fer à cheval (fig. 99, B)

fer. $\mathrm{L}: 11,9 \mathrm{~cm}, 1: 10,5 \mathrm{~cm}$, ép.max. : 0,7 cm.

fer de forme ovale très usé, percé de cinq trous apparents. Les bords sont légérement ondulés par l'estampage des perforations ; les extrémités des branches sont appointées par l'usure. (Medieval Catalogue 1954, p.112-117 ; Démians d'Archimbaud 1980, p.452)

Fer à cheval (fig. 99, C)

fer. $\mathrm{L}: 13 \mathrm{~cm}, 1$ de la branche : $3,5 \mathrm{~cm}$, ép moyenne : 0,4 cm

moitié de fer, percée de deux trous rectangulaires. Un tampon, de forme approximativement circulaire, est rajouté à l'avant du fer ; sa surface quadrillée par incisions, est usée. L'extrémité de la branche est repliée pour former un crampon. La 
largeur de la branche et ses aménagements incitent à y voir soit un fer de cheval d'attelage, peut-être pour la marche sur un sol gelé, soit un fer pathologique destiné à corriger un défaut d'aplomb.

Clou de fer à cheval (fig. 99, D)

fer. $\mathrm{L}: 6,5 \mathrm{~cm}$, ép de la tige : $0,2 \mathrm{~cm}, 0,4 \mathrm{~cm}$.

clou de ferrage de forme moderne: tête carrée $0,9 \mathrm{~cm}$ de côté dont les bords sont légèrement chanfreinés, tige à section rectangulaire terminée par un "grain d'orge " petit biseau destiné à faciliter l'introduction du clou dans la come du sabot.

(C.A.N 1987 : XVe s. n 786, p. 200).

\section{9 : Equipement équestre}

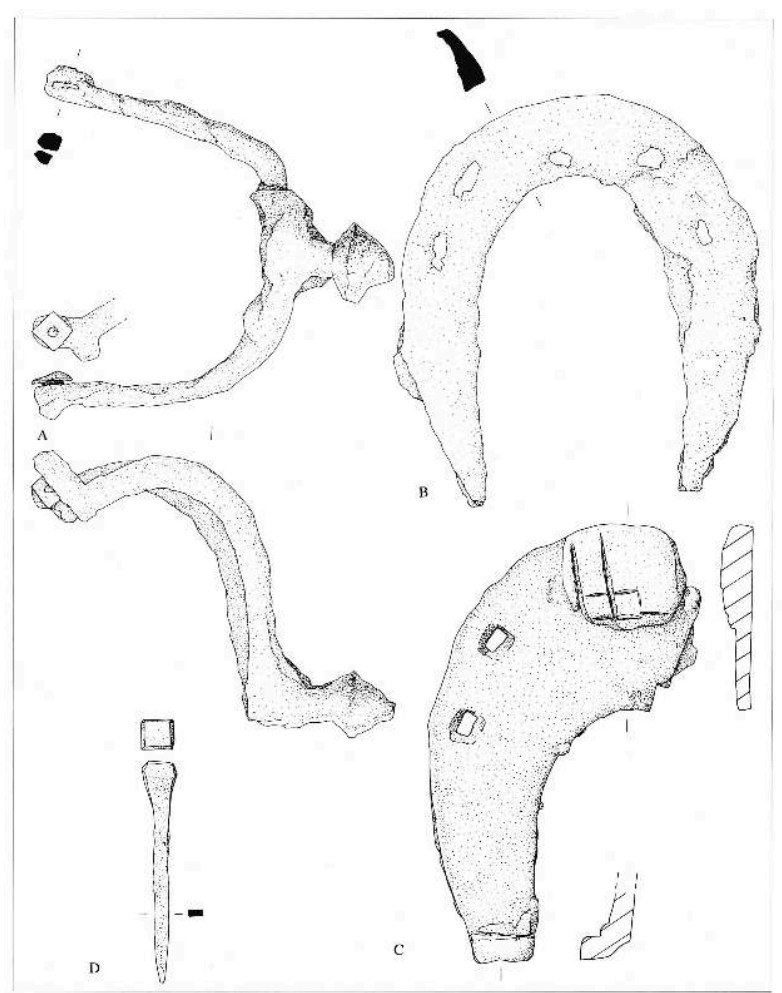

Grande boucle et passant de courroie (fig. 100, A)

fer. L : $7 \mathrm{~cm}, 1: 4 \mathrm{~cm}$, ép : 0,6 cm.

fer $\mathrm{L}: 3,9 \mathrm{~cm}, 1: 2,4 \mathrm{~cm}$, ép : $0,3 \mathrm{~cm}$.

ensemble composé d'une grande boucle de forme ovale, ardillon droit et d'un anneau rectangulaire destiné à maintenir l'extrémité de la courroie. Il s'agit peut-être d'une boucle de sous-ventrière ou d'un élément de harnais (Démians d'Archibaud 1980, p. 484).

Plaque décorative (fig. 100, B)

bronze doré $\mathrm{L}: 5,3 \mathrm{~cm}, 1: 3,5 \mathrm{~cm}$, ép : 0,1 cm, XVIe s.

plaque en forme de trident portant des traces de dorure et munie de quatre crochets de fixation sur le revers servant de décor à une courroie de harnachement. 

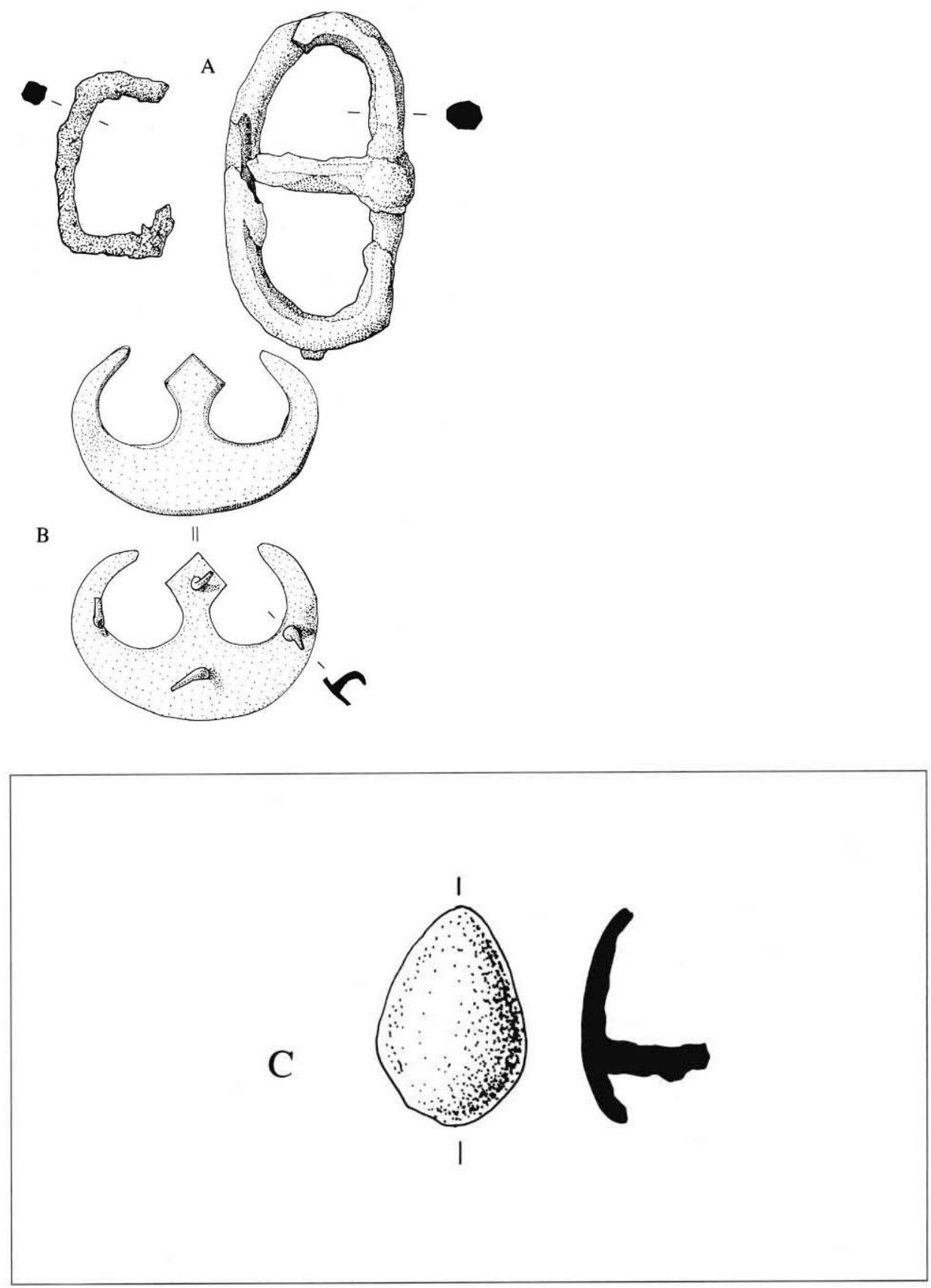

\section{Couture}

Le travail de couture est illustré par de nombreux objets, tous retrouvés dans un contexte du début du XVIe s. Sont mis en relation avec la couture, des fils de bronze servant éventuellement à faire des petites boucles pour fixer des pièces de vêtements. Ces boucles pouvaient également être utilisées pour séparer ou maintenir des mèches de cheveux.

os. $\mathrm{L}: 3,7 \mathrm{~cm}, 0,1 \mathrm{~cm}<\mathrm{larg}>0,4 \mathrm{~cm}$, ép : $1 \mathrm{~mm}$. 
tête d'aiguille de couture, à section ovale et à chas circulaire $\mathrm{D}: 1,5 \mathrm{~mm}$ La pointe est cassée.

57 Aiguille (fig. 101, B)

bronze ou laiton. $\mathrm{L}: 5,1 \mathrm{~cm}, 1<\mathrm{D}>; 3 \mathrm{~mm}$.

aiguille de couture à section circulaire et à chas ovale $(1 \mathrm{~mm}, 4 \mathrm{~mm})$ (Rieb-Salch 1973, $n^{\circ} 210$, p. 42).

Dé de couture (fig. 101, C)

bronze. $\mathrm{H}: 1,8 \mathrm{~cm}, \mathrm{D}: 1,6 \mathrm{~cm}$, ép : $0,1 \mathrm{~cm}$.

dé de couture réalisé à partir d'une tôle emboutie de forme tronconique à fond fermé, décoré à l'exception du tiers inférieur de rangées de petites incisions (Rieb-Salch 1973, $n^{\circ} 215$ p. 42 ; Démians d'Archimbaud 1980, p. 464, type n ${ }^{\circ}$ ).

Ciseaux de couture (fig. 101, D)

bronze. L : $14 \mathrm{~cm}, 1$ max. : 4,2 cm, ép : 0,5 cm.

ciseaux dont les lames, recouvertes d'oxyde de fer, sont placées en $\mathrm{X}$ de manière à se mouvoir autour d'un rivet (D. : 0,2 cm) ; les branches sont décorées d'incisions, d'ajours en forme de coeurs renversés et d'anneaux. Les anneaux de préhension à ouverture ovale présentent des facettes sur leur pourtour extérieur (d'Allemagne 1928, t. .2, p. 264-265).

\section{Ciseaux (fig. 101, E)}

fer. $\mathrm{L}: 18,5 \mathrm{~cm}, 1: 7,7 \mathrm{~cm}$, ép des lames : 0,2 cm.

grands ciseaux à lames rectilignes terminées par une pointe en feuille de laurier. Les branches coudées, à anneaux de préhension ovales, ne sont pas fermées mais formées par courbure des extrémités effilées (Medieval catalogue 1954, p. 150-153; Démians

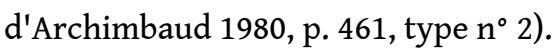

101 : Couture

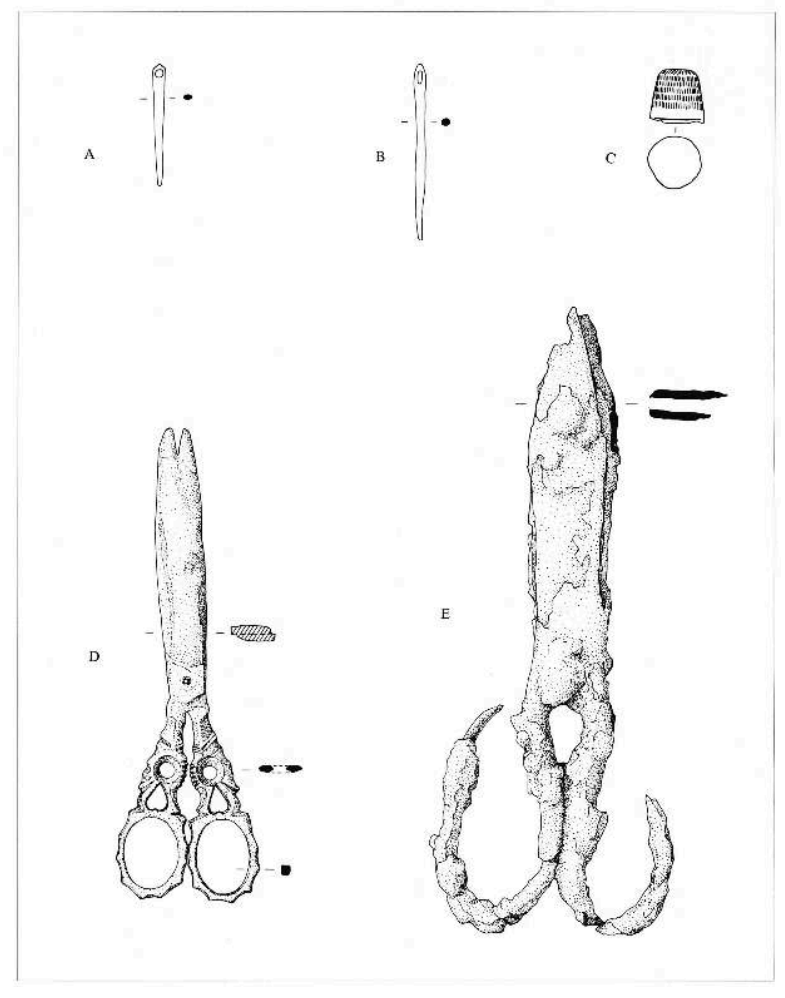




\section{Outillage}

61 exercée dans le cadre du château, mais peuvent correspondre aux travaux de réparation et d'entretien de l'édifice. Ils illustrent le travail de la pierre (massette) ou le travail du bois (tarière, herminette).

62 Tetu de tailleur de pierre (fig. 102)

fer. $\mathrm{L}: 22 \mathrm{~cm}, 1$ max. : 5,8 cm, ép : 4,5 cm, côté de la douille : $4 \mathrm{~cm}, 3 \mathrm{~cm}$, XVIe s. tetu présentant un côté carré et un côté tranchant parallèle au manche ; le sommet du manche en bois est conservé dans l'oxydation.

102 : Têtu de tailleur de pierre

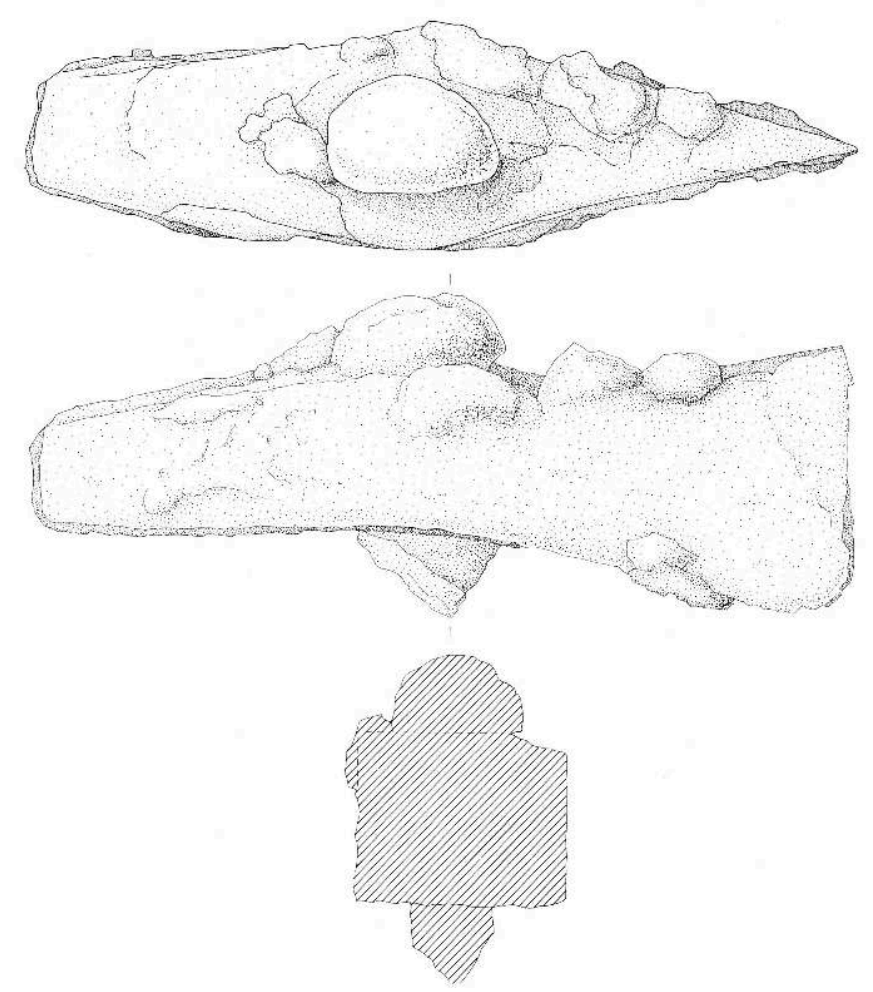

Herminette (ou aissette ou asse) (fig. 103, A)

fer. $\mathrm{L}: 20,4 \mathrm{~cm}, \mathrm{I}: 5,2 \mathrm{~cm}, 0,2 \mathrm{~cm}, 1 \mathrm{~cm}$, côtés de la douilles : $1,3 \mathrm{~cm}, 3 \mathrm{~cm}$, XVIe $\mathrm{s}$.

tête d'herminette à emmanchement quadrangulaire ; branches de section rectangulaire présentant un côté tranchant arrondi et l'autre formant une pointe oblique.

Tarière à tête vrillée (fig.103, B)

fer. L : $16,5 \mathrm{~cm}, 0,8 \mathrm{~cm}, 1,3 \mathrm{~cm}$, XVIe s.

tarière à section circulaire terminée par une spire formant la vrille, la soie conique (long. 2,5 cm) porte des traces de bois imprimées sur l'oxydation. Il s'agit vraisemblablement d'un outil indépendant et non pas d'une mèche adaptable sur un vilebrequin (Démians d'Archimbaud 1980, p.459). 


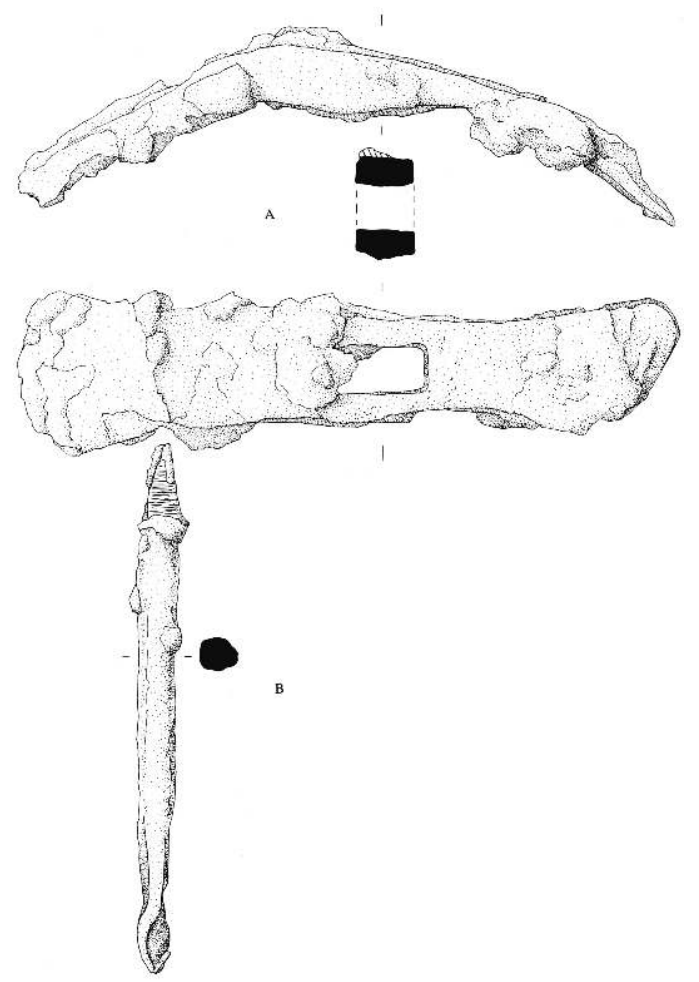

\section{Accessoires de vêtements}

Les objets vestimentaires trouvés au Vuache illustrent l'époque de transition des formes du costume qui voit, sous l'influence italienne, la disparition des usages médiévaux (robes souples) au profit de costumes aux formes géométriques: corps rigides et jupes triangulaires aux lignes épanouies faits dans de riches étoffes, avec une abondance de fourrures, de broderies et de bijoux. C'est également l'époque des premiers livres de modèles et de l'apparition des costumes régionaux.

Epingles à tête sphérique (fig. 104) bronze. 


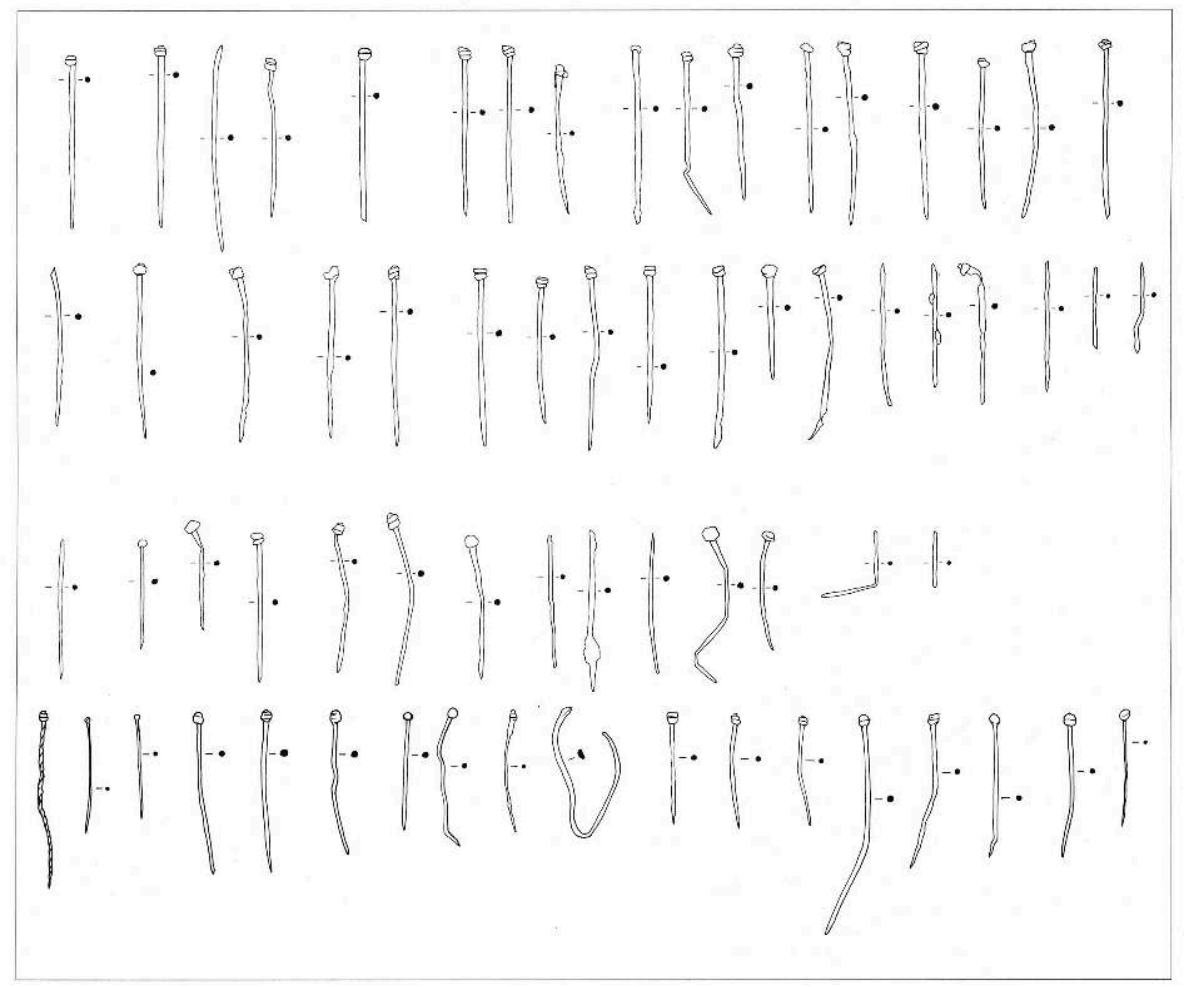

67 Au total 106 épingles ont été retrouvées dans les niveaux des XVIe et XVIIe s. La forme sphérique de la tête est obtenue par enroulement de la tige. De tailles variables, elles se répartissent cependant en deux groupes: le premier regroupant les plus petites (58 exemplaires) d'une longueur variant de $2,4 \mathrm{~cm}$ à $3 \mathrm{~cm}$, D. de la tige : $0,5 \mathrm{~mm}$, et le second (48 exemplaires) d'une longueur variant de $3 \mathrm{~cm}$ à $5,2 \mathrm{~cm}$, D. de la tige $1 \mathrm{~mm}$. Ce type d'épingle, connu du XIIIe au XVIIIe s. servait autant au travail de couture qu'à la fixation de pièces de vêtement : manches, guimpes (A.H.M. 1977, n 117-119, p. 134 ; Démians d'Archimbaud 1980, p. 516).

Troussoir (fig. 105)

bronze. L : $12 \mathrm{~cm}$, XVIe s.

accessoire passé dans la ceinture et servant à relever les jupes pour faciliter la marche. Il est composé de trois éléments : un crochet formé d'une tige de bronze repliée et dont une extrémité forme un anneau, un pendentif fait à partir d'un fil plié de manière à former deux boucles aux extrémités. Autour de celui-ci est enroulé un fil de bronze (D : $0,5 \mathrm{~mm}$ ). Sa partie centrale est décorée de six rangées de bouclettes formées par un fil de bronze entourant deux rangées du précédent et enfin, une chaîne à maillons torsadés qui se fixait à la ceinture (le pendentif présente des similitudes avec A.H.M. $1977, n^{\circ} 162$, p. 154). 
105 : Troussoir (x 2 environ)

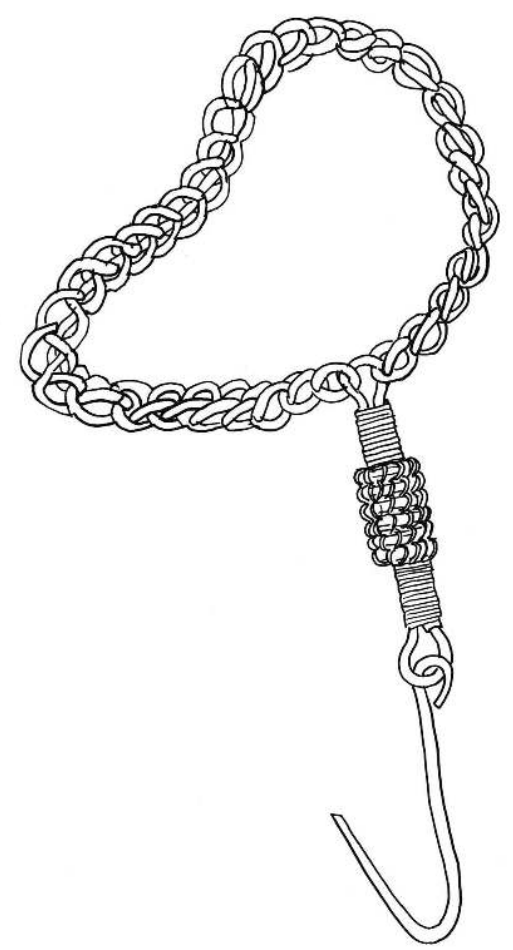

69 Fragment de galon d'argent (fig. 106)

fil d'argent. L : 2,7 cm, $1: 1,5 \mathrm{~cm}$, ép : 0,02 cm, XVIe s.

fil d'argent torsadé autour d'un fil textile (disparu), formant un galon de décoration vestimentaire.

106 : Galon d'argent

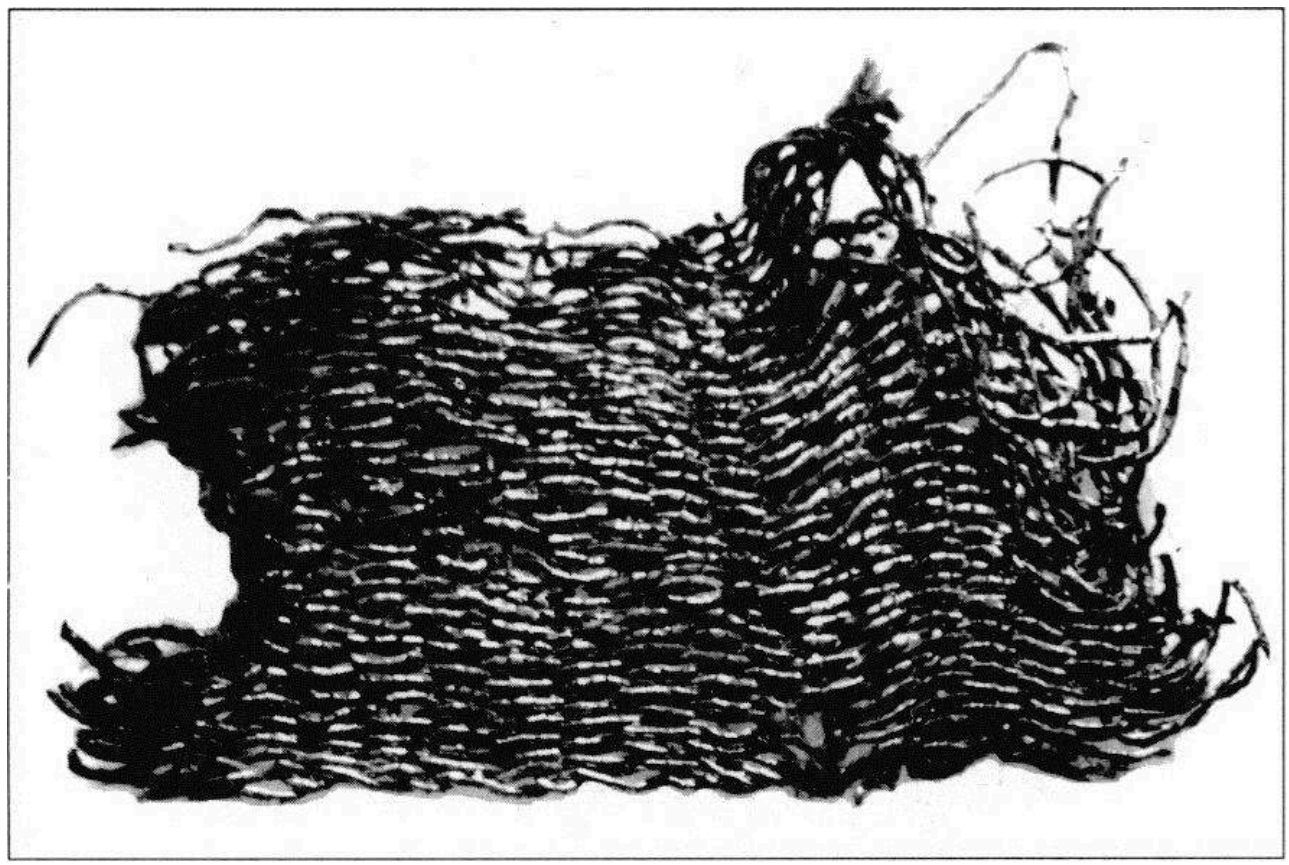


70 Fragment de galon de bronze (fig. 107, A)

bronze. L : 4,5 cm, $1: 1,4 \mathrm{~cm}$, ép : 0,5 cm, XVIe s.

fil de bronze (D : 0,5 $\mathrm{mm}$ ) tressé sur trois rangs en double fil (Démians d'Archimbaud 1980, p. 516).

71 Boucle de fil de bronze (fig. 107, B)

bronze. D : $1 \mathrm{~cm}$, D. tige : $0,1 \mathrm{~cm}$ XVIe s.

fil de bronze torsadé pour former une petite boucle circulaire.

72 Boucle de fil de bronze (fig. 107, C)

bronze. $\mathrm{L}: 1,2 \mathrm{~cm}, 1: 0,8 \mathrm{~cm}$, D. tige : 0,1 cm, XVIe s.

fil de bronze enroulé sur deux rangs pour former une petite boucle rectangulaire.

107 : - A : Galon de bronze

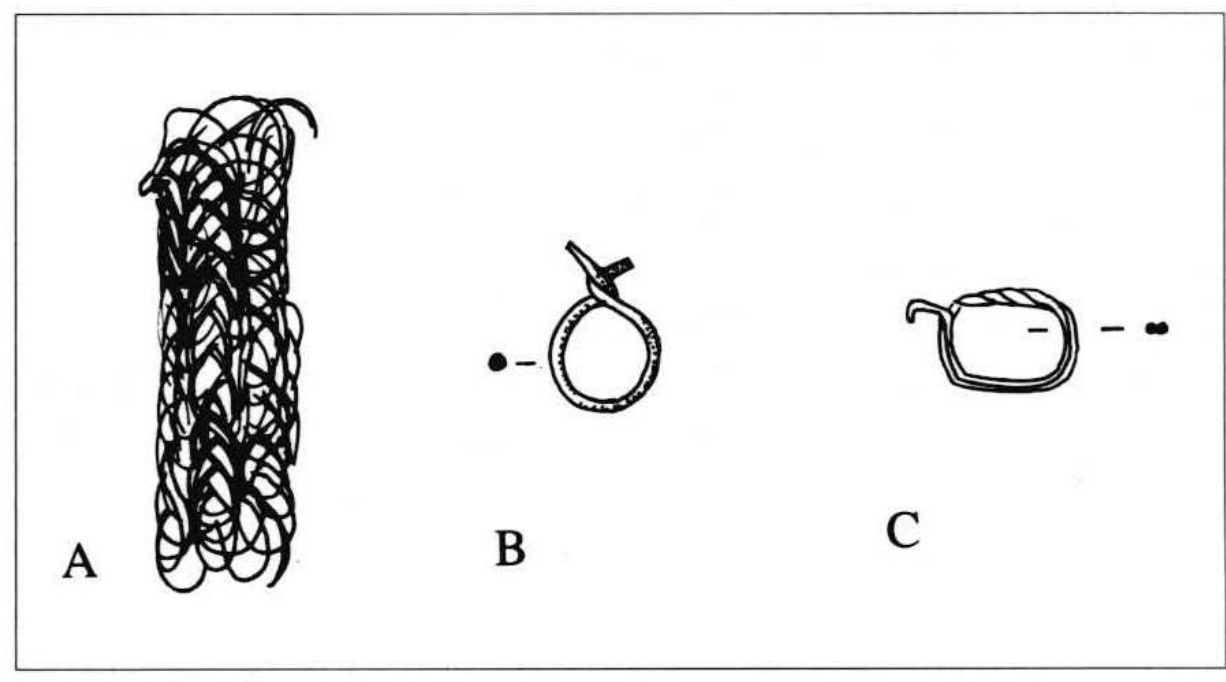

73 - Aiguillettes

Fait attesté dès le 1er tiers du XVe s. et perdurant jusqu'au règne de Louis XIV, les vêtements, masculins et féminins, étaient fermés ou décorés par des aiguillettes: cordons, ganses ou tresses dont les deux extrémités sont ferrées (fig. 108, A) (Arnold, 1985).

Huit petits ferrets d'aiguillettes, du XVIe s., formés de fines plaques de bronze enroulées de forme conique, ont été exhumés au Vuache. Leurs dimensions sont approximativement les mêmes. Un seul ferret correspond à une aiguillette de grande taille. 


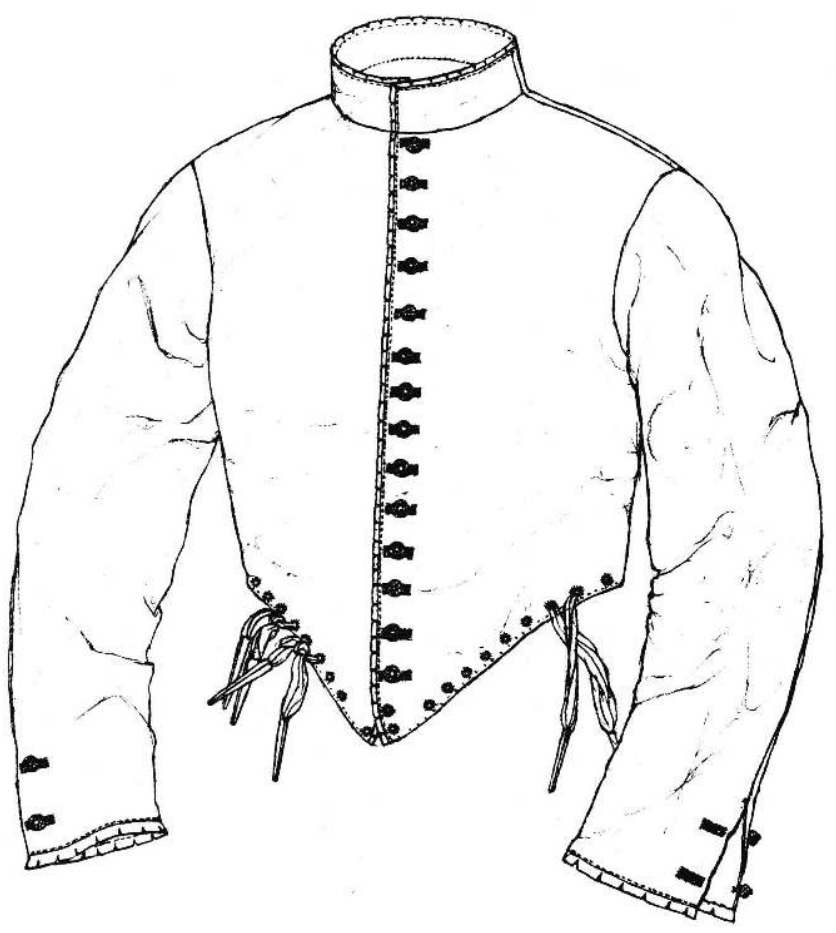

Palazzo Pitti, Florence, 1574

74 Ferrets d'aiguillette (fig. 108, B) bronze

$\mathrm{H}: 2,4 \mathrm{~cm}, 0,01 \mathrm{~cm}<\mathrm{D}>0,025 \mathrm{~cm}$

$\mathrm{H}: 2,4 \mathrm{~cm}, 0,05 \mathrm{~cm}<\mathrm{D}>0,25 \mathrm{~cm}$

$\mathrm{H}: 2,4 \mathrm{~cm}, 0,05 \mathrm{~cm}<\mathrm{D}>0,25 \mathrm{~cm}$

$\mathrm{H}: 1,6 \mathrm{~cm}, \mathrm{D}: 0,2 \mathrm{~cm}$

$\mathrm{H}: 2,9 \mathrm{~cm}, 0,15 \mathrm{~cm}<\mathrm{D}>0,2 \mathrm{~cm}$

$\mathrm{H}: 3 \mathrm{~cm}, 0,1 \mathrm{~cm}<\mathrm{D}>0,25 \mathrm{~cm}$

$\mathrm{H}: 2,2 \mathrm{~cm}, 0,18 \mathrm{~cm}<\mathrm{D}>0,22 \mathrm{~cm}$

(Rieb-Salch 1973, n 379, p. 62 ; Démians d'Archimbaud 1980, p. 516)

- B : Petits ferrets
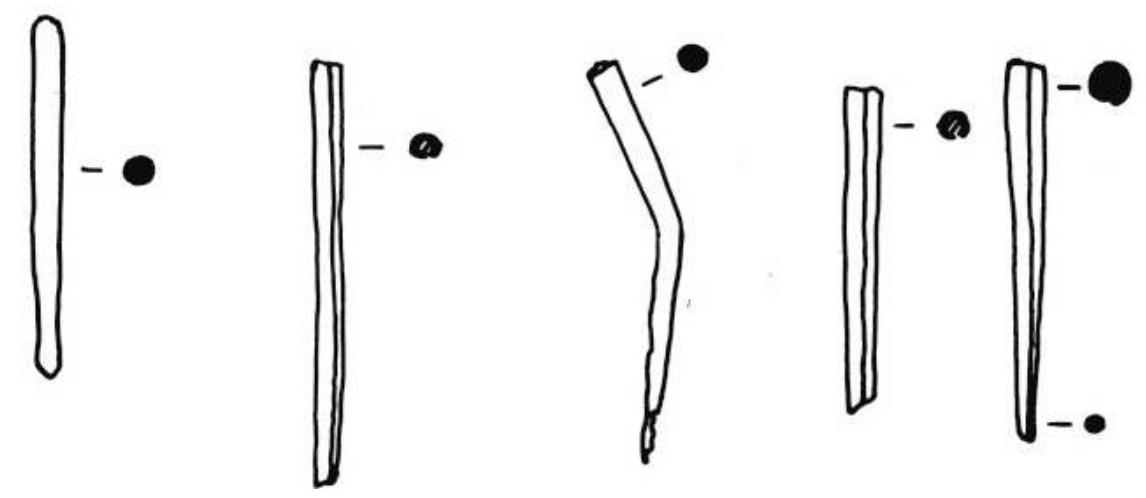
bronze. L : 4,7 cm, ép : 0,1 mm, $3 \mathrm{~mm}, 6 \mathrm{~mm}$, XVIe s.

grand ferret d'aiguillette tronconique formé d'une plaque de bronze repliée.

$-C$ : Grand ferret

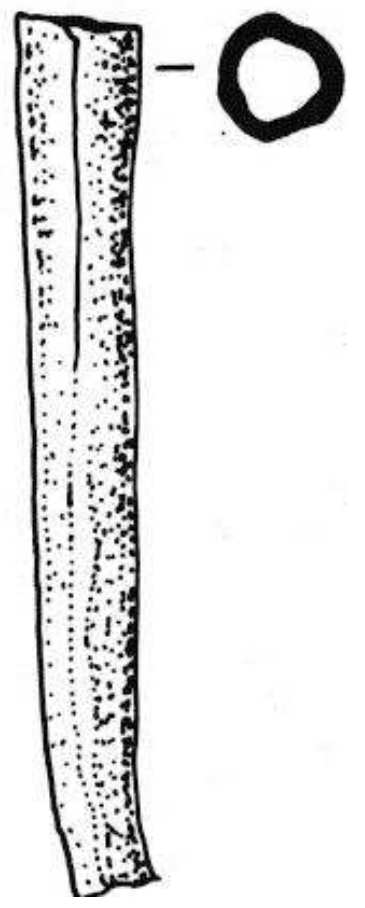

\section{Éléments pour pièces vestimentaires en cuir}

Quelques boucles et pièces métalliques correspondent à la fixation d'accessoires vestimentaires en cuir.

Boucle (fig. 109, A)

bronze. D : $2 \mathrm{~cm}$, ép : $0,2 \mathrm{~cm}$, XVIe-XVIIe s.

boucle circulaire à double fenêtre, tige périmétrale de section ogivale; côté plat vers l'intérieur; axe central galbé présentant un étranglement central de $0,2 \mathrm{~cm}$ pour l'ancrage de l'ardillon manquant.

Boucle (fig. 109, B)

bronze. D : $2 \mathrm{~cm}$, ép : 0,2 cm, XVIe-XVIIe s.

boucle circulaire à double fenêtre, incurvée en son milieu; tige de section triangulaire aux angles adoucis, ardillon manquant (Rieb-Salch 1973, $\mathrm{n}^{\circ}$ 353. p. 59).

Boucle (fig. 109, C)

fer. $\mathrm{L}: 3 \mathrm{~cm}, 1: 2,8 \mathrm{~cm}$, XVIe-XVIIe $\mathrm{s}$.

boucle à double fenêtre de section circulaire, légèrement incurvée au centre et présentant un retrécissement de part et d'autre de la tige centrale pour la fixation de l'ardillon.

bronze. L : 4,1 cm, $1: 2 \mathrm{~cm}$, ép : 0,1 cm, XVIe s. 
chape rectangulaire dont la boucle manque, formée d'une plaquette rectangulaire repliée. Le côté interne est moins large $(1,4 \mathrm{~cm})$ et moins long $(3,6 \mathrm{~cm})$ que le côté externe, large de $2 \mathrm{~cm}$ et long de $4,1 \mathrm{~cm}$; cinq perforations $(\mathrm{D}: 0,2 \mathrm{~cm})$ servaient à la fixation sur une bande de cuir : un rivet cylindrique est conservé (Rieb-Salch 1973, $\mathrm{n}^{\circ}$ 340 et 342, p. 5 ; Démians d'Archimbaud 1980 p. 502-503).

Oeillet riveté (fig. 109, E)

bronze. D : $2 \mathrm{~cm}$, ép : $0,1 \mathrm{~cm}$.

petite rondelle à bord biseauté et à perforation centrale $(\mathrm{D}: 0,7 \mathrm{~cm})$, munie de trois rivets disposés en triangle ( $\mathrm{L}: 0,5 \mathrm{~cm}, \mathrm{D}: 1,5 \mathrm{~mm})$, dont deux conservent leur bague de fixation; elle servait probablement à renforcer un oeillet d'objet en cuir. (Démians d'Archimbaud 1980, p. 514)

109 : Eléments pour pièces vestimentaires en cuir

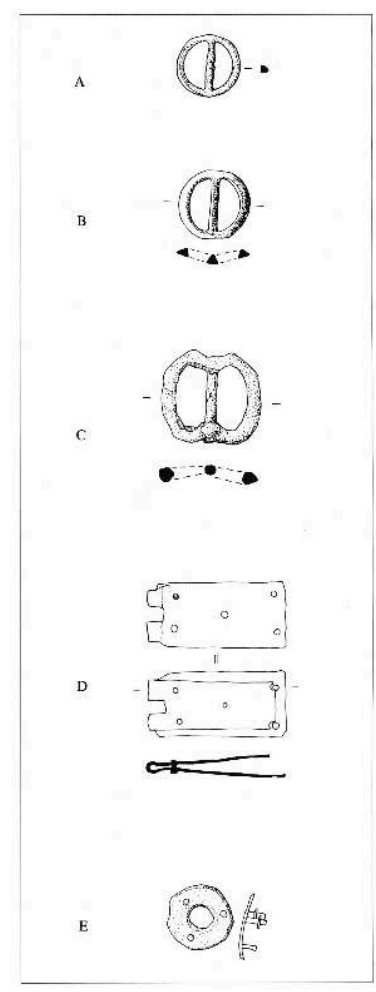

\section{Parure et bijoux}

La parure, complémentaire du costume, est représentée par deux perles de bois et surtout par une très belle bague en or.

Fragment de perle de bois (fig. 110, A)

bois. $\mathrm{L}: 2,3 \mathrm{~cm}, 1: 1,7 \mathrm{~cm}$, XVIe $\mathrm{s}$.

perle ovoïde à facettes obliques de bois noir.

Perle de bois (fig. 110, B)

bois. $\mathrm{L}: 1,2 \mathrm{~cm}, 1: 1 \mathrm{~cm}$, XVIe $\mathrm{s}$.

perle de bois noir, approximativement sphérique, décorée de profondes entailles obliques en chevrons, les faces saillantes sont gravées de petites étoiles. 
Bague en or (fig. 110, C) (photo 4ème de couverture)

or, rubis, saphir. D : $1,78 \mathrm{~cm}$, fin XVe-début XVII s.

bague en or à chaton double associant un rubis et un saphir rectangulaires taillés « en quarré » et sertis, au centre de fleurons trilobes, selon le type de monture désigné comme "bâte à cuvettes ». Les épaules sont décorées par ciselure de deux rangs de chevrons sur les bords inférieur et supérieur, de part et d'autre d'une bande s'élargissant pour former une boucle de chaque côté du chaton. Ce type de bague, associant deux pierres différentes, est généralement considéré comme anneau de fiançailles ou de mariage, les petites dimensions incitent à voir ici un bijou féminin ${ }^{19}$.

110 : Bijoux et parure

A

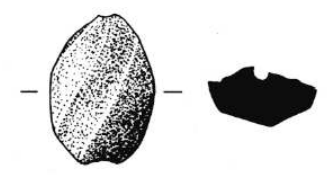

B
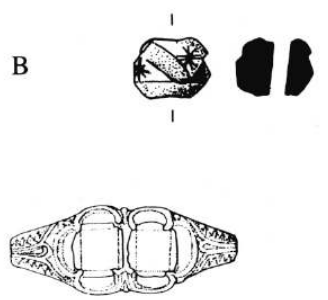

$\mathrm{C}$
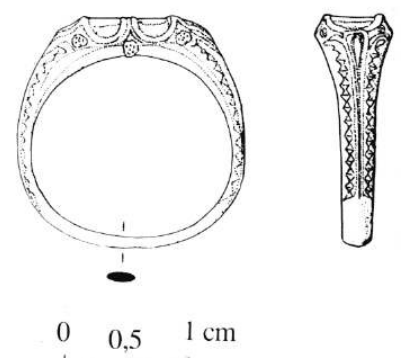

\section{Objets de toilette}

\section{os. L : 5,1 cm, XVIe s.}

épingle à tête sphérique $(\mathrm{D}: 0,8 \mathrm{~cm})$. La tige est à section carrée dans sa partie supérieure $(0,3 \mathrm{~cm}$ de côté sur une longueur de $2,2 \mathrm{~cm})$ et à section circulaire dans sa partie inférieure $(\mathrm{D}: 0,3 \mathrm{~cm})$. Cet objet pouvait également servir à tracer une raie dans la chevelure (d'Allemagne 1928, t. .2, p. 224-225).

88

Cuillère à fard ? (fig. 111, B)

bronze. $\mathrm{L}: 8,2 \mathrm{~cm}, \mathrm{D}: 1,5 \mathrm{~cm}$ XVIe s.

tige de bronze dont une extrémité effilée est légèrement tordue, peut-être accidentellement. L'autre est façonnée en cuilleron de forme ovale, dans l'axe de la tige. Les bords se sont désagrégés, ainsi que la patine de la pointe, après sa mise au 
jour : il pourrait s'agir d'une cuillère à onguent ou à fard (Rieb-Salch $1973: \mathrm{n}^{\circ} 202, \mathrm{p}$. 39).

111 : Objets de toilette

A

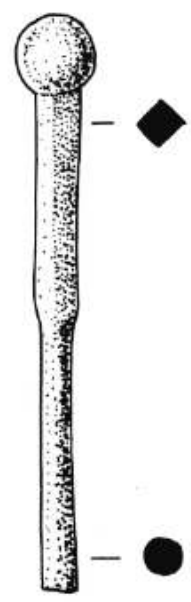

B

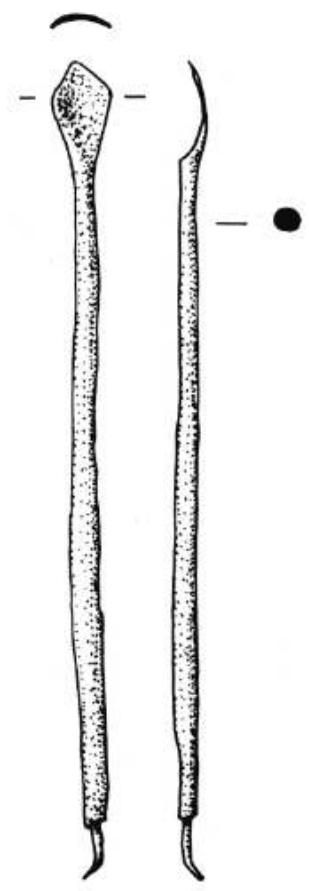

\section{Ustensiles de cuisine}

L'équipement ménager métallique, complémentaire des récipients de céramique et de verre, n'est représenté que par deux lames de couteaux, un fragment de louche et un fragment de petite coupelle en bronze trouvée dans le bâtiment annexe interprété comme cellier.

Couteau (fig. 112, A)

fer. $\mathrm{L}: 9 \mathrm{~cm}, 1: 1 \mathrm{~cm}$, ép : 0,25 cm, XVIe s.

lame de couteau très détériorée, soie de section quadrangulaire. La pointe est cassée, le bord est droit et le tranchant s'incurve à son extrémité pour former une pointe arrondie.

91 Couteau (fig. 112, B)

fer. $\mathrm{L}: 7,6 \mathrm{~cm}, 1: 1,75 \mathrm{~cm}$, D de la soie : 0,6 cm XVIe $\mathrm{s}$.

lame de couteau dont la pointe est cassée. Le dos est rectiligne ; la base du tranchant est arrondie et la soie, de section circulaire, forme un petit talon à la base du dos de la lame. 
112 : Couteaux

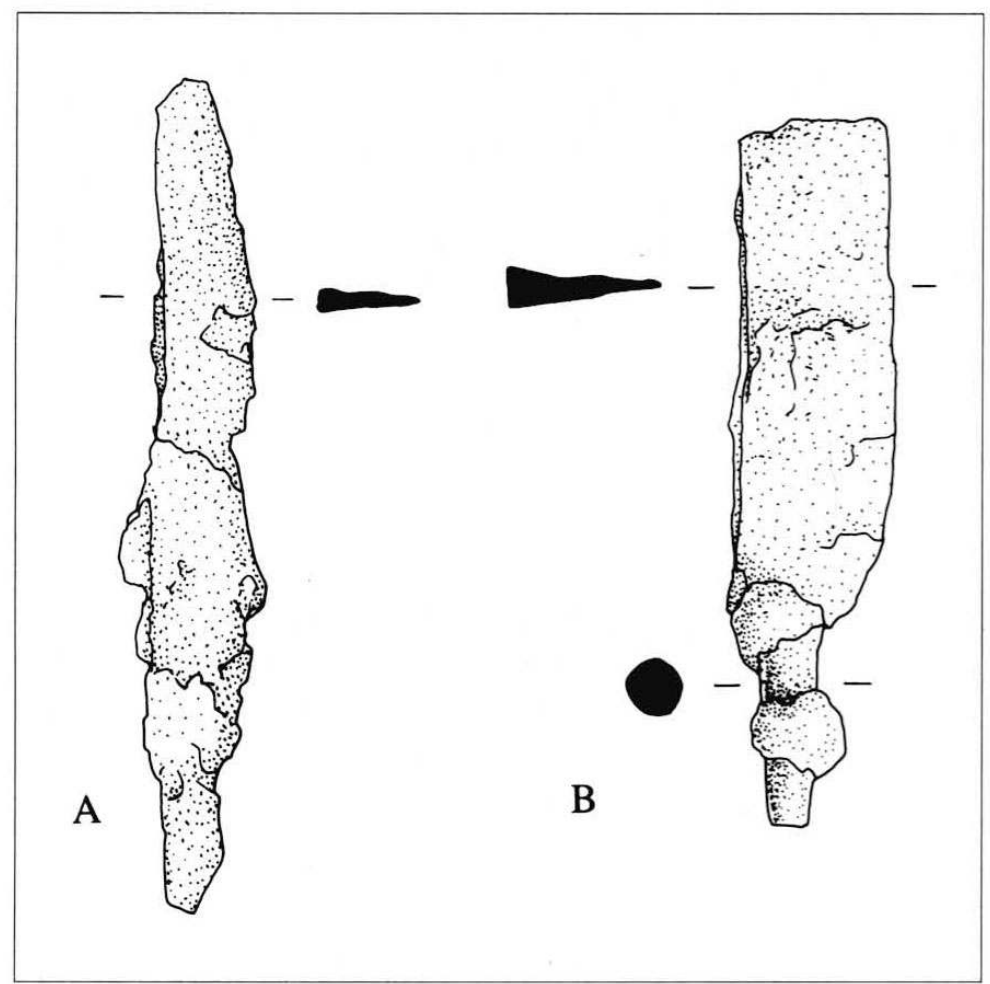

92 Louche (fig. 113, A)

fer. L : 17,5 cm, $1: 1,2 \mathrm{~cm}, 1,9 \mathrm{~cm}$, ép : 0,4 cm, XVIe s.

ustensile très détérioré : l'extrémité du manche et la plus grande partie du cuilleron manquent; celui-ci était hémisphérique $(D: 8 \mathrm{~cm})$; le manche est droit, de section rectangulaire, et s'élargit de la base au sommet. 
113 A : Louche

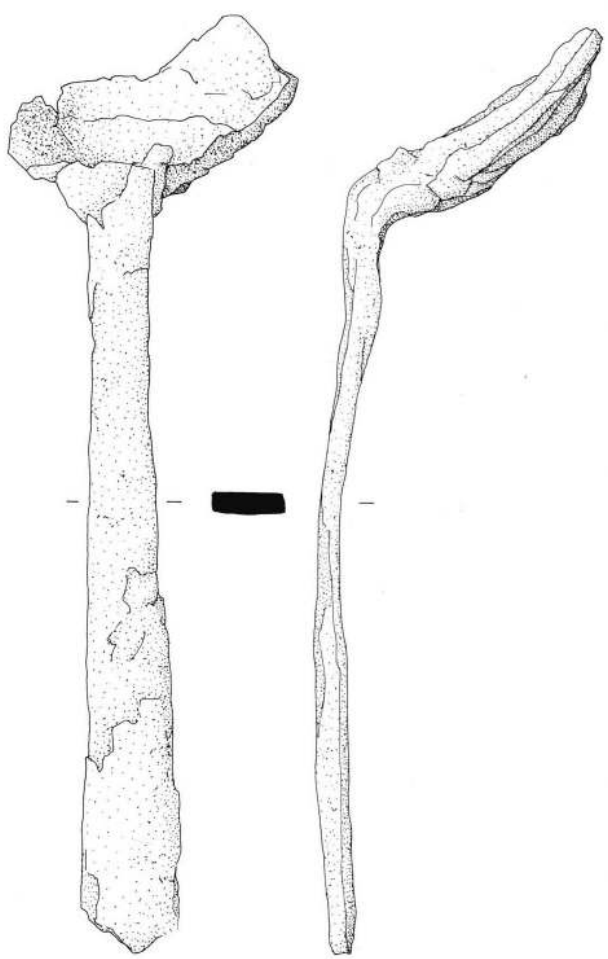

Fragment de coupelle (fig. 113, B)

bronze. L : $8 \mathrm{~cm}, 1: 3,2 \mathrm{~cm}$, ép : 0,1 cm, XVIe-XVIIe s.

fragment de bord d'une petite coupelle hémisphérique, dont la lèvre circulaire est obtenue par enroulement du bord.

\section{B : Coupelle}

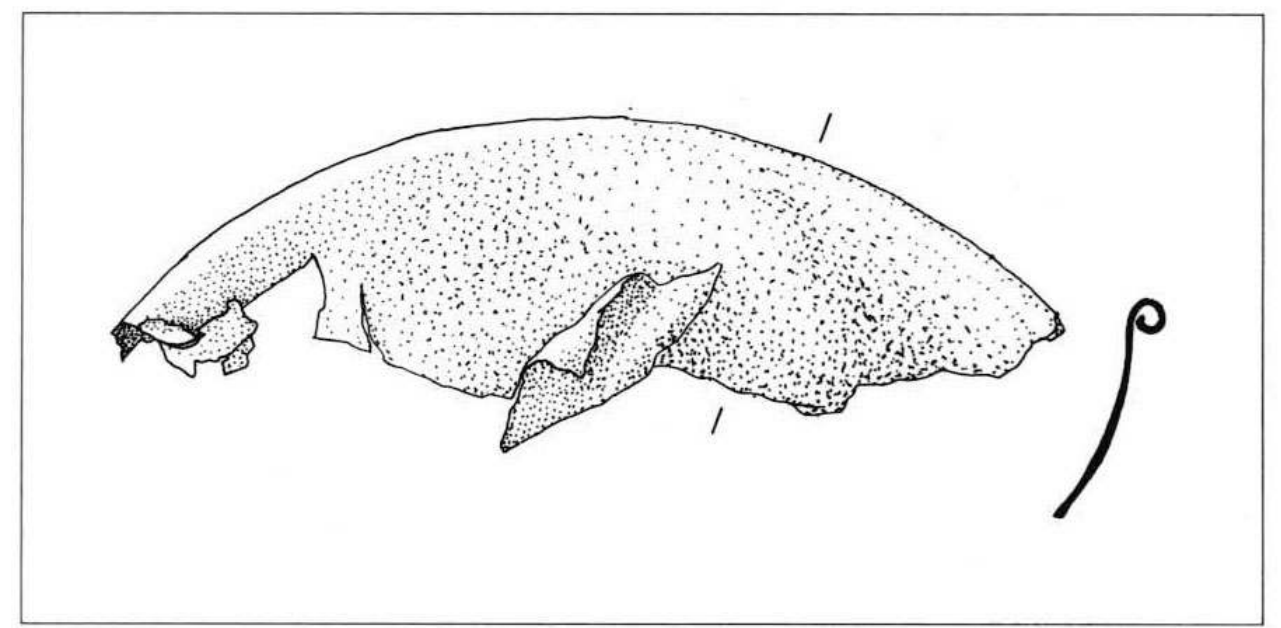

\section{Objets divers}

Comme le démontrent quelques objets, d'autres activités, étaient également pratiquées dans l'enceinte du château du Vuache: écritures, musique et jeux, mais aussi de dévotion, récitation de patenôtres. 


\section{fer. $\mathrm{L}: 5,5 \mathrm{~cm}, 1: 3,4 \mathrm{~cm}$, XVIe $\mathrm{s}$.}

tige de fer formant un anneau piriforme à base plate et à deux branches dont les extrémités, cassées, sont soudées par l'oxydation. Une languette de section rectangulaire est soudée à la base, sa vibration amplifiée par la bouche du joueur émettait le son désiré (A.H.M. 1977, nº 909, p. 477 ; Rieb-Salch 1973, n 146, p. 28).

Grelot (fig. 114, B)

fer. D : 2,5 cm, XVIe s.

sphère surmontée par un anneau de fixation cubique; l'oxydation masque une éventuelle ouverture de la sphère et celle de l'anneau.

Cheville d'instrument à corde ? (fig. 114, C)

os ou ivoire. $\mathrm{L}: 2,1 \mathrm{~cm}, 1: 1 \mathrm{~cm}, 0,3 \mathrm{~cm}, 1 \mathrm{~cm}$, XVIe s.

pièce rectangulaire, à profil composite, décoré de cupules; son revers est poli par l'usage ; la base cassée présentait une forme cylindrique. Cette interprétation comme cheville pour tendre les cordes d'un instrument de musique est cependant hypothétique.

114 : Instruments de musique

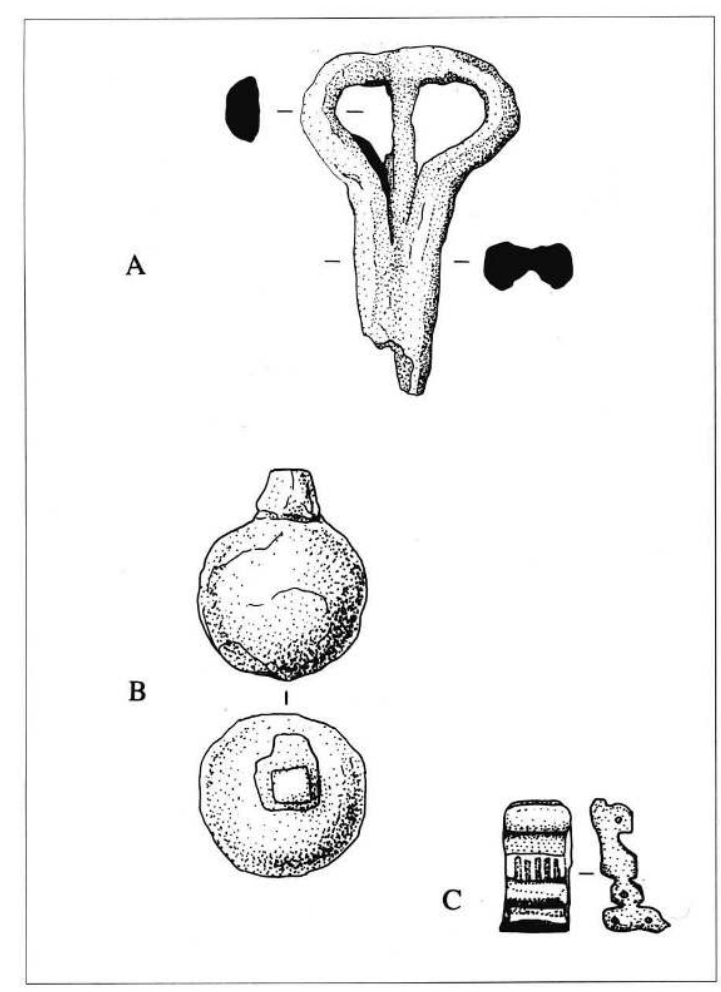

Dé de jeux (fig. 115, A) os. côté : 0,9 cm, XIIIe s. petit dé en os dont les ponctuations sont marquées par des cercles concentriques, système de numérotation moderne : la somme des faces opposées est égale à sept (Rieb-Salch 1973, n 115, p. 28).

Dé de jeux (fig. 115, B) os. côté : 0,8 cm, XVI-XVIIe s. petit dé en os dont les ponctuations sont marquées par des cupules, systéme de numérotation moderne (RiebSalch 1973, n 132, p. 28). 


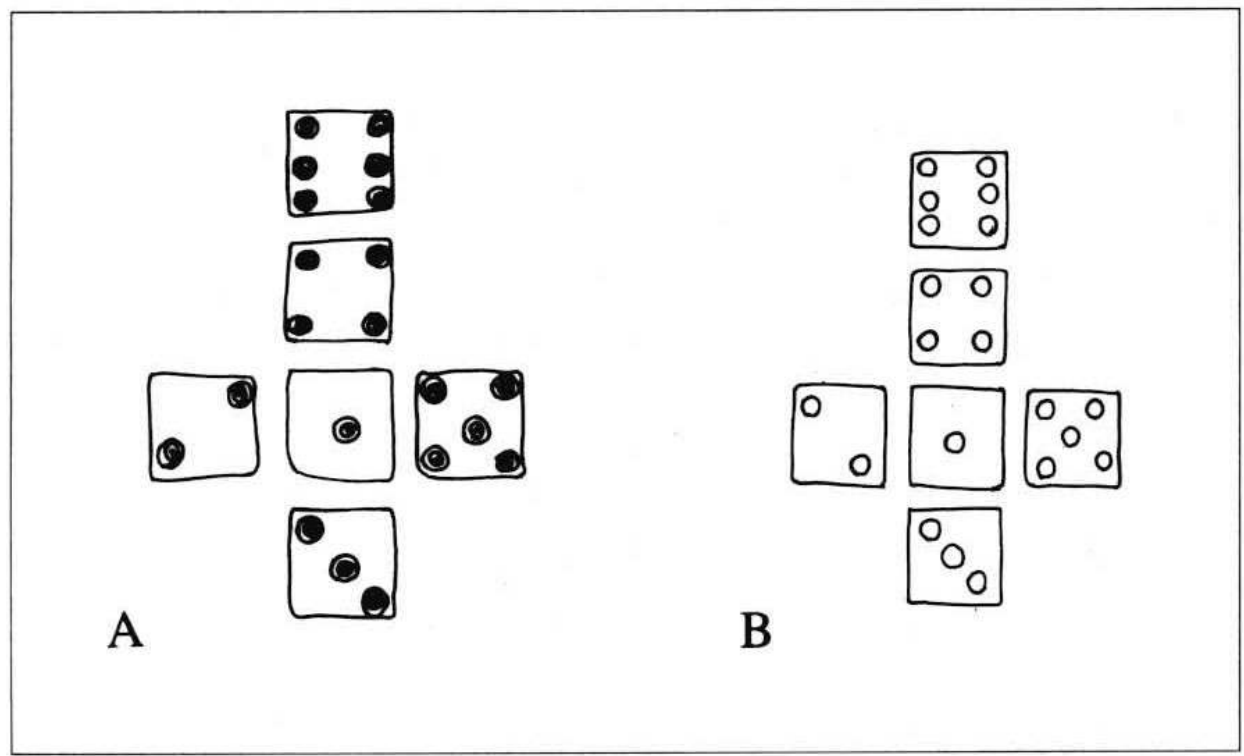

Fragment de chapelet (fig. 116)

os et bronze. $\mathrm{L}: 5 \mathrm{~cm}$, XVIe s.

quatre grains d'os $(\mathrm{D}: 0,8 \mathrm{~cm})$ décorés de profondes incisions obliques et de fines rainures perpendiculaires à la perforation, montés sur des maillons de fil de bronze torsadé (D : 0,5 mm) formant deux anneaux de part et d'autre de la perle, la torsade étant cachée à l'intérieur (Rieb-Salch 1973, n² 249, p. 45).

116 : Chapelet

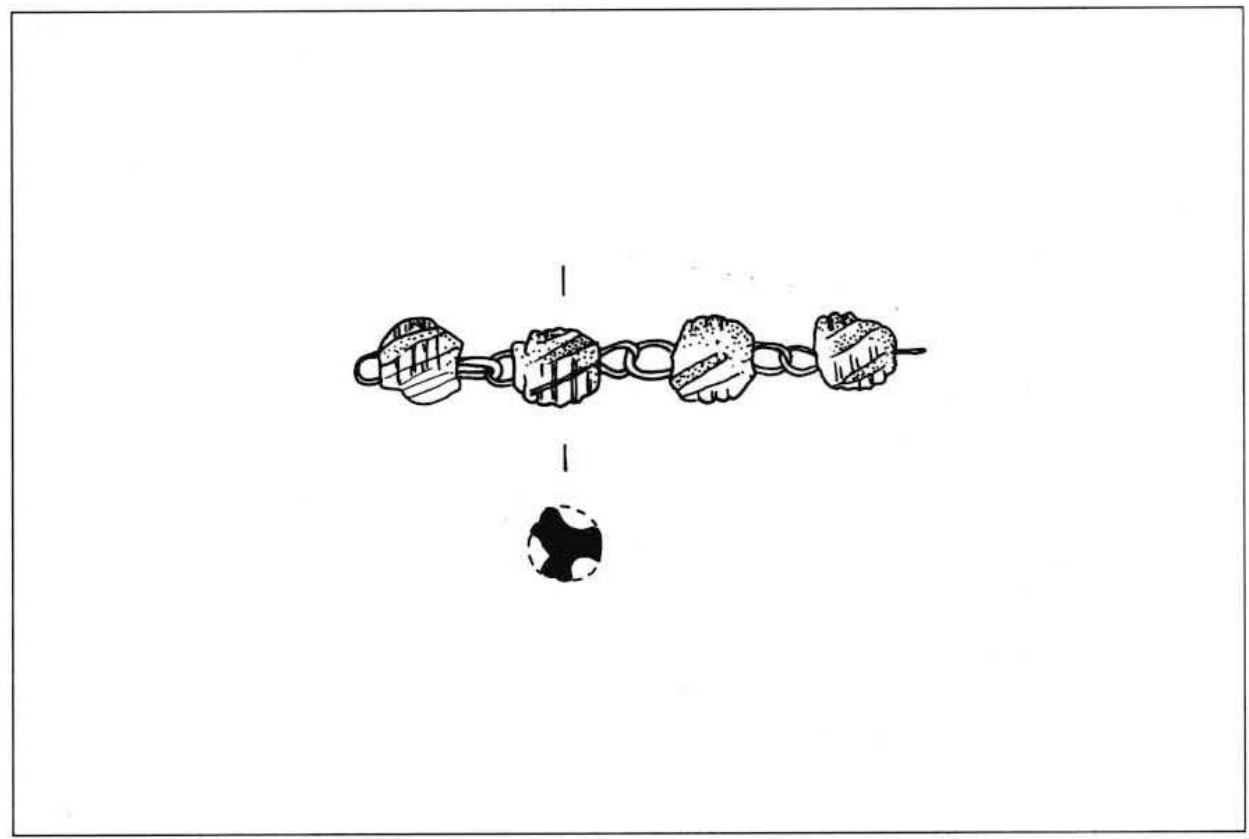

Sceau matrice (fig. 117)

bronze. $\mathrm{H}: 2,1 \mathrm{~cm}, \mathrm{D}: 2 \mathrm{~cm}$, XVIe s.

petit sceau circulaire à corps piriforme surmonté d'un anneau de préhension, avec dans 
le champ, les initiales PC surmontées d'une croix ; entouré de la légende inversée :«+ S(igillum) PETRI DE CUVAT X » (Medieval Catalogue 1954, fig. 90, p. 295).

117 : Sceau matrice

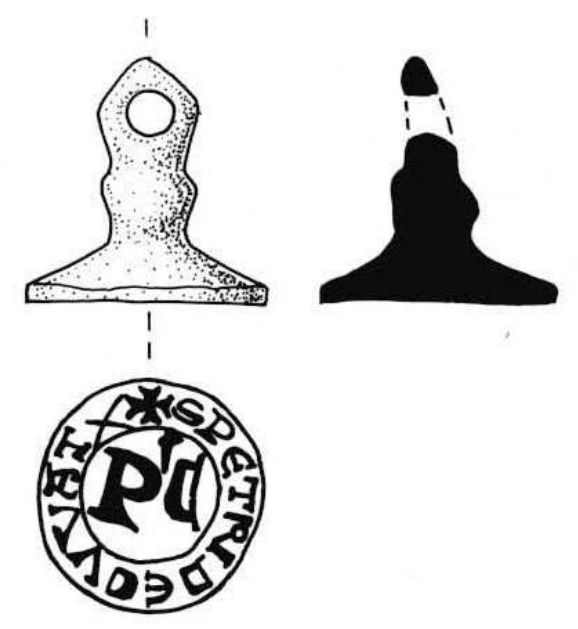

\section{Les monnaies}

102 Un lot de 16 monnaies a été collecté lors des fouilles L'ensemble de la période d'occupation est représenté du XIIIe au XVIIe s. Il s'agit essentiellement de monnaies seigneuriales ${ }^{20}$.

\section{XIIle siècle?}

1 : Evêché de Genève

Denier anonyme, Genève, XIIIe s.-XVe s.

S.C P E T R V S

tête à gauche

+ GENEVAS

croix pattée cantonnée d'un $\mathrm{S}$ au 1 et d'un besant au 4 .

argent ; $17 \mathrm{~mm}$. Poids : 0,7 g.

Martin, 1965, p. 25.

zone 2, prise dans le mortier du mur M 25 (fig. 118).

\section{XIVe siècle}

2 : Baronnie de Vaud

Louis 11(1302-1350)

Obole, Nyon, 1302-1350

LVD (OVICVS)

croix pattée cantonnée d'un trèfle au 2 et d'un besant au 3. 
(+DE SABAVDI) A

temple tétrastyle

argent ; $12 \mathrm{~mm}$. Poids : 0,3 g.

Martin 1989, p. 129, n 16,13

zone 8 sond.1, C. 803

1053 : Baronnie de Vaud

Louis II (1302-1350)

Obole, Nyon, 1302-1350

+ LVDOVICV(S)

croix pattée, cantonnée d'un tréfle au 2 et d'un besant au 3.

(+ DESABA VDI)A, trois points superposés

temple tétrastyle

argent ; 13 mm..Poids : 0,3 g.

Martin 1989, p. 129, $\mathrm{n}^{\circ} 16,13$

(zone 1, aire A, sond. 1, couche d'occupation C. 103 (fig. 118).

1064 : Comté de Genevois ;

Amédée III(1320-1365)

Denier, Annecy, 1360-1362

(+ A M) E D E V S (C O M E S)

croix formée de quatre billettes dans un quadrilobe.

(+ G E B) EN (N) E N S I S

écu dans un quadrilobe

argent ; $15 \mathrm{~mm}$. Poids : 0,2 g.

Demole 1883, p. 20-21 du tiré-à-part, $n^{\circ} 5$, pl.1 et 6

Lebascle 1986, p. 36, (5)

zone 8, sond.1, C. 803

1075 : Comté de Genevois

Pierre (1374-1391)

Denier, Annecy, 1374-1391

+ P(E T R)V S : C (O) M E S

croix formée de quatre billettes dans un quadrilobe.

+ GE B (E N) N E)N S I S

écu dans un quadrilobe

argent ; $15 \mathrm{~mm}$. Poids : 0,6 g.

Demole 1883, p. 23 du tiré-à-part, $n^{\circ} 8$, pl. 2 et 8

Lebascle 1986, p. 37

zone 8 , sond. 1, couche d'occupation C 803 (fig. 118)

\section{XVe siècle}

6 : Duché de Bourgogne

Philippe le Bon, (1419-1467)

Double tournois, Auxonne? 1421-1423

(+ P)8DVX8ET8COMES8BVR (G)

armes de Bourgogne nouveau couvrant le champ.

+ DVPLEX8TVRONVS8B V(R)

croix pattée 
billon ; $22 \mathrm{~mm}$. Poids : $1,5 \mathrm{~g}$.

Dumas-Dubourg 1988, n 15-10-1

zone 2, hors stratigraphie (fig. 118)

7 : Duché de Bourgogne

Philippe le Bon (1419-1467)

Engrogne, Auxonne, 1420-1423 ou 1446

+ (PHS) :DVX :ET :CO(ME)S :BVRGODI

armes aux sept quartiers couvrant le champ

+ (A N)S ERNA( :D :)E :AVXONNA

croix pattée cantonnée de deux lions, et de deux lis.

billon ; $21 \mathrm{~mm}$. Poids : 0,65 g.

Dumas-Dubourg 1988, $\mathrm{n}^{\circ}$ 15-13

zone 4, couche de démolition C. 401 (fig. 118)

1108 : Evêché de Lausanne

Benoît de Montferrand (1476-1491)

Denier, Lausanne, 1476-1491

(+BoD)oMONTE(FAoEPSoLA)

écu dans un trilobe

+ (A)VE (oMARIAoGRAoPLE)

croix fleurdelisée

billon ; $15 \mathrm{~mm}$. Poids : 0,65 g

Dolivo $1961, \mathrm{n}^{\circ} 74$

Zone 3, hors stratigraphie.

\section{XVle siècle}

1119 : Evêché de Lausanne

Sébastien de Montfaucon (1517-1536)

Denier, Lausanne, 1517-1536

o (+ S E B) A (S TIA N V S) o D

écu posé sur une crosse

+ MONET(ALAVS)AN

croix fleurdelisée

billon ; $16 \mathrm{~mm}$. Poids : 0,6 g

Dolivo 1961, $\mathrm{n}^{\circ} 98$

zone 1, aire A, couche d'occupation,C 103 (fig. 118).

10 : Duché de Savoie

Emmanuel-Philibert (1553-1580)

Quart de gros, Aoste, Octobre 1544 et Février 1559

+ E :PHILIBER :DVX :SABAV

F E R T entre deux doubles traits

+ ET :AVG :PRETORIE :N. V.

croix tréflée

billon ; $17 \mathrm{~mm}$. Poids : 0,8 g.

Simonetti 1967, p. 64,2)

zone 4 , sur sol C. 404 (fig. 118). 


\section{XVle - XVIle siècle}

11311 : Duché de Savoie

Charles Emmanuel I (1580-1630)

Quart de gros,Chambéry ou Gex, 1580-1587

sans légende

C E couronné et trois roses dans le champ

sans légende

croix tréflée dans un quadrilobe cantonné de points,

cuivre ; $14 \mathrm{~mm}$. Poids : 0,7 g.

Simonetti 1967, $\mathrm{n}^{\circ} 83,3$ à 5

zone 5 , aire C, sond. 4, couche de démolition C. 144 fig. 118).

11412 : Duché de Lorraine

Charles III (1545-1608)

Quart de plaque ou denier de Nancy, contremarqué vers 1621

(+ C A R O. ) D. G. L O T(A R.B.DV X)

écu couronné

(+ M O N E T A. F A) C T A.N A N

épée en pal ; contremarque à l'alèrion au revers.

billon : $15 \mathrm{~mm}$. Poids : 0,4 g.

de Saulcy 1841, pl. XVIII, 6

zone 1 , aire $\mathrm{B}$, hors stratigraphie

11513 : monnaie non identifiée (XVe-XVIe s. ?)

(+) DENAR()

type non visible

(+). CIVITA (S) R()

croix pattée

billon ; 16 mm.Poids : 0,5 g.

zone 1, aire A, couche de démolition, C 102 (fig. 118). 


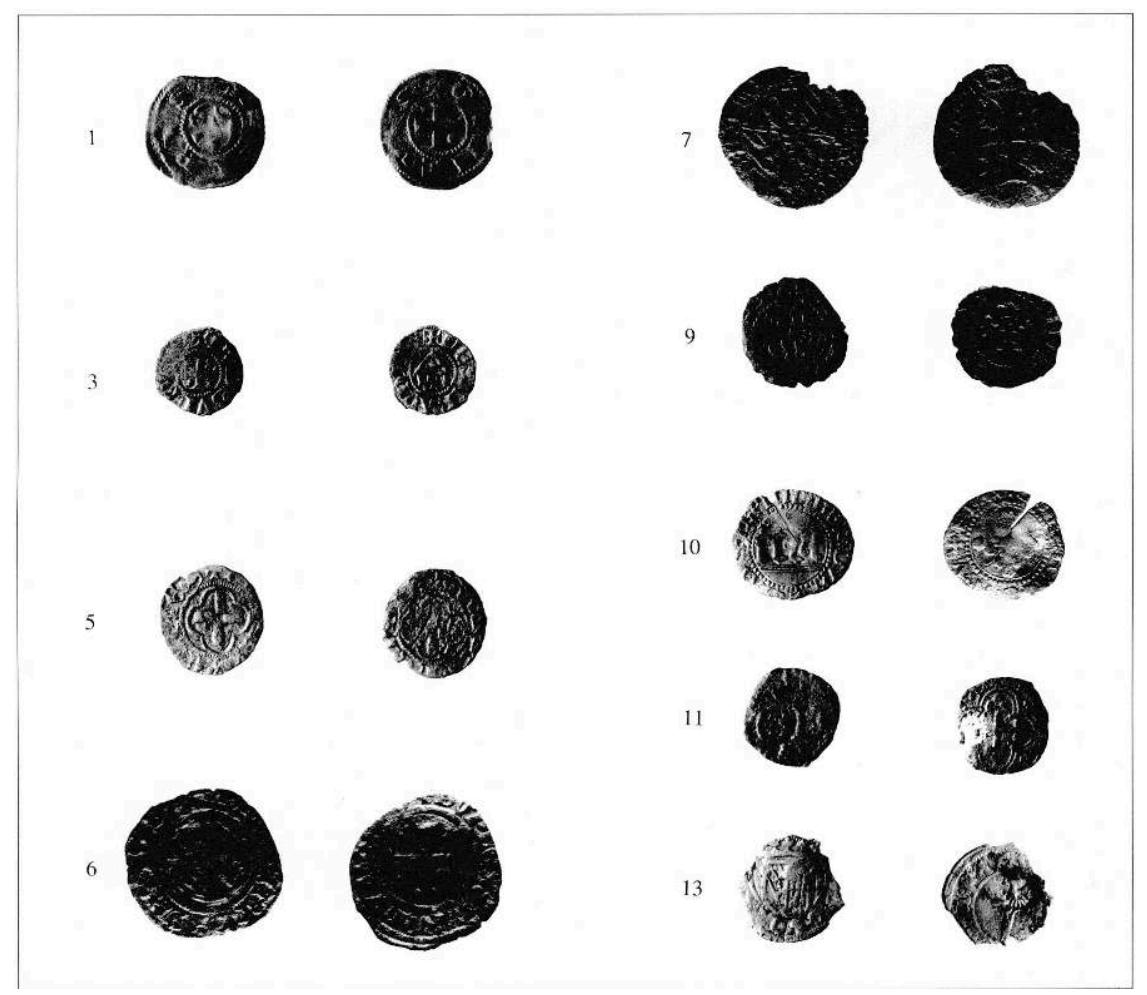

\section{NOTES}

18. L'ensemble du matériel découvert au château du Vuache a été déposé au musée d'Annecy, où certaines pièces feront l'objet d'une présentation publique.

19. Notice rédigée à partir de l'étude de la bague par E. Taburet-Delahaye, conservateur au département des Objets d'Art du Musée du Louvre.

20. L'identification des monnaies a été faite par M. Dhenin (Bibliothèque Nationale). 


\title{
Annexe 2. La vaisselle de terre
}

\author{
Bruna Maccari-Poisson
}

1 Les sondages archéologiques effectués sur le site du château du Vuache ont restitué un mobilier céramique peu abondant et qui ne documente pas toutes les périodes d'occupation. L'ensemble du matériel est constitué de 768 fragments répartis de façon fort disproportionnée en cinq groupes (fig. 119) :

119 : Répartition des types céramiques

\begin{tabular}{|c|c|c|c|c|c|}
\hline \multicolumn{3}{|c|}{ Céramique Médiévale } & \multicolumn{3}{c|}{ Céramique Moderne } \\
\hline $\mathrm{A}$ & $\mathrm{B}$ & $\mathrm{C}$ & $\mathrm{D}$ & $\mathrm{E}$ & Divers \\
\hline $2,70 \%$ & $4,40 \%$ & $9,20 \%$ & $9,00 \%$ & $73,70 \%$ & $1,00 \%$ \\
\hline
\end{tabular}

- Céramique à pâte grise, sans revêtement.

- Céramique à pâte rouge, sans revêtement.

- Céramique à pâte rouge, décorée sous glaçure parsemée incolore.

- Céramique à pâte rouge décorée ou non sous glaçure couvrante incolore (imitation de faïence?).

- Céramique à pâte blanche et glaçure verte.

2 La faiblesse de l'échantillonnage est toutefois compensée par la précision des critères de datation apportés par la fouille et l'étude historique menée en parallèle. Ainsi est-il possible, désormais, de mieux apprécier la chronologie de deux catégories de vaisselle bien répandues dans la région Rhône-Alpes : la céramique médiévale très décorée et les poteries à glaçure verte sur pâte blanche du début de l'époque moderne. Le mobilier du Vuache comble quelques-uns des inévitables hiatus d'une chronologie régionale établie au fur et à mesure de découvertes ponctuelles.

En ce qui concerne l'époque médiévale, les seules couches qui aient restitué un mobilier suffisamment significatif sont datées du XIVe s. (C. 447, 805 et 4013). A côté d'un groupe de fragments sans revêtement, non identifiables ( 52 tessons en pâte grise ou bistre), se signalent surtout deux fragments de cruche partiellement recouverts de glaçure incolore et décorés de bandes de barbotine molettée et de pastilles en relief (fig. 120). 


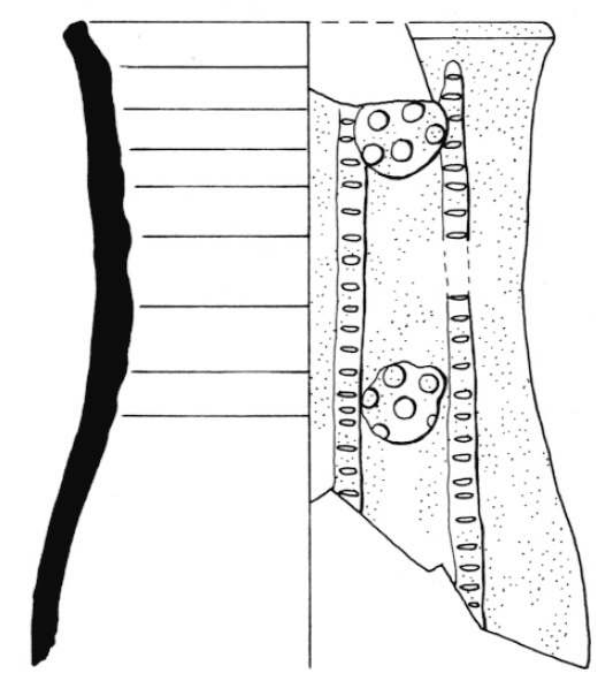

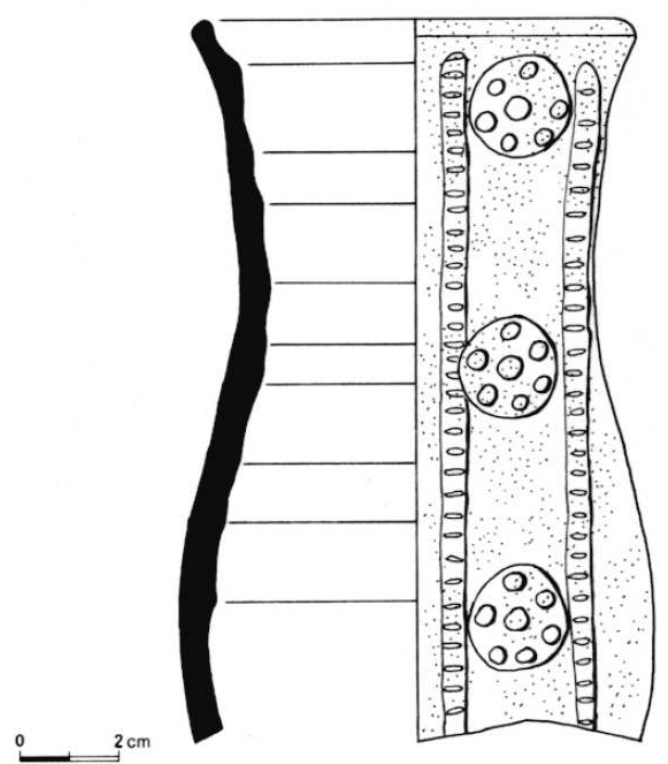

4 La pâte rouge est assez grossière et comporte quelques inclusions blanches. Le revêtement vitreux est granuleux et disposé très irrégulièrement, par taches éparses, sans recouvrir toute la surface. Les fragments conservés permettent d'imaginer la silhouette d'un profil ovoïde, probablement monté sur un fond étroit. Le col, haut et presque cylindrique, se poursuit sans interruption jusqu'au rebord qui se termine par une lèvre légèrement concave à l'intérieur (diamètre maximum : 9,6/11 cm; diamètre ouverture : $9 / 10 \mathrm{~cm}$; épaisseur : environ $0,6 \mathrm{~cm}$ ).

5 Le type de décor et le profil de ces pichets se rapprochent étroitement d'un ensemble de vases retrouvé à Anse dans le Rhône lors des fouilles du château des Tours (Vicard, 1984). L'étude du mobilier d'Anse propose, pour ce type de pichet (type 2), une datation du milieu à la fin du XIIIe s., sur la base des trouvailles monétaires associées et des analyses dendrochronologiques. En revanche, cette même production semble avoir disparu, à Anse, dans le matériel attribuable au XIVe s.

La découverte de deux exemplaires semblables dans les sondages du château du Vuache soulève le problème de la datation des productions de ce type. Les éléments de datation apportés par ce nouveau site situent, en effet, ce matériel en plein XIVe s.

7 Sans doute l'ensemble des pichets d'Anse correspond-t-il à l'apparition et à la période de forte diffusion des poteries très décorées. Le site de Vulbens a, d'ailleurs, restitué quelques petits fragments de cette catégorie de récipients dans les couches d'occupation du XIIIe s. (3 tessons dans la C. 907). Mais, il faut désormais envisager que leur utilisation se soit prolongée dans le temps, au moins dans une partie du XIVe..

Certes, plusieurs éléments interviennent pour nuancer cette hypothèse, sans pour autant remettre en cause les datations fournies par les deux sites. Tout d'abord l'éloignement des deux lieux de découverte; d'apparence très proche, ces vases peuvent provenir d'ateliers distincts, le second imitant formes et décors de poteries qui, ailleurs, ont déjà cessé d'être fabriquées. Seule la comparaison de la composition des pâtes céramiques entre les lots permettra d'avancer sur ce sujet. 
Pour le moment on se contentera de souligner que le petit ensemble du Vuache fournit de nouvelles données dont il faudra tenir compte dans les études futures sur les céramiques très décorées du Moyen Age, afin de nuancer, voire d'affiner, la datation d'autres trouvailles de ce type de production dans notre région comme celles de Vienne, dans l'Isère (Tardieu, 1986), ou celles des fouilles du métro à Lyon, dont l'étude est en cours.

Dans le remblai de la tranchée de fondation de l'escalier à vis, construit à la fin du XVe ou au début du XVIe s., ont été retrouvées deux formes céramiques complètement brûlées qui correspondent à deux vases de type albarello (fig. 121). Ces poteries de forme cylindrique, à fond plat, présentent en leur milieu un léger étranglement pour en faciliter la préhension; un bourrelet ourle l'ouverture, permettant de ficeler le parchemin ou le tissu qui servait de couvercle; du moins ceci était l'intention d'origine. En plus de leur forme caractéristique, les albarelli sont généralement décorés sur un fond d'émail blanc et appartiennent à ce type de production traditionnellement appelée « faïence ».

121 : Albarelli en faïence

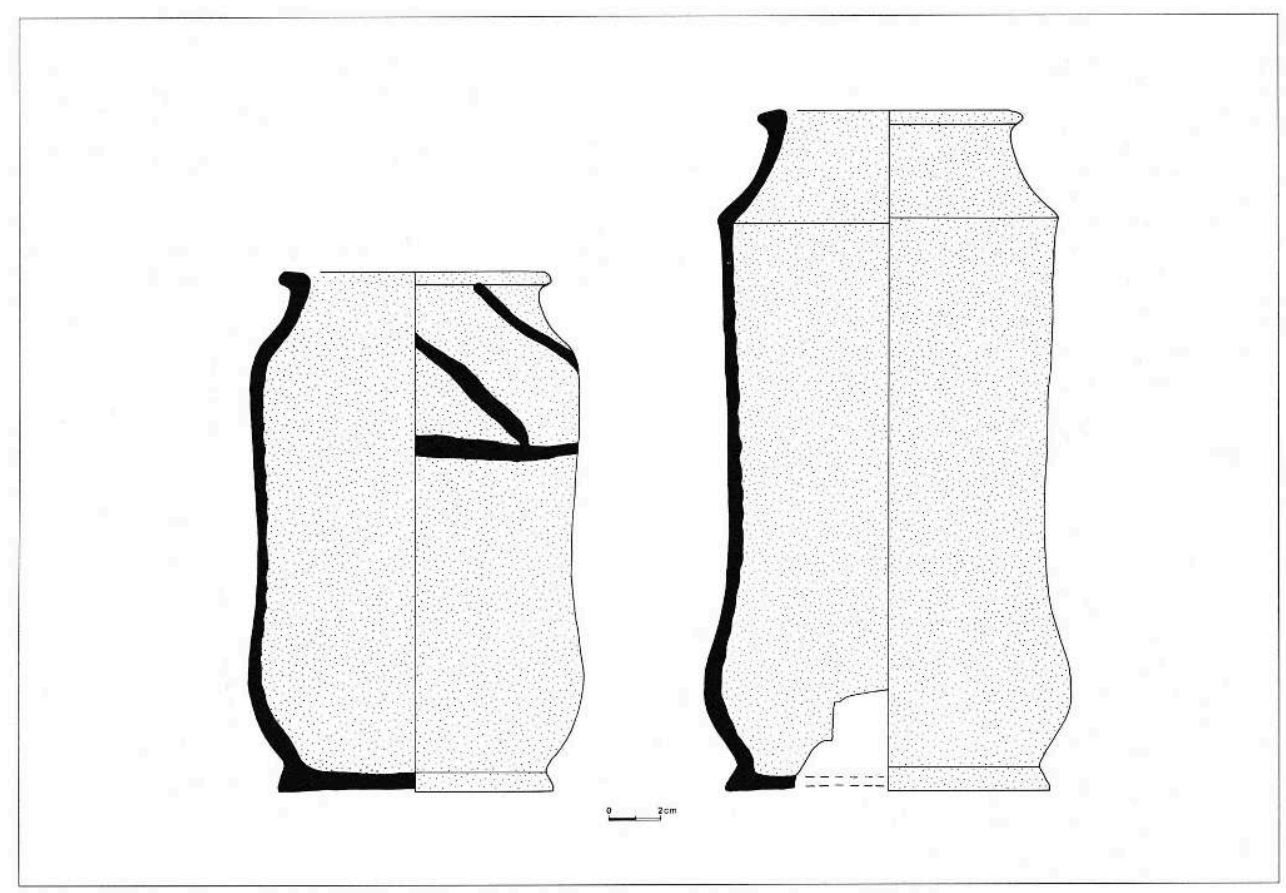

11 Les exemplaires issus des fouilles du château du Vuache ne sont cependant pas des faïences, mais veulent probablement les imiter, puisque la forme est bien typique. Le revêtement, interne et externe, est constitué d'une glaçure couvrante incolore, sans aucune adjonction d'étain qui permettrait d'obtenir le fond blanc opaque des faïences. De ce fait, le rouge de la pâte apparaît sous la glaçure lui donnant une coloration légèrement orangée. Le plus petit des deux récipients $(\mathrm{h}: 20 \mathrm{~cm})$ est décoré sur le haut de la panse de larges bandes obliques en brun, délimitées par une bande horizontale, toujours en brun. Le deuxième, plus haut $(\mathrm{h}: 26 \mathrm{~cm})$ semble n'avoir jamais eu de décor, ou du moins il a totalement disparu : les fragments sont fortement norcis et altérés par le feu. Ces deux albarelli sont chronologiquement antérieurs à 1536, date de l'incendie du château, mais rien n'exclut qu'ils soient un peu plus anciens. Des publications 
récentes montrent que les potiers tradionnels ont largement contribué à répandre l'usage de l'albarello, concurrençant ainsi les faïenciers. Une impressionnante série du XVIe s. a, par exemple, été mise au jour à Paris (thermes de Cluny). Il s'agit de grésou de terre cuite vernissée (Ravoire, 1991).

Le dernier groupe de céramiques restitué par les fouilles est de loin le plus nombreux. Dans les couches correspondant à l'occupation qui se situe entre 1536 et 1612, ont été mis au jour 565 fragments d'une production très homogène : céramiques en pâte très claire presque blanche, toujours recouvertes d'une glaçure verte très brillante, de couleur vive. Bien que souvent fragmentaires, plusieurs formes ont pu être restituées et, sauf rares exceptions, elles correspondent à des poteries culinaires.

Les formes les plus répandues sont la petite marmite tripode dont les deux anses opposéees partent de la lèvre (fig. $\mathbf{1 2 2}, \mathbf{n}^{\circ} \mathbf{1}$ ) et le coquemar avec une seule anse placée au milieu de la panse (fig. 122, $\mathbf{n}^{\circ}$ 2). Dans tous les cas la lèvre est évasée et la panse globulaire. Les trois petits supports excentrés sont associés à un fond plat ou bombé. La glaçure ne recouvre intégralement que la surface interne.

Le deuxième type correspond à des pots à cuire de plus grande taille, tous fragmentaires (fig. 122, $n^{\circ}$ 3). L'anse, posée contre la lèvre évasée, est généralement de section ronde et de profil anguleux, formant une sorte d'anneau. Parfois la panse est renforçée par des cordons verticaux, mais ce détail n'est pas présent sur tous les exemplaires de grandes marmites.

Plus rares, presque exceptionnelles, sont les autre formes: deux fragments attestent l'existence de bols et on constate aussi la présence de couvercles.

\section{2 : Céramiques culinaires en pâte blanche et à glaçure verte}
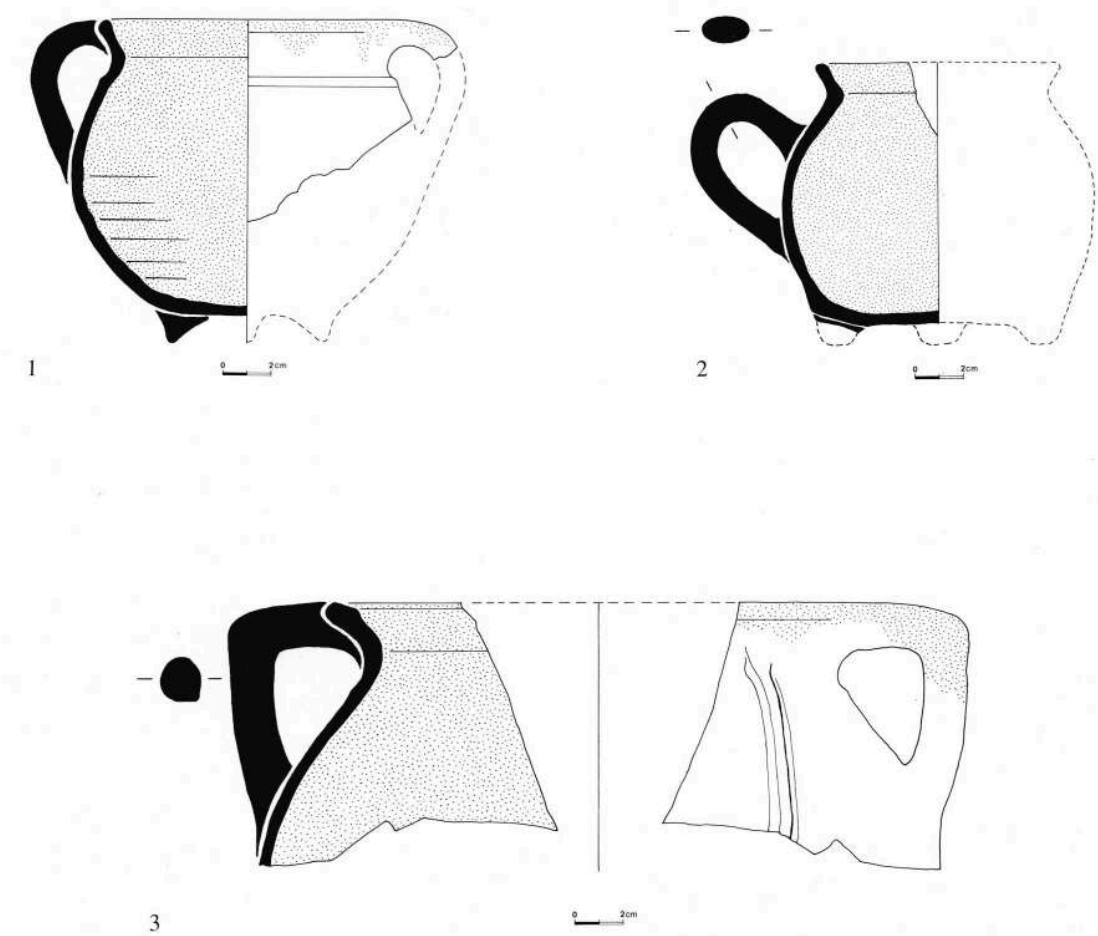

Les poteries en pâte blanche et glaçure verte sont très répandues dans la région RhôneAlpes, notamment au nord-est de Lyon et, depuis plusieurs années, elles font l'objet 
d'une étude de synthèse par les chercheurs régionaux (programme H 19: ateliers céramiques médiévaux et modernes de la région Rhône-Alpes). Inventaires, prospections et analyses de composition des pâtes ont démontré la communauté d'origine de ce type de vaisselle, le « service vert ", largement diffusé à partir d'ateliers très actifs implantés à Meillonnas au nord-est de Bourg-en-Bresse, dans l'Ain (A la fortune du pot, 1990, pp. 193-198 $)^{21}$. Les nombreuses trouvailles régionales ne fournissent en réalité que peu d'éléments de datation. Seules les fouilles du Vuache et celles de plusieurs sites lyonnais permettent actuellement de préciser la chronologie de ce type de production ${ }^{22}$. D'où l'intérêt de la documentation fournie par ces sites, dont le mobilier est issu d'un même centre de production ${ }^{23}$.

17 La possibilité de comparer les céramiques de Vulbens et celles de Lyon permet de mieux saisir la durée de leur diffusion et d'entrevoir, en même temps, une évolution dans la typologie des formes. À Lyon, on trouve une abondance de formes ouvertes pour la table, tandis qu'elles sont quasiment absentes en Savoie; il est d'autant plus intéressant de noter que cela correspond à un léger décalage chronologique. Les fouilles du Vuache proposent une datation entre 1536 et 1612, tandis que le matériel lyonnais est attribuable à la première moitié du XVIIe s. Les différences typologiques observées ne sont donc pas uniquement imputables à la nature différente des lieux d'utilisation : poste militaire excentré et milieu urbain. On peut envisager la possibilité que les ateliers aient d'abord produit des poteries culinaires et que la vaisselle de table ne soit apparue que plus tardivement.

Que ce soit pour la céramique de table très décorée du Moyen Âge ou pour le « service vert » bien diversifié de l'époque moderne, le château du Vuache à Vulbens fournit, à partir d'un lot certes restreint, des comparaisons et des critères de datation qui font notablement progresser notre connaissance de la céramique régionale.

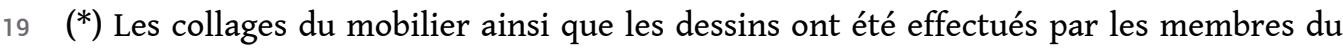
projet collectif de recherche mentionné ci-dessus.

\section{NOTES}

21. Sous la direction d'E. Faure-Boucharlat, conservateur du patrimoine, ce groupe se propose de mettre en commun les études des chercheurs dans différents domaines de la céramologie et bénéficie du soutien de C.S.R.A. dans le cadre du programme H 19. Le programme de recherche sur les céramiques connues également sous le nom de "service vert" est pratiquement achevé et sera publié très prochainement.

22. Fouilles du Métro sous la direction de F. Villedieu, puis J. Burnouf ; fouilles de la Z.A.C. SaintVincent sous la direction de J. P. Lascoux; fouilles de la place A. Poncet sous la direction de C. Becker.

23. Les analyses effectuées par le laboratoire de Céramologie de Lyon (U.R.A. 3 du C.N.R.S.) ont confirmé que la composition des pâtes céramique de Lyon et Vulbens présente de telles similitudes qu'il s'agit sans doute de productions d'un même atelier, ou du moins d'un même centre de potiers. 


\title{
Annexe 3. La vaisselle de verre
}

\author{
Danielle Foy
}

15009 fragments de verre ont été recueillis. Ce sont essentiellement des débris de gobeleterie puisque 86 pièces seulement sont des verres à vitre ; ils sont très oxydés, et de ce fait leur teinte d'origine n'est pas toujours perceptible. Il semble pourtant que la plupart soient non colorés ; la teinte bleue est reconnaissable sur 4 fragments au moins. L'aspect noirâtre de ces verres plats qui se délitent, contraste avec la matière des verres creux. Ceuxci presque toujours incolores, on gardé leur transparence et leur brillance. Aucune analyse ne nous permet de connaître la composition des verres, mais l'état de conservation laisse penser que le verre plat est potassique et la gobeleterie sodique. Il reste bien sûr à vérifier ces intuitions.

2 Le matériel est inégalement réparti sur le site ; l'essentiel provient de quatre zones et plus particulièrement de la couche 155 qui renfermait plus de $50 \%$ de l'ensemble comme le montre le tableau ci-dessous. 


\begin{tabular}{|c|c|c|}
\hline $\mathrm{N}^{\circ}$ couches & fragments gobeleterie & fragments verre à vitre \\
\hline 155 & 2498 & \\
805 & 1031 & 6 \\
1103 & 612 & \\
5006 & 302 & \\
145 & 186 & 31 \\
217 & 74 & 33 \\
803 & 70 & 17 \\
103 & 62 & \\
143 & 57 & \\
102 & 12 & \\
403 & 6 & \\
147 & 6 & \\
414 & 4 & \\
401 & 1 & \\
\cline { 2 - 3 } & 4921 & \\
\hline
\end{tabular}

3 Les différents lots de verre ne se différencient guère, à l'exception de l'ensemble de la couche 805 qui, homogène, semble dater du XIVe s. D'autres débris médiévaux apparaissent dans d'autres contextes, mais ceux-ci renferment surtout du matériel attribuable au XVIe s. C'est à cette période qu'appartient l'essentiel des verres exhumés. Seules deux ou trois pièces pourraient être plus tardives (première moitié du XVIIe s. ?).

4 Les recollages entre les différents contextes sont exceptionnels : c'est en partie dû à la répétition des mêmes formes sur tout le site et à l'extrême fragmentation des verres. On a souvent observé l'éparpillement d'une bouteille du XIVe s. entre les couches 803 et 805. Cet état de conservation a aussi rendu difficile l'identification des objets. De nombreux tessons ne peuvent être attribués à des formes précises. A partir des 4921 débris nous n'avons pu individualiser que 152 objets; la majorité d'entre eux étant reconnus par plusieurs éléments.

5 Les pièces les plus complètes $\left(n^{\circ} 15,25,32,38,49\right.$ et 67$)$ ont déjà été publiées et montrées au public (Foy, 1989 : catalogue de l'exposition; A Travers....notices 261, 271, $276,302,329,337)$.

$6 \quad$ Afin d'éviter les répétitions, nous avons opté pour une présentation par type de verre. Un tableau récapitulatif (fig. 123 a, b, c) permet cependant d'évaluer la richesse de chacun des contextes. Les illustrations respectent elles aussi le lieu de découverte puisque chaque planche regroupe les verres issus d'une même couche stratigraphique ; les objets ont néanmoins été aussi ordonnés en fonctions de leur forme (les planches, avec les objets numérotés, sont regroupées en fin d'annexe p. 116 à 126). 


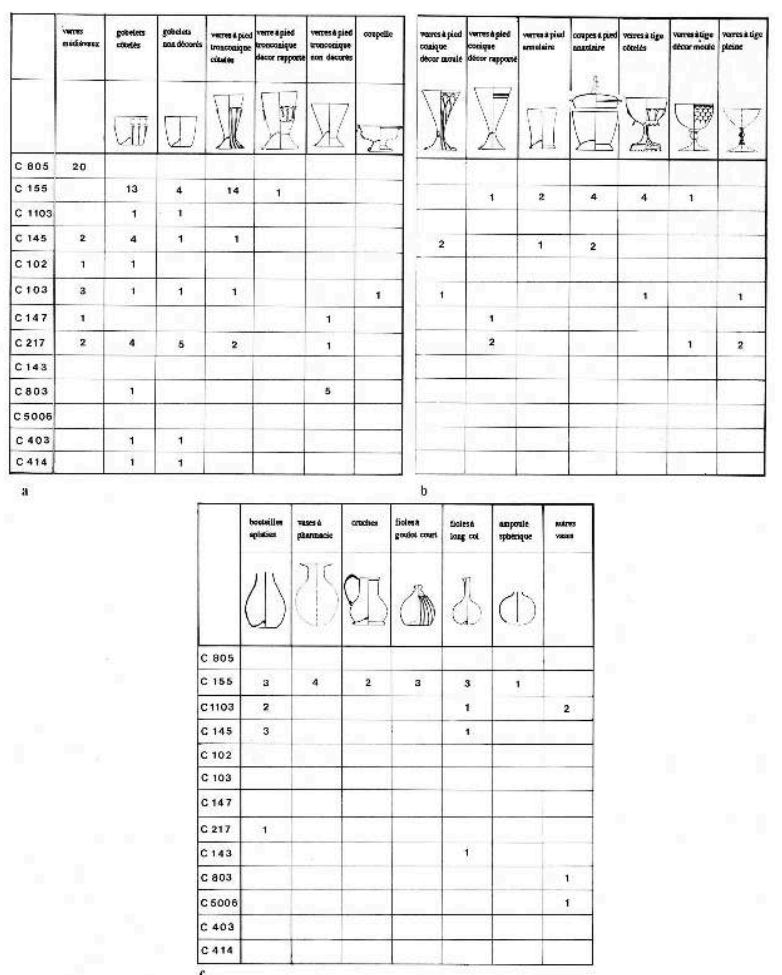

\section{Les verres médiévaux}

7 Le lot le plus ancien provient de la couche d'occupation d'une petite tour (zone 8, C. 805). Les 1031 fragments n'ont permis d'identifier qu'une vingtaine de pièces, pour la plupart des verres à boire réalisés dans une matière très fine qui a gardé sa transparence. Quelques débris seulement sont opaques.

8 Le gobelet à décor moulé domine. Quinze exemplaires ont été dénombrés à partir des fonds. Les pastilles ovales losangées ou rondes forment une trame lâche ou serrée sur les parois verticales ou très légèrement inclinées $\left(n^{\circ} 5,1,2,6,9,10,11\right)$. Ce décor, obtenu au moule, apparaît sur le pourtour du fond et couvre la pièce jusqu'à $20 \mathrm{~mm}$ environ du rebord. Aucun profil n'a pu être complètement restitué. L'étude graphique suggère cependant des pièces élancées: leur hauteur avoisine les $70 \mathrm{~mm}$; les fonds varient de 50 à $60 \mathrm{~mm}$ de diamètre et les embouchures de 75 à $80 \mathrm{~mm}$, ce qui donne un profil presque cylindrique.

Plus rares sont les gobelets nervurés $\left(n^{\circ} 5\right)$. $D^{\prime}$ autres avaient en guise de lèvre un fil bleu rapporté, qui fait aussi office de décor $\left(n^{\circ} 13\right)$. Onze fragments de rebord ont cette ornementation; nous ne savons pas si elle était associée à des motifs moulés. L'absence de fonds pouvant être sûrement associés à ces débris n'autorise aucune estimation numérique.

Un gobelet à décor de gouttes de verre rapportées a été reconnu. Trois éléments pourraient faire partie de la même pièce : un fragment de fond entouré d'un cordon dentelé $\left(n^{\circ} 4\right)$, un débris de paroi ornée d'une petite goutte de verre $\left(n^{\circ} 3\right)$ et peutêtre un rebord très évasé $\left(n^{\circ} 7\right)$. Le dernier verre à boire n'est pas un gobelet. Le fragment 
qui subsiste provient d'un fond au pourtour replié $\left(n^{\circ} 12\right)$; il appartient à un verre conique ou tronconique. Cette pièce ne peut être datée avec certitude.

11 Les vases à liquide ne sont représentés que par deux pièces. Un petit fond côtelé $\left(n^{\circ} 5\right)$ de même taille que les gobelets mais beaucoup plus épais et quelques tessons de panse ne suffisent pas à définir la forme générale de la fiole. L'autre récipient $\left(\mathrm{n}^{\circ} 8\right)$ a été soufflé dans un verre de teinte verdâtre d'une épaisseur beaucoup plus importante. De cette bouteille il reste : un goulot bagué d'un cordon incisé, des fragments de panse moulée et un fond portant le décor caractéristique de pétales rayonnants. Cette dernière forme et les précédentes relèvent de types de verreries bien connues au XIVe s.

12 Les gobelets incolores à décor de gouttes rapportées apparaissent dans la deuxième moitié du XIIIe s. dans presque toute l'Europe. Ces découvertes exceptionnelles en Angleterre (Charleston, 1984, p. 23), sont beaucoup plus fréquentes en Italie (Whitehouse, 1983), Midi de la France et Yougoslavie (Kojic-Wenzel, 1967). Des trouvailles faites au nord des Alpes, en Suisse, Allemagne (Baumgartner, 1985) et est de la France (Rieb, 1986, p. 7587) non négligeables posent le problème des lieux de fabrication. Rares sont pourtant les centres de production qui ont été mis en évidence. L'atelier de Corinthe, dont la datation première a justement été mise en question (Withehouse 1991) et l'officine varoise de Planter (Foy, 1988, p. 210) produisaient au XIIIe s. ce type de verre qui semble perdurer encore au siècle suivant en Italie. La carte des découvertes des gobelets incolores à décor moulé ou à fil bleu rapporté est toute aussi large et les centres de fabrications, en dehors de ceux du Midi bien assurés en Languedoc (Lambert, 1972), Provence (Foy, 1988) et Italie, restent hypothétiques. Les bouteilles en verre verdâtre ( $\left.n^{\circ} 8\right)$ semblent essentiellement concentrées en Italie du Nord (FossatiMannoni, 1975, p. 61), Midi de la France (Foy, 1988, p. 241250) et Espagne.

En conclusion nous pouvons donc dater cet ensemble de verreries autour du XIVe s. Son origine, vraisemblablement méridionale, ne peut être précisée.

Les quelques autres fragments de verres médiévaux recueillis ailleurs n'enrichissent pas le répertoire des formes énumérées ci-dessus. Des parois de gobelets décorées de fils de verre bleu déposés en colimaçon sous un faisceau de filets bleus horizontaux étaient dans la couche 145 ( $\mathrm{n}^{\circ} 64$, a et b) ainsi qu'un rebord plus large orné d'un unique listel bleu ( $\left.\mathrm{n}^{\circ} 65\right)$. D'autres débris de verreries à décor rapporté bleu étaient dans les couches $147\left(n^{\circ} 84\right)$ et $217\left(n^{\circ} 75\right)$ (gobelet à filet bleu et côtes moulées) ainsi que $403\left(n^{\circ}\right.$ 93). Des gobelets incolores à décor moulé ne subsistent que sous forme de minuscules fragments dans la couche $103\left(\mathrm{n}^{\circ}\right.$ 95). Un débris de fond de verre à cordon dentelé était dans le même contexte ( $\left.n^{\circ} 94\right)$.

Tous ces verres exhumés dans des couches riches en matériel moderne doivent être considérés comme des objets résiduels.

\section{Les verres modernes}

La série la plus importante, provenant de la couche 155, contient presque tout l'éventail des formes exhumées dans les fouilles du château du Vuache. Dans le tableau récapitulatif (fig. $123 \mathrm{a}, \mathrm{b}, \mathrm{c}$ ), nous avons distingué 14 types de verres à boire et 7 sortes de récipients. 


\section{Verres à boire}

\section{Les gobelets}

17 C'est une des formes les plus communes mais une seule pièce a pu être entièrement reconstituée ( $\left.n^{\circ} 15\right)$ (fig. 124) ; les plus nombreux sont côtelés. Nous en comptons 27 exemplaires au moins dont près de la moitié dans la couche 155. En verre parfaitement incolore et transparent, ils sont larges et trapus. Leur ouverture de $80 \mathrm{~mm}$ de diamètre en moyenne est à peine plus importante que la largeur des fonds (70 mm environ). Ils ont été soufflés dans des moules qui ont imprimé des côtes verticales épaissies à leurs extrémités. Ces nervures sont en nombre variable, le plus souvent compris entre 8 et 12 $\left(n^{\circ} 14,15,17,18,20\right)$; parfois elles sont très resserrées ( $n^{\circ} 87$ et 88$)$. Dans un seul cas le sommet des nervures est légèrement incurvé $\left(n^{\circ} 16\right)$. Les parois évasées à leur base sont ensuite verticales dans le tiers supérieur qui n'est pas touché par le décor. Nous avons essayé de distinguer les gobelets non décorés $\left(\mathrm{n}^{\circ} 19,20,21\right)$; cependant la découverte de fonds unis ne signifient pas une absence totale de décor sur les autres parties du verre.

\section{4 : Gobelet côtelé, $n^{\circ} 15$}

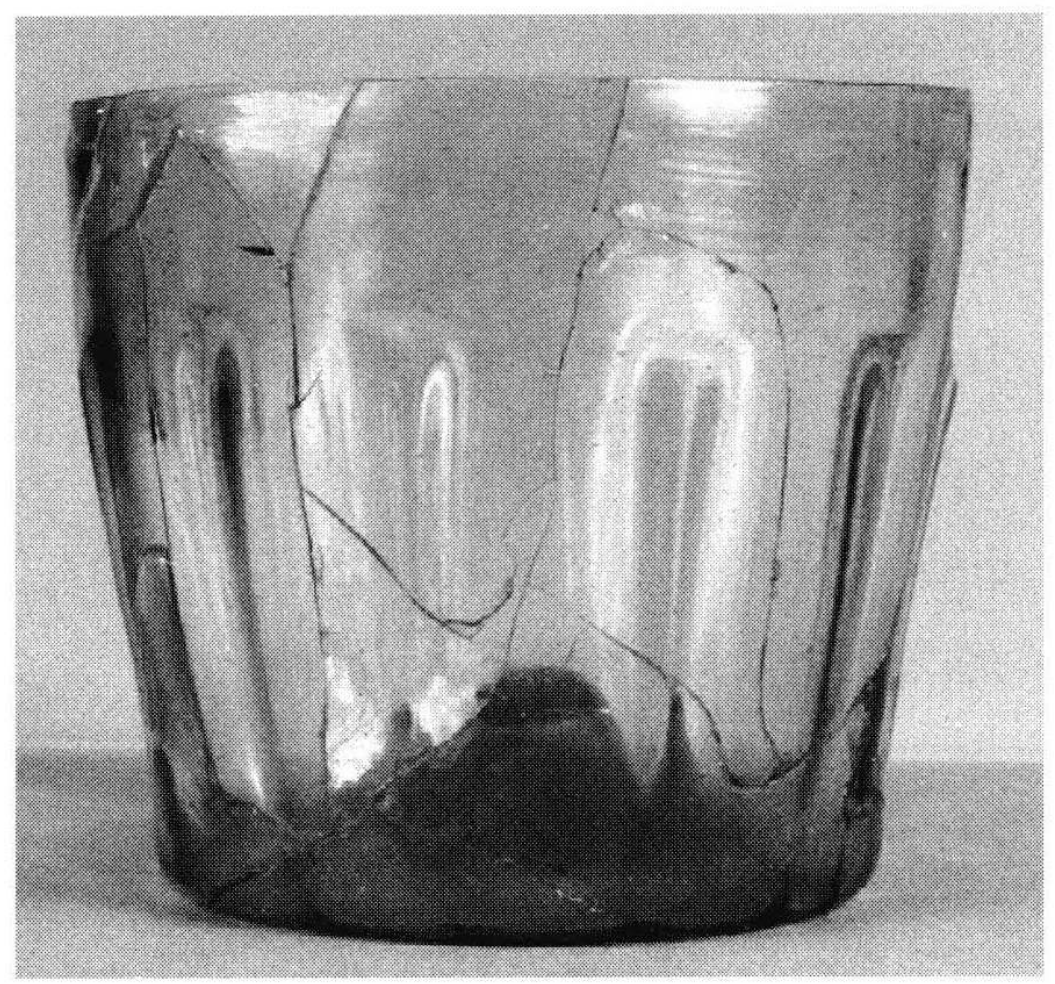

Le gobelet côtelé présent sur de nombreux sites est daté de la fin du XVe s. et de la première moitié du XVIe s. On le connaît par les fouilles des pays de la Loire; principalement à Tours (Motteau, 1981, $n^{\circ} 1$ à 5) et Orléans (Barrera, 1987, $n^{\circ} 149$ ) et la région parisienne (A Travers..., notices 248,249 ). Le profil de ces pièces de comparaison est cependant plus élancé. Beaucoup plus proches sont les trouvailles de Montauban (Foy, 1986) et surtout de Delft (Baumgartner, 1988, notice 456) et de Lyon (A Travers..., notice 260 ). 


\section{Les verres à pied}

19 Après les gobelets, les verres à pied sont les formes de verre à boire les plus usitées. Comme les précédents, ils sont réalisés dans une seule paraison (c'est-à-dire dans une même masse de verre) puisque le pied n'est pas rajouté mais formé par simple refoulement à l'intérieur de l'objet. Les formes des pieds : tronconiques ou coniques, les proportions entre le contenant et le support, les procédés décoratifs permettent de différencier une multitude de variantes. Nous commencerons par les verres à pied tronconique, côtelés qui forment la catégorie la plus courante.

\section{Les verres à pied tronconique côtelés}

Nous avons comptabilisé 18 exemplaires à partir des fonds. Mais cette série était sans doute beaucoup plus importante car plusieurs centaines de fragments de rebords et de parois côtelés ont pu être isolés. On les trouve principalement dans la couche 155 : plus du tiers des fragments recueillis dans ce contexte appartiennent à ce type d'objet et à 14 individus au moins. Quelques dizaines de débris seulement ont été exhumés des couches 145,103 et 107.

21 C'est donc le matériel de la couche 155 qui autorise à définir cette catégorie de verres. La simplicité de la forme n'exclut pas une harmonie due tout d'abord aux proportions : le contenant effilé à la manière d'une flûte fait plus des trois-quarts de la hauteur totale de la pièce. Le pied tronconique n'est pas massif. L'exemplaire restitué ( $\left.n^{\circ} 25\right)$ (fig. 125) qui atteint $185 \mathrm{~mm}$ de haut démontre que ces verres à boire sont parmi les plus grands réalisés à cette époque. Le raffinement de la forme n'est pas, comme bien souvent dans les verres à tige du XVIe s., au détriment de la capacité du verre à boire. Le décor moulé de nervures, élargies et en fort relief à leur sommet, donne au profil de ces verres un galbe qui accentue l'élégance sans détruire le caractère longiligne. Les côtes atteignent la base des pièces et leur relief crée sur le pourtour du pied des festons. Elles semblent être toujours au nombre de douze sur des pièces qui n'ont pas toujours le même gabarit. L'examen des pieds montre que leur diamètre se situe entre 80 et $98 \mathrm{~mm}$; mais la plupart ont $95 \mathrm{~mm}$. Ce décor nervuré n'atteint jamais le rebord; le bandeau laissé lisse sous le bord a environ $40 \mathrm{~mm}$ de large. L'aspect de ces nervures est tout à fait comparable au décor des gobelets étudiés précédemment. Quelques variantes existent : deux verres, dont on ignore la forme générale, possèdent 12 nervures arrondies à leur extrémité ( $n^{\circ} 30$ et 79$)$. 


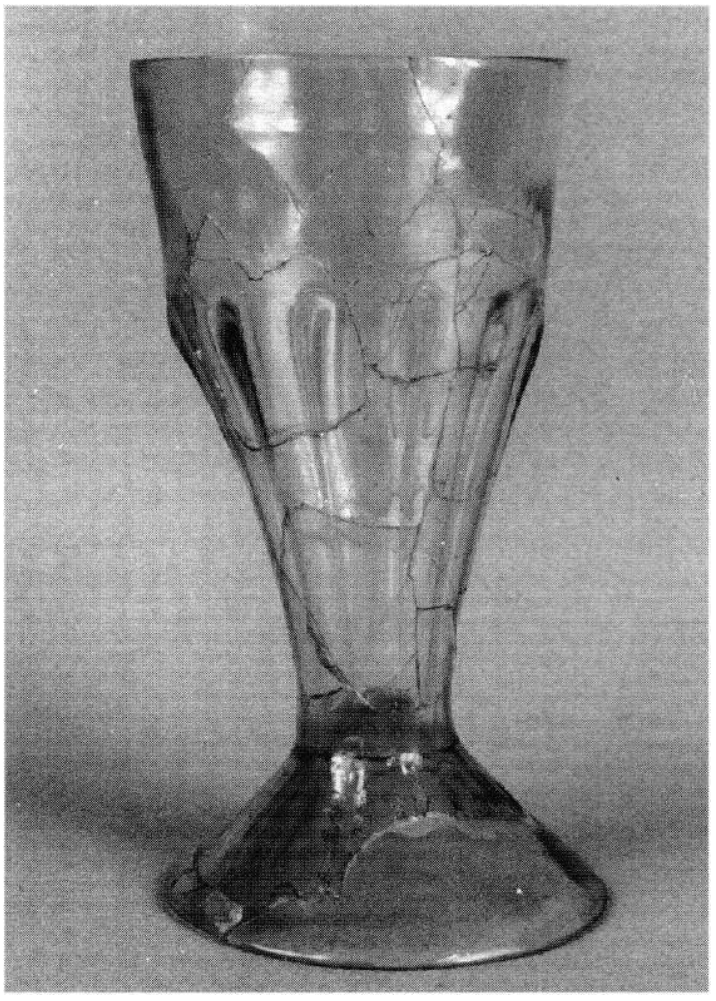

Il faut souligner l'originalité de ces verres; nous ne leur connaissons aucun équivalent.

\section{Les verres à pied tronconique à décor rapporté}

On a peut-être utilisé dans le château du Vuache d'autres verres à pied tronconique portant un décor moulé, mais différent des nervures décrites ci-dessus. Il n'en reste malheureusement que très peu d'indices. Il a bien été retrouvé des fragments décorés de gaufrage ou de petites pastilles moulées mais rien ne permet de dire à quel type de verre ils appartenaient (gobelet? verre à pied tronconique? verre à tige? coupe ?). Nous nous sommes seulement risqué à rapprocher des débris de parois décorés de grains de riz (C. 145) d'un verre à pied tronconique portant le même décor et trouvé à Lyon (A Travers..., notice 272).

24 L'existence d'un verre à pied agrémenté de filets rapportés est plus sûre, bien qu'il ne reste de cette pièce que la partie haute $\left(n^{\circ} 23\right)$. Sur les parois légèrement évasées, à 44 $\mathrm{mm}$ du rebord, l'artisan a appliqué un cordon de verre, lequel a été étiré à intervalles réguliers de manière à former des festons. Entre chacun d'eux, sous l'arc, apparaît un filet vertical indiquant un décor plus ample. On peut imaginer une deuxième frise festonnée, dans le sens inverse de la première, c'est-à-dire par un allongement vers le haut. Bien que mutilé, ce décor rapporté peut être comparé à celui d'une pièce orléanaise (Barrera, 1987, n 160, A Travers..., notice 281) ou aux fragments découverts dans une fosse dépotoir à Lille (Gemehl, 1986, $\mathrm{n}^{\circ} 60$ ) ou encore au verre du Louvre muni d'un double cordon festonné (A Travers..., notice 297). Tous ces verres sont datés de la fin du XVe ou du XVIe s. 


\section{Les verres à pied tronconique probablement non décorés}

Ces verres beaucoup plus communs ne sont représentés sur ce site que par cinq exemplaires incomplets. Cinq pieds étaient dans les couches 147 ( $\left.\mathrm{n}^{\circ} 85\right), 145$ ( $\left.\mathrm{n}^{\circ} 70-71\right)$ et 217. Nous n'avons pas pu remonter une seule pièce pour connaître son profil complet. Cependant on peut associer deux fragments provenant de la couche 145 : un élément de paroi $\left(n^{\circ} 70\right)$ et de pied $\left(n^{\circ} 71\right)$ pour constituer un verre à coupe évasée. Cette forme probable est celle de nombreuses pièces découvertes à Châlons-sur-Marne (Cabart, 1985, fig. 3,5 et fig. 21,8 et A Travers.., notice 266), Tours (Motteau, 1981, nº 19 et A Travers..., notice 270), Besançon (A Travers... p.406 $\mathrm{n}^{\circ} \mathrm{H}$ et I) ou encore à Martigues (A Travers..., notice 267) ou Avignon (Foy, 1980, fig. 67-2) pour donner quelques exemples. L'absence de décor sur le fond ne signifie pas que le contenant était forcément démuni de toute ornementation: un fil pouvait être rapporté sous le rebord comme on peut le voir sur une trouvaille du Louvre (A Travers..., notice 268). Tous ces verres sont datés du dernier quart du XVe s. ou du milieu du XVIe s.

\section{Les verres à pied conique}

Ils sont réalisés selon le même procédé que les précédents mais se différencient de ceux-ci par leur profil plus fin. Les coupes coniques étant très reserrées à leur base, la jonction avec le pied est nettement marquée. Nous avons dénombré 7 pièces mais aucune n'est complète.

Pourtant dans la couche 145 , les éléments de deux coupes, richement ornées ( $\mathrm{n}^{\circ} 66$ et 67), pourraient être associés à deux pieds coniques côtelés ( $n^{\circ} 68$ et 61 ), car la base de ces coupes est aussi nervurée. Sur le verre $n^{\circ} 67$ les côtes ne sont plus rectilignes mais sinueuses ; régulièrement elles ont été élargies ou au contraire étranglées pour former des emboîtements de figures ovales ou en losangées. Ce décor qui s'arrête à quelques millimètres du rebord est surmonté de petits polygones et triangles irréguliers logés dans les écoinçons.

La seconde pièce $\left(n^{\circ}\right.$ 66) a la particularité de posséder un décor appliqué et un décor moulé. Son pied (peut-être le fragment $n^{\circ}$ 68) était sans doute couvert de fines côtes verticales qui, à mi-hauteur de la coupe, se rejoignent en couronne. Dans la moitié supérieure, le décor plus confus, se prolonge en chevrons; au sommet, ces lignes brisées s'enroulent sur elles-mêmes. A ce décor moulé complexe s'ajoute une ornementation rapportée: un filet de teinte aujourd'hui mauve encercle six fois l'ouverture et se surimpose en partie aux motifs moulés.

La combinaison des procédés décoratifs moulés et appliqués n'est pas rare sur les verres à pied conique, mais généralement les filets rapportés sont en verre blanc opaque et les dessins estampés sont plus simples (Barrera, 1987, n² 210, Motteau, 1985, $\mathrm{n}^{\circ}$ 196).

Les verres à pied conique uniquement ornementés de filets de verre blanc laiteux enroulés sur le rebord sont très communs au XVIe s. Deux pièces au moins étaient conservées dans la couche 212 ; seuls restent les rebords ( $n^{\circ} 76$ et 77 ). Les pieds non décorés trouvés dans les contextes $C .155$ et $147\left(n^{\circ} 86\right)$ peuvent faire partie de pièces similaires. 


\section{Les verres à pied annulaire}

31 Les verres à boire ont l'aspect de gobelets parce que leur pied est réduit à un anneau creux de moins d'un centimètre de hauteur. Pourtant ce pied formé par refoulement de la pâte vitreuse à l'intérieur de l'objet, est techniquement comparable aux fabrications précédentes (verres à pied tronconique ou conique). Nous ne connaissons pas la forme complète de ce verre dont trois exemplaires au moins peuvent être dénombrés. Un pied provient de C. 145 et deux autres ( $n^{\circ} 44$ et 46$)$ de C. 155 . Dans ce dernier contexte nous avons étudié des débris de parois $\left(\mathrm{n}^{\circ} 42-43\right)$ qui vraisemblablement font partie du même modèle de verrerie. La matière fine, incolore, dépourvue de tout décor a rendu les tentatives de recollage difficiles. L'inclinaison des parois à partir des fonds ou des rebords permet de distinguer des verres cylindriques $\left(\mathrm{n}^{\circ} 43\right.$ et 46$)$ et tronconiques $\left(\mathrm{n}^{\circ}\right.$ 44). Les pieds ont 70 à $80 \mathrm{~mm}$ de diamètre et les ouvertures 82 à $115 \mathrm{~mm}$.

Dans la même matière et de la même manière sont réalisées des formes plus larges que nous désignons sous le générique de coupelles. L'une a pu être restituée ( $\left.\mathrm{n}^{\circ} 38\right)$ (fig. 126). C'est un objet trapu de $103 \mathrm{~mm}$ de hauteur pour un diamètre à l'ouverture de 122 $\mathrm{mm}$. Les fonds découverts en C. 145 et C. 155 sont toujours compris entre 100 et 112 $\mathrm{mm}$. Ces pièces de la taille d'un bol ont pu aussi bien servir de verres à boire que de récipients à contenir divers produits. Ils pouvaient être fermés par un couvercle. Le seul retrouvé $\left(n^{\circ} 37\right)$ est de taille tout à fait proportionnelle à la coupelle. Soufflé dans un verre de même aspect, il est comme cerclé par un anneau creux obtenu par pincement de la paroi. Sa base de $112 \mathrm{~mm}$ de diamètre pouvait aisément être introduite dans la coupelle. Ce couvercle se calait ensuite parfaitement puisqu'il atteint à mihauteur, sous l'anneau, la largeur exacte de l'orifice du vase qu'il couvrait. La partie supérieure manque; il faut restituer au centre un bouton de préhension: une simple boule ou, plus vraisemblablement un bouton haut et mouluré, comme une tige de verre à boire, avec laquelle, fragmenté, il peut être confondu. Des trouvailles alsaciennes datées du XVIe s. nous permettent de visualiser la forme complète de ce couvercle (A Travers..., p. 416, $\mathrm{n}^{\circ} 30$ ). 


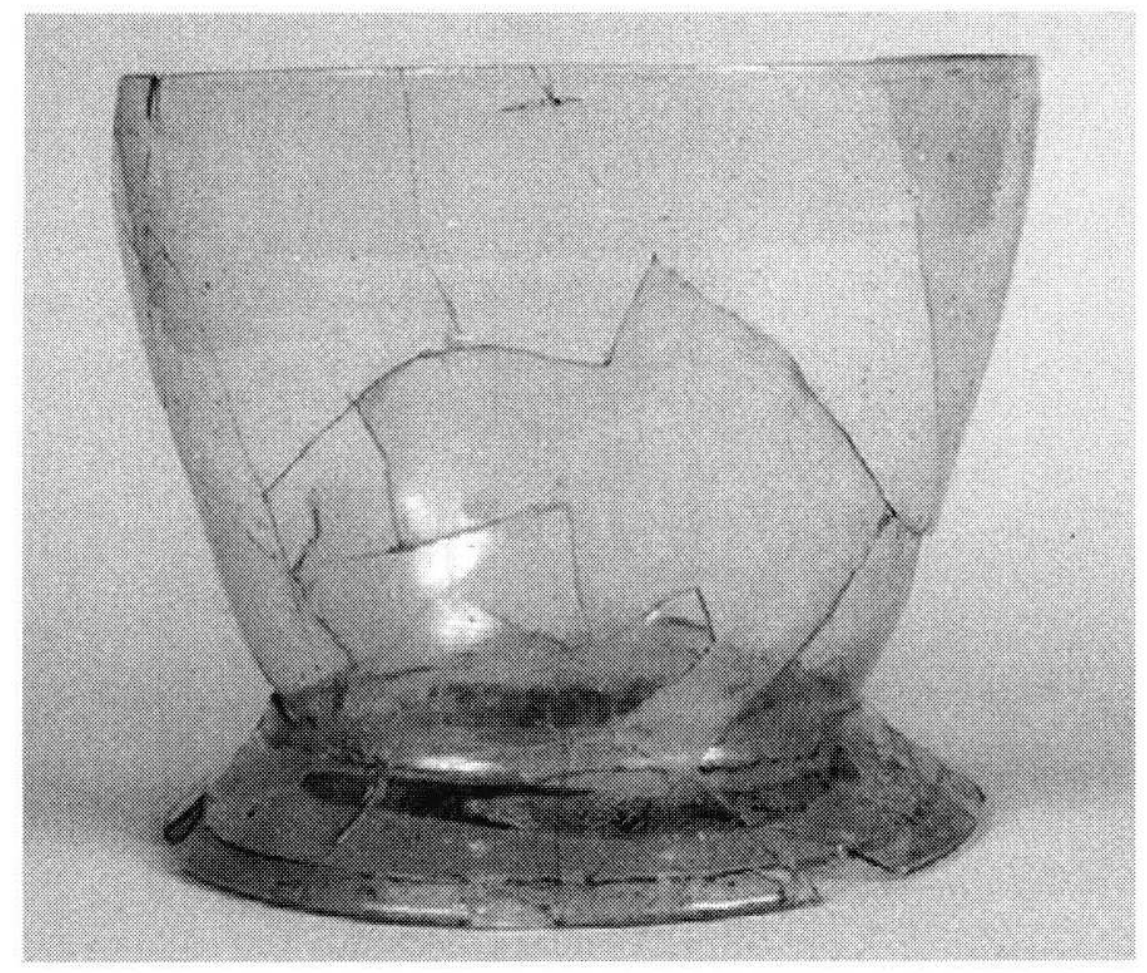

\section{Les verres à tige}

33 Ce sont les verres à boire les plus sophistiqués de l'ensemble. Le groupe le plus homogène se compose de six pièces dont quatre proviennent de $C .155$ ( $n^{\circ} 32$ à 35 ), une de $\mathrm{C} 103$ ( $\left.n^{\circ} 92\right)$, la dernière est hors stratigraphie ( $\left.n^{\circ} 36\right)$. Ces verres sont incomplets à l'exception d'un d'entre eux ( $\left.\mathrm{n}^{\circ} 32\right)$ (fig. 127). Ils ne sont pas identiques mais tous ont une coupe hémisphérique décorée de côtes épaisses, supportée par une tige creuse. Au décor moulé est associée une ornementation appliquée. Les 10 ou 12 nervures qui couvrent le pied, la tige et la coupe sont droites; dans un seul cas elles s'inclinent un peu vers la droite $\left(n^{\circ} 33\right)$. Ce décor semble absent sur une pièce $\left(n^{\circ} 36\right)$. L'ornementation rapportée se trouve à la base de la coupe et du pied, quelquefois autour de la tige. Sur la pièce reconstituée on remarque les deux cordons de verres hauts et plats, tous deux pareillement échancrés dans un souci évident de symétrie; le cordon inférieur constitue une sorte de piedouche qui surélève l'objet de $15 \mathrm{~mm}$. Sur un autre exemplaire, l'ajout inférieur ne surhausse pas le verre mais élargit son pied: assez étroit et à peine ondé il entoure le pied $\left(n^{\circ} 36\right)$. Sur les tiges on note des bagues qui font office de bouton de préhension : l'une forme un anneau plat $\left(n^{\circ} 36\right)$; la seconde est plus élaborée : elle est faite d'un filet ondé enroulé trois fois autour de la tige ( $\mathrm{n}^{\circ}$ 35). 


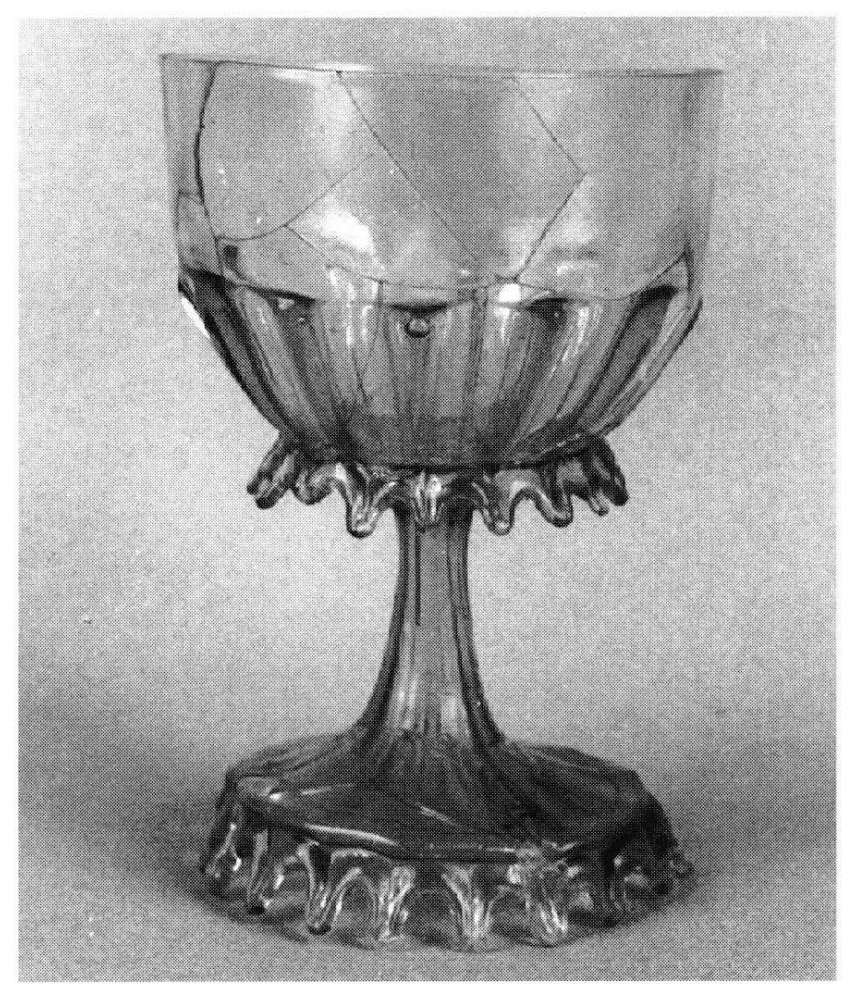

34 Ces belles productions sont tout à fait représentatives des premiers verres « façon de Venise » qui sont soufflés dès la fin du XVe et au XVIe s. dans une partie de l'Europe par des verriers italiens émigrés ou par des artisans autochtones ralliés à leurs goût. Ces verres de Vulbens sont comparables à des trouvailles lyonnaises (A Travers..., $\mathrm{n}^{\circ}$ 303) et martégales (Foy, 1988, fig. 135 et 136 et A Travers...,.n² 299) de l'extrême fin du XVe s. ou du début du XVIe s.

La seconde série de verres à tige est beaucoup plus mal définie: deux coupes hémisphériques décorées de figures hexagonales moulées et parfois d'un fil appliqué ( $n^{\circ} 24$ et 74 ) étaient sans doute portées par une tige moulurée pleine ou creuse comme certaines pièces trouvées dans les fouilles du Louvre (A Travers..., p. 388, n 89,91, 92). Ce type, postérieur au milieu du XVIe s., était encore en usage au début du siècle suivant.

36 Les deux tiges pleines découvertes dans le contexte 217 appartenaient à des verres différents: l'une d'elle avait une coupe vraisemblablement conique ( $\left.n^{\circ} 80\right)$, l'autre devait porter une coupe hémisphérique $\left(n^{\circ} 81\right)$. Ces pièces incomplètes ne peuvent être datées sûrement ; elles se situent peut-être dans le XVIIe s.

\section{Les coupelles}

37 Quelques pieds tronconiques assimilés à des supports de verre à boire ont pu appartenir à des coupelles ; mais le seul fragment qui puisse être reconnu formellement comme un élément de coupelle, est un rebord incolore ourlé vers l'extérieur ( $\left.n^{\circ} 91\right)$; à l'intérieur du repli, il retient un fil de verre bleu. Bien que réduite, cette pièce peut être rapprochée d'une coupelle trouvée à Lyon et datée du début du XVIe s.; son rebord enfermait aussi un fil bleu (A Travers..., $n^{\circ}$ 308). Notons cependant que la plupart des 
coupelles comparables à celle de Lyon, sont datées plus tardivement (deuxième moitié XVIe-début XVIIe s.).

\section{Formes fermées}

\section{Les bouteilles aux flancs aplatis} relativement courts (40 à $50 \mathrm{~mm}$ de hauteur) ont un rebord à marli plat de 110 à 112 $\mathrm{mm}$ de diamètre ( $\mathrm{n}^{\circ} 52$ à 54 ). Ces ouvertures caractéristiques sont celles de vases à pharmacie, de ballons de chimie pour la distillation ou d'urinaux. Leur panse devait être ovoïde. Ils sont réalisés dans un verre incolore et leurs fragments peuvent parfois se confondre avec ceux de la forme précédente, d'autant plus que les bouteilles aplaties semblent avoir aussi une embouchure large ; il n'est d'ailleurs pas impossible qu'il y ait confusion entre les deux formes. Cependant nous n'avons pas pu apparenter aux bords caractéristiques des vases à pharmacie, des panses aplaties et des fonds ovales; il nous paraît plus raisonnable d'imaginer pour ces vases des fonds épais, quelquefois bombés $\left(n^{\circ} 57,58\right)$ car on sait que les ballons de chimie et les urinaux ont habituellement un fond convexe.

\section{Les cruches}

Deux spécimens seulement sont reconnus, ils étaient dans le contexte 155. Le mieux conservé est de teinte presque incolore, légèrement ambré $\left(n^{\circ} 47\right)$ (fig. 128). Il atteint $144 \mathrm{~mm}$ de hauteur et $118 \mathrm{~mm}$ de large au maximum. Le col cylindrique a un rebord ourlé en dedans ce qui lui donne l'aspect d'un bandeau plat à l'extérieur. Le bec est pincé. La panse repose sur un pied annulaire non rapporté. L'anse nervurée relie le rebord à la panse en décrivant un arc qui dépasse la hauteur du corps de la pièce. 


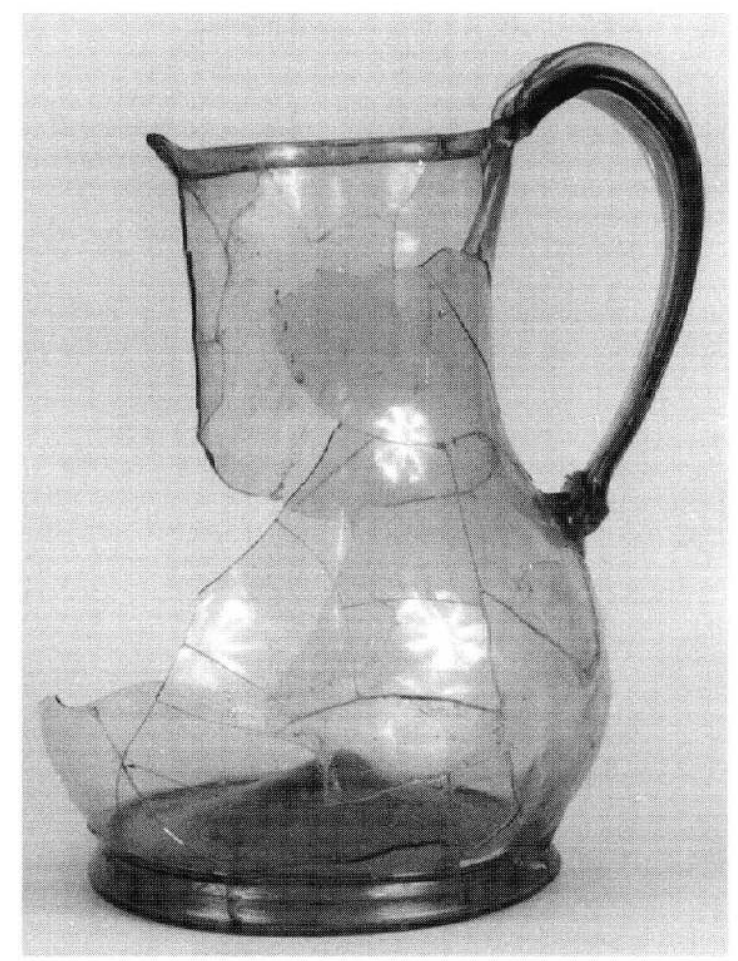

La seconde cruche était sans doute la plus raffinée: son col galbé est couvert de nervures qui devaient s'étendre sur la panse. L'anse nervurée n'est pas surhaussée ( ${ }^{\circ}$ 48).

Ces deux cruches sont les seuls vases de cet ensemble munis d'anse et de bec verseur. Ils peuvent être comparés à une cruche trouvée à Sedan, datée du XVIe s. (A Travers..., $\left.\mathrm{n}^{\circ} 338\right)$; celleci diffère surtout par son pied tronconique très haut.

\section{Les petites fioles côtelées}

Elles sont au nombre de trois: l'une est de teinte rosée $\left(n^{\circ} 56\right)$; les autres sont verdâtres ( $n^{\circ} 49$ et 51$)$. Toutes sont couvertes de nervures jusqu'au rebord ou jusqu'à l'épaulement. Leur col est très court et leur hauteur ne devrait pas excéder $110 \mathrm{~mm}$. La mieux conservée, sans doute la plus grande ( $\left.{ }^{\circ} 49\right)$ (fig. 129), atteint $108 \mathrm{~mm}$; sa panse piriforme est aplatie. La séparation avec le col est nettement marquée par un étranglement. Le rebord rentrant ne laisse qu'un orifice de $9 \mathrm{~mm}$. Une petite anse relie le bord à l'épaulement. 


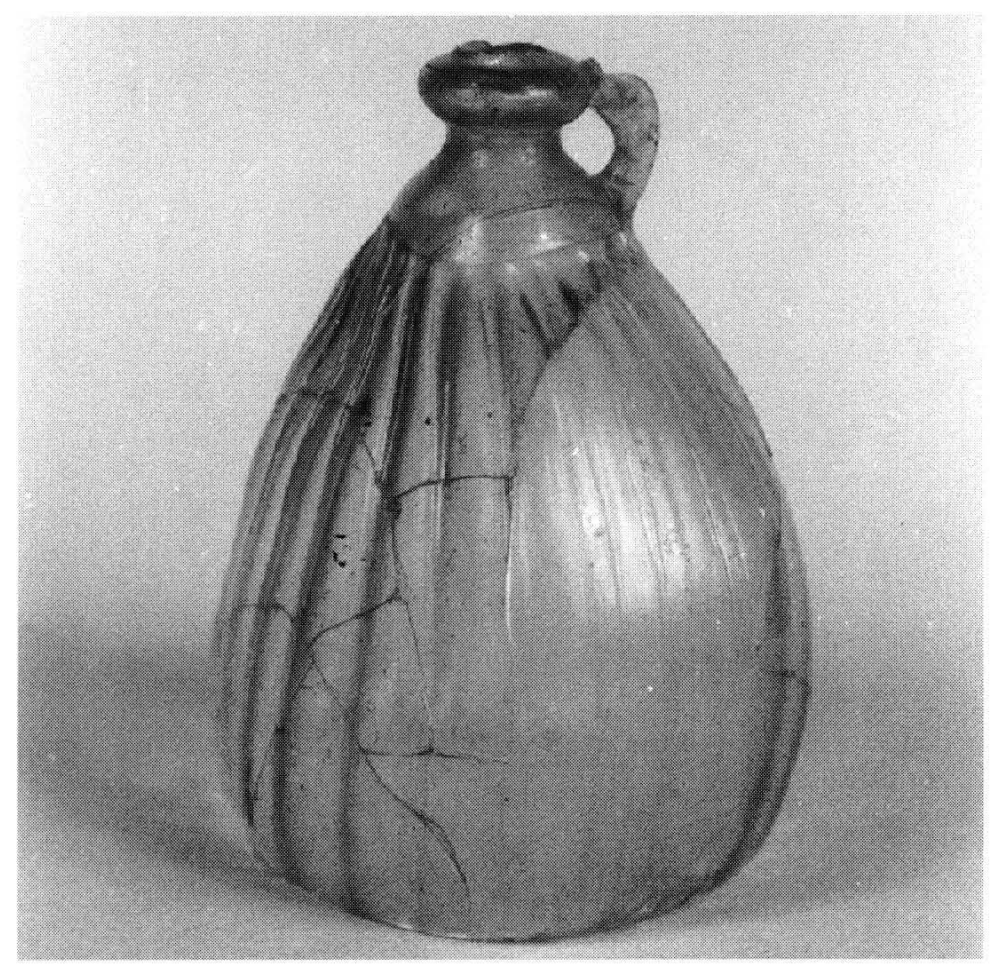

Les deux autres pièces ( $n^{\circ}$ 50-51) sont beaucoup plus communes; leur panse globulaire ne possédait pas d'anse. Les petits flacons de ce type, côtelés ou plus rarement décorés de petits pointillés ont été fréquemment retrouvés dans des niveaux d'habitat (souvent dans des dépotoirs), dans des tombes ou encore dans des autels. Ces trouvailles sont courantes en France, à Châlons-sur-Marne (Cabart, 1985, n 25 à 28 ; A Travers..., n 324 à 326), à Orléans (Barrera, 1987, $\mathrm{n}^{\circ}$ 348, 349 ; A Travers..., $\mathrm{n}^{\circ}$ 327), Sedan (A Travers..., $\mathrm{n}^{\circ} 328$ ), dans le Doubs (Barrelet, 1953, pl. XXVIIIb) et Albi (A Travers..., $\mathrm{n}^{\circ}$ 323), en Belgique (Chambon, 1955, p. 55) et en Allemagne (Rademacher, 1933, p. 186). Les fioles trouvées dans des autels sont interprétées comme des ampoules de consécration ; il est vraisemblable que celles qui étaient dans des tombes aient contenu de l'eau bénite. Mais ce n'est certainement pas la fonction première de ces objets communs qui, vu leur petitesse, ont pu contenir des produits relativement précieux (parfum, potions...). Les inventeurs s'accordent pour les dater de l'extrême fin du XVe s. ou du début XVIe s., à l'exception de la petite bouteille trouvée à Liège qui serait ( ?) plus ancienne.

\section{Les fioles a long col}

Ces bouteilles ne sont attestées que par des fragments de goulot en verre verdâtre ( $\mathrm{n}^{\circ}$ 58 et 59) ou bleuté. Le diamètre de ces cols est compris entre 16 et $40 \mathrm{~mm}$. 6 pièces ont été recensées. Il faut rajouter à celles-ci un fragment de goulot en verre coloré bleu dans la masse et décoré en surface de points en verre blanc.

\section{L'ampoule sphérique}

Cette forme incomplète n'est représentée que par un seul exemplaire. Ce petit récipient $\left(n^{\circ} 55\right)$ en verre verdâtre et épais a une panse presque parfaitement sphérique. Nous 
ignorons le profil du col et du fond. La forme et l'épaisseur particulière de ce verre rare correspondent probablement à une fonction bien précise, peut-être dans le domaine médical ( ?).

Les verres trouvés à Vulbens constituent l'un des plus beaux ensembles de verreries du XVIe s. exhumés de terre ${ }^{24}$. Ils montrent d'abord l'homogénéité de la vaisselle en verre en usage dans le courant du XVIe s. (surtout la première moitié). Ces verres trouvés au Nord des Alpes sont en effet comparables à de nombreuses découvertes du Nord, du Centre et du Sud de la France. Cependant quelques formes originales contribuent à enrichir le répertoire des verreries de la Renaissance.

PI. I : Verreries médiévales, C. 805

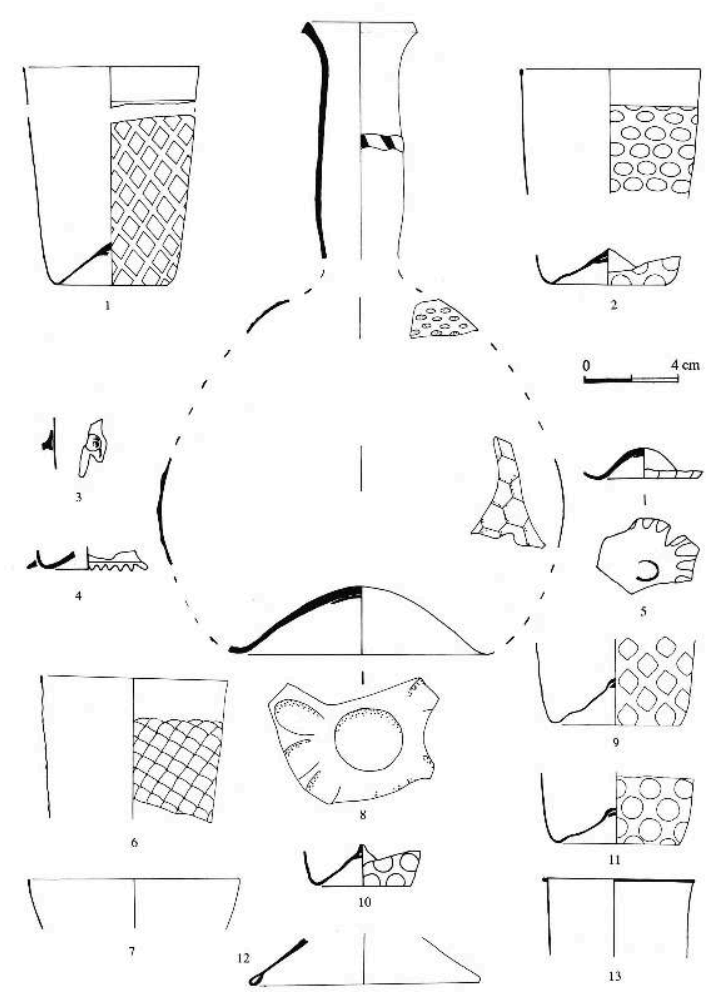


PI. II : Gobelets, verre à pied tronconique à décor appliqué, $n^{\circ} 23$ et verre à tige à décor moulé, $n^{\circ} 24$, C. 155

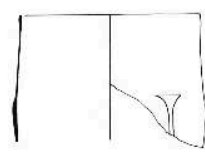

14
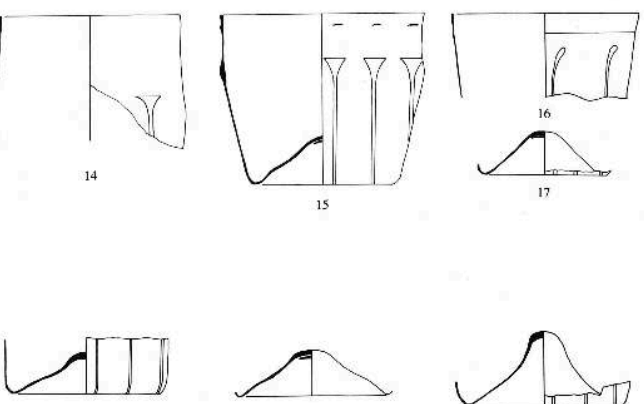
$\lim _{\rightarrow \infty}^{5 \pi n}$

is
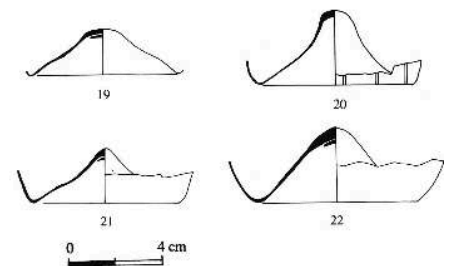
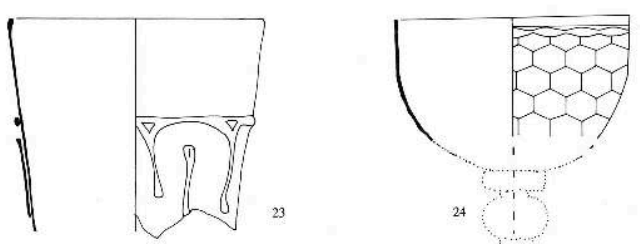

PI. III : Verres à pied tronconique, C. 155
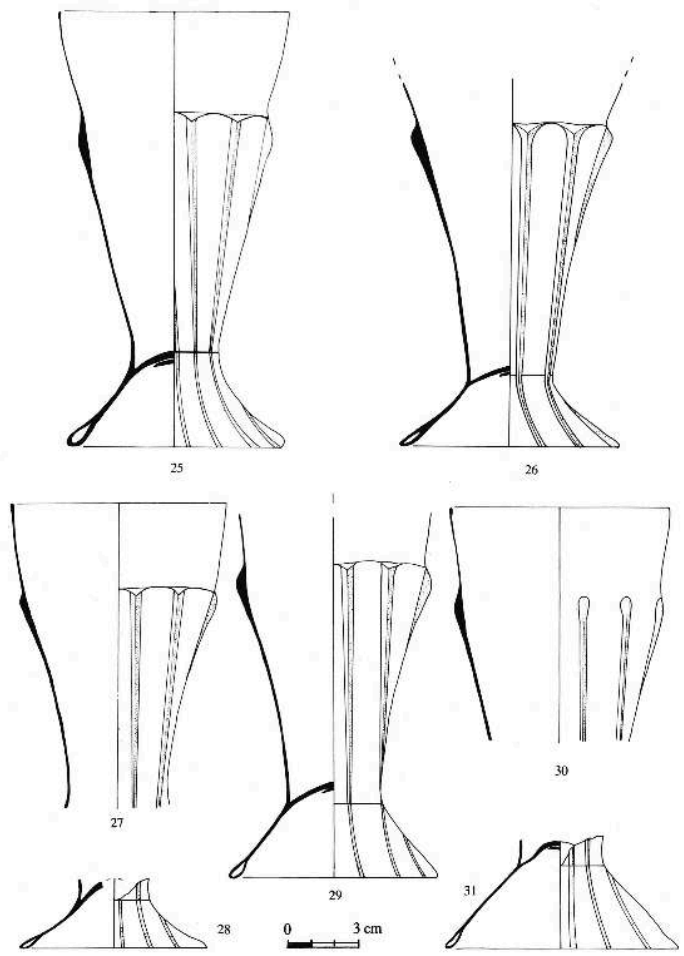
PI. IV : Verres à tige creuse à décor côtelé, C. 155 (sauf $n^{\circ} 36$, hors stratigraphie)
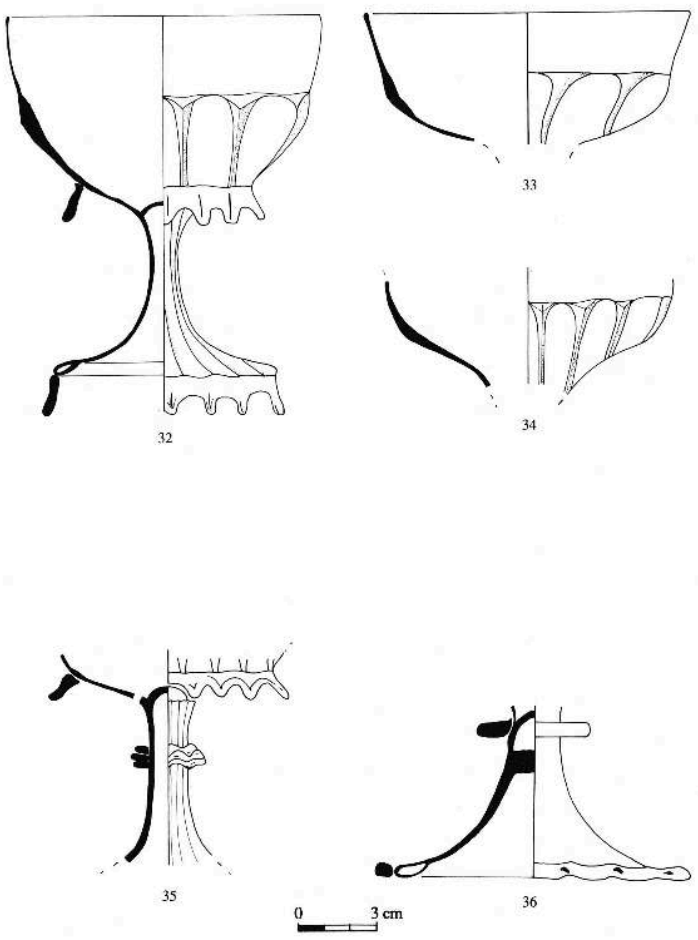

PI. V : Verres à pied annulaire, C. 155

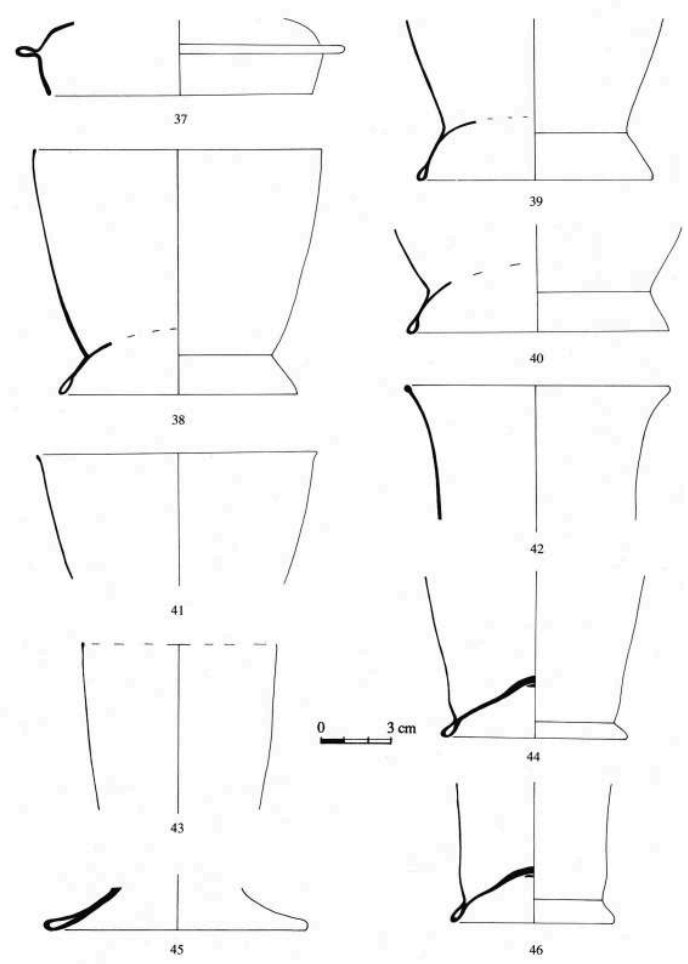


PI VI : Cruches, C. 155

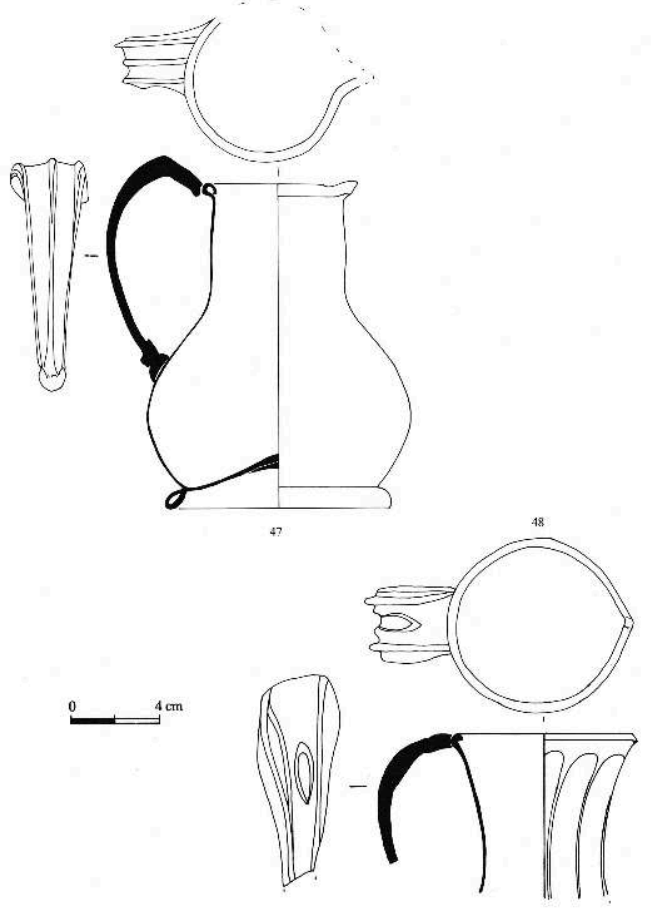

$\mathrm{PI}$. VII : Fioles à goulot court, $n^{\circ} 49$ à 51 , et à long col, $n^{\circ} 58$ à $60, ;$ ampoule, $n^{\circ} 55$; vases à pharmacie, $n^{\circ} 52$ à $54, C .155$
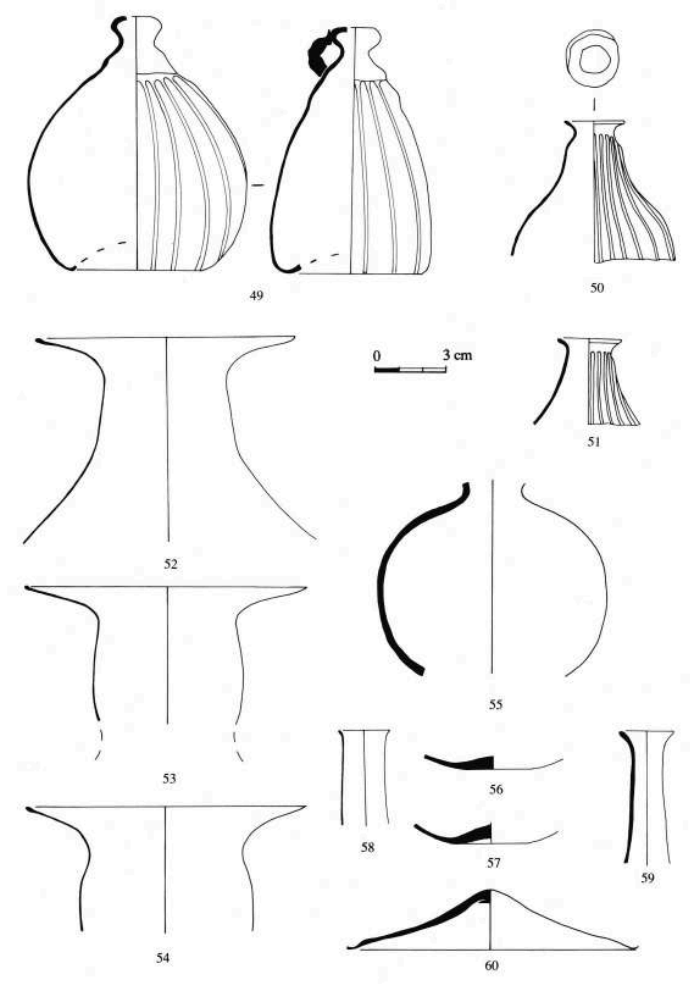
PI. VIII : Bouteilles à panse aplatie, C. 155

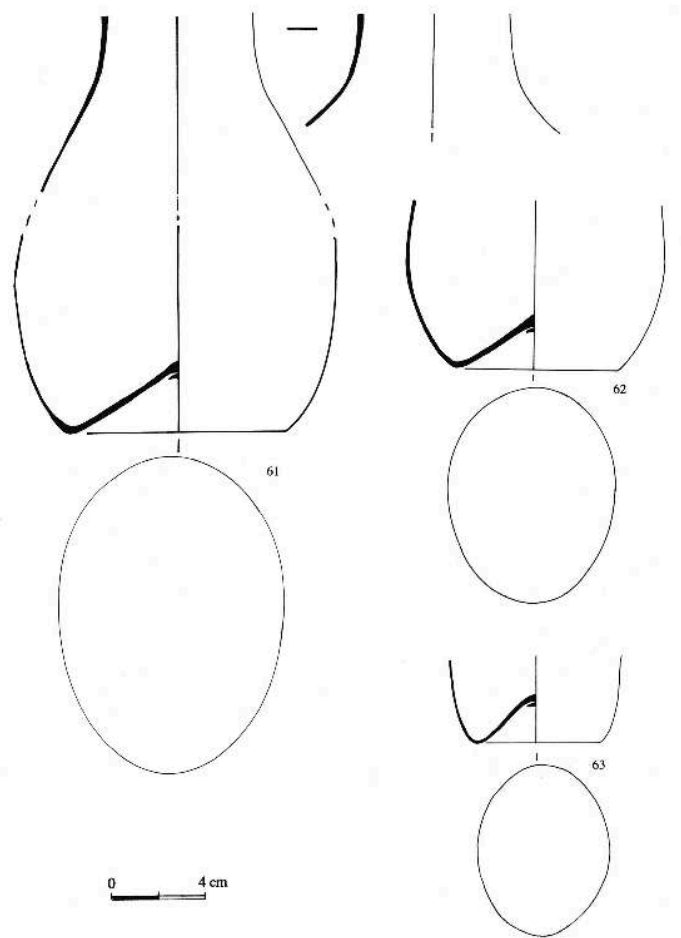

$\mathrm{PI}$. IX : Verres médiévaux, $\mathrm{n}^{\circ} 6465$, verres à pied conique $\mathrm{n}^{\circ} 66$ à 69 , et à pied tronconique, $\mathrm{n}^{\circ} 70$, 71, C. 145
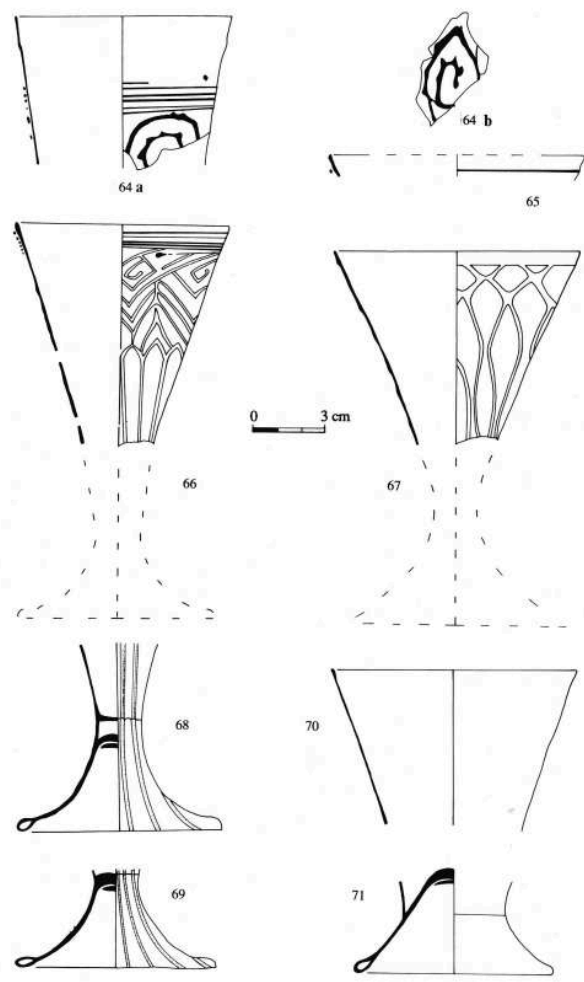
PI. X : Bouteilles, C. 145, et verres de la couche 217

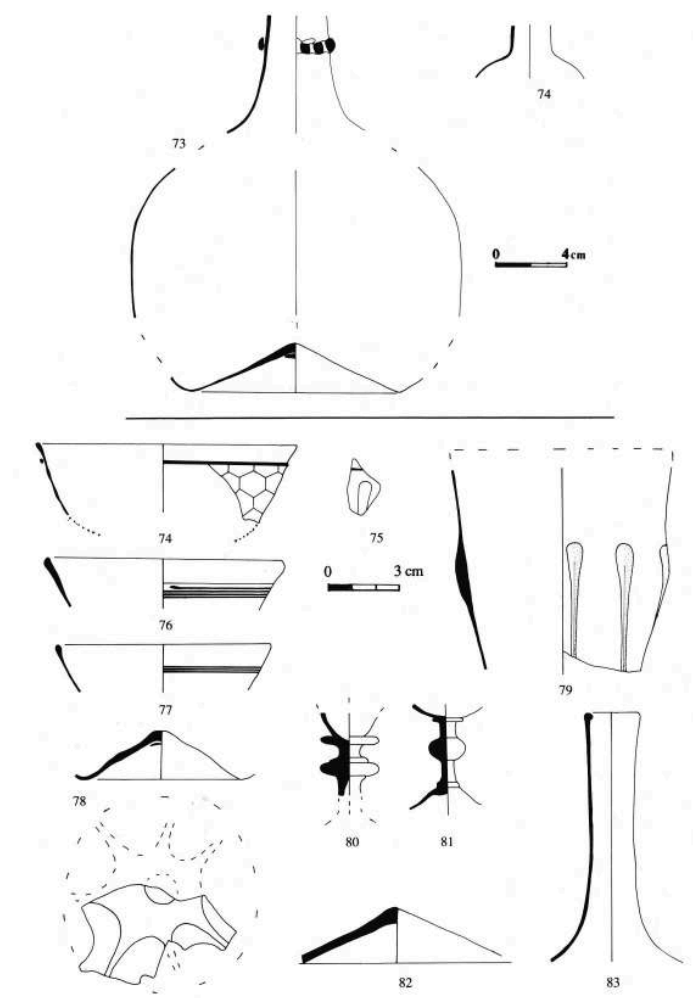

PI. XI : nº 84 à 86 C. $147 ; n^{\circ} 87$ à 89 : C. $403 ; n^{\circ} 90$ à $96:$ C. 103 (sauf n $93:$ C. 102)

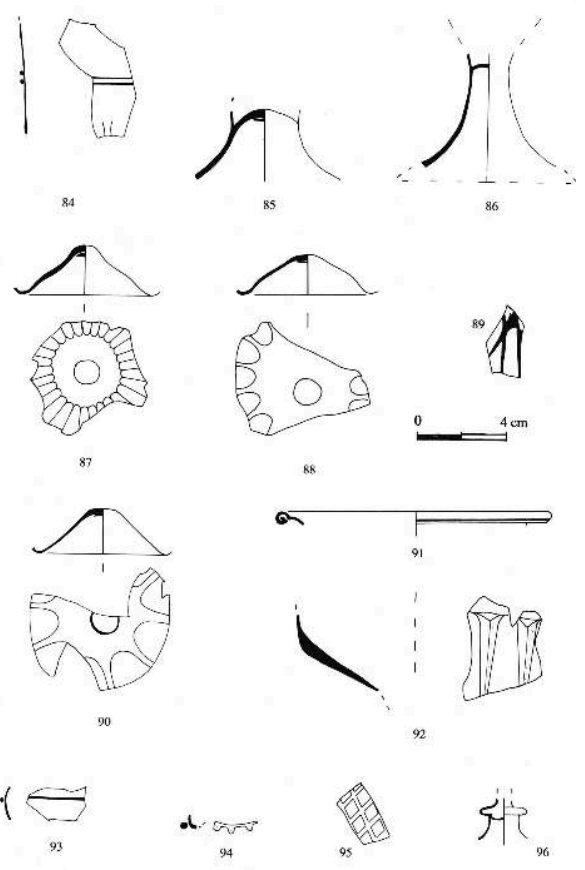




\section{NOTES}

24. Les pièces 15, 25, 32, 38, 47, 49 ont été restaurées au Laboratoire de Restauration de métaux, verres et céramiques archéologiques (C.R.E.A.) de la Ville de Vienne (38). 


\section{Annexe 4. La faune}

\section{Claude Olive et Louis de Roguin}

1 Nous commencerons cette étude, la faune domestique et sauvage durant la construction, l'occupation et la destruction du château du Vuache(XIIIe-XVIIIe s.), par un exposé concernant chaque période d'occupation pièce par pièce. La figure (fig. 130) nous donne un aperçu de la distribution des restes sur l'ensemble du site, à chaque phase.

130 : Proportion des restes osseux pour chacune des époques

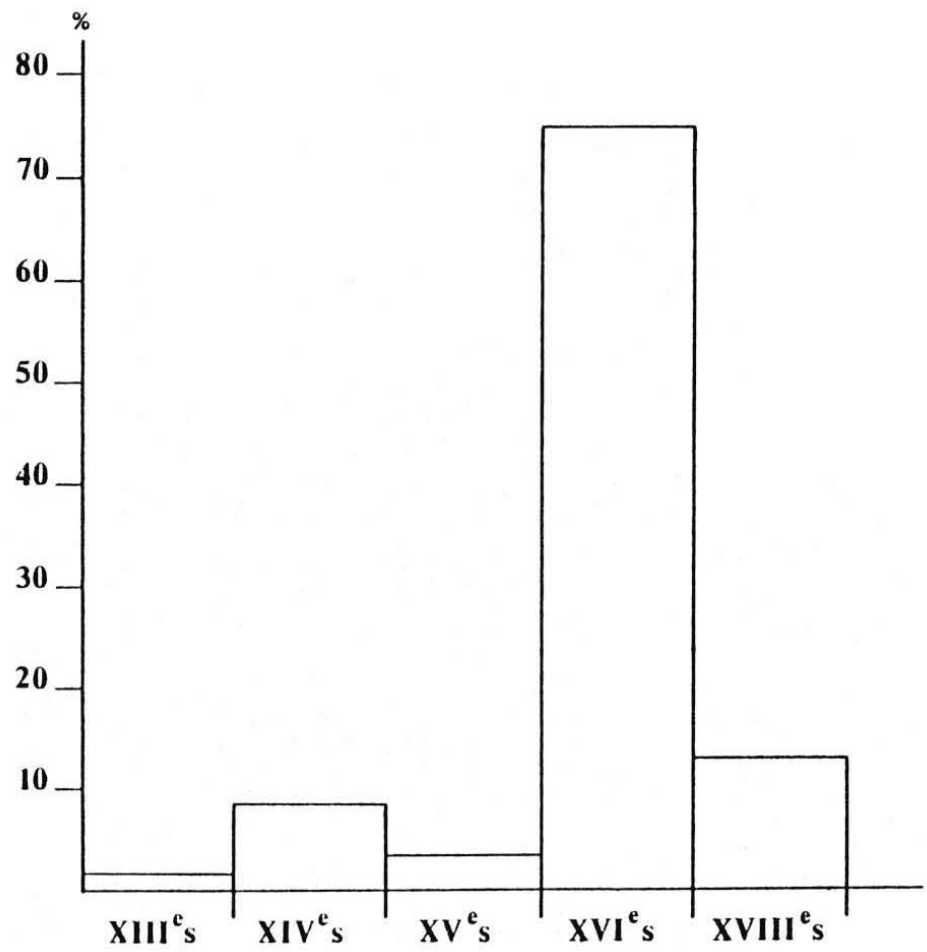




\section{Le XIIle siècle}

\section{Zones 1 et 2}

Pièces II et IV

2 Les fragments de boeuf retrouvés dans la pièce IV (planche III) ont été attribués à deux individus, l'un âgé de 6 à 12 mois, l'autre ayant plus de 30 mois. Il est possible que les deux éléments osseux situés dans la pièce II (fragments de bassin et de patte postérieure) appartiennent à l'individu le plus âgé de la pièce IV, en effet, rien ne nous indique que le fragment de patte antérieure situé dans cette pièce puisse être attribué à un individu différent.

3 Parmi les restes de suidés, dans la pièce IV nous avons reconnu les éléments anatomiques de deux individus, l'un très jeune d'environ 3 mois dont nous ne pouvons dire s'il s'agit d'un animal sauvage ou domestique, la parenté trop proche de certaines espèces ne permet pas toujours la distinction des jeunes animaux ; l'autre, est un porc (Sus scrofa dom), mâle, âgé de 18 à 24 mois.

Tableau 1 : Inventaire des restes osseux (total : 30)

\begin{tabular}{|l|c|c|}
\hline Distribution des restes & $\begin{array}{c}\text { Zone 1 } \\
\text { pièce IV }\end{array}$ & $\begin{array}{c}\text { Zone 2 } \\
\text { pièce II }\end{array}$ \\
\hline fragments indéterminés & 16 & 2 \\
fragments de côtes & 1 & 2 \\
fragments de vertèbres & 2 & 3 \\
boeuf & 4 & 7 \\
suidès & 23 & \\
\hline TOTAL & & \\
\hline
\end{tabular}

Comme nous le voyons, les restes sont peu nombreux, mais nous pouvons également préciser que leur valeur alimentaire n'est pas très importante : restes de mandibule, de pattes et un fragment de bassin : ceci ne peut apporter de grosses quantités de viande.

Dans la pièce II, les quelques ossements attribués à cette espèce sont différents de ceux retrouvés dans la pièce IV, leur robustesse est nettement supérieure, ils appartiennent donc à un autre individu adulte. L'absence de données métriques ne nous permet pas de préciser si ces éléments anatomiques appartiennent à un sanglier (Sus scrofa scrofa) ou à un porc mâle adulte plus robuste.

6 Ces restes de suidés semblent correspondre à des parties plus charnues que celles des bovidés. En effet, à part les deux fragments de mandibules pouvant être, comme chez le boeuf, rattachés à la consommation de la langue, nous avons les restes d'une épaule, de deux jarrets et d'une partie de filet. 


\section{Le XIVe siècle}

\section{Zone 4}

$7 \quad$ Les restes de boeuf domestique (Bos taurus domest), bien que peu nombreux ont été attribués à trois individus différents: l'un très jeune, âgé d'à peine 3 mois et deux autres sujets dont les âges dépassaient 2 ans pour l'un et 4 ans pour l'autre.

8 Ces éléments osseux appartiennent à différentes parties des animaux : crâne, épaule, jarret et patte antérieurs, cuisse, jarret et patte postérieurs, un seul fragment de côte.

9 Parmi les porcs domestiques, nous avons dénombré quatre individus : une femelle de 6 à 12 mois, un mâle de 12 à 18 mois, puis deux autres sujets dont nous n'avons pas pu déterminer le sexe : le premier âgé de 18 à 24 mois, le second de plus de 3 ans.

10 Les restes osseux retrouvés sur chacune des surfaces archéologiquement reconnues, paraissent se compléter: ainsi les restes crâniens s'associent entre eux, il en est de même pour les os provenant d'un jarret antérieur et d'un jambon.

11 De même, il semble que les os de caprinés proviennent d'un même mouton (Ovis aries), âgé d'environ 2 ans. L'ensemble de l'animal est à peu près représenté, il est possible que son abattage ait eu lieu sur place.

Tableau 2 : Inventaire des restes osseux (total : 420)

\begin{tabular}{|l|c|c|}
\hline Distributions & $\begin{array}{c}\text { Zone 4 } \\
\text { des restes }\end{array}$ & $\begin{array}{c}\text { Zone 8 } \\
\text { C403, C448, C450, C451 }\end{array}$ \\
\hline fragts indét. & 80 & 58 \\
fragts de côtes & 41 & 30 \\
fragts de vertèbres & 9 & 13 \\
boeuf & 24 & 14 \\
suidés & 24 & 43 \\
mouton & 18 & 5 \\
volaille & 5 & 51 \\
ours brun & 1 & 1 \\
colombides & & 1 \\
mollusques & 2 & 216 \\
\hline TOTAL & 204 & \\
\hline
\end{tabular}

Les gallinacés domestiques ne sont représentés que par deux individus du genre Gallus (la poule domestique), un sujet juvénile et un adulte.

13 Nous voyons apparaître les prémices de la chasse avec un fragment de mandibule d'ours brun (Ursus arctos). Le ramassage des animaux consommables tels que l'escargot 
dit de «Bourgogne » (Helix pomatia) et l'escargot des bois (Cepea nemoralis) semble avoir déjà été pratiqué.

\section{Zone 8}

e boeuf dont les restes ont été retrouvés dans cette aire est âgé d'au moins 4 ans. Les os que nous avons attribués à cette espèce dans cette pièce sont associés à une épaule et un jarret antérieur gauches, complétant la partie droite retrouvée dans la zone 4, des éléments de bassin fournissent la preuve du prélèvement de viande de type rumsteack (ces éléments osseux n'étaient pas présents dans la zone 4). Nous pensons donc que ces os peuvent appartenir à l'un des sujets, de même âge et que nous avons dénombrés dans la zone 4

porcins sont représentés par deux individus : une femelle dont l'âge se situe entre 12 et 18 mois et un second animal âgé d'environ 2 ans. Les ossements rejetés après consommation de la viande sont des restes de crânes (préparation probable de la tête et de la cervelle) puis d'une épaule complète avec le jarret antérieur, d'un jambon et enfin des " pieds ». L'analyse des restes, attribués à l'animal le plus âgé, laisse supposer qu'ils appartiendraient au porc dont l'âge se situe entre 18 et 24 mois, dans la zone 4 . Le mouton a été consommé sous la forme d'une épaule. La volaille est bien présente avec une dizaine d'individus, dont trois poulets et six poules adultes, parmi lesquelles trois étaient prêtes à pondre (Driver, 1982).

Un seul élément osseux se rapporte au pigeon, et il ne nous permet pas de décider s'il appartient à un pigeon biset sauvage (Columba livia) ou à sa forme domestique (Columba livia domest). Mais d'après l'analyse métrique pratiquée sur ce fragment, ce ne peut être un os appartenant à un pigeon ramier (Columba palumbus) (Fick, 1974). Cependant les comptes de châtellenie du XIVe s. signalent un colombier, ce qui pourrait signifier la présence de pigeons sinon domestiques, au moins apprivoisés.

17 Parmi la faune sauvage, seul l'escargot dit de « Bourgogne » est représenté.

\section{Le XVe siècle}

\section{Zone 1}

\section{Pièce IV}

Cette pièce, comme nous le voyons, est très pauvre en restes osseux : seul un fragment de côte représente l'espèce porcine. L'élément de patte postérieure d'équidé (Equus sp) (partie proximitale d'un tibia) est cependant intéressant puisque, porteur de découpe et de morsures, il prouve la consommation de cette espèce. Aucune caractéristique ne permet de préciser si nous avons affaire à un cheval, un poney ou un mulet. L'âne semblant exclu, à première vue, par la dimension de cette diaphyse. 


\section{Zone 5}

\section{Pièces VI et VII}

19 Les ossements de boeuf retrouvés sur les deux surfaces proviennent probablement d'un même animal : dans chacune des pièces nous retrouvons un élément appartenant à un même bassin.

20 Cependant la pièce VII a livré des ossements des parties antérieure et postérieure fournissant gîte et macreuse, donc plutôt riches en viande, tandis que dans la pièce VI, ce ne sont qu'un fragment de maxillaire et l'extrémité proximale d'une patte postérieure qui nous sont parvenus: éléments assez pauvres du point de vue alimentaire.

21 Les quartiers de porc qui ont fourni les os retrouvés dans les deux pièces appartiennent à trois individus : deux ont été abattus entre 12 et 18 mois et le troisième après 18 mois.

Dans la pièce VII ce sont les éléments d'une seule épaule qui ont été reconnus; dans la pièce VI en plus d'une épaule, nous constatons la présence de restes d'un jarret postérieur, les fragments d'un bassin signalent le prélèvement d'une pointe de filet et les éléments crâniens attestent de la préparation de la tête.

23 Le mouton est présent dans les deux pièces avec les restes de deux épaules et des pattes antérieures et postérieures. De plus, dans la pièce VI, un fragment de mandibule portant des stries sur la face interne pourrait signifier la consommation de la langue. L'ensemble provient d'un sujet âgé de plus de 12 mois.

24 La volaille est représentée par deux poules adultes pour l'ensemble de la zone.

25 Un élément osseux, laissé après la consommation d'une aile, a été attribué à une oie, probablement domestique, d'après l'aspect robuste de l'os.

Un corps vertébral de lagomorphe retrouvé dans la pièce VII a pu être spécifiquement déterminé (Bonato 1986) et atteste la chasse au lièvre commun (Lepus capensis). La présence d'un os d'oiseau de petite taille, tel un moineau, dans la pièce VI, laisse supposer le piègeage de certaines espèces aviaires, pour améliorer « l'ordinaire ».

Ainsi les périodes d'occupation, entre le XIVe et le XVe s., se distinguent bien de la phase de construction du XIIIe s. En premier lieu, par une plus grande abondance des restes osseux ce qui peut s'interpréter par une présence plus permanente des hommes. Mais aussi peut-être par un autre statut social de ces hommes qui prennent le temps de chasser. Car si le ramassage des escargots et le piègeage ou la chasse des petites espèces ne demandent pas un grand investissement en temps et en hommes, la poursuite et l'abattage d'un ours nécessitent une certaine organisation. 
Tableau 3 : Inventaire des restes osseux (total : 210)

\begin{tabular}{|l|c|c|c|}
\hline Distribution & ZONE 1 & \multicolumn{2}{|c|}{ ZONE 5 } \\
des restes & Pièce IV & Pièce VI & Pièce VII \\
\hline & & & \\
fragts indéter. & & 76 & 28 \\
fragts de côtes & & 36 & 14 \\
fragts de vertèbres & & 2 & 2 \\
boeuf & 1 & 9 & 3 \\
suidés & & 3 & 4 \\
mouton & 1 & 10 & 6 \\
équidé & & 10 & 1 \\
basse-cour & & & \\
lagomorphe & & 140 & 68 \\
oiseaux sauvages & & & \\
\hline
\end{tabular}

\section{Le XVle siècle}

\section{L'occupation militaire}

Les premières observations que nous pouvons faire sur cette phase d'occupation est d'une part l'abondance des restes osseux et l'importante fragmentation des ossements sur certaines zones, ainsi que la présence constante d'espèces sauvages sur ces mêmes zones.

\section{Zones 1 et 5}

\section{Pièces IV, VI et VII}

Une analyse minutieuse du matériel osseux permet d'affirmer la relation étroite entre ces deux zones d'occupation. En effet, il est impossible de dissocier les restes osseux des principales espèces domestiques et de certaines espèces sauvages prélevés dans les trois pièces.

Les fragments retrouvés dans la pièce IV, excepté celui d'équidé, qui a fourni une épaule, sont des rejets sans aucune valeur alimentaire, du type phalanges ou dents. Les pièces VI et VII fonctionnent en parfaite coordination, tous les restes des trois principales espèces domestiques se complètent totalement.

Pour le boeuf on ne trouve aucune différence dans la distribution des quartiers au niveau de la valeur en viande, mais les restes sont plus abondants dans la pièce VII. Toutes les parties sont représentées.Trois animaux sont à la base de ces restes osseux : 
un sujet âgé de 3 à 6 mois, un autre dont l'âge est compris entre 18 et 30 mois et le troisième avait entre 4 et 6 ans.

Le porc est également mieux représenté dans cette pièce, cependant si les parties antérieures ont été reconnues dans les deux pièces, il faut noter que les parties postérieures : filet, jambon, jarret ne se retrouvent que dans la pièce VII. Cinq animaux ont fourni les pièces de viande : un individu de 6 mois environ, une femelle de 12 mois au plus, deux sujets âgés de 18 à 24 mois, l'un d'eux était un mâle, le cinquième avait dépassé 3 ans $1 / 2$.

L'essentiel des restes de mouton se trouve dans la pièce VII. Seuls quelques fragments de côtes et un os hyoïde (os soutenant la langue) indiquant la consommation de cet abat, sont abandonnés dans la pièce V. Les restes provenant de la pièce VII sont attribuables à un minimum de cinq individus. L'un n'a pas 3 mois, trois sujets ont un âge compris entre 18 et 36 mois et le dernier a dépassé 4 ans. Un crâne et les deux hémi-mandibules, le tout très fragmenté, appartenant à un sujet d'environ 20 mois, indiquent la préparation possible de la tête et certainement la consommation de la cervelle.

Nous avons également retrouvé les éléments de plusieurs épaules (fig. 131), de gigots, de pattes et de côtes montrant une nourriture variée et relativement abondante. Dans ces trois pièces, on retrouve peu d'éléments crâniens des espèces décrites ci-dessus et si toutes les parties des animaux sont représentées, elles ne concernent pas la totalité des individus dénombrés. Excepté dans la pièce IV, où les restes osseux ne sont que deux fragments de pattes, la volaille est bien individualisée dans chacune des deux autre pièces. Ainsi dans la pièce VI, on peut décompter les restes de cinq sujets, deux poulets et trois poules. Dans la pièce VII, ce sont au moins sept individus adultes dont 2 poules prêtes à pondre et cinq poulets qui ont été consommés. Dans les deux cas, l'ensemble du squelette est présent. 
131 : Restes osseux d'une épaule d'agneau retrouvés dans la pièce VII au XVle siècle

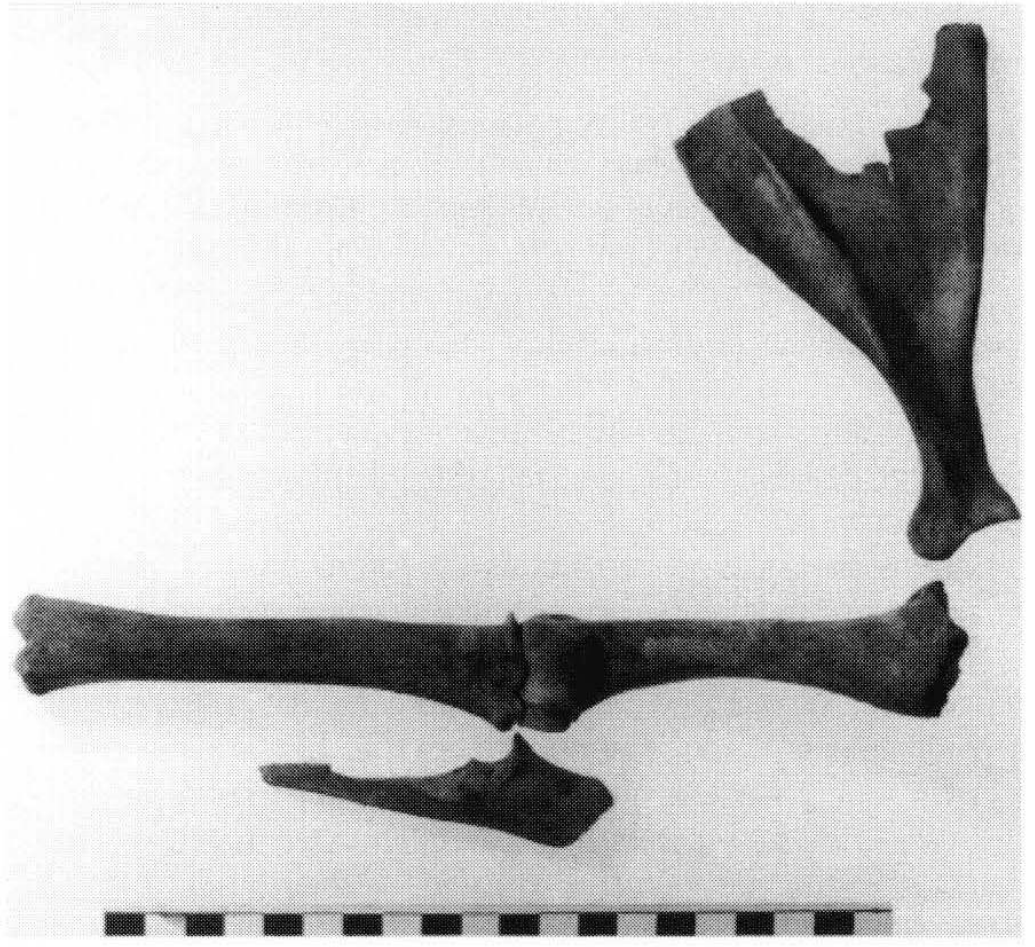

37 Il faut signaler également sur cette aire d'occupation quelques restes d'oie domestique (Anser anser domest.).

38 L'activité cynégétique reconnue sur ces zones sera traitée avec celle des autres aires d'occupation. 
Tableau 4 : Inventaire des restes osseux (total 4 111)

\begin{tabular}{|c|c|c|c|c|c|c|}
\hline \multirow{2}{*}{$\begin{array}{l}\text { Distribution } \\
\text { des restes }\end{array}$} & \multicolumn{2}{|c|}{ ZONE 1} & \multirow{2}{*}{$\begin{array}{c}\text { ZONE } 5 \\
\text { Pièce VII }\end{array}$} & \multirow[t]{2}{*}{ ZONE 4} & \multirow[t]{2}{*}{ ZONE 8} & \multirow[t]{2}{*}{ ZONE 12} \\
\hline & Pièce IV & Pièce V & & & & \\
\hline Fragts indét. & 16 & 103 & 231 & 24 & 1834 & 15 \\
\hline Fragts de côtes & 6 & 18 & 51 & 31 & 152 & 17 \\
\hline Fragts de vert. & 1 & 10 & 35 & 1 & 82 & \\
\hline boeuf & 1 & 28 & 93 & 7 & 78 & 14 \\
\hline porc & 6 & 29 & 234 & 6 & 153 & 16 \\
\hline mouton & 1 & 10 & 168 & 8 & 105 & 3 \\
\hline équidés & 1 & & & & & 1 \\
\hline basse cour & 2 & 24 & 172 & 1 & 187 & 2 \\
\hline colombides & & & & & 2 & \\
\hline cerf élaphe & & 3 & 1 & 4 & 3 & 3 \\
\hline sanglier & & 2 & 3 & & 2 & \\
\hline lagomorphes & & & 9 & & 38 & \\
\hline ours brun & & 1 & & & 20 & \\
\hline renard & & 3 & & & & \\
\hline oiseaux sauvages & 1 & 1 & 7 & & 9 & \\
\hline poissons & & 7 & & & 5 & \\
\hline mollusques & 2 & 2 & 1 & 4 & & \\
\hline TOTAL & 37 & 242 & 1005 & 86 & 2670 & 71 \\
\hline
\end{tabular}

\section{Zones 4,8 et 12}

En comparant les restes osseux des trois principales espèces domestiques, analysés dans les zones 1 et 5 , avec ceux des zones 4,8 et 12, nous voyons que les éléments anatomiques manquants s'y retrouvent. En particulier certains éléments crâniens.

Cependant d'autres sujets, pour chacune des espèces, sont venus augmenter la quantité de viande consommée sur ces trois zones.

41 C'est ainsi pour les bovins, nous trouvons un second animal dont l'âge dépasse 5 ans, avec les restes de membres antérieur et postérieur.

Deux porcs d'environ 18 mois ont fourni quelques pièces de viande supplémentaires (deux jambons, une épaule, trois jarrets et des morceaux placés près des côtes et vertèbres). Le secteur 4 a livré la partie arrière d'un crâne de porc adulte : la face avait été séparée du neuro-crâne par un coup net (fig. 132). 


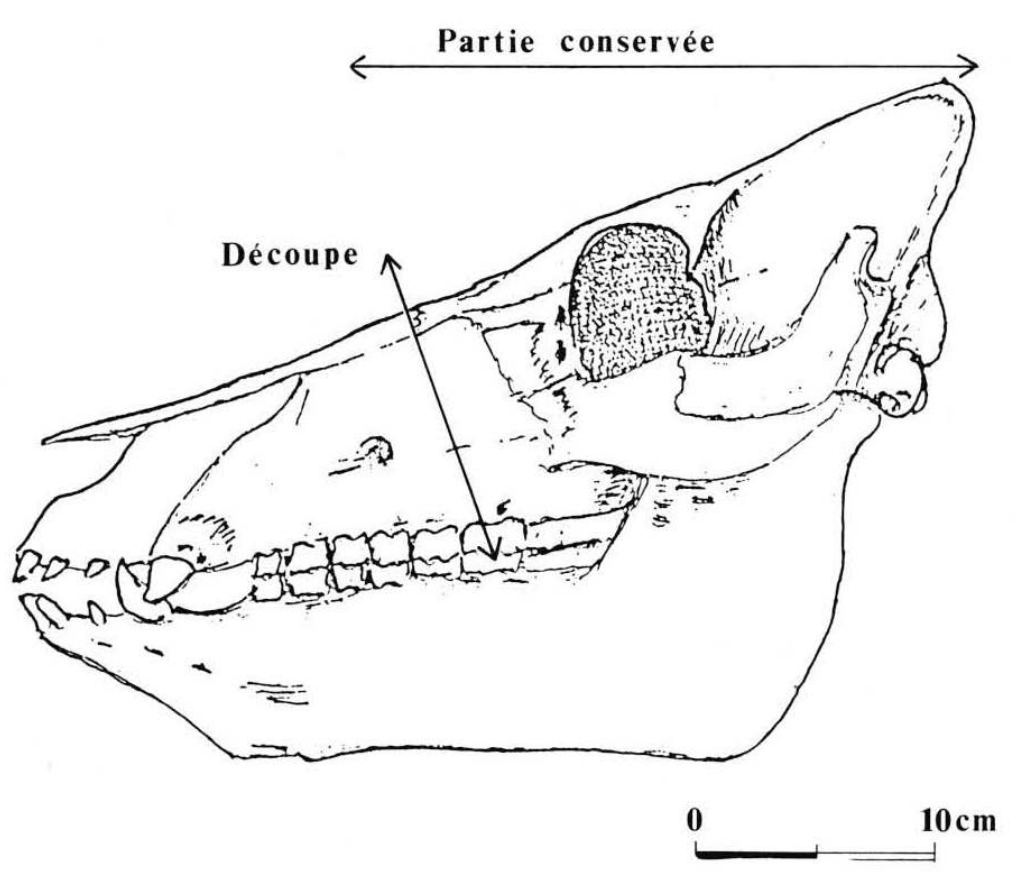

Un seul mouton de plus de quatre ans est à ajouter au corpus des cinq individus dénombrés précédemment. Quelques fragments crâniens, des éléments d'épaule, de gigot et de pattes ont permis de déceler la présence de cet animal.

Les zones 4 et 12, bien que pauvres en nombre spécifiquement attribué, ont livré des éléments de valeur alimentaire comparable aux autres surfaces.

C'est dans la zone 12 qu'un fragment de sabot d'équidé a été déposé.

C'est essentiellement dans la zone 8 que nous trouvons la basse-cour, avec huit poules et deux coqs adultes, huit poulets, quelques restes de deux oies : l'une adulte, l'autre juvénile. Le pigeon (Columba livia $s p$ ) est également présent, la remarque que nous avions faite à propos de cette espèce, dans la phase d'occupation du XIVe s., est valable cette fois encore.

47 L'importance des fragments indéterminés, réduits le plus souvent à des esquilles de moins de deux grammes, et la grande fragmentation des vertèbres et des côtes, rendant difficile leur attribution à une espèce précise sont à l'origine de très grand nombre d'ossements de la zone 8.

Cette fragmentation, importante dans toutes les zones et à toutes les époques est due à deux phénomènes: la préparation et la consommation des quartiers de viande et surtout le piétinement qui affine cette fragmentation. L'activité cynégétique, remarquée sur toutes les zones, est assez variée.

Les lagomorphes sont les animaux les plus souvent chassés. Nous avons dénombré au moins six lièvres, un jeune et cinq adultes dont les restes se retrouvent essentiellement dans la zone 8. Les ossements retrouvés dans la pièce VII correspondent à deux pattes antérieures avec l'épaule et une patte postérieure avec un fragment de rable; ces 
ossements manquant dans la zone 8, nous pouvons supposer qu'ils appartiennent aux individus dont les restes ont été rejetés dans cette zone.

Sur cette même aire, nous avons reconnu les éléments osseux d'un lapin de garenne (Oryctolagus cuniculus) et particulièrement deux fragments de deux radius, appartenant au même individu : un gauche, un droit, tranchés au-dessus de l'épiphyse distale des os (fig. 133). Cette découpe pourrait être le résultat de la préparation culinaire.

\section{3 : Les flèches indiquent la découpe des deux pattes antérieures du lapin au XVle siècle}

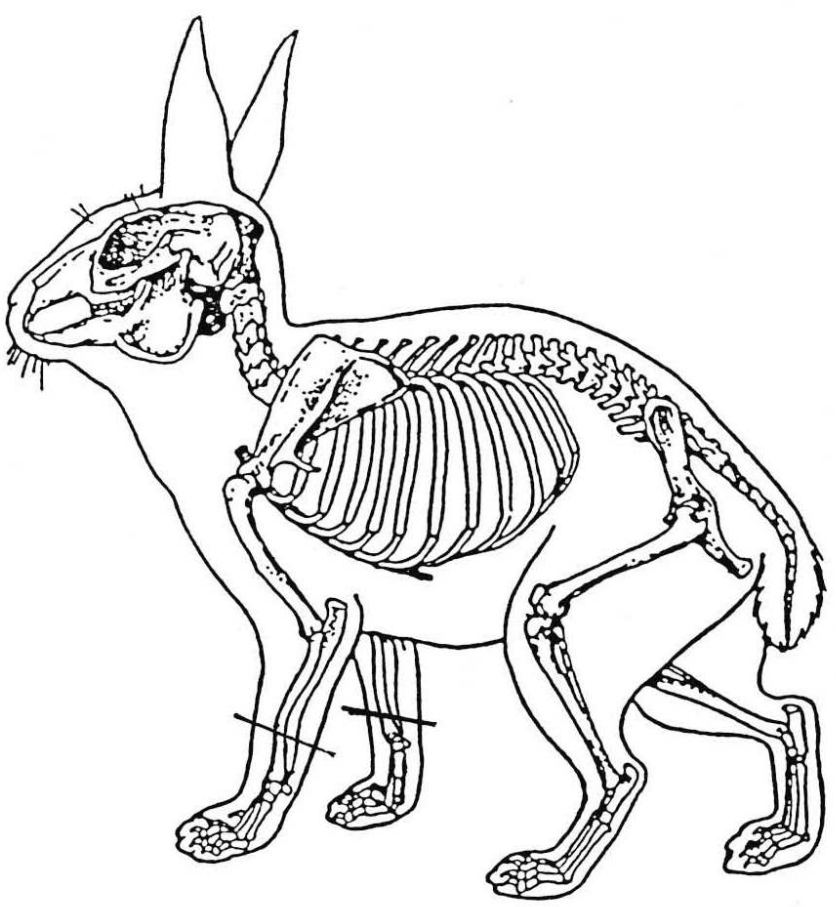

Nous avons classé dans sanglier quelques éléments osseux paraissant sortir, par leur robustesse, des restes de porc domestique. En effet, bien que son âge ne dépasse pas 24 mois, l'analyse morphométrique (les tables métriques sont à la disposition des lecteurs, s'adresser à l'auteur de l'annexe) de ces quelques fragments d'os le situe très au-dessus des mêmes mesures prises sur les porcs.

Deux cerfs (Cervus elaphus) ont été chassés, l'un encore juvénile, l'autre adulte. La pièce de viande la plus importante se trouve dans la zone 4, une épaule semble-t-il. Ailleurs, ce ne sont que fragments de mandibules ou extrémités de pattes.

L'ours brun (Ursus arctos) est représenté par un fragment de mandibule droite très robuste dans la zone 4 et par les restes d'une patte postérieure, presque complète, dans la zone 8. Ceci pourrait indiquer un dépouillage et un dépeçage sur place.

Le renard (Vulpes vulpes) a certainement été chassé essentiellement pour sa fourrure. $C^{\prime}$ est dans la pièce $V$ que se trouvaient les quelques restes appartenant à cet animal.

La faune aviaire est assez bien représentée. Les restes d'un faucon, non spécifiquement reconnu, (Falco sp.) pourrait être à l'origine de la diversité des espèces. La chasse au vol est depuis longtemps, un des moyens pour ce procurer les petites espèces animales, oiseaux et mammifères. 
57 Ainsi parmi ces oiseaux que nous avons pu identifier se trouvent le merle noir (Turdus merula), deux espèces de perdrix (Kraft 1972) : la perdrix grise (Perdix perdix), assez commune, qui niche et vit dans les champs et les friches, la perdrix bartavelle (Alectoris graeca), qui affectionne les régions montagneuses, les zones pierreuses et peu boisées et les versant plutôt ensoleillés. Nous pouvons encore citer la gélinotte des bois (Tetrastes bonasia) et le petit coq de bruyère également appelé tetras lyre (Lyrurus tetrix).

A ces différentes espèces nous devons ajouter les restes d'une oie rieuse (Anser albifrons) ou d'une bernache nonnette (Branta leucopsis) nous n'avons pas pu trancher, malgré les données métriques d'un humérus reportées sur le diagramme établi par A. Bacher, dans son étude sur la détermination des cygnes et des oies (1967) (fig. 134). Ces données se trouvent dans la marge de variation des deux espèces. Le fragment crânien ne nous a pas davantage aidé.

134 : Position sur le diagramme d'A. Bacher (1972) de l'ansériné retrouvé dans la zone 1, au XVle s. : oie rieuse (Anser albifron) ou bernache nonette (Branta leucopsis)

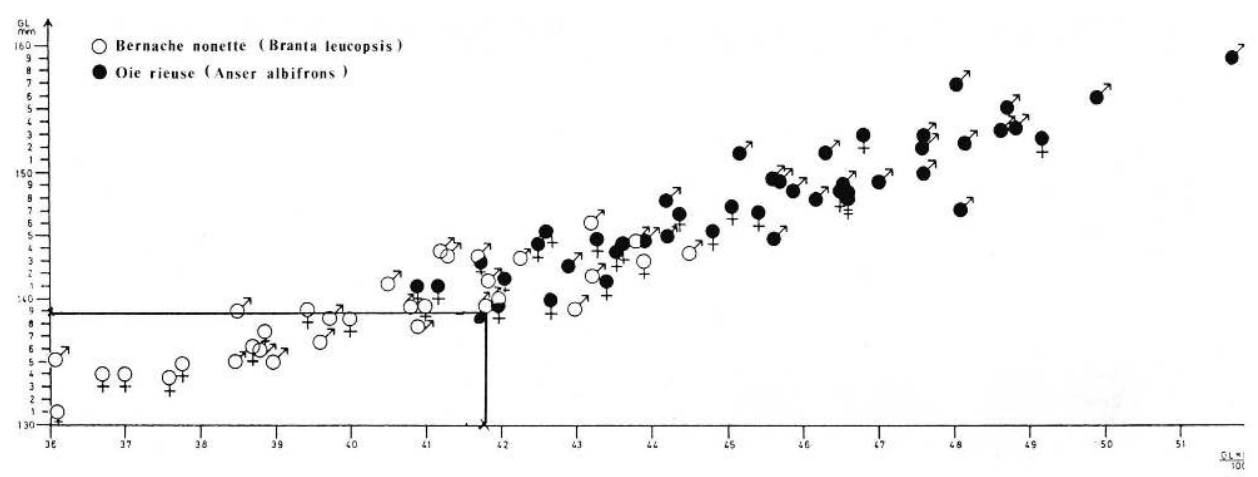

Les deux oiseaux sont des migrateurs, parfois égarés jusque dans nos régions, durant la saison d'hiver. Des traces de découpe ont été observées sur l'extrémité distale de l'humérus ; cet os correspond à l'aile.

60 A cette activité cynégétique, il faut ajouter la pêche. Les espèces identifiées par $\mathrm{N}$. Berset-Desse sont le brochet (Esox lucius), la carpe (Cyprinus carpio) et probablement la truite (Salmo trutta).

61 Le ramassage des escargots est encore pratiqué. Il s'agit cette fois d'une seule espèce : l'escargot des vignes, que nous connaissons sous le nom d'escargot de Bourgogne (Helix pomatia).

Comme on le voit, cette période d'occupation se signale à la fois par l'abondance en matériel osseux, mais aussi par la diversité des espèces consommées.

Les petites quantités d'ossements retrouvés dans les zones 1,4 et 12 pourraient laisser supposer que ces surfaces étaient des lieux d'habitation, tandis que les zones 5 et 8 où l'on retrouve une forte proportion d'os esquillés et de fragments crâniens seraient, pour la première essentiellement un secteur de rejet et pour la seconde à la fois zone de rejet mais aussi aire d'abattage du porc et du mouton tout en n'éliminant pas une zone de campement non permanent. 


\section{Le XVIIIe siècle}

\section{Zones 1,4 et 8}

64

Les trois zones sont interdépendantes, phénomène que nous avions déjà constaté pour les périodes antérieures. Les fragments de côtes et de vertèbres recueillis sur l'ensemble du site sont attribuables à des espèces de taille moyenne comme les porcins et les ovins.

Les restes de bovins proviennent de trois individus âgés respectivement de 3 mois environ, de 12 à 24 mois et de 8 à 10 ans. Ils n'ont pas une très grande valeur alimentaire, ce sont des fragments de mandibules et d'extrémités de pattes.

Les porcs sont également représentés, en majorité, par les mêmes types d'éléments anatomiques, auxquels il faut cependant ajouter quelques fragments rattachables à un jambon et à deux jarrets. Trois sujets sont à l'origine de ces restes dont les âges se situent entre 3 et 6 mois, entre 18 et 24 mois et au-delà de 3 ans $1 / 2$.

67 Nous avons également quelques os de foetus. Il faut préciser que le sujet âgé de 18 à 24 mois est une femelle, peut-être doiton mettre ces deux animaux en relation.

Les caprinés sont, semble-t-il, encore représentés essentiellement par des moutons. En effet, excepté un jeune sujet de 3 à 6 mois, pour lequel nous ne pouvons préciser l'espèce : chèvre (Capra hircus) ou mouton puisque, comme nous l'avons dit, au début de notre exposé, à propos du sanglier et du porc, certaines espèces, morphologiquement très proches, sont difficilement identifiables dans leur période juvénile. Donc, excepté ce sujet, les trois autres sont des ovins ; l'un sub-adulte : 18 à 24 mois, les deux autres adultes : respectivement 24 à 36 mois et plus de 3 ans $1 / 2$.

Les fragments osseux abandonnés sont nettement plus intéressants que pour les deux espèces précédentes. Ce sont les restes d'épaules, de gigots, de selles et de côtes que nous avons identifiés. Là encore, nous devons signaler la présence d'un foetus.

La volaille est très nettement prépondérante avec treize poules adultes et cinq poulets.

Il faut également noter quelques restes d'oie domestique provenant de deux individus : un jeune et un adulte.

72 La chasse bien que très discrètement présente par le nombre de restes, est significativement intéressante par sa diversité. On y retrouve l'ours brun (fig. 135) ainsi que le sanglier et le cerf elaphe (Cervus elaphus), trois espèces indiquant la forêt proche. 
Tableau 5 : Inventaires des restes osseux (total : 708)

\begin{tabular}{|l|c|c|c|}
\hline Distribution & $\begin{array}{c}\text { ZONE 1 } \\
\text { pièce IV }\end{array}$ & ZONE 4 & ZONE 8 \\
\hline des restes & 194 & 14 & 36 \\
Fragts indéter. & 75 & 66 & \\
Fragts de côtes & 27 & 10 & 2 \\
Fragts de vertèbres & 18 & & 7 \\
boeuf & 63 & 1 & 3 \\
porc & 30 & & 6 \\
mouton & 140 & 1 & 1 \\
basse cour & 1 & & \\
cerf elaphe & 3 & & \\
sanglier & 1 & & \\
lagomorphes & 1 & 6 & \\
ours brun & 1 & & \\
oiseaux sauvages & 554 & 98 & 56 \\
mollusques & & & \\
\hline TOTAL & & & \\
\hline
\end{tabular}

135 : Canine d'ours brun (Ursus arctos) retrouvée parmi les restes osseux du XIIle siècle

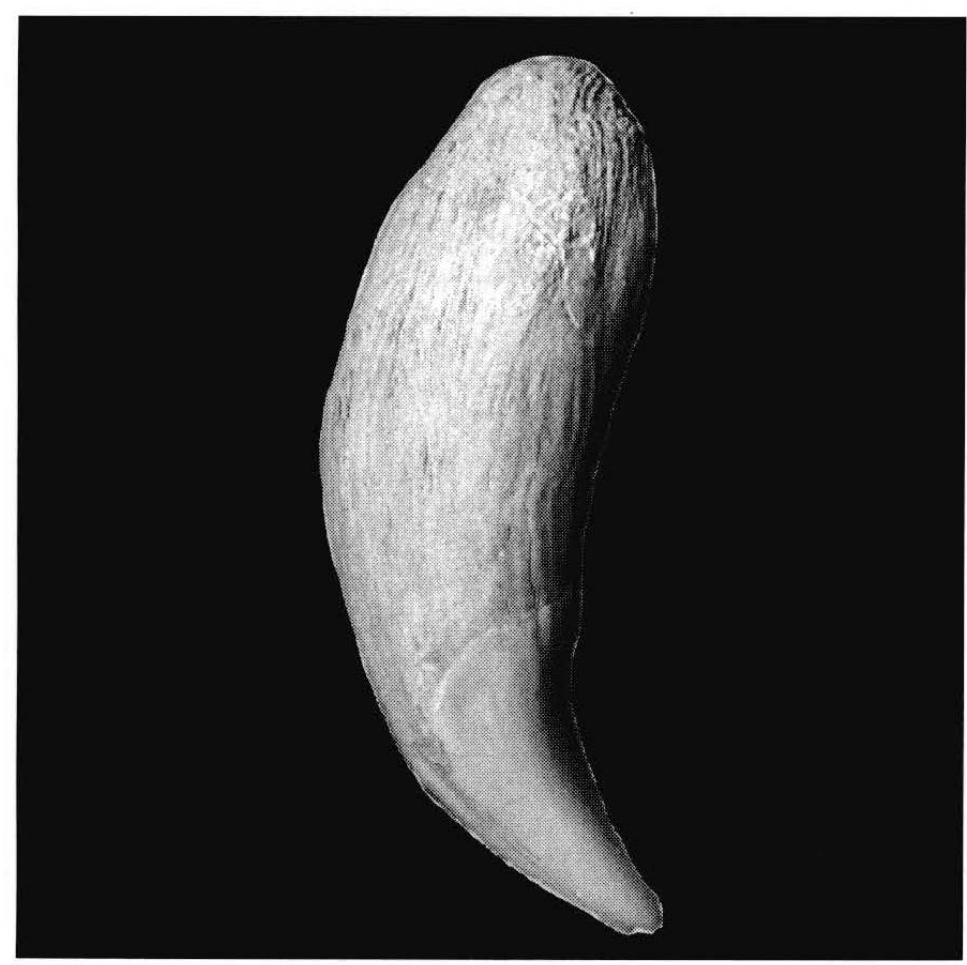

73 Les oiseaux sauvages ne sont représentés que par un élément appartenant à un turdidé non spécifiquement déterminé : merle noir ou grive. 
Quant aux mollusques, nous retrouvons toujours l'escargot de vignes.

Quelle que soit la fonction du site durant cette période, on ne voit pas la rupture avec les époques passées dans la composition faunique servant à l'alimentation carnée.

\section{L'alimentation carnée entre le XIVe et le XVIle siècle}

Nous proposons un tableau résumant les proportions, en pourcentages, des espèces domestiques consommées durant les différentes périodes. Il nous a semblé raisonnable de ne pas inclure le XIIIe $s$. dans cette rétrospective : l'occupation paraît très ponctuelle et le nombre de restes trop pauvre pour faire ce genre d'approche.

7 Le site n'ayant pas pu être fouillé exhaustivement, nous prendrons ces chiffres comme des tendances et non comme des affirmations définitives. La valeur des pourcentages entre les espèces doit également être utilisée avec précaution, une poule consommée entière sur les lieux fournira forcément plus de restes osseux qu'un jambon, un gigot ou un morceau de jarret de boeuf.

7 Cependant on voit que ces ensembles montrent une certaine continuité dans l'exploitation du cheptel. A aucun moment une espèce ne disparaît au profit d'une autre.

79 Cette permanence se reflète également dans les classes d'âges d'abattage des animaux ayant fourni la matière carnée.

La morphologie des trois principales espèces du cheptel nous paraît très difficile à appréhender, au moins jusqu'au XVIe s.

Tableau 6 : Représentation, en pourcentages, du nombre de restes attribués aux espèces domestiques consommées durant l'occupation du site

\begin{tabular}{|l|c|c|c|c|}
\hline $\begin{array}{l}\text { Phases } \\
\text { d'occupation }\end{array}$ & Boeuf & Porc & Mouton & Basse-cour \\
\hline & & & & \\
XIVe s. & $20,50 \%$ & $36,50 \%$ & $12,50 \%$ & $30,50 \%$ \\
XVe s. & $14,00 \%$ & $26,50 \%$ & $18,50 \%$ & $41,00 \%$ \\
XVIe s. & $16,00 \%$ & $33,00 \%$ & $22,00 \%$ & $29,00 \%$ \\
XVIIes. & $9,00 \%$ & $25,00 \%$ & $13,00 \%$ & $53,00 \%$ \\
\hline
\end{tabular}

L'analyse directe des caractères propres à chaque espèce est quasiment inexistante.

Le boeuf ne nous laisse aucune observation sur sa morphologie crânienne ou la forme de ses cornes, ou même la hauteur au garrot. Seules quelques rares données métriques permettent un petit essai comparatif, d'une part avec les données fournies par le travail de V. Forest (1987), sur la région Rhône-Alpes, pour une période s'étendant entre le Xe et le XIVe s., concernant différents types d'habitats et d'autre part avec l'ostéométrie des bovinés du monastère de la Charité-sur-Loire dans la Nièvre, XIe XVIIe s. (Audoin-Rouzeau, 1983). Nous voyons que nos boeufs sont très comparables, au 
moins par la robustesse à ceux dont les restes ont été analysés dans les deux travaux. Durant les périodes médiévales un type de boeuf est assez répandu: de taille assez basse : 1,10 m à 1,20 m au garrot, le crâne était plutôt large et les cornes peu enroulées et souvent courtes. Les sources ethnologiques laissent supposer que les races de bovinés réparties dans la région vers la fin du XIXe s. au moins, se limitaient à deux groupes assez rustiques : la Tarine et l'Abondance (Cuisenier 1979 - Boiville 1984).

Le XVIe et le XVIIIe s. nous ont laissé quelques indices sur le porc et le mouton. Ainsi au XVIe s., nous trouvons un élément crânien de porc dont l'amorce du profil le situe dans un groupe d'apparence plutôt rustique, mais cependant assez robuste si on compare les quelques données métriques de notre site et celles fournies par le travail de V. Forest, indiquant des porcins plus frêles. Une hauteur reconstituée à partir d'un os de la patte postérieure (l'astragale) donne $73 \mathrm{~cm}$ au garrot. Cependant, cet os, pris comme référence, est peu fiable puisqu'il ne nous permet pas de savoir si l'animal auquel il appartenait avait fini sa croissance, la densité de l'os permet seulement de dire qu'il avait certainement plus de 12 mois. Mais peut-être s'agit-il d'un sujet sub-adulte qui gagnera encore quelques centimètres jusqu'à l'ossification complète de son squelette. Si nous confrontons les mêmes données à celles de la Charité-sur-Loire, nous voyons que la robustesse des porcs adultes du Vuache et celle du monastère est sensiblement la même.

$\mathrm{Au}$ XVIIIe s., deux hauteurs calculées sur des os longs appartenant à deux individus dont l'âge minimal est, dans ce cas, au moins 2 ans, atteignent 78 et $81,5 \mathrm{~cm}$ au garrot. Celà nous donne une indication sur le type de porc élévé à cette époque, tailles assez modestes si on se réfère aux données de la Charité au XVIe s. qui peuvent atteindre 90 $\mathrm{cm}$. Leur robustesse paraît inchangée.

Le mouton ne laisse de sa morphologie que quelques données métriques à partir du XIVe s. Il semble que ces animaux soient sensiblement plus robustes et plus hauts que ceux de la Charité-sur-Loire durant les mêmes périodes.

Tableau 7 : Distribution des classes d'âges du boeuf, du porc et du mouton

\begin{tabular}{|c|c|c|c|c|c|c|}
\hline $\begin{array}{l}\text { PHASES } \\
\text { D'OCCUPATION }\end{array}$ & $\begin{array}{l}\text { BOEUF } \\
\text { N.M.I. }\end{array}$ & C.A. & $\begin{array}{l}\text { PORC } \\
\text { N.M.I. }\end{array}$ & C.A. & $\begin{array}{c}\text { MOUTON } \\
\text { N.M.I. }\end{array}$ & C.A. \\
\hline XIVes. & $\begin{array}{l}1 \\
1 \\
1\end{array}$ & $\begin{array}{c}3 \mathrm{~m} . \\
24 \mathrm{~m} . \\
48 \mathrm{~m} .\end{array}$ & $\begin{array}{l}1 \\
1 \\
1 \\
1\end{array}$ & $\begin{array}{c}6 / 12 \mathrm{~m} . \\
12 / 18 \mathrm{~m} . \\
18 / 24 \mathrm{~m} . \\
\text { plus de } 36 \mathrm{~m} .\end{array}$ & 1 & $24 \mathrm{~m}$. \\
\hline XVe s. & 1 & + de 4 a. & $\begin{array}{l}2 \\
1\end{array}$ & $\begin{array}{c}12 / 18 \mathrm{~m} . \\
\text { plus de } 18 \mathrm{~m} .\end{array}$ & 1 & + de $12 \mathrm{~m}$ \\
\hline XVIe s. & $\begin{array}{l}1 \\
1 \\
1\end{array}$ & $\begin{array}{c}3 / 6 \mathrm{~m} . \\
\text { 18/24 m. } \\
\text { 4/6 a. }\end{array}$ & $\begin{array}{l}1 \\
1 \\
4 \\
1\end{array}$ & $\begin{array}{c}6 \mathrm{~m} . \\
12 \mathrm{~m} . \\
18 / 24 \mathrm{~m} . \\
\text { plus de } 36 \mathrm{~m} .\end{array}$ & $\begin{array}{l}1 \\
3 \\
2\end{array}$ & $\begin{array}{c}3 \mathrm{~m} . \\
18 / 24 \mathrm{~m} . \\
+ \text { de } 4 \mathrm{a} .\end{array}$ \\
\hline XVIIe s. & $\begin{array}{l}1 \\
1 \\
1\end{array}$ & $\begin{array}{c}3 \mathrm{~m} . \\
12 / 24 \mathrm{~m} . \\
8 / 10 \mathrm{a} .\end{array}$ & $\begin{array}{l}1 \\
1 \\
1\end{array}$ & $\begin{array}{c}3 / 6 \mathrm{~m} . \\
18 / 24 \mathrm{~m} . \\
3 / 5 \mathrm{a} .\end{array}$ & $\begin{array}{l}1 \\
1 \\
2\end{array}$ & $\begin{array}{c}3 / 6 \mathrm{~m} . \\
18 / 24 \mathrm{~m} . \\
24 / 36 \mathrm{~m} .\end{array}$ \\
\hline
\end{tabular}

N.M.I : nombre minimum d'individus. C.A : classes d'âges, en mois (m.) ou en années (a.), ce sont évidemment des âges approximatifs. 
Tableau 8 : Distribution des hauteurs au garrot en centimètres, des moutons par élément anatomique à différentes périodes

\begin{tabular}{|l|c|c|c|}
\hline & XIVe s. & XVIe s. & XVIIe s. \\
\hline & & & \\
Métacarpe & 57,5 & 63,5 & \\
Métatarse & & 57 & \\
Calcaneum & & $65-66,5-68,0$ & \\
Astragale & 66 & $64-65,0-66,5$ & $62,0-66,5$ \\
& & $67-70$ & \\
\hline
\end{tabular}
trois brebis, âgées de plus de 24 mois. Le calcaneum, os associé à l'astragale dans la patte postérieure, possède un tubercule qui s'ossifie vers trois ans chez les caprinés, c'est donc la limite inférieure de l'âge des trois individus pour lesquels nous avons calculé la taille. Les hauteurs fournies par l'astragale, os dont la fiabilité dans cette reconstitution, ainsi que nous l'avons déjà souligné, est très incertaine, sont malgré tout supérieures à celles calculées à partir d'os dont nous avons pu donner un âge minimal.

Nous ne possédons aucun renseignement sur l'apparence de ces ovins, s'ils étaient armés et dans ce cas la forme des cornes: plus ou moins enroulées. Quant à leur utilisation, on sait qu'ils étaient autant exploités pour leur chair, pour leur lait que pour la laine et la peau. Cette dernière a été largement utilisée dans les manufactures de parchemin. données sont fournies par des femelles (Driver, 1982), seules quelques mesures nettement supérieures semblent pouvoir être attribuées à des mâles. Des restes de tibio-tarses (os de la patte) portant des ergots très forts nous le confirment. En comparant l'ensemble de ces mesures avec celles publiées dans la thèse de $\mathrm{R}$. Thesing (1977), nous pouvons dire que nos gallinacés domestiques se situent tout à fait dans les diverses populations médiévales et modernes qui ont fourni les données de ce travail.

Il semble donc que toutes les perturbations guerrières, les changements politiques, n'aient pas trop affecté les traditions de ce petit terroir. En quatre siècles on ne voit pas de réel changement dans l'exploitation du cheptel. Bien que l'inégalité des échantillons recueillis pour chacune des époques puisse être considérée comme un léger handicap, nous croyons pouvoir dire que les habitudes locales, dans la consommation des animaux d'élevage, quelques fussent les habitants des lieux, seigneurs ou militaires, ont dépassé les différences.

Enfin, pour terminer sur ce qui pourrait être une anecdote, mais entre dans la description de la vie quotidienne, il faut souligner la présence, au XVIe s., durant la phase d'occupation militaire, de sept astragales de moutons (zone 8, C. 803). Ces 
ossements sont depuis longtemps les objets de base d'un jeu communément appelé «jeu d'osselets». Les militaires cantonnés sur le Vuache, pratiquaient-ils ce passetemps durant les longues heures de surveillance ?...

91 *Identification des poissons: N. Berset-Desse. Unité d'Archéozoologie - C.R.A./CNRS Valbonne 06565 Cedex

\section{Les micromammifères}

92 Parmi les animaux sauvages du château du Vuache se trouvent un certain nombre de micromammifères autochtones ou commensaux de l'homme.

93 Il s'agit de 197 os ou fragments d'os, représentant les espèces suivantes: INSECTIVORES: taupe commune (Talpa europaea), musaraigne musette (Crocidura russula) et RONGEURS : mulot à collier (Apodemus flavicollis), rat noir (Rattus rattus)

94 C'est le rat noir, espèce commensale de l'homme, qui domine largement cette microfaune, puisque $94 \%$ des restes osseux lui sont attribués.

Ces restes proviennent de 3 zones du château.

- Zone 1 (cave nord-est du logis) : dans la pièce $V$, nous avons 3 restes de rat noir : 1 fémur et 2 tibias gauches, parmi 250 restes d'origine alimentaire.

-Zone 5 (bâtiment annexe nord-est) : dans la petite pièce VII, le rat noir ne figure que par 2 os : 1 fémur et 1 tibia gauches. Il s'y trouvait en outre un fémur droit de taupe commune.

-Zone 8 (tour nord-ouest) : Dans cette tour, deux couches d'époques différentes ont livré des restes de rat noir. La couche C 805 (XIVe s.) renfermait un fémur gauche. En revanche, la couche 803 (XVIe s.) est beaucoup plus riche. Elle correspond à la période de bivouac de troupes françaises (1536-1559), après le démantèlement du château par les Bernois (1536). Cette couche d'occupation très importante a livré, outre plus de 600 ossements d'origine alimentaire, 190 restes osseux de micromammifères.

Ce sont : musaraigne musette : 1 crâne partiel (moitié antérieure avec dents); mulot à collier : 4 tibias ; rat noir : 185 os, correspondant à au moins 33 individus, à savoir :

971 crâne

12 mandibules ( $6 \mathrm{~g} ., 6 \mathrm{~d}$.)

2 fragments de crâne

22 coxaux (11g.. 11 d.)

58 fémurs ( $31 \mathrm{~g} ., 27 \mathrm{~d}$.)

59 tibias ( 26 g., 33 d.)

15 humérus $(5 \mathrm{~g} ., 10 \mathrm{~d}$.)

8 cubitus ( 4 g., 4 d.)

5 radius

1 scapula

2 vertèbres

98 L'abondance du rat noir dans cette couche est en relation avec la quantité importante de restes d'origine alimentaire, illustrant plus de 20 ans d'occupation permanente. La taille de certains os longs montre que ces rats étaient effectivement bien nourris. Les fémurs ont une longueur de 30-35 mm et les tibias qui atteignent plus de $38 \mathrm{~mm}$ sont assez nombreux (maximum 38,7 mm). Des tibias encore plus longs ont été trouvés dans 
d'autres sites : 40,9 mm à Andone (Charente Xe-XIe s.) (Costiou et Grenouilloux, 1985), ou même 42,5 mm à la Charité-sur-Loire au XIVe s. (Audoin-Rouzeau, 1983).

99 Ces données extrêmes ont localement posé le problème de la présence éventuelle du surmulot (Ratus norvegicus), mais cette question ne semble pas devoir être soulevée au château du Vuache. 


\section{Annexe 5. Inventaire de 1612}

1 Cet inventaire fut dressé en 1612, lors de la passation de pouvoirs entre deux chatelains. Le texte original, écrit sur un cahier de treize pages dont les bords sont malheureusement très abimés, est en vieux français; il est ici transcrit en français moderne. Certains termes sont cependant restés obscurs et sont en gras dans le texte. Ce document est conservé aux Archives départementales de HauteSavoie (A.D.H.S. 7 J. 493).

2 ( $\left.f^{\circ} 1\right)$ Inventaire des meubles remis à Mr. Pierre Laurens, nouveau gestionnaire du château $d u$ Vuache par Mr. Jean Jaques Bosson, ancien gestionnaire du dit lieu ainsi que l'état du dit château où sont les meubles inventoriés

3 Premièrement le grand portail près du chemin public tout découvert sans charpente, sauf des poutres ayant été remises. Les épars ${ }^{1}$ de celui-ci au nombre de quatre avec un verrou derrière. Item le colombier au milieu de la cour dûment arrangé, l'intérieur peint en blanc, l'extérieur couvert de chaume et il est peuplé de pigeons, ceci fait par Mr. Bosson. La porte avec ses épars, verrou et serrure sans clé. Il n'y a aucune échelle.

4 Item au nord de la grange, deux brydons, en partie couverts de bardeaux, avec leurs portes et verrous pris dans d'autres brydons, $d u$ fait que le dessus du portail étant tombé, ils étaient en partie découverts.

5 Item la grange et l'étable mitoyennes ayant au nord, la..... C'y sont trouvées douze poutres de sapin. La porte de la grange avec sa serrure et sa clé de ......

6 ( $\left.f^{\circ} 2\right)$ Item au nord, l'étable avec une porte déjà abimée avec ses épars, verrou et serrure et clé. Dans cette étable, ne s'est trouvée que la moitié du ratelier, les stalles en bon état et deux fenêtres grillagées, à l'ouest, avec leurs chassis faits par M. Bosson. L'étable est équipée de pièces métalliques dont une extrémité est recourbée sans intérêt pour soutenir le fourrage ; il y a aussi un châlit en sapin fait par M. Bosson. Les épars de la porte de l'étable sont vacillantes.

7 La Grand-Cour du château est close par une pallissade faite par M. Bosson et il y a un bâtiment aussi fait par lui.

Item la seconde entrée du château avec sa porte convenablement arrangée sauf le dessous qui n'est pas doublé. La dite porte, doublée de fer, est pourvue de sa serrure, de sa clé et d'un verrou de fer par derrière; elle s'ouvre sur des gros pivots de fer avec une barre transversale attachée par huit pièces métalliques et sur celle-ci, il y a un gros verrou avec ses gaches, une chaîne en fer 
et une serrure sans clé. Les épars de cette porte ont deux lyevres de fer pour tenir les pivots et trois appées de fer sur la moitié du côté attaché et entrant dans.....

(fo 3) Sa porte : épars et verrou, la fenêtre avec son volet faits par Mr Bosson.

Item l'autre bâtiment contre la courtine correctement aménagé avec sa porte munie d'une serrure et d'un verrou.

Item la première porte de la tour dûment doublée avec ses épars et ses serrure, verrou et clé faits par Mr Bosson.

Item la porte de la prison dûment doublée avec des barreaux de fer disposés en croix, ses serrure, clé et verrou muni d'un cotte verrou en fer.

Item à l'étage supérieur, la porte avec ses sépars et au donjon de la tour, il n'y a aucune porte. La toiture est en assez bon état, sauf quelques tuiles qui ont été arrachées par le vent.

Item la porte de la tour ruinée avec ses épars, verrou, clé et serrure.

Item la pièce proche de la tour avec une porte munie de ses épars, serrure et verrou.

Item la dernière pièce ayant deux portes avec leurs épars et verrous.

Plus au bâtiment appellé pressoir (cellier) s'est trouvé le pressoir en bon état avec ses équipements, une cuve de chêne cerclée, contenant vingt quatre seytiers (mesure de capacité). Le four, étant dans ce bâtiment, est en bon état...

$\left(f^{\circ} 4\right)$... soutenir le fourrage, une porte en sapin sans épar ni verrou. Une fenêtre faite dans la courtine par Mr Bosson, sans serrure.

Item la première porte de l'escalier à vis avec ses épars brisés et son verrou sans clé, près de laquelle, il y a une fenêtre grillagée avec ses volets et verrous.

Item la seconde porte donnant dans la cuisine avec ses épars, serrure et verrou.

La porte de la salle à un épar ayant ses serrure, verrou et entreverroil.

En la salle, les quatre fenêtres ont leurs volets de peu de valeur et toutes leurs épars et verrous sauf une qui n'a pas de verrou, deux des fenêtres sont du côté nord avec leurs volets et épars; le linteau de bois est rompu en sept endroits.

Item dans la salle, un châlit en noyer à quatre piliers abîmés et auquel il manque un des rideaux.

Item la porte de la cuisine avec ses sépars, loquet, poignée, plaque de métal et soublicquet sans serrure ni clé.

5 Item la porte de l'endroit où l'on conserve les provisions avec ses épars, serrure et clé. Une boucle de fer y pend, trois...

( $\left.f^{\circ} 5\right)$ Une pièce avec sa porte à barreaux de bois et avec ses épars, serrure et verrou. Les barres en bois occupant tout un côté de la pièce.

Deux landiers de fer identiques sont dans la cuisine, ils ont chacun une plaque rectangulaire à leur sommet. Une broche tournante, une broche en dessous... chacun cinq crochets, les deux chenets de fer attachés à la cheminée en une crémaillière.

Plus une table de noyer avec ses tréteaux, la porte de l'armoire avec ses épars, un petit buffet à deux portes ayant leurs épars sans verrou ni serrure.

Item la porte de l'escalier avec ses épars. Les deux fenêtres de la cuisine sont pourvues de barreaux de fer et de leurs épars et verrous. Un des deux chassis a été fait par Mr Bosson.

Item la porte de la chambre de Madame garnie de ses épars, verrou et loquet. 
Plus en cette chambre, il y a un lit à colonnes torses en noyer, le fond est en sapin, les rideaux et le ciel sont en toile peinte.

Un autre lit en noyer.

Un banc sous lequel il y a un coffre dont il forme le couvercle, ouvragé.

Une table à quatre pieds, sur un côté, elle n'a pas de soubspieds.

Un buffet.

( $f^{\circ}$ 6) Une armoire près de la fenêtre avec ses portes à quatre volets ayant leurs épars.

La fenêtre de la chambre avec son volet, ses épars, verrou et son chassis.

Deux landiers sont dans cette chambre, outre un quelatiere du lit précédent.

Plus dans la chambre à côté de celle de Madame se sont trouvées deux portes, l'une en noyer et l'autre en sapin. La première est pourvue d'un verrou et d'un loquet, toutes deux ont leurs épars et poignées.

Plus un châlit à quatre colonnes en bois, le fond en sapin et le dais en toile imprimée.

Item une armoire en noyer à quatre portes, celles de dessous arrachées et celles du dessus fermant à clé et ayant leurs épars, serrure et clés.

Plus un banc-coffre en sapin dont la moitié du couvercle est cassée.

Plus un ratelier en noyer servant à ranger les armes.

Plus un lit en noyer mais dont le fond est en sapin, garni d'un rideau formant une sorte de tente.

Plus une table en noyer avec son tréteau de peu de valeur.

Plus deux portes sortant de la dite chambre vers l'escalier...

( $\left.f^{\circ} 7\right)$ Plus la fenêtre à meneau sur laquelle il n'y a aucun fer si ce n'est un bâton et un derveillets $^{2}$. Ces fenêtres ont leurs volets, épars et verrous sauf une de celles du dessus où le verrou manque.

Une armoire avec sa porte en sapin ayant ses épars et verrou mais sans serrure.

Plus la porte d'une petite pièce avec ses épars, serrure et clé et dans laquelle s'est trouvée une petite table de noyer.

Le plafond de cette chambre est rompu en deux endroits.

Plus la chambre au dessus de celle des chambrières, s'est trouvée la porte avec sa serrure et son loquet.

Plus dans cette chambre, deux fenètres avec leurs verrous et épars.

Item dans la chambre au dessus de celle de madame s'est trouvée une porte avec sa serrure et sa clé.

Plus un lit de noyer ouvragé dont le fond est en sapin, dessous faits par Mr Bosson.

Le volet de la fenêtre de cette chambre n'a pas de verrou mais a ses épars et son chassis.

Plus la porte de cette chambre en sapin avec ses épars.

Plus dans la chambre située entre cette dernière et l'escalier à vis, s'est trouvée une porte avec ses épars et serrure sans clé et deux volets avec...

58 ( $\left.f^{\circ} 8\right)$ Plus dans la chambre située au dessus de la cuisine dont deux des parois sont en planches de chêne, a été trouvée une porte en bois de peuplier avec ses épars, serrure et clé.

Plus dans cette pièce, il y a un petit buffet de sapin sans serrure. 
Plus dans le grand grenier, il y a une porte de sapin avec ses épars, serrure et verrou.

Plus au grenier au dessus (des chambres?), il y a une table carrée, une porte avec ses épars,serrure et clé et un quart servant à mesurer portant la marque du château.

Plus deux tonneaux en sapin de peu de valeur.

Plus au pied de l'escalier, est une armoire avec ses épars, verrou, serrure et clé. La serrure et sa clé ont été faites par Mr Bosson.

Plus la porte de la première cave, dûment doublée, ayant ses épars, verrou et clé.

Plus une autre petite porte de sapin donnant dans la cour et qui a ses épars faits par Mr Bosson.

Plus quatre boucles defer accrochées à la voûte.

La seconde cave a une porte en sapin avec ses épars, serrure et clé.

Plus dans la...(fo 9$)$ serrure, loquet: un châlit en noyer de peu de valeur et n'ayant que trois piliers.

Plus un coffre ouvragé en noyer avec ses épars sans serrure ni clé.

Plus un châlit sans valeur.

Plus un mortier sans pilon.

Plus un pot de chambre pesant une livre et déjà cassé.

Plus une mauvaise marmite toute cassée contenant environ trois quarterons (mesure de capacité).

Plus une poéle de peu de valeur contenant environ une sallée (mesure de capacité).

Plus un levier de fer, un grand panier d'osier avec ses garnitures sauf une des boucles.

Plus une bassinoire sans valeur et dont le bassin est détaché.

Trois chandeliers de laiton, deux petits et un grand. L'un d'eux est cassé au milieu.

Une lèchefrite de fer sans manche et sans valeur.

Une paire de balances.

Un grill de fer rompu auquel manquent trois barres.

deux couteaux à couper...

( $\left.f^{\circ} 10\right)$ Un poelon abimé dont le manche en fer est rompu.

une casserolle d'airain au manche en fer, toute cassée.

Une louche de laiton rompue dont le manche est en partie en fer:

Une louche percée de laiton, une chaufferette de fer avec ses anneaux.

Plus un harnais servant pour la charette.

Plus une paire de ciseaux en fer servant au feu.

Plus un atron (trépied) de fer à trois pointes.

Deux houes pour le jardin: deux balles de canon.

Un tableau de ta Vierge dans un cadre doré.

Plus une petite table de peu de valeur.

Plus deux mauvaises chaises.

Plus trois petites couvertures en drap de Pise blanc de peu de valeur et une pièce d'étoffe de laine blanche d'une valeur moyenne. 
Plus le jardin clos de pallisades vieilles et rompues.

Plus les butins (culture de vigne) prés du château avec leurs barres transversales.

Plus les vignes de Tary, la petite vigne du Lavandier en assez bon état.

Plus le champ de la...

( $\left.f^{\circ} 11\right)$ Plus un nouveau moulin en assez bon état saufl'étang qui est encore en partie rempli. Les chenaux en assez bon état, la charpente et la toiture ont été refaites. Deux meules et leurs cuves couvertes d'une entremoy larche de peu de valeur.

Plus un coffre ayant ses épars sans clé ni verrou et de peu de valeur.

La porte du moulin abimée avec sa serrure sans clé.

Plus devant la porte du moulin, la roue en assez bon état.

Plus le battoir avec sa cruche, son trépied et ses autres édifices et artifices réunis sous un toit. Le tout en assez bon état.

L'étang en....

Le moulin de Lavandier avec toutes ses dépendances en assez bon état sauf une partie de la couverture récemment emportée par le vent.

Plus deux boites et deux cassines avec leurs serrures de moyenne valeur. L'ensemble pesant soixante huit livres. Les cassines n'ayant chacune qu'une serrure.

( $\left.f^{\circ} 12\right)$ Plus quatre rideaux de lit à franges de peu de valeur.

Plus treize livres de plats et d'assiettes d'étain en partie cassés.

Plus un cuveau et deux pots sans brisure pesant le tout quinze livres.

Plus une aiguière et une salière pesant une livre et demi.

Plus un tombereau de peu de valeur que Mr Jehan Jaques Gay détient.

Plus un banc de noyer de peu de valeur.

Plus une scie de scieurs de long.

Plus une bêche.

Plus une balance romaine sans pomble.

Plus un crible rond servant à cribler le blé.

Plus une benne que Mr Chambon détient et qui lui a été remise par Mr Ayme Collomb.

Plus la forêt (bois domanial) et autres bois déspendants du Vuache.

Plus neuf fauconneaux (pièces d'artillerie légères) ou arquebuses dont deux sont en laiton et en fonte et montés sur deux obuls de peu de valeur.

Du vingtcinquième (???) mille six cents douze, tous les meubles inventoriés ont été remis par Mr Bosson à Mr Pierre Laurens lequel s'en charge et s'en porte garant.

$\left(f^{\circ} 13\right)$

Obligation de messieurs.... en cela requis. Pour tout ce qui précédé, Mr Bosson dit avoir rénové les choses mentionnées et certifie véritable ainsi qu'il affirme par foi et serment. Mrs Bosson et Laurent ont signé la minute faite dans le château du Vuache, en présence de Mr Claude Mugnier, curé de Dingy, Claude Deluermoz de Vulbens et Martin Estallaz de Chevrier témoins requis et par moi Bernard Perret, notaire ducal en Genevois, qui le présent ai reçu en étant requis et je l'ai expédié en faveur de Mr Bosson et des siens et en foi de vérité, j'ai signé ici. 


\section{NOTES}

1. épar : $1 /$ pièce de bois servant à maintenir l'écartement entre deux autres pièces, on utilise aussi les mots : entrait, entrepise, entretoise, traverse. 2/ barre servant à fermer une porte

2. : d'esveille : de vigilance, de surveillance? 


\section{Bibliographie}

Amsterdam Historisch Museum 1977 : Opgravingen in Amsterdam Amsterdam, 1977.

Arnold 1985 : ARNOLD (J.) : Patterns of fashion. The cut and construction of clothes for men and women 1560-1620. M/Drama book, New York, 1985.

Audoin-Rouzeau 1983 : AUDOIN-ROUZEAU (F.) : Archéozoologie de la Charité-sur-Loire médiévale. Thèse de 3e cycle, Université Paris I, 1983.

Babel 1963 : BABEL (A.) : Histoire économique de Genève des origines au début du XVIe s. Genève, éd. Jullien, t. 1, 1963.

Bacher 1967 : BACHER (A.): Vergleichend morphologische Untersuchungen an Einzenknöchen des postcranialen Skeletts in Mitteleuropa vorkommender Schwäne und Gânse. InauguralDissertation. Universität München, 1967.

Barbero 1980 : BARBERO (D.) : Paroisses et communes de France. Dictionnaire d'histoire administrative et de démographie. Haute-Savoie. Paris, éd. du CNRS, 1980.

Barrelet 1953 : BARRELET (J.) : La verrerie en France de l'époque gallo-romaine à nos jours. Paris, éd. Larousse, 1953.

Barrera 1987 : BARRERA (J.) : La verrerie du XIVe au XVIe s. recueillie à Orléans. Annales du 10e congrès de l'Association Internationale pour l'Histoire du Verre. Madrid-Segovie, 1987, p. 341-360.

Baumgartner 1985: BAUMGARTNER (E.): Glasfunde des 13. und 14. Jahrhunderts von des Frohburg (kanton Solothurn) Zeitschrift fiir Schweizerische Archàologie und Kunstgeschichte, Band 42/3, 1985, p. 157-172.

Baumgartner 1988 : BAUMGARTNER (E.) et KRUEGER (I.): Phonix aus Sand und Asche, glas des Mittelalters. Catalogue d'Exposition, Munich, éd. Klinkhard et Biermann, 1988.

Beatrix 1851 : BEATRIX (J. F) : Histoire du Pays de Gex. Dumoulin et Rouet, Lyon, 1851.

Blondel 1956 : BLONDEL (L.) : Les châteaux de l'ancien diocèse de Genève. Mémoires et Documents publiés par la Société d'Histoire et d'Archéologie de Genève. Genève, éd. A. Jullien, t. 7, 1956.

Boiville 1984 : BOIVILLE (P.) : La race bovine tarentaise.Thèse Ecole Nationale Vétérinaire d'Alfort, Faculté de Médecine de Créteil, 1984.

Bonato 1986 : BONATO (L.) : Etude comparée des os de la colonne vertébrale et du thorax du lapin domestique (Orytolagus cuniculus L.) et du lièvre (Lepus europaeus c.) Application de la diagnose differentielle.Thèse Ecole Nationale Vétérinaire d'Alfort, Faculté de Médecine de Créteil, 1986.

Bonnassie 1981 : BONNASSIE (P.) : L'histoire médièvale, les 50 mots clefs. Toulouse, éd. Privat, 1981. 
Bordeaux 1858 : BORDEAUX (R.) : Serrurerie du Moyen Age. Paris, éd. Aubry, 1858.

Boutruche 1970 : BOUTRUCHE (R.) : Seigneurie et féodalité. Paris, éd. Aubier, 2 vol. 1968-1970.

Boyer 1979 : BOYER (R.) : Les noms de lieux de la région du Mont-Blanc. Bonneville, 1979. Réed. 1987, Sallanches, éd. Mythra.

Brocart-Plaut, 1988 : BROCART-PLAUT (M.), SIROT-CHALMIN (E.) BAUD (H) et MARIOTTE (J.Y.) : Châteaux et maisons fortes savoyards. Roanne, éd. Horwath, 1988.

Broise 1974: BROISE (P.): Genève et son territoire dans l'Antiquité, de la conquête romaine à l'occupation burgonde (Atlas). Bruxelles, R.E.L., vol. 129, coll. Latomus, 1974.

Brondy, 1985 : BRONDY (R.), DEMOTZ (B.), et LEGLAY (J. P.) : La Savoie de Tan mil à la réforme. (XIXVIe s.) Rennes, éd. Ouest-France, 1985.

Bruchet 1977 : BRUCHET (M.) : Notice sur l'ancien cadastre de Savoie. Annecy, éd. originale de 1896, reéd. 1977,1988

Bruchet 1979 : BRUCHET (M.) : L'abolition des droits féodaux en Savoie (1761-1793). Collection des documents inédits sur l'histoire économique de la révolution française. Annecy, Herisson 1908, 638 p. Marseille, Laffitte reprints, 1979.

Burlet 1916 : BURLET (Chanoine J.) : Le culte de Dieu, de la Vierge et des Saints en Savoie. Chambéry, 1916.

Cabart 1985 : CABART (H.) : Fouille de quatre fosses (XVeXVIIe s.) situées dans le quartier SaintDominique à Châlonssur-Marne (Marne). Bulletin de la Société Archéologique Champenoise, nº 4, 1985, p. 31-66.

Chambon 1955 : CHAMBON (R.) : L'Histoire de la verrerie en Belgique du IIe s. à nos jours. Bruxelles, 1955.

Channel 1934 : CHANNEL (A.) : Etudes sur la taille des pierres au Moyen Age. Bulletin Monumental, Paris, 1934, p. 435-450.

Chapelot, 1980 : CHAPELOT (J.) et FOSSIER (R.) : Le village et la maison au Moyen Age. Paris, éd. Hachette, 1980.

Chapelot, 1985 : CHAPELOT (O.) et BENOIT (P.) : Pierre et Métal dans le bâtiment au Moyen Age. Paris, éd. EHESS, 1985.

Charleston 1984 : CHARLESTON (R.J.) : English Glass and the glass used in England circa 400-1940. Londres, 1984.

Cholley 1925 : CHOLLEY (A.) : Les Préalpes de Savoie et leur Avant-Pays, étude de géographie régionale. Paris, éd. Armand Colin, 1925.

Chompret 1946 : CHOMPRET (J.): Les faïences françaises primitives d'aprés les apothicairerie hospitalières. Paris, 1946.

Colardelle 1981 : COLARDELlE (M) (sous la direction de). Des burgondes à Bayard, mille ans de Moyen Age.Catalogue de l'exposition, Grenoble, 1981.

Costa de Beauregard 1774: Marquis COSTA DE BEAUREGARD: Essai sur l'améloriation de l'agriculture dans les pays monteux et en particulier en Savoie. Chambéry, Impr. F. Garrin, 1774.

Costiou 1985 : COSTIOU (P.) et GRENOUILLOUX (A.) : Avant les Croisades, les rats médiévaux d'Andone (950-1028). France-Anthropozoologica, 3 p. 16-21, 1985.

Cuisenier 1979 : CUISENIER (J.) (sous la direction de) : Les sources régionales de la Savoie. Paris, éd. Fayard, 1979.

D'Allemagne 1891 : D'ALLEMAGNE (H. R.) : Histoire du luminaire. Paris, éd. Picard, 1891.

D'Allemagne 1928 : D'ALLEMAGNE (H. R.) : Les accessoires du costume et du mobilier. Paris, éd. Schemit, 3 vol., 1928. 
D'Allemagne 1968 : D'ALLEMAGNE (H. R.) : Decorative Antique Ironwork. A pictorial Treasury NewYork. Ed. Dover, reédition du catalogue de 1924,1968.

Dauzat 1963 : DAUZAT (A.) et ROSTAING (C.) Dictionnaire étymologique des noms de lieux en France. Paris, éd. Larousse, 1963, réed. Librairie Guenegaud, s. d.

De Bouard 1973-1974 : DE BOUARD (M.) : De l'aula au donjon, les fouilles de la chapelle à Douéla-Fontaine (Xe-XIe s.) Archéologie médiévale t. III-IV p. 5-110, Centre de Recherches en Archéologie Médiévale, Caen, 1973-74.

De Foras 1863-1938: DE FORAS (comte A. de.) Armorial et nobiliaire de l'ancien duché de Savoie. Grenoble, éd. Allier, 1863-1938, 6 vol. et 1 vol. de suppl.

Démians d'Archimbaud 1980 : DEMIANS D'ARCHIMBAUD (G.) : Les fouilles de Rougiers, (Var). Contribution à l'archéologie de l'habitat rural médiéval en pays méditerranéeen. Paris, éd. du CNRS. 1980.

Demole 1883 : DEMOLE (E.) : L'atelier monétaire des comtes du Genevois à Annecy. Mémoires de la Société d'Histoire et d'Archéologie. Genève, t.XXII, 1883.

Demotz 1981 : DEMOTZ (B.) : Les fortifications de pierre dans le comté de Savoie. Actes du congrès des sociétés savantes de Savoie à Saint-Jean-de-Maurienne, 1980, Soldats et armées en Savoie, ChambéryMontmélian, 1981, p. 119-134.

Demotz 1982 : DEMOTZ (B.) : La noblesse et ses résidences en Savoie, Annecy. Revue Savoisienne, 1982, p. 129-141

Demotz 1982 : DEMOTZ (B.) et PERRET (A.) : Châteaux forts en Savoie. $N^{\circ}$ spécial de L'Histoire en Savoie, Chambéry, 1982.

Desormaux 1902 : DESORMAUX (J.) et CONSTANTIN (A.) : Dictionnaire savoyard. Annecy, éd. Gardet, 1902.

Devos 1978 : DEVOS (R.), GABION (R.), MARIOTTE (J.Y.), NICOLAS (J.) et ABRY (C.) La pratique des documents anciens. Sources et méthodes de l'histoire de la Savoie. Annecy, vol. II, 1978, 336 p.

Dolivo 1961 : DOLIVO (D.) : Catalogue des monnaies Suisses, II, les monnaies de Tévëché de Lausanne. Berne, 1961.

Driesh 1976 : DRIESH (A. Von den) : A guide to the measurements of animal bones. Peabody Museum, Bulletin I, Harvard University, 1976.

Driver 1982 : DRIVER (J.) : Medullary bone as indicator of sex in bird remains from archaeological sites in WILSON (B.) and al.: Ageing and sexing animal bones from archaeological site, B.A.R. British Series 109, 1982.

Duby 1962 : DUBY (G.) : L'économie rurale et la vie des campagnes dans l'occident médiéval (France, Angleterre, Empire, IX-XVe s.) ; essai de synthèse et perspectives de recherches. Paris, éd. Montaigne, 1962, 2 vol.

Duby 1972 : DUBY (G.) : Hommes et structures du Moyen Age: t. 1 : la société chevaleresque, t. 2 Seigneurs et paysans. Paris, éd. Flammarion, 1972.

Dufournet 1978 : DUFOURNET (P.): Pour une archéologie du paysage. Une communauté agraire sécrète, son territoire, Bassy et alentours (Haute Savoie et Ain). Paris, éd. Picard, 1978.

Dumas-Dubourg 1988 : DUMAS-DUBOURG (F.) : Le monnayage des ducs de Bourgogne. Louvain-laNeuve, Université Catholique de Louvain, 1988.

Duparc 1978 : DUPARC (P.) : Le comté de Genève IXe-XVe s. Mémoires et Documents publiés par la Société d'Histoire et d'Archéologie de Genève, $\mathrm{t}$ 39. Genève, éd. Julien, 1978 et Paris éd. Picard, 1955.

Erlande-Brandebourg 1982 : ERLANDE-BRANDEBOURG (A.) : L'architecture militaire au temps de Philippe-Auguste: une nouvelle conception de la défense in : La France de Philippe Auguste. Paris, éd. du CNRS, p. 595-603, 1982. 
Faure-Boucharlat 1990 : FAURE-BOUCHARLAT (E.) : A la fortune du pot : la cuisine et la table à Lyon et Vienne, X-XIX e s. d'après les fouilles archéologiques. Lyon, Catalogue de l'exposition, Lyon, Vienne, Mâcon. Musée de la Civilisation gallo-romaine, 1990-1991, 234 p..

Fenouillet 1913: FENOUILLET (F): Monographie de la commune de Savigny. Mémoires et Documents publiés par la Société Savoisienne d'Histoire et d'Archéologie. Chambéry, 1913, p. 103423.

Fick 1974 : FICK (O.K.W.) : Vergleigend morphologische Untersuchungen an Einzenknöcken europaïscher Taubenarten. Inaugural Dissertation, Universität München, 1974.

Fino 1977 : FINO (J.F.) : Forteresses de la France médiévale. Paris, éd. Picard, 1977.

Forest 1987 : FOREST (V.) : Vestiges fauniques osseux du XVe au XVIe s. en Rhône-Alpes. Thèse, Ecole Vétérinaire de Lyon, Université Claude-Bernard de Lyon, 1987.

Fossati 1975 : FOSSATI (S.) et MANNONI (T.) : Lo scavo della vetraria di Monte Lecco, Archeologia medievale 2, p. 31-97, 1975.

Fournier 1978 : FOURNIER (G.) : Le château dans la France médiévale, essai de sociologie monumentale. Paris, éd. Aubier Montaigne, 1978.

Foy 1986: FOY (D.): Verres du XIVe au XVIe s. provenant de la place de la Cathédrale à Montauban (Tarn et Garonne). Archéologie du Midi Médiéval, t. 4, 1986, p. 83-91.

Foy 1988 : FOY (D.) : Le verre médiéval et son artisanat en France méditerranéenne. Paris, CNRS, 1988.

Foy 1989 : FOY (D.) et SENNEQUIER (G.) : A travers le verre du Moyen Age à la Renaissance. Catalogue de l'exposition, Musée et monuments départementaux de Seine-Maritime, Rouen, 1989.

Furetière 1688 : FURETIERE (A.) : Dictionnaire Universelle. Rééd. Paris, Le Robert, 1978.

Ganter 1971 : GANTER (E.) : Compessières au temps des commandeurs, histoire de la commanderie de Genevois de l'ordre de Saint Jean-de-Jérusalem dit de-Rhodes dit de-Malte. Genève, éd. Maritgay, 1971.

Gardelles 1972 : GARDELLES (J.) : Les châteaux du Moyen Age dans la France du Sud-Ouest, la Gascogne anglaise de 1216 à 1327. Paris, Arts et métiers graphiques, bibliothèque de la Société Française d'Archéologie, 3, 1972.

Gavard 1940 : GAVARD (G) : Valleiry-la Paroisse. Annemasse, imp. Commerciale, 1940.

Gay 1887: GAY (V.) : Glossaire archéologique du Moyen Age et de la Renaissance Paris, 2 vol., éd. Librairie de la société bibliographique, 1887.

Gay 1894 : GAY (V) : Lettre à la Revue Savoisienne (notes sur le Rhône au Vuache). Annecy, éd. F. Abry, 1894.

Gemehl 1986 : GEMEHL (D.) : La verrerie dans G. BLIECK et A.VADET : Vaisselle et nourriture au XVIe s. à Lille (Nord). Revue Archéologique de Picardie 1|2 1986, p. 129-134.

Gilliard 1935: GILLIARD (C) : La conquête du pays de Vaud par les Bernois. Lausanne, éd. La Concorde, 1935.

Godefroy 1930 : GODEFROY (F.) : Lexique de l'ancien français. Paris, 1930. Réed. Paris, éd. H. Champion, 1971.

Godefroy 1930 : GODEFROY (R.) : Géographie de la Savoie. Chambéry, 1930.

Greimas 1989 : GREIMAS (A. J.) : Dictionnaire de l'ancien français Paris, reéd. Larousse, 1989.

Gros 1973 : GROS (Chanoine A.) : Dictionnaire étymologique des noms de lieux de la Savoie, Belley, 1935, reéd. Chambéry, imprimeries réunies, 1973.

Guichenon 1662 : GUICHENON (S.) : Histoire de la souveraineté des Dombes.

Guichonnet 1955 : GUICHONNET (P.) : Le cadastre savoyard de 1738 et son utilisation pour les recherches d'histoire et de géographie sociales. Revue de Géographie Alpine t. XLIII, Grenoble, 1955. 
Guichonnet 1973 : GUICHONNET (P.) (sous la direction de) : Histoire de la Savoie. Coll. Univers de la France et des pays francophones. Toulouse, éd. Privat, 1973.

Guichonnet 1974 : GUICHONNET (P.) (sous la direction de) : Histoire de Genève. Coll. Univers de la France et des pays francophones. Toulouse, éd. Privat, 1974.

Halbout 1987 : HALBOUT (P.) PILET (C.), et VAUDOUR (C.). Corpus des objets domestiques et des armes en fer de Normandie du Ier au XVe s.Cahier des Annales de Normandie $\mathrm{n}^{\circ} 20$. Centre archéologique de Normandie, Caen, 1987.

Hoffman 1965 : HOFFMAN (B.) : La quincaillerie antique. Paris, 1965.

Huguet 1929 : HUGUET (E.) : Dictionnaire de la langue française du XVIe s. Paris, éd. H. Champion, 1929.

Jacquet 1978 : JACQUET (A.) : Saint Julien en Genevois. Belley, éd. Impr. du Bugey, 1978.

Jayet, 1931 : JAYET (A.) et AMONDRUZ (G.) : Découverte d'une station magdalénienne près de Frangy (Haute-Savoie). Comptes rendus des séances de la Société de Physique, d'Histoire naturelle et d'Archéologie de Genève. Genève, t. 48, n³, 1931.

Kojic 1967 : KOJIC (L.) et WENZEL (M.) : Medieval glass found in Yugoslavia, Journal of Glass Studies 9,1967, p. 76-93.

Kraft 1972: KRAFT (E.): Vergleichend morphologische Untersuchungen an Einzelknocken Nord und Mitteleuropaïscher kleinerer Hiinervögel Inaugural Dissertation, Universität Miinchen, 1972.

Lacroix 1954 : LACROIX (T.): Toponymes du type "chez $\mathrm{x}$ ". Revue internationale d'onomastique. Paris, 1954.

Lambert 1972 : LAMBERT (N.) : La seube : témoin de l'art du verre en France méridionale du BasEmpire à la fin du Moyen Age, Journal of Glass Studies XIV, 1972, p. 77-116.

Latouche 1931 : LATOUCHE (R.) : Les idées actuelles sur les Sarrasins dans les Alpes. Revue de géographie Alpine, t. XIX., 1931, p. 199-206.

Lebascle 1986: LEBASCLE (M.-C.) BOILEAU (R.): Les émissions monétaires des comtes de Genevois au palais de l'isle d'Annecy dans la seconde moitié du XIVe s. Annesci, 27,1986.

Lecoq 1973 : LECOQ (R.) : Serrurerie ancienne, techniques et oeuvre. Paris, Librairie Geldalge, 1973.

Lequin 1970 : LEQUIN (Y.), RIMBAUD (C.), et MARIOTTE (J.Y.) : La Savoie au Moyen Age. Textes et Documents d'Archives. Mémoires et Documents publiés par la Société Savoisienne d'Histoire et d'Archéologie, t. LXXXIII, Chambéry, 1970.

Longnon 1979 : LONGNON (A.) : Les noms de lieux de la France, leur origine, leur signification, leurs transformations. Paris, lib. Champion, 1979.

Lullin, 1867 : LULLIN (P.) et LEFORT (C.) : Regeste genevois, répertoire chronologique et analytique des documents imprimés relatifs à l'histoire de la ville et du diocèse de Genève avant 1312. Genève, Mémoires et documents ; Société d'Histoire et d'Archéologie de Genève, t. 16, 1867.

Manteyer 1924 : MANTEYER (G. de) : Les origines chrétiennes de la Viennoise, de la Narbonnaise seconde et des Alpes Maritimes. Aix, éd. Imp. Peyrol, 1924.

Mariotte, 1981 : MARIOTTE (J.Y.), BAUD (H.), CHALLAMEL (J. B.) et GUERRIER (A.) : Histoire des communes savoyardes. t. III : Le Genevois et Lac d'Annecy. Roanne, éd. Horvath, 1981.

Marteaux 1894 : MARTEAUX (C.) : Les noms de lieux en - acus en Haute-Savoie. Annecy. Revue Savoisienne, p. 106-206, 1894.

Marteaux 1935, 1937, 1938 : MARTEAUX (Ch.) Répertoire des noms de lieux de l'arrondissement d'Annecy d'après le cadastre de 1730. Annecy. Mémoires et Documents publiés par l'Académie florimontane, 3 vol., 1935,1937,1938. 
Marteaux 1941 : MARTEAUX (c.): Hydronymes prélatins : Haute-Savoie, Isère. Annecy, Revue Savoisienne, p. 59-75, 1941.

Martin 1965 : MARTIN (C.) : La trouvaille monétaire de la Joux. Revue Suisse de Numismatique, vol. $44,1965$.

Martin 1989 : MARTIN (C.) : Les princes de Savoie et leur atelier monétaire de Nyon, in La Maison de Savoie et le Pays de Vaud. Lausanne, 1989.

Medieval Catalogue 1954 : London Museum, Londres, 1954.

Mersier 1923 : MERSIER (A.): Hourds et machicoulis. Paris, Bulletin Monumental, vol. 92, p. 116-119, 1923.

Michaelis 1978 : MICHAELIS (R.F.) : Old domestic base metal candlesticks from 13th to 19th century, Woodbridge Suffolk, Antique collectors'club, 1978.

Montendon 1922 : MONTENDON (R.) : Genève des origines aux invasions arabes. Genève, éd. Georg, 1922.

Motteau 1981 : MOTTEAU (J.) : Gobelets et verres à boire, XVe-XVIIe s., : Recherches sur Tours 1, 1981, p. 85-101.

Motteau 1985 : MOTTEAU (J.) : Etude sur la verrerie des fouilles de Tours. 1973-1982 Recherches sur Tours 4,1985.

Musée Savoisien 1980 : Le cadastre sarde de 1730 en Savoie. Chambéry, 1980, Impr. Fisnoël 1980.

Musset 1971 : MUSSET (L.) : Les invasions, le second assaut contre l'Europe chrétienne VIIe - XIe s. Paris, P.U.F., Nlle Clio, 1965, réed. 1971

Noel 1968 : NOEL (P.) : Technologie de la pierre taillée. Dictionnaire des termes couramment employés dans l'extraction, l'emploi et la conservation de la pierre de taille. Paris, Soc. de Diffusion des Techniques du Bâtiment et des Travaux Publics, 2 vol., 374 p.. 1968.

Oursel 1953 : OURSEL (R.) : Répertoire des églises du diocèse d'Annecy. Revue du diocèse d'Annecy. Annecy, juin 1953.

Pegorier 1963 : PEGORIER (A.) : Glossaire des termes dialectaux permettant de trouver le sens d'un grand nombre de toponymes de la nouvelle carte de France. Saint-Amand-deMontrond, imp. de l'I.G.N., 1963.

Pergot 1977 : PERGOT (abbé) : N'ignorez pas Sainte-Victoire. Bulletin paroissial "survol", janvier 1977.

Perillat 1966 : PERILLAT (J. L.): Les paysages agraires de Bas-Chablais, Thonon. Mémoires et Documents de l'Académie Chablaisienne, t. LVII, p. 6-152, 1966.

Perret 1966 : PERRET (A.), OURSEL (R.), MARIOTTE (J.Y.) et ROUBERT (J.) : Archives de l'ancien duché de Savoie, inventaire, t.1 : archives de cour. Annecy, éd. Gardet, 1966.

Poncet 1973 : PONCET (A.L.) : Châtelains et sujets dans la campagne genevoise 1536-1792 Genève, éd. Presses Universitaires Romandes, 1973.

Poupardin 1907 : POUPARDIN (R) : Le Royaume de Bourgogne (883-1038). Paris, éd. H. Champion, 1907.

Querrien 1988 : QUERRIEN (A.) : Un village médiéval en BasBerry, Moulins-sur-Céphons. Saint-Amand Montrond, éd. Ass. des Amis du Musée de Saint-Vic., 1988.

Rademacher 1933 : RADEMACHER (F.) : Die deutschen Glàser des Mittelalters. Berlin, éd. B. Hessling Verlag, 1933.

Ravoire 1991 : RAVOIRE (F.) : Un ensemble céramique du XVIe s. : la fosse L1 des thermes de Cluny à Paris. Archéologie Médiévale, t. XXI, 1991, pp. 209-270. 
Rebord 1922 : REBORD (C.M.) : Visites pastorales du diocèse de Genève, 1411-1920. Annecy, éd. J. Abry, 2 vol., 1922.

Reinaud 1836 : REINAUD (M.) : Invasion des sarrasins en

France, en Savoie, Piémont et Suisse. Paris, éd. DondeyDupré,1836.

Rieb 1973 : RIEB (J. P.) et SALCH (C. L.) : Aspects de la vie au Moyen Age et à la Renaissance. Dix ans de fouilles. Chantiers d'Etudes Médiévales. Strasbourg, 1973, n 11.

Rieb 1986 : RIEB (J. P.): Verrerie, dans L'Encyclopédie de l'Alsace, vol.12; La vie matérielle, p. 7586-7598. Strasbourg, éd. Publitotal, 1986.

Ritter 1974: RITTER (R.): L'architecture militaire du Moyen Age. Paris, éd. Fayard, coll. "Résurrection du Passé", 1974.

Rousseau 1960 : ROUSSEAU (R.) : Les registres paroissiaux et d'Etat-civil de Dingy-en-Vuache au XVIIIe s. Actes du 85e congrès des S.S., 1960, Histoire moderne et contemporaine, pp. 439-468.

Sailhan 1991 : SAILHAN (P) : La Fortification, Histoire et Dictionnaire. Paris, éd. Tallandier, 1991.

Salch, 1977 : SALCH (Ch. L.), BURNOUF (J.) et FINO (J.F.) ; Atlas des châteaux forts en France. Strasbourg, éd. Publitotal, 1977.

Salch 1978 : SALCH (Ch. L.) : Atlas des villes et villages fortifiés en France et au Moyen Age. Strasbourg, éd. Publitotal, 1978.

Saulcy de 1841 : SAULCY DE (F.) : Recherches sur les monnaies des ducs héréditaires de Lorraine. Metz, 1841.

Simonetti 1967 : SIMONETTI (L.) : Monete italiane medioevali e moderne, 1, Casa Savoia. Ravenna, Tip. Poggiali, 1967.

Tardieu 1986: TARDIEU (J.) et FAURE-BOUCHARLAT (E.): Sauvetage archéologique place du pilori à Vienne : Bull, de la Société des Amis de Vienne : L'archéologie médiévale à Vienne, n81. Vienne 1986, fasc. 3-4, p. 47-60.

Taylor 1963 : TAYLOR (A.J.) : Some notes on the savoyards in North Wales, 1277-1300 with special reference to the savoyard element in the construction of Harlech castle Genève. Revue Genava, 1963.

Taylor 1978 : TAYLOR (A.J.) : Castle building in the thirteenth century Wales and Savoy. Londres, The British Academy, 1978.

Taylor 1985 : TAYLOR (A.J.) : Studies in castles and castlebuilding. London and Ronceverte, The hambledon press, 1985.

Thesing 1977 : THESING (R.) : Die grössenentwicklung des Haushuhns in vor und frühgeschichtlicher Zeit. InauguralDissertation, Universität München, 1977.

Thury 1899 : THURY (C.) : Le Salève, description scientifique et pittoresque. Genève, éd. Georg, 1899.

Tissot 1880 : TISSOT (E.) : Observations météorologiques faites à Annecy et dans le département de Haute-Savoie. Revue Savoisienne, $\mathrm{n}^{\circ} 9$ p. 110, Annecy, 1880.

Van Berchem 1972 : VAN BERCHEM (D.) L'établissement des Burgondes en Sapaudia. Publication du centre européen d'études burgondo-médianes, Genève, 1972.

Varaschin 1982 : VARASCHIN (A.) : Le Rhône impossible voie de passage antique et médiévale. Archéologia n¹69, pp 48-56. août 1982

Vicard 1984 : VICARD (T.) : Principes pour une évolution de la céramique régionale (le XIIIe s. dans le département du Rhône.) Mémoire de Maîtrise, Université Lyon II, 1984 (dactylographié.)

Viollet Le Duc 1980 : D'après VIOLLET LE DUC (E.) : Encyclopédie Médiévale, tome II, Mobilier et fin de l'architecture, refonte du : Dictionnaire raisonné du mobilier. Paris, éd. Heimadal, 1980.

Vuy 1889 : VUY (J.) : Origine du nom Faramaz. Annecy, Revue Savoisienne, t. 10, p. 502-528,1889. 
Withehouse 1983: WITHEHOUSE (D.): Medieval Glass in Italy: some recent developments, Journal of Glass Studies 25. 1983, p. 115-120.

Withehouse 1991 : WITHEHOUSE (D.) : Glassmaking at Corinth : a reassessment Ateliers de verriers de l'antiquité à la période pré-industrielle, actes des 4ème rencontres de l'Association Française pour l'Archéologie du Verre. Rouen, 1991, p. 73-82.

Wipf 1982 : WIPF (G.R.) : Noms de lieux des pays franco-provencaux. Chambéry, imprimeries réunies, 1982. 


\section{Crédits}

\section{Dessins, plans, graphiques et cartes}

1 Tous les dessins au trait du volume, du dépliant et de l'annexe 1, ont été effectués par F. Raynaud, Mis au net par : M.-N. Baudrand

B. Maccari-Poisson : fig. 120, 121, 122

D. Foy : les planches de l'annexe 3

C. Olive : fig. $130,132,133,134$

\section{Clichés photographiques}

2 Toutes les photos du volume ont été effectuées par : F. Raynaud, sauf :

P. Platier : fig. 3, 4, 38

O. Guillon; A.D.H.S. : fig. 7, 8

B. Claret, CIHAM : fig. 106, 118

J.-B. Latour : fig. 124, 125, 126, 127, 128, 129

G. Dajoz : Museum d'Histoire Naturelle, Genève : fig. 131, 135

Quatrième de couverture : Studio A. Gérard (Annecy) 